Filipe Antonio de Coan Ramos

\title{
ANÁLISE NUMÉRICA DE \\ BLOCOS SOBRE DEZ ESTACAS: \\ CÁLCULO DAS REAÇÕES DE APOIO
}

Dissertação apresentada ao Departamento de Engenharia de Estrutura da EESC-USP, como parte dos requisitos necessários à obtenção do título de Mestre em Engenharia de Estruturas.

Orientador: José Samuel Giongo 
AUTORIZO A REPRODUÇÃO E DIVULGAÇÃO TOTAL OU PARCIAL DESTE TRABALHO, POR QUALQUER MEIO CONVENCIONAL OU ELETRÔNICO, PARA FINS DE ESTUDO E PESQUISA, DESDE QUE CITADA A FONTE.

Ficha catalográfica preparada pela Seção de Tratamento da Informação do Serviço de Biblioteca - EESC/USP

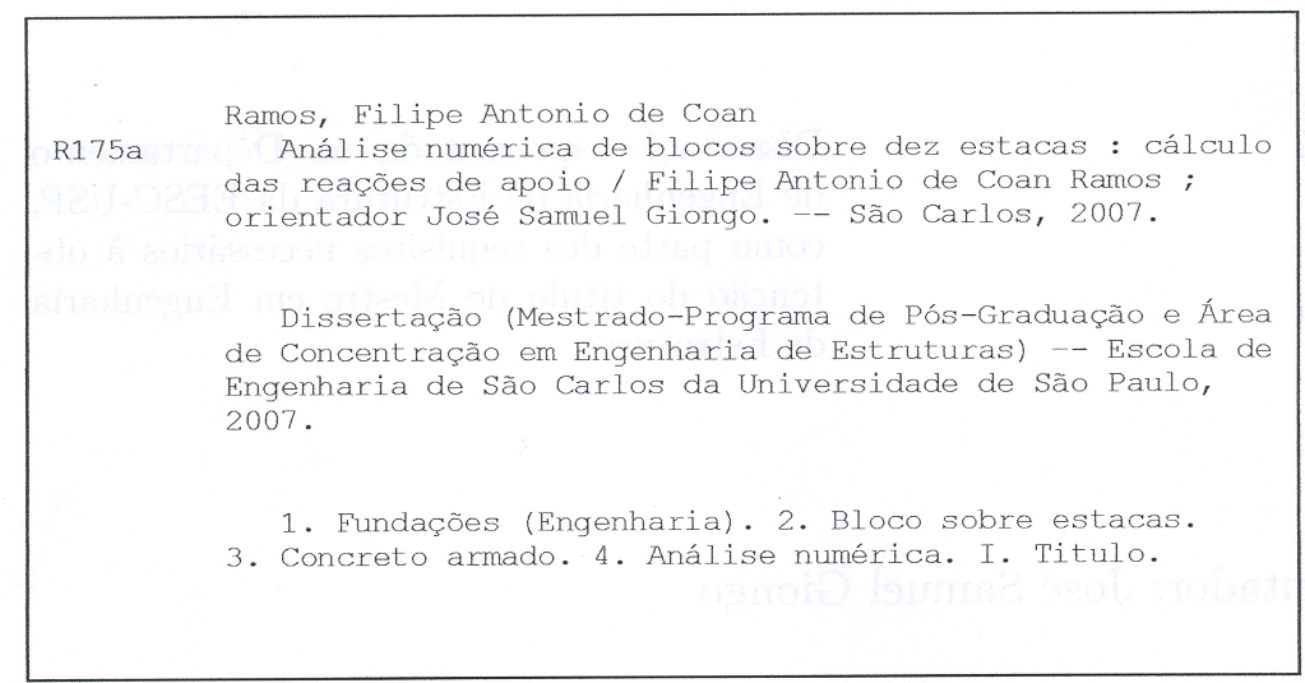


Candidato: Engenheiro FILIPE ANTONIO DE COAN RAMOS

Dissertação defendida e julgada em 14/09/2007 perante a Comissão Julgadora:

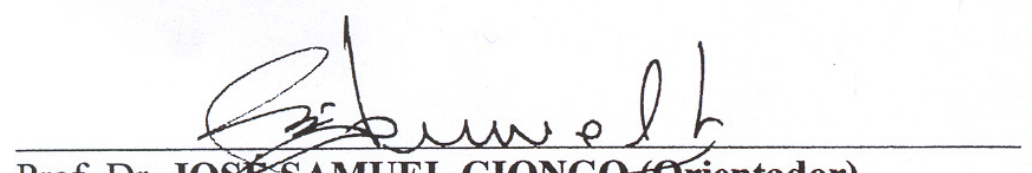

Prof. Dr. JOSE' SAMUEL GIONGO(Orientador)

(Escola de Engenharia de São Carlos/USP)

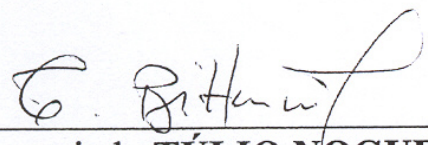

Prof. Associado TÚLIO NOGUEIRA BITTENCOURT

(Escola Politécnica/USP)

Prof. Titular JOSÉ HENRIQUE ALBIERO

(Escola de Engenharia de São Carlos/USP)

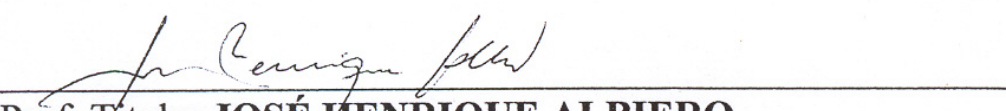

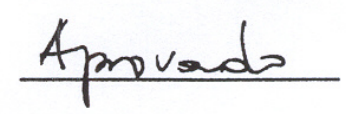

aprovado

storsic do

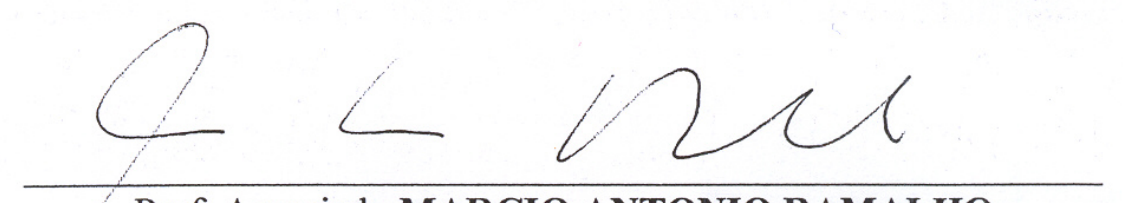

Prof. Associado MARCIO ANTONIO RAMALHO

Coordenador do Programa de Pós-Graduação em

Engenharia Civil (Engenharia de Estruturas)

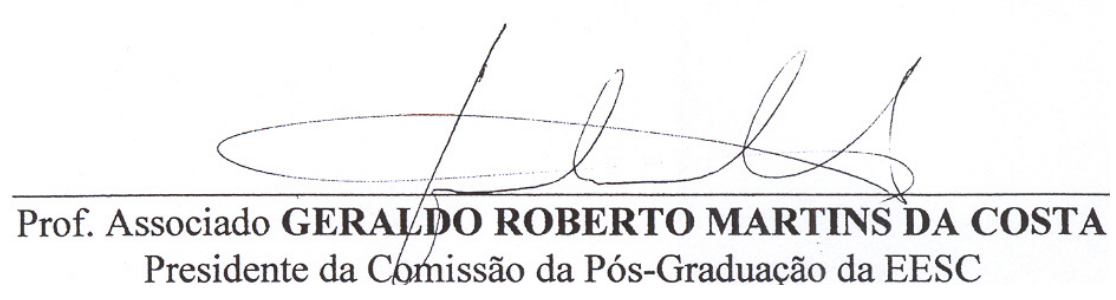


Aos meus pais Antonio e Branca, à minha irmã Carol e minha namorada Camila 


\section{Agradecimentos}

A DEUS, pelas bênçãos concedidas para a realização desse trabalho, pela força dada para conseguir vencer mais essa etapa na minha vida, e por estar sempre ao meu lado me ajudando e me amparando.

À minha amada família que em mais uma ocasião me deu irrestrito apoio para a realização de mais esta etapa.

Aos meus familiares, que mesmo estando distantes ficaram torcendo e apoiando.

A meu amor, Camila, pelas alegrias, pelo apoio e incentivo nas horas difíceis e pelo amor dedicado a min, e também agradecendo a sua família.

Quero agradecer ao professor e orientador José Samuel Giongo e ao Rodrigo Gustavo Delalibera pela amizade, dedicação e orientação ao longo desse trabalho.

A todos os professores e funcionários do Departamento de Engenharia de Estruturas (SET) pela ajuda.

Para que eu não cometa nenhum equívoco de esquecer alguém serei mais generalista em meus agradecimentos, mas de qualquer forma eu agradeço a todos que me ajudaram para a realização desse trabalho. Por isso quero agradecer a todos os companheiros que dividiram as moradias em que passei. Aos colegas do mestrado e do doutorado do Departamento que me apoiaram e me ajudaram. Aos colegas de turma do mestrado. Aos colegas de sala (sala 7) do mestrado que me ajudaram diariamente.

E finalmente um agradecimento especial para Luiz e Pedro pela sincera amizade e pelos ótimos momentos que passamos juntos. 
"Tudo posso naquele que me fortalece" Filipenses 4:13 


\section{Sumário}

Lista de Figuras..................................... xv

Lista de Tabelas $\ldots \ldots \ldots \ldots \ldots \ldots \ldots \ldots \ldots \ldots \ldots \ldots \ldots \ldots \ldots \ldots \ldots \ldots \ldots \ldots$

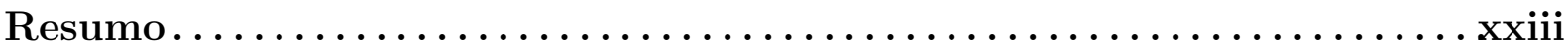

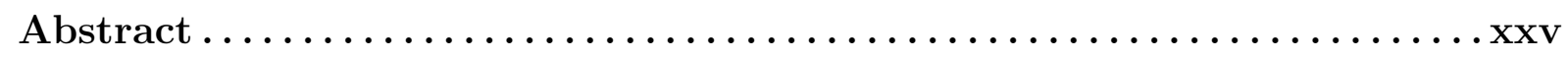

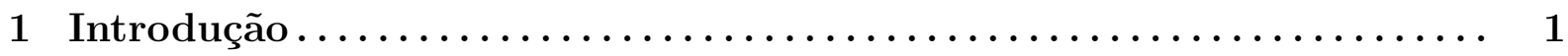

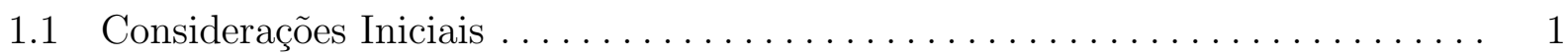

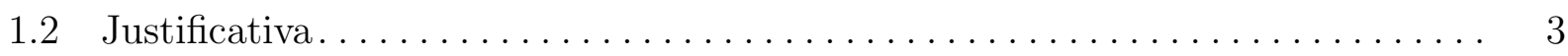

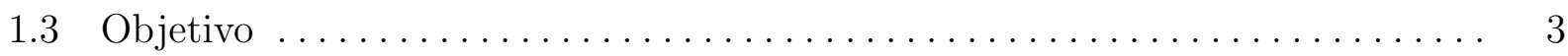

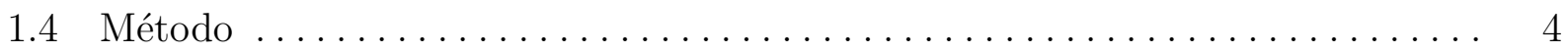

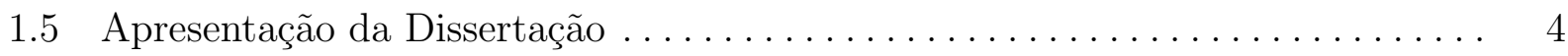

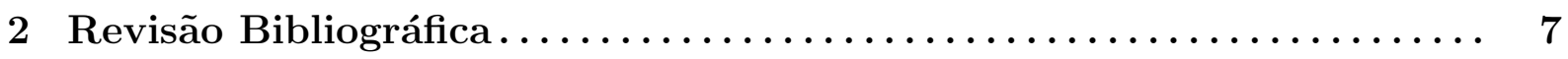

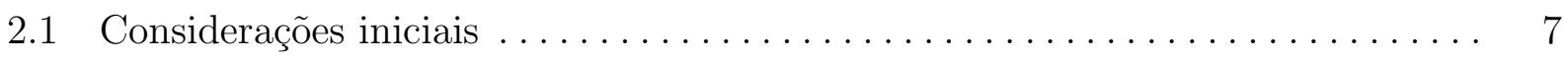

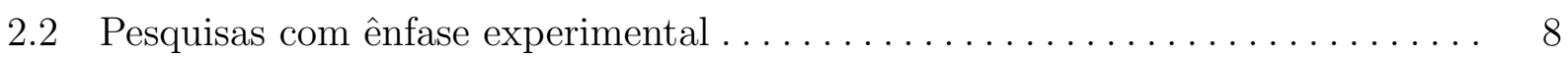

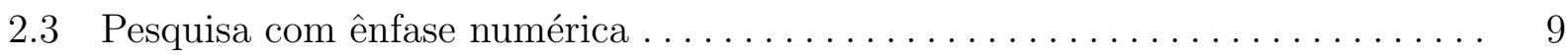

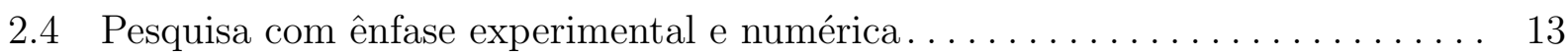

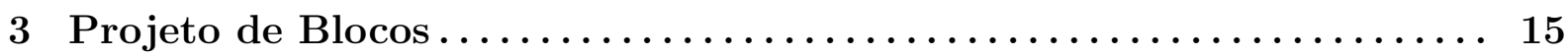

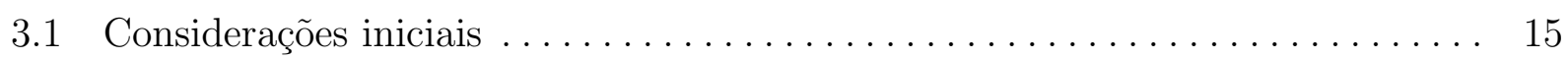

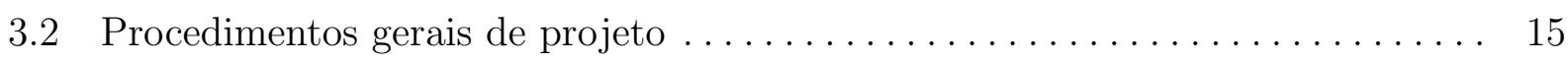

3.3 Cálculo das ações nas estacas $\ldots \ldots \ldots \ldots \ldots \ldots \ldots \ldots \ldots \ldots \ldots \ldots \ldots \ldots \ldots \ldots \ldots \ldots$ 
3.4 Processo do Boletim $n^{\circ} 73$ do CEB-FIP $(1970) \ldots \ldots \ldots \ldots \ldots \ldots \ldots \ldots \ldots$

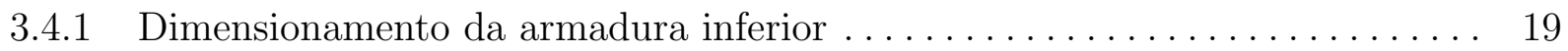

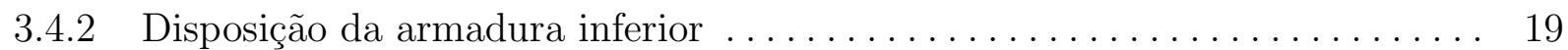

3.4.3 Condição de aderência das barras da armadura principal $\ldots \ldots \ldots \ldots \ldots \ldots .20$

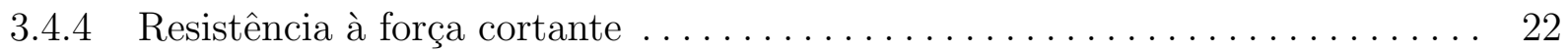

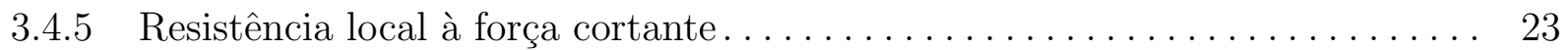

4 Aspectos da Modelagem Numérica .................... 25

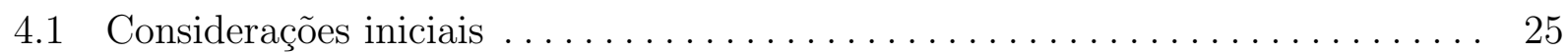

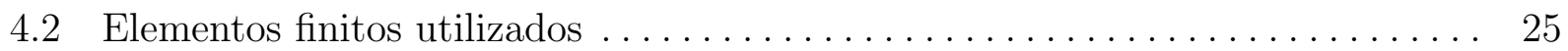

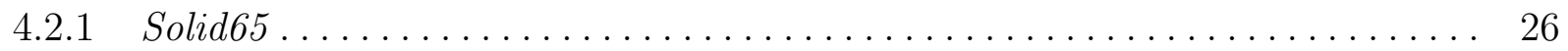

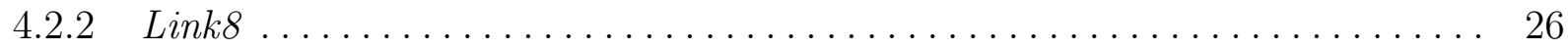

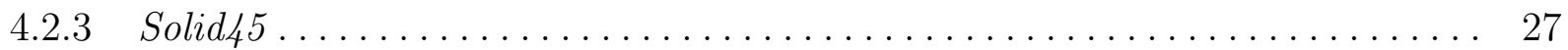

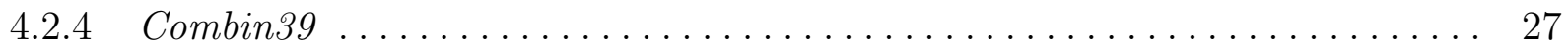

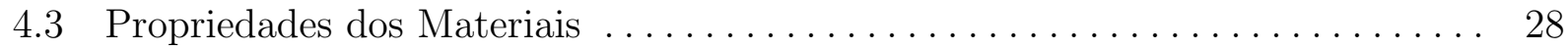

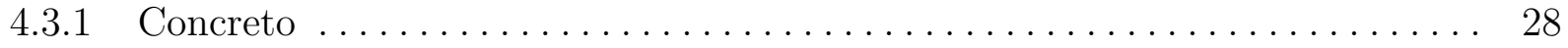

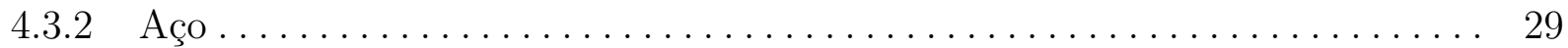

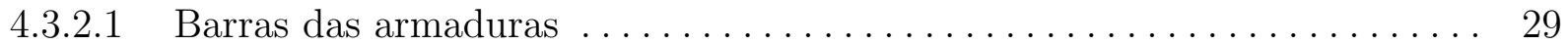

4.3.2.2 Placa no topo do pilar e na base da estaca. . . . . . . . . . . . . . . 29

4.3 .3 Solo. . . . . . . . . . . . . . . . . . . . . . . . . . . . . . . . . . 30

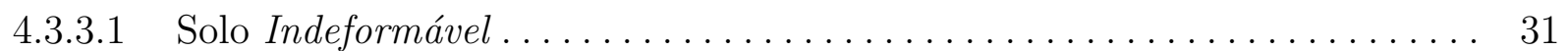

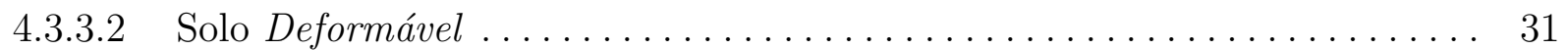

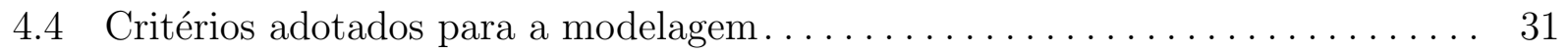

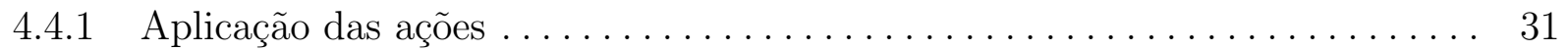

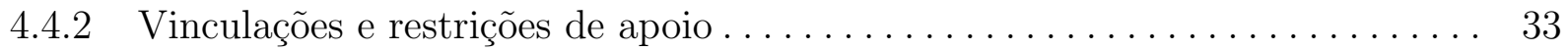

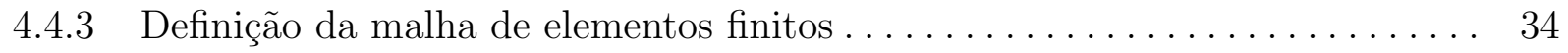

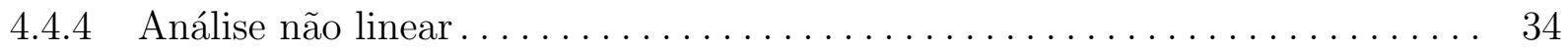




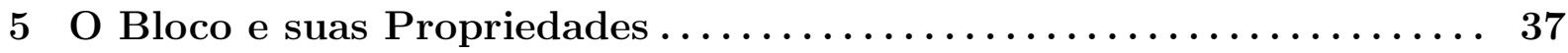

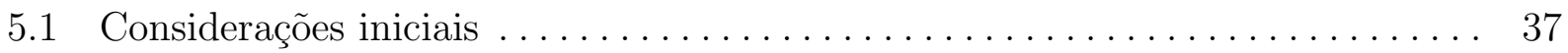

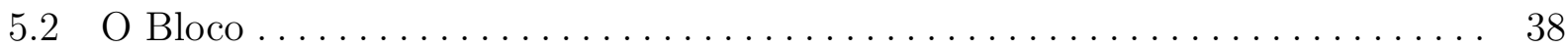

$5.2 .1 \quad$ Propriedades Geométricas................................ 38

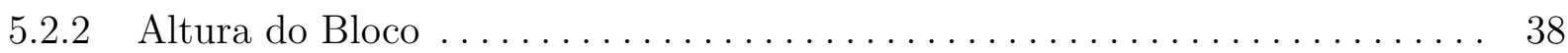

$5.3 \quad$ Casos de Forças Aplicadas . . . . . . . . . . . . . . . . . . . . . . . . . . . . . . . . 39

$5.4 \quad$ Modelos Adotados . ....................................... 41

5.5 Verificações e Valores de Projeto ................................ 41

5.5 .1 Reação Nas Estacas . . . . . . . . . . . . . . . . . . . . . . . . . . . . 42

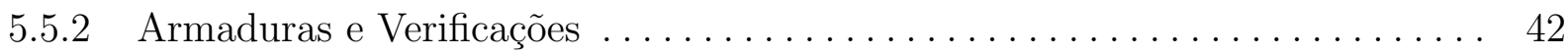

6 Resultados e Análise dos Resultados ...................... 45

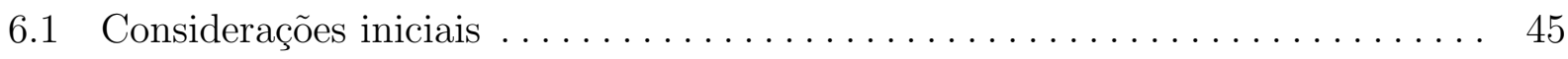

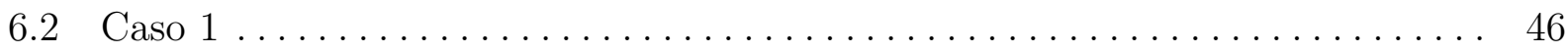

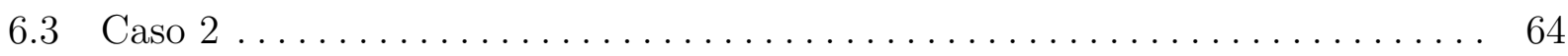

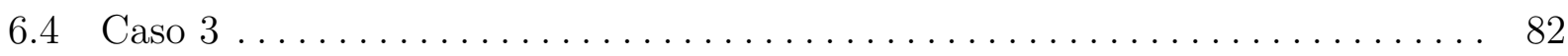

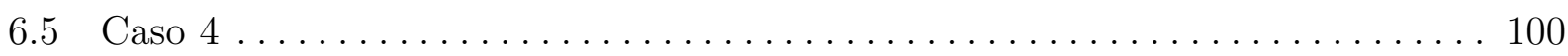

7 Conclusão............................................119

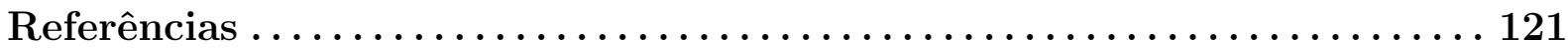

Apêndice A - Script do Bloco ............................ 125

Apêndice B - Resultados Extras ........................... 155 


\section{Lista de Figuras}

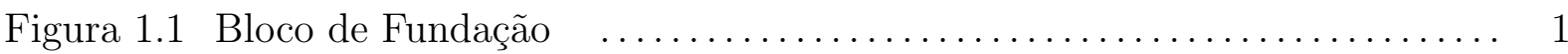

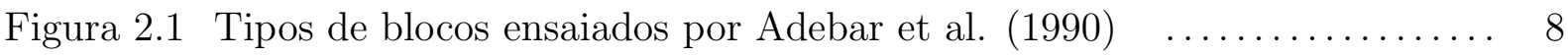

Figura 2.2 Modelo de bielas e tirantes proposto por Adebar et al. (1990) _..... 9

Figura 2.3 Bloco analisado por Iyer \& Sam $(1991) \quad \ldots \ldots \ldots \ldots \ldots \ldots \ldots \ldots \ldots$

Figura 2.4 Bloco analisado por Iyer \& Sam $(1995) \quad \ldots \ldots \ldots \ldots \ldots \ldots \ldots \ldots \ldots . \ldots \ldots$

Figura 3.1 Método da Superposição (Alonso, 1983) .................... 17

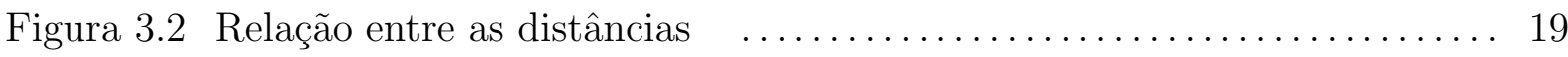

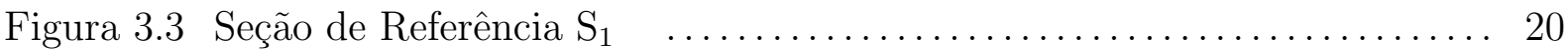

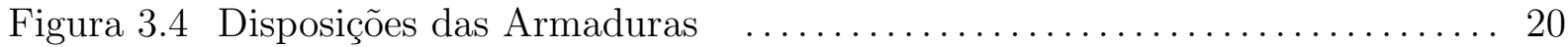

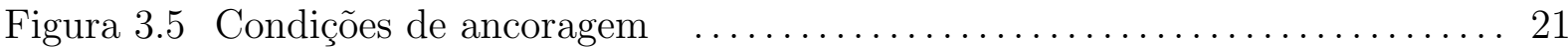

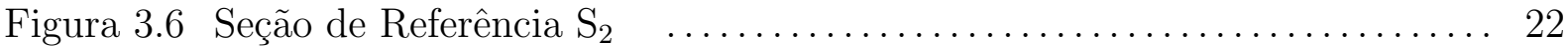

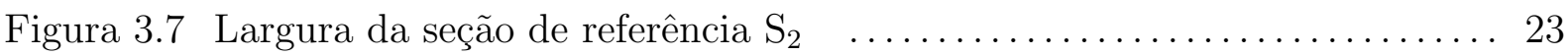

Figura 3.8 Seção de referência para o cálculo da força cortante $\ldots \ldots \ldots \ldots \ldots . \ldots 24$

Figura 4.1 Elemento Solid65. (Fonte: Ansys User's Manual) $\ldots \ldots \ldots \ldots \ldots \ldots \ldots 26$

Figura 4.2 Elemento Link8. (Fonte: Ansys User's Manual) $\ldots \ldots \ldots \ldots \ldots \ldots \ldots 27$

Figura 4.3 Elemento Solid45. (Fonte: Ansys User's Manual) $\ldots \ldots \ldots \ldots \ldots \ldots .27$

Figura 4.4 Elemento Combin39. (Fonte: Ansys User's Manual) $\ldots \ldots \ldots \ldots \ldots \ldots 28$

Figura 4.5 Curva Tensão vs. deformação do concreto $\quad$....................... 29

Figura 4.6 Curva tensão vs. deformação do aço das barras $\ldots \ldots \ldots \ldots \ldots \ldots \ldots . \ldots 30$

Figura 4.7 Comportamento da mola para solo deformável $\ldots \ldots \ldots \ldots \ldots \ldots \ldots 32$

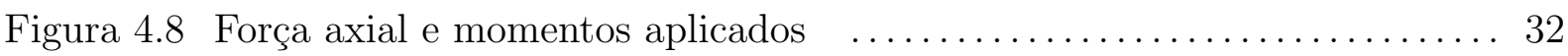

Figura 4.9 Restrições impostas ao modelo $\ldots \ldots \ldots \ldots \ldots \ldots \ldots \ldots \ldots \ldots \ldots \ldots \ldots$

Figura 5.1 Propriedades geométrica do bloco $\ldots \ldots \ldots \ldots \ldots \ldots \ldots \ldots \ldots \ldots \ldots \ldots$ 
Figura 5.2 Bloco Tridimensional Analisado $\quad \ldots \ldots \ldots \ldots \ldots \ldots \ldots \ldots \ldots \ldots \ldots \ldots$

Figura 6.1 Comparação entre as alturas para estaca 4 do Caso $1 \quad \ldots \ldots \ldots \ldots \ldots 49$

Figura 6.2 Comparação entre as alturas para estaca 1 do Caso $1 \quad \ldots \ldots \ldots \ldots \ldots .50$

Figura 6.3 Comparação entre as alturas para estaca 2 do Caso $1 \quad \ldots \ldots \ldots \ldots \ldots$..... 51

Figura 6.4 Reações nas estacas ao longo da aplicação das ações para bloco com altura

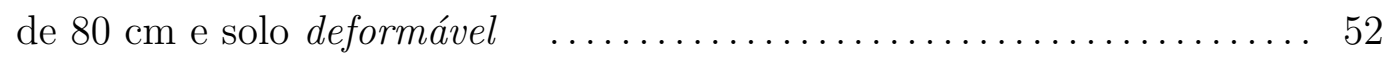

Figura 6.5 Reações nas estacas ao longo da aplicação das ações para bloco com altura

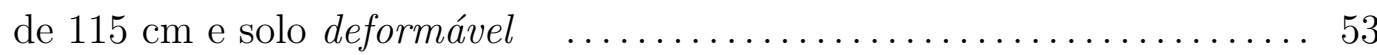

Figura 6.6 Reações nas estacas ao longo da aplicação das ações para bloco com altura

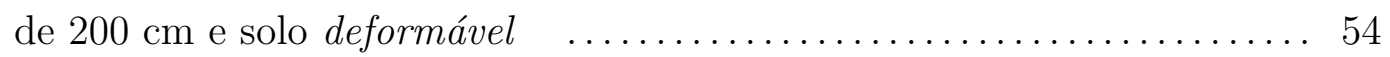

Figura 6.7 Reações nas estacas ao longo da aplicação das ações para bloco com altura

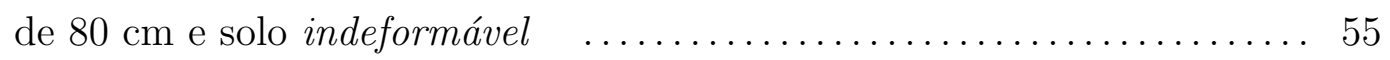

Figura 6.8 Reações nas estacas ao longo da aplicação das ações para bloco com altura

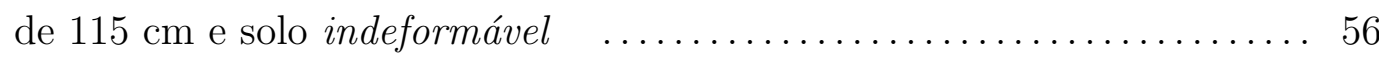

Figura 6.9 Reações nas estacas ao longo da aplicação das ações para bloco com altura

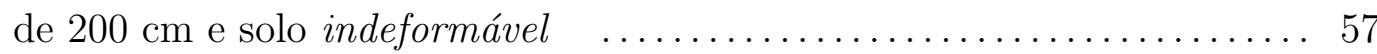

Figura 6.10 Campos de tensão de compressão - bloco com altura de $80 \mathrm{~cm}$ para solo deformável - valores em $\mathrm{kN} / \mathrm{cm}^{2}$

Figura 6.11 Campos de tensão de compressão - bloco com altura de $80 \mathrm{~cm}$ para solo indeformável - valores em $\mathrm{kN} / \mathrm{cm}^{2}$

Figura 6.12 Campos de tensão de compressão - bloco com altura de $115 \mathrm{~cm}$ para solo deformável - valores em $\mathrm{kN} / \mathrm{cm}^{2}$

Figura 6.13 Campos de tensão de compressão - bloco com altura de $115 \mathrm{~cm}$ para solo indeformável - valores em $\mathrm{kN} / \mathrm{cm}^{2}$

Figura 6.14 Campos de tensão de compressão - bloco com altura de $200 \mathrm{~cm}$ para solo deformável - valores em $\mathrm{kN} / \mathrm{cm}^{2}$

Figura 6.15 Campos de tensão de compressão - bloco com altura de $200 \mathrm{~cm}$ para solo indeformável - valores em $\mathrm{kN} / \mathrm{cm}^{2}$

Figura 6.16 Comparação entre as alturas para estacas 1 e 2 do Caso 2 67 
Figura 6.17 Comparação entre as alturas para estacas 3 e 4 do Caso $2 \quad \ldots \ldots \ldots .68$

Figura 6.18 Comparação entre as alturas para estacas 5 e 6 do Caso $2 \ldots \ldots \ldots 6$

Figura 6.19 Comparação entre as alturas para estacas 7 e 8 do Caso 2 ...... 69

Figura 6.20 Comparação entre as alturas para estacas 9 e 10 do Caso 2 ....... 69

Figura 6.21 Reações nas estacas ao longo da aplicação das ações para bloco com altura

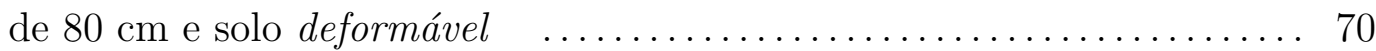

Figura 6.22 Reações nas estacas ao longo da aplicação das ações para bloco com altura

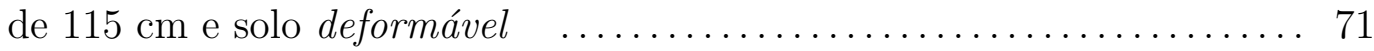

Figura 6.23 Reações nas estacas ao longo da aplicação das ações para bloco com altura

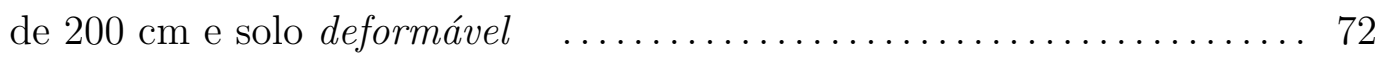

Figura 6.24 Reações nas estacas ao longo da aplicação das ações para bloco com altura de $80 \mathrm{~cm}$ e solo indeformável

Figura 6.25 Reações nas estacas ao longo da aplicação das ações para bloco com altura de $115 \mathrm{~cm}$ e solo indeformável

Figura 6.26 Reações nas estacas ao longo da aplicação das ações para bloco com altura

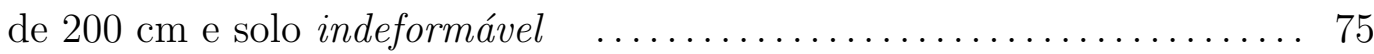

Figura 6.27 Campos de tensão de compressão - bloco com altura de $80 \mathrm{~cm}$ para solo deformável - valores em $\mathrm{kN} / \mathrm{cm}^{2}$

Figura 6.28 Campos de tensão de compressão - bloco com altura de $80 \mathrm{~cm}$ para solo

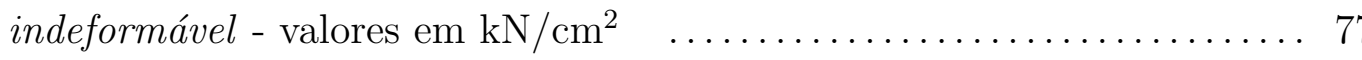

Figura 6.29 Campos de tensão de compressão - bloco com altura de $115 \mathrm{~cm}$ para solo deformável - valores em $\mathrm{kN} / \mathrm{cm}^{2}$

Figura 6.30 Campos de tensão de compressão - bloco com altura de $115 \mathrm{~cm}$ para solo indeformável - valores em $\mathrm{kN} / \mathrm{cm}^{2}$

Figura 6.31 Campos de tensão de compressão - bloco com altura de $200 \mathrm{~cm}$ para solo deformável - valores em $\mathrm{kN} / \mathrm{cm}^{2}$

Figura 6.32 Campos de tensão de compressão - bloco com altura de $200 \mathrm{~cm}$ para solo indeformável - valores em $\mathrm{kN} / \mathrm{cm}^{2}$

Figura 6.33 Comparação entre as alturas para estacas 1 e 2 do Caso 3 
Figura 6.34 Comparação entre as alturas para estacas 3 e 4 do Caso $3 \quad \ldots \ldots \ldots .86$

Figura 6.35 Comparação entre as alturas para estacas 5 e 6 do Caso $3 \quad \ldots \ldots \ldots$... 86

Figura 6.36 Comparação entre as alturas para estacas 7 e 8 do Caso $3 \quad \ldots \ldots \ldots . .67$

Figura 6.37 Comparação entre as alturas para estacas 9 e 10 do Caso $3 \quad \ldots \ldots \ldots .87$

Figura 6.38 Reações nas estacas ao longo da aplicação das ações para bloco com altura

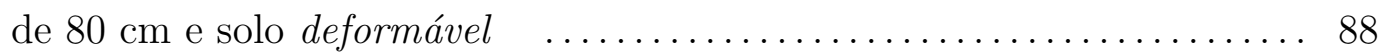

Figura 6.39 Reações nas estacas ao longo da aplicação das ações para bloco com altura de $115 \mathrm{~cm}$ e solo deformável $\ldots \ldots \ldots \ldots \ldots \ldots \ldots \ldots \ldots \ldots \ldots \ldots . \ldots \ldots$

Figura 6.40 Reações nas estacas ao longo da aplicação das ações para bloco com altura de $200 \mathrm{~cm}$ e solo deformável ........................... 90

Figura 6.41 Reações nas estacas ao longo da aplicação das ações para bloco com altura

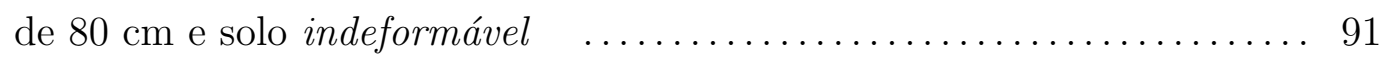

Figura 6.42 Reações nas estacas ao longo da aplicação das ações para bloco com altura

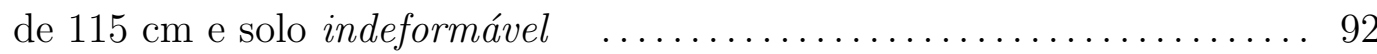

Figura 6.43 Reações nas estacas ao longo da aplicação das ações para bloco com altura de $200 \mathrm{~cm}$ e solo indeformável

Figura 6.44 Campos de tensão de compressão - bloco com altura de $80 \mathrm{~cm}$ para solo deformável - valores em $\mathrm{kN} / \mathrm{cm}^{2}$

Figura 6.45 Campos de tensão de compressão - bloco com altura de $80 \mathrm{~cm}$ para solo indeformável - valores em $\mathrm{kN} / \mathrm{cm}^{2}$

Figura 6.46 Campos de tensão de compressão - bloco com altura de $115 \mathrm{~cm}$ para solo deformável - valores em $\mathrm{kN} / \mathrm{cm}^{2}$

Figura 6.47 Campos de tensão de compressão - bloco com altura de $115 \mathrm{~cm}$ para solo indeformável - valores em $\mathrm{kN} / \mathrm{cm}^{2}$

Figura 6.48 Campos de tensão de compressão - bloco com altura de $200 \mathrm{~cm}$ para solo deformável - valores em $\mathrm{kN} / \mathrm{cm}^{2}$

Figura 6.49 Campos de tensão de compressão - bloco com altura de $200 \mathrm{~cm}$ para solo indeformável - valores em $\mathrm{kN} / \mathrm{cm}^{2}$

Figura 6.50 Comparação entre as alturas para estacas 1 e 2 do Caso 4 103 
Figura 6.51 Comparação entre as alturas para estacas 3 e 4 do Caso 4 ......... 104

Figura 6.52 Comparação entre as alturas para estacas 5 e 6 do Caso 4 ........ 104

Figura 6.53 Comparação entre as alturas para estacas 7 e 8 do Caso 4 ......... 105

Figura 6.54 Comparação entre as alturas para estacas 9 e 10 do Caso $4 \quad \ldots \ldots \ldots .105$

Figura 6.55 Reações nas estacas ao longo da aplicação das ações para bloco com altura de $80 \mathrm{~cm}$ e solo deformável ............................. 106

Figura 6.56 Reações nas estacas ao longo da aplicação das ações para bloco com altura

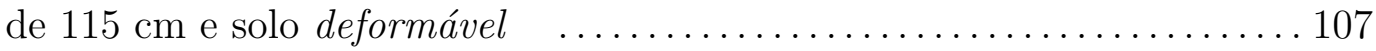

Figura 6.57 Reações nas estacas ao longo da aplicação das ações para bloco com altura de $200 \mathrm{~cm}$ e solo deformável ............................... 108

Figura 6.58 Reações nas estacas ao longo da aplicação das ações para bloco com altura de $80 \mathrm{~cm}$ e solo indeformável

Figura 6.59 Reações nas estacas ao longo da aplicação das ações para bloco com altura de $115 \mathrm{~cm}$ e solo indeformável ............................ 110

Figura 6.60 Reações nas estacas ao longo da aplicação das ações para bloco com altura

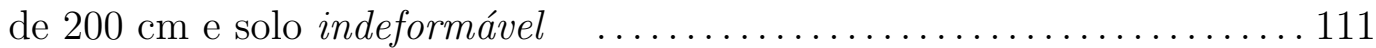

Figura 6.61 Campos de tensão de compressão - bloco com altura de $80 \mathrm{~cm}$ para solo deformável - valores em $\mathrm{kN} / \mathrm{cm}^{2}$

Figura 6.62 Campos de tensão de compressão - bloco com altura de $80 \mathrm{~cm}$ para solo indeformável - valores em $\mathrm{kN} / \mathrm{cm}^{2}$

Figura 6.63 Campos de tensão de compressão - bloco com altura de $115 \mathrm{~cm}$ para solo deformável - valores em $\mathrm{kN} / \mathrm{cm}^{2} \quad \ldots \ldots \ldots \ldots \ldots \ldots \ldots \ldots \ldots \ldots \ldots \ldots \ldots \ldots \ldots$

Figura 6.64 Campos de tensão de compressão - bloco com altura de $115 \mathrm{~cm}$ para solo indeformável - valores em $\mathrm{kN} / \mathrm{cm}^{2}$

Figura 6.65 Campos de tensão de compressão - bloco com altura de $200 \mathrm{~cm}$ para solo deformável - valores em $\mathrm{kN} / \mathrm{cm}^{2}$

Figura 6.66 Campos de tensão de compressão - bloco com altura de $200 \mathrm{~cm}$ para solo indeformável - valores em $\mathrm{kN} / \mathrm{cm}^{2}$ 


\section{Lista de Tabelas}

Tabela 4.1 Descrição dos parâmetros do material concreto $\quad \ldots \ldots \ldots \ldots \ldots \ldots \ldots . \ldots 29$

Tabela 5.1 Nome no bloco simulado e sua altura $\quad \ldots \ldots \ldots \ldots \ldots \ldots \ldots \ldots \ldots \ldots$

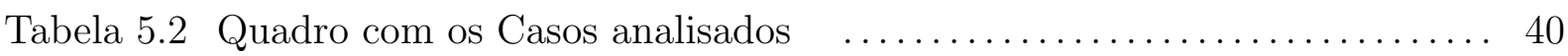

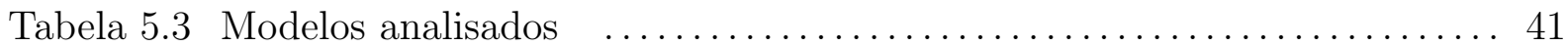

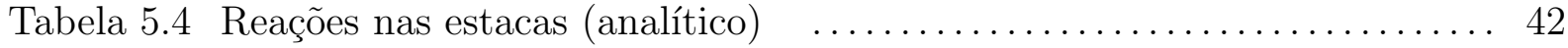

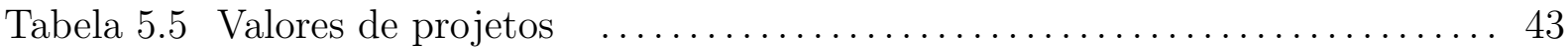

Tabela 6.1 Reações nas estacas para o Caso 1 em bloco com altura de $80 \mathrm{~cm} \quad \ldots .46$

Tabela 6.2 Reações nas estacas para o Caso 1 em bloco com altura de $115 \mathrm{~cm} \quad \ldots \quad 47$

Tabela 6.3 Reações nas estacas para o Caso 1 em bloco com altura de $200 \mathrm{~cm} \quad \ldots \quad 48$

Tabela 6.4 Reações nas estacas para o Caso 2 em bloco com altura de $80 \mathrm{~cm} \quad \ldots .64$

Tabela 6.5 Reações nas estacas para o Caso 2 em bloco com altura de $115 \mathrm{~cm} \quad \ldots 65$

Tabela 6.6 Reações nas estacas para o Caso 2 em bloco com altura de $200 \mathrm{~cm} \quad \ldots 66$

Tabela 6.7 Reações nas estacas para o Caso $3 \mathrm{em}$ bloco com altura de $80 \mathrm{~cm} \quad \ldots .82$

Tabela 6.8 Reações nas estacas para o Caso 3 em bloco com altura de $115 \mathrm{~cm} \quad \ldots 83$

Tabela 6.9 Reações nas estacas para o Caso $3 \mathrm{em}$ bloco com altura de $200 \mathrm{~cm} \quad \ldots 84$

Tabela 6.10 Reações nas estacas para o Caso 4 em bloco com altura de $80 \mathrm{~cm} \quad \ldots 100$

Tabela 6.11 Reações nas estacas para o Caso 4 em bloco com altura de $115 \mathrm{~cm} \quad \ldots 101$

Tabela 6.12 Reações nas estacas para o Caso 4 em bloco com altura de $200 \mathrm{~cm} \quad \ldots 102$

Tabela B.1 Reações nas estacas para o Caso 1 em bloco com altura de $115 \mathrm{~cm}$ e

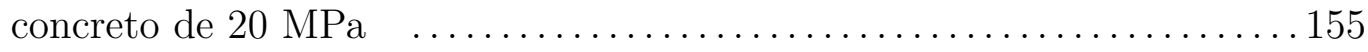

Tabela B.2 Reações nas estacas para o Caso 1 em bloco com altura de $115 \mathrm{~cm}$ e

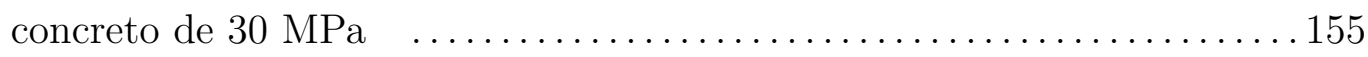

Tabela B.3 Reações nas estacas para o Caso 1 em bloco com altura de $115 \mathrm{~cm}$ e

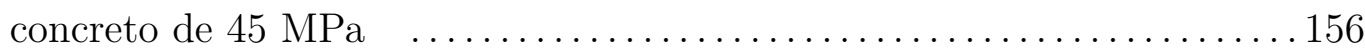


Tabela B.4 Reações nas estacas para o Caso 2 em bloco com altura de $115 \mathrm{~cm}$ e

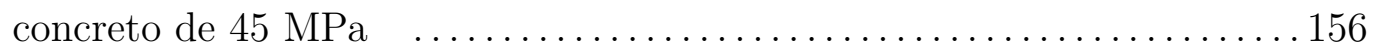




\section{Resumo}

RAMOS, F. A. C. (2007). Análise Numérica de Blocos sobre Dez Estacas: Cálculo das Reações de Apoio. São Carlos. Dissertação (Mestrado) - Escola de Engenharia de São Carlos, Universidade de São Paulo.

Blocos sobre estacas ou blocos de coroamento são elementos estruturais usados para transferir as ações da superestrutura para um conjunto de estacas. São encontrados em infraestruturas de pontes e edifícios. O conhecimento de seu real comportamento estrutural é de fundamental importância, pois são elementos estruturais que garantem a segurança de toda a estrutura. Ainda não há consenso pelo meio técnico quanto o seu real comportamento estrutural. O processo de cálculo usualmente empregado pelo meio técnico para a determinação das reações nas estacas é o método da superposição dos efeitos. Esse método não considera a interação do elemento estrutural com o tipo solo em que as estacas estão apoiadas, nem a altura do bloco. Com a ajuda de análise numérica feita em programa de computador baseado nos Métodos dos Elementos Finitos (MEF) foram simulados blocos variando parâmetros como a altura do bloco e os tipos de vinculação das estacas (solo). Para que houvesse a interação da estrutura com o solo foram propostos dois tipos de solos: solo deformável e solo indeformável. Os blocos analisados foram submetidos as ações de força centrada e momentos variando as suas intensidades. Os resultados mostram que o tipo de vinculação das estacas e a variação da altura do bloco modificaram significativamente o comportamento estrutural do bloco. A situação mais crítica para o bloco foi aquela em que se consideravam as estacas apoiadas em solo do tipo indeformável, chegando-se a resultados de reações nas estacas com diferenças a mais de 200\%. Foi possível perceber que mesmo com solo do tipo deformável as estacas na região central do bloco foram as mais solicitadas. E em função da análise numérica conclui-se que os resultados obtidos são de grande importância.

Palavras-chave: blocos sobre estacas; concreto armado; fundações; análise numérica. 


\section{Abstract}

RAMOS, F. A. C. (2007). Numerical Analysis of Cap Supported on Ten Piles: Calculus of Piles' Reaction. São Carlos. Dissertation (Master) - School of Engineering of São Carlos, University of São Paulo.

Piles caps are structural elements used to transfer actions of the superstructure to a group of piles. They are found in infrastructures of bridges and buildings. The knowledge of its real structural behavior presents fundamental importance, once piles caps are structural elements that guarantee the safety of all the structure. There is no consensus yet between specialists on its real structural behavior. The traditional calculation process usually used to determine piles reaction is the superposition effect method. This method does not consider the interaction of the structural element with the type of soil where piles are supported, nor the height of the cap. With the aid of numerical analysis made in computer program based on the Finite Elements Method (FEM), caps have been simulated varying parameters as caps height and the types where piles are supported (soil). In order to have the interaction of the structure with the soil, two types of soil have been considered: compressible soil and incompressible soil. The caps analyzed were submitted the action where centered force and moments have been considered varying its intensities. The results show that the type of pile support and the variation of cap height significantly modified the structural behavior of the cap. The most critical situation for the cap was that one considering the piles supported in soil incompressible, reaching results of piles' reactions with more than $200 \%$ of differences. The piles in the central region of the cap have been the most requested on compressible soil type. In function of the numerical analysis, we conclude that the results obtained are of great importance.

Keywords: pile-caps; reinforced concrete; footing; numerical analysis. 


\section{CAPÍtulo \\ Introdução}

\subsection{Considerações Iniciais}

Os blocos sobre estacas são estruturas tridimensionais de concreto armado usados principalmente para a transferência das ações provenientes da superestrutura para um conjunto de estacas (figura 1.1). São elementos estruturais comumente encontrados em infraestruturas de obras como pontes e edifícios.

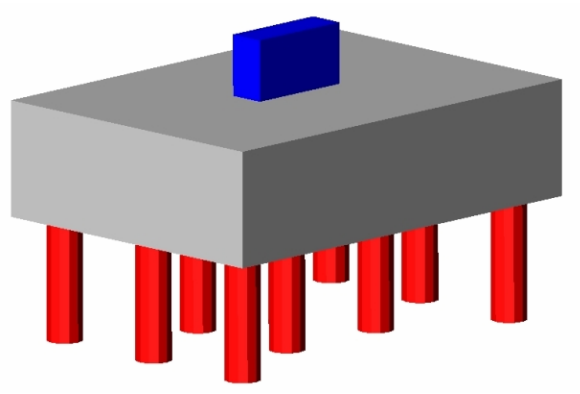

Figura 1.1: Bloco de Fundação

A escolha do tipo de fundação por estacas é feita após terem sido satisfeitas algumas condições técnicas e econômicas da obra, cujo fator determinante para a escolha é a resistência do solo. Fundações em estacas são adotadas quando a camada resistente do solo, que serve para o apoio da fundação, está em níveis mais profundas. E havendo a necessidade da utilização de estacas, é construído um bloco de coroamento, também denominado bloco sobre estacas.

O conhecimento do comportamento real do elemento estrutural bloco é de importância fundamental, pois sua inspeção visual, após a construção é de grande dificuldade. Esses elementos estruturais são fundamentais para a segurança da superestrutura.

As primeiras pesquisas realizadas foram feitas considerando dois aspectos, análise teórica elástica linear e ensaios experimentais. Sendo o primeiro, dividido em dois métodos: 
a analogia de bielas e tirantes (Blévot \& Frémy (1967)) e a teoria de viga (CEB-FIP 1970).

Os modelos de cálculos utilizados para o dimensionamento de blocos, consideram métodos aproximados. Tanto o modelo de bielas e tirantes, Blévot \& Frémy (1967), como o modelo utilizado pelo CEB-FIP (1970), são aproximações para o cálculo do dimensionamento. A recomendação para o uso da teoria de flexão para o dimensionamento de blocos é feita pelos códigos Americanos (ACI-318 (1995)) e Britânico (BS 8110, 1985), que consideram algumas simplificações quanto à geometria e às propriedades dos materiais. $\mathrm{O}$ Método do CEB-FIP (1970), também utiliza a teoria de flexão para o dimensionamento de blocos, adotando seções de referência. Normalmente a teoria de viga é aplicada em blocos flexíveis, e a analogia das bielas e tirantes aos blocos rígidos.

Nos últimos anos, grande partes dos pesquisadores estão concentrando suas pesquisas em análise da simulação numérica computacional. As primeiras análises numéricas realizadas consideravam apenas o comportamento elástico linear, levando em consideração apenas os resultados da avaliação dos fluxos de tensões principais, não levando em conta as não linearidades, para aplicação do modelo de bielas e tirantes. No trabalho de Delalibela (2006), foram feitos ensaios experimentais, com blocos sobre duas estaca, e simulação numérica computacional utilizando a não linearidades física do material e geométrica do elemento. Essa simulação computacional representa o comportamento do bloco com uma maior precisão, comparado com os modelos reais ensaiados em laboratório.

Atualmente o dimensionamento de bloco pelos métodos tratam-os de modo simplificado, não levando em consideração muitos fatores que influenciam em seu comportamento, como por exemplo o comportamento mecânico do conjunto aço/concreto e a interação solo/estrutura.

A norma brasileira NBR 6118:2003 considera os blocos sobre estaca como sendo elementos estruturais especiais, classificando o comportamento em rígidos e flexíveis. A norma também não apresenta nenhum roteiro para a verificação e o dimensionamento dos elementos, mas indica que deve ser usada a análise linear, análise plástica ou a análise nãolinear. Menciona também o uso do método dos elementos finitos e método das diferenças finitas para a análise linear, sendo recomendado utilizar o modelo de bielas e tirantes tridimensionais.

Os métodos usuais empregados para o projeto de blocos sobre estacas, utilizado pelo meio técnico no Brasil, são o método do CEB-FIP (1970) e o Método das Bielas e Tirantes. No caso de blocos com muitas estacas, a teoria do modelo de bielas e tirantes não 
se aplica, pois não se sabe o real comportamento desses elementos, sendo mais utilizado o modelo do CEB-FIP (1970).

Munhoz (2004) em sua análise numérica computacional constatou que as estacas logo abaixo do eixo do pilar recebiam a maior parcela da força quando comparada com estacas mais afastadas do eixo do pilar. O modelo de cálculo adota, para força centrada, como sendo a força atuante no pilar igualmente distribuída entre o número de estacas. Isso mostra que é necessário, uma adaptação das hipóteses utilizadas.

Essa falta de conhecimento sobre qual é o melhor método, ou qual é o método mais apropriado para o dimensionamento de blocos sobre muitas estacas, dá um motivo razoável para o aprofundamento das pesquisas e o estudo do comportamento dos blocos. É necessário, porém, dispor do método de cálculo que atenda as necessidades do real comportamento para que o projetista dimensione de forma correta e segura, melhorando o projeto estrutural e estabelecendo critérios para a verificação.

\subsection{Justificativa}

Os modelos de cálculo utilizados atualmente para o dimensionamento de blocos, baseiam-se em muitas simplificações. Existem algumas divergências entre os métodos analíticos e as normas utilizadas para o dimensionamento, principalmente, quando se tratam de blocos sobre muitas estacas.

O principal método utilizado para o dimensionamento de blocos sobre muitas estacas é o do CEB-FIP (1970). Ele utiliza a teoria da flexão por meio da análise das seções críticas, o que não corresponde com o modelo real do bloco.

\subsection{Objetivo}

Este trabalho estuda o comportamento de blocos sobre dez estacas, tendo como objetivo analise dos fluxos de tensões em suas direções principais, fazendo uma comparação entre os métodos analíticos utilizados para o dimensionamento e a análise numérica. 


\subsection{Método}

Inicialmente foram feitas análises dos blocos por meio dos códigos usados para o dimensionamento, com relação à verificação da segurança do bloco e o cálculo das armaduras necessárias para o bloco.

Posteriormente os modelos foram reproduzidos em computador com o auxilio de programa em elementos finitos MEF, o ANSYS ${ }^{\circledR}$ (ANalyser SYStem - ANSYS, Inc.).

Após o processamento, a comparação entre os resultados do modelo de cálculo e o numérico permitiam calcular as reacões nas estacas e determinar os fluxos de tensões em suas direções principais.

Todos os modelos dos blocos de concreto armado analisados levaram em consideração as armaduras principais, a não linearidade física do material e geométrica do elemento, a fissuração do concreto e o escoamento das barras de aço das armaduras, fazendo uma simulação numérica do bloco real.

\subsection{Apresentação da Dissertação}

A dissertação é dividida em sete capítulos. Sendo este o primeiro que apresenta a introdução do tema, justificativa e objetivo do trabalho.

No Capítulo 2 é apresentada uma revisão bibliográfica descrevendo os principais trabalhos desenvolvidos na área tanto no contexto mundial como no Brasil.

O Capítulo 3 descreve os critérios de projeto e método para o dimensionamento de bloco sobre muitas estacas. São apresentados os principais métodos analíticos utilizados no projeto de bloco sobre estacas e as principais sugestões de alguns autores.

No Capítulo 4 são apresentados os aspectos da modelagem numérica, como o tipo de elemento utilizado, modelos constitutivos e considerações sobre a análise não-linear e principalmente o tipo de vinculação empregada.

Já no Capítulo 5 são apresentadas as propriedades do bloco adotado para a análise numérica, como por exemplo as alturas adotadas, os casos de aplicação das ações e as armaduras.

O Capítulo 6 são apresentados os resultados obtidos com a análise numérica, bem como as discussões e comentários dos mesmo. 
Finalmente no Capítulo 7 são apresentadas as conclusões do trabalho, bem como sugestões para trabalhos futuros. 


\section{CAPÍtUlo}

\section{Revisão Bibliográfica}

\subsection{Considerações iniciais}

Trabalhos científicos na área de engenharia estrutural feitos a respeito de blocos de fundação em concreto com número de estacas maior que 5 ou 6 são pouco na literatura técnica, principalmente trabalhos na área experimental. Porém, em áreas como a geotecnia há uma série de trabalhos publicados a respeito de blocos apoiados em várias estacas, porém não levam em consideração a análise estrutural do bloco, mas sim a interação das estacas com o solo e o comportamento do solo. Esses trabalhos não serão analisados aqui pois, não é o objetivo deste trabalho.

Blévot \& Frémy (1967) realizaram ensaios em blocos sobre duas, três e quatro estacas totalizando mais de cem blocos, submetidos à ação de força centrada, com a finalidade de estudar os comportamentos destes elementos estruturais, verificando a teoria de bielas e a influência de diferentes tipos de arranjos de armadura.

Mautoni (1972) realizou ensaios em blocos sobre duas estacas, e suas principais conclusões foram um método para determinar a força de ruína do bloco e a determinação do mecanismo de colapso.

Taylor e Clarke (1976) ensaiaram blocos com quadro estacas, para verificar a influência do tipo do arranjo da armadura no comportamento estrutural do bloco. Os pesquisadores verificaram que a força última pode ser de até $30 \%$ dependendo do tipo de arranjo de armadura.

Miguel (2000) realizou ensaio experimental e análise numérica, por meio do Método dos Elementos Finitos, de blocos de concreto armado sobre três estacas submetidos a ação de força centrada. O objetivo principal era verificar a formação de fissuras e o modo de ruptura. A autora concluiu que o método das bielas desenvolvido por Blévot \& Frémy (1967) mostrou ser conservativo, indicando margem de segurança de $12 \%$. 
Munhoz (2004) realizou análise numérica computacional de blocos com até 5 estacas, verificando a existência de um fluxo de tensões predominante para as estacas logo abaixo do pilar no mesmo eixo vertical. Sua análise, contudo, não contemplava as não-linearidades física e geométrica.

\subsection{Pesquisas com ênfase experimental}

Adebar et al. (1990) realizaram ensaios em seis tipos de blocos de concreto com quatro e seis estacas, com a finalidade de examinar o modelo de bielas e tirantes tridimensional. Os tipos diferentes de modelos ensaiados são apresentado na figura 2.1.

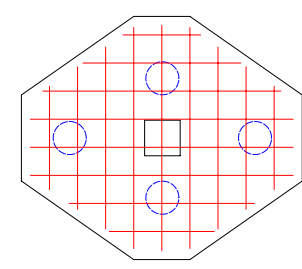

a

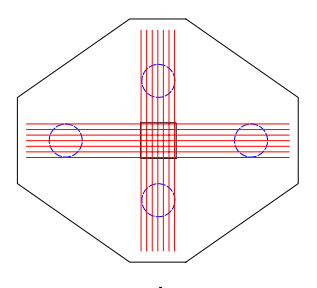

d

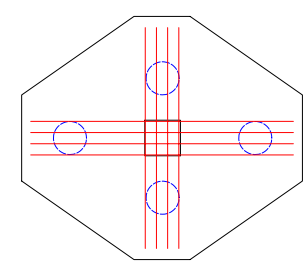

b

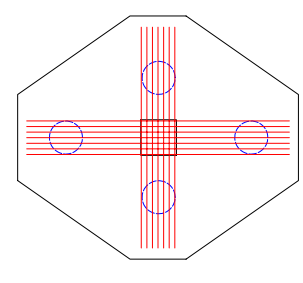

e

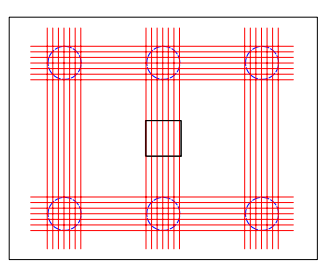

C

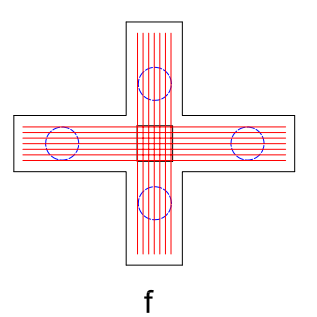

Figura 2.1: Tipos de blocos ensaiados por Adebar et al. (1990)

Os modelos foram dimensionados seguindo os critérios do ACI 318 (1983) e pelo Método das Bielas e Tirantes. O modelo $a$ foi dimensionado segundo o ACI 318 (1983). Os modelo $b, c$ e $d$ foram dimensionados pelo Método das Bielas e Tirantes. No modelo $d$ a armadura era o dobro do modelo $b$ e o modelo $e$ tinha as mesmas características do modelo $d$, mas com armadura distribuída segundo o ACI 318 (1983). O modelo $f$ era idêntico ao modelo $d$, porém sem os quatro cantos de concreto.

Nos ensaios experimentais foram observadas as seguintes relações: força vs. deslocamento, força distribuída entre as estacas, as deformações nas barras da armadura e forças de fissuração e de ruptura.

O modelo do bloco a rompeu com aproximadamente $83 \%$ da força prevista utilizando os critérios do ACI 318 (1983). Nos modelos dos blocos $b$ e $c$ as duas estacas mais 
próximas ao pilar suportaram a maior parcela das forças inicialmente. Após o escoamento das armaduras nas direções dessas estacas é que o regime dos fluxos das forças foi alterado, porém não ocorrendo uma redistribuição significativa das forças antes do colapso. Com comportamento semelhante aos anteriores os blocos $d$ e $e$ atingiram a ruína antes do escoamento das armaduras. O modelo do bloco $f$ se comportou como sendo duas vigas ortogonalmente interseptadas pelo meio, com ruína por cisalhamento da viga mais curta e sem escoamento das armaduras longitudinais.

Adebar et al. (1990) concluíram que os procedimentos indicados pelo ACI 318 (1983) não foram compatíveis com os resultados experimentais. Pois os critérios não levam em consideração a altura útil do bloco e desprezava a influência da quantidade e distribuição das barras da armadura longitudinal. O Modelo de Bielas e Tirantes representou melhor o comportamento estrutural dos blocos.

Os autores sugeriram um modelo refinado de bielas e tirantes baseado nas observações experimentais e resultados numéricos, obtidos por meio do Método dos Elementos Finitos (ver figura 2.2a). Nota-se na figura 2.2b que entre os pontos de aplicação de força, surgem tensões de tração. No modelo sugerido, essas tensões de tração são absorvidas por um tirante na região central da biela de compressão, posicionado entre a cabeça da estaca e a base do pilar.

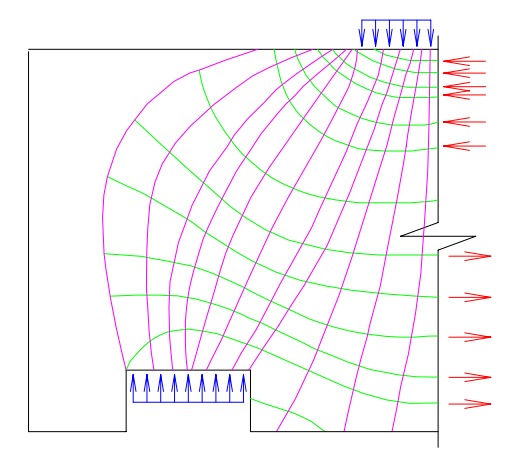

a

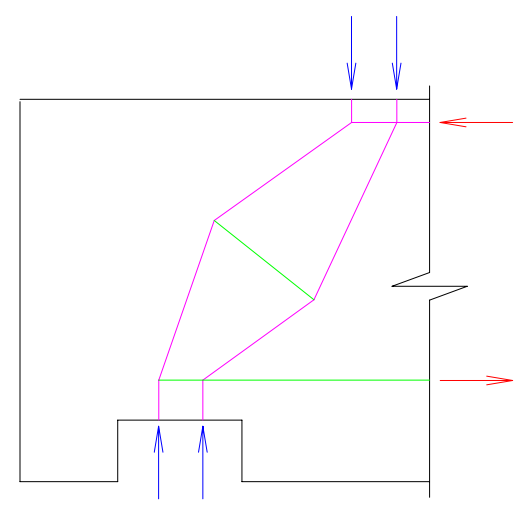

b

Figura 2.2: Modelo de bielas e tirantes proposto por Adebar et al. (1990)

\subsection{Pesquisa com ênfase numérica}

Iyer \& Sam (1991) estudaram o comportamento de blocos sobre três estacas por meio de análise elástica linear tridimensional. Apresentaram uma solução para as equações 
da teoria da elasticidade, dadas em termos de vetor de Galerkin. No método proposto, as distribuições de tensões no bloco foram obtidas considerando as condições de contorno pela superposição de quatro soluções elásticas tridimensionais, para um bloco retangular sujeito a diferentes carregamentos em suas faces. Na figura 2.3 pode ser visto um modelo de bloco analisado.

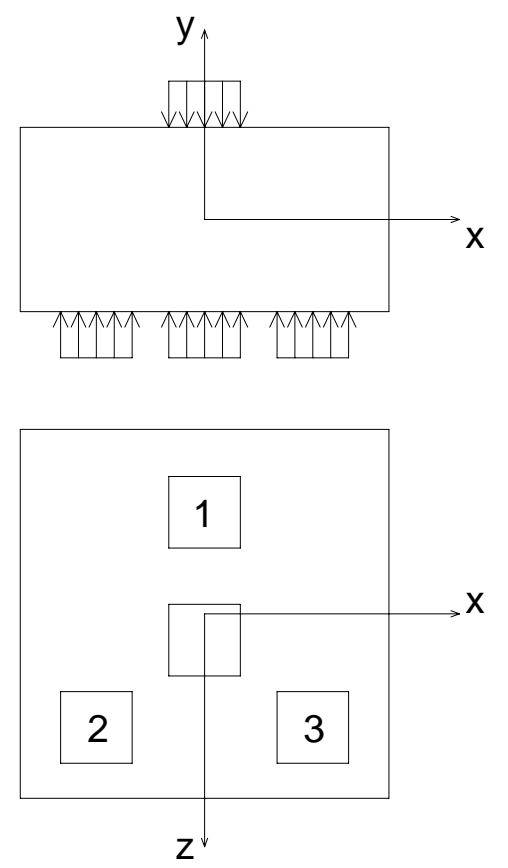

Figura 2.3: Bloco analisado por Iyer \& Sam (1991)

Apesar dos blocos serem em concreto armado, admitiu-se que os mesmos tinham comportamento elástico e linear e constituídas de material homogêneo e isotrópico, pois, a distribuição de tensões sugere uma solução inicial fornecendo critérios para estudos mais refinados.

Os pesquisadores concluíram que nem a analogia de treliça proposta por Blévot \& Frémy (1967) e a teoria de flexão, que considera o bloco como sendo uma viga apoiada em estacas são satisfatórios, pois as tensões máximas não conferem com precisão a sua localização.

Em 1992, Iyer \& Sam (1992) conduziram análises análogas feitas na pesquisa desenvolvida por eles em 1991, para blocos sobre duas e quatro estacas.

Iyer \& Sam (1995 - a) realizaram análise em blocos sobre quatro estacas. A análise foi baseada no método dos elementos finitos e foi considerado a não linearidade física do material concreto. O objetivo do trabalho era analisar os resultados de força e 
deslocamento, deformação da armadura, a formação de fissuras e da força de ruína. Os autores constataram que para pequenas intensidades de forças o comportamento de viga foi predominante nos blocos, enquanto que para grandes intensidades de forças o bloco resistiu pela ação da biela, indiferente do arranjo da armadura. A análise via método dos elementos finitos utilizando a não linearidade do material concreto foi capaz de estimar com precisão o comportamento e a força última dos blocos de concreto.

Iyer \& Sam $(1995$ - b) investigaram a influência em diferentes tipos de arranjo de armadura em blocos sobre quatro estacas. Os tipos de arranjo de armadura utilizados foram armadura em malha, armadura entre estacas e armadura nas diagonais. Os tipos de arranjo de armadura podem ser visto na figura 2.4. Os resultados obtidos divergiram dos resultados obtidos por outros pesquisadores que realizaram ensaios experimentais. A divergência ocorreu porque o bloco com armadura distribuída entre estacas não apresentou a maior força última. A maior força última foi em bloco com armadura distribuída em malha. O problema ocorreu em função do elemento finito utilizado que, provavelmente, para o concreto era o mesmo para as barras. Quando houve a ruína do elemento de concreto, este não transmitia mais as forças para os outros elementos.
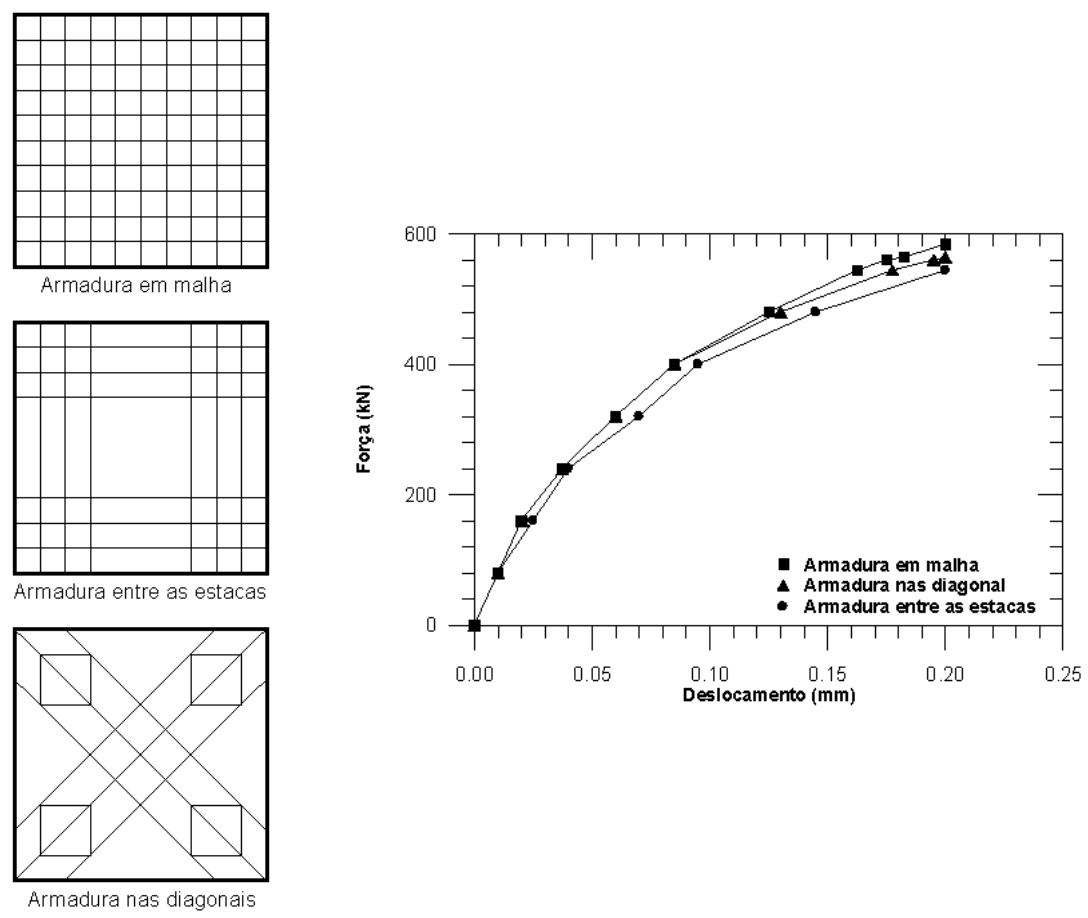

Figura 2.4: Bloco analisado por Iyer \& Sam (1995)

Delalibera \& Giongo (2004 - a) simularam numericamente blocos sobre duas estacas. O objetivo dos pesquisadores era investigar a influência que as dimensões em planta do pilar e das estacas provocam no comportamento estrutural dos blocos. Foram levadas 
em consideração para a análise numérica as não linearidades física do material e geométrica do elemento estrutural e a aderência perfeita entre o aço e o concreto. Os autores concluíram, por meio de análise estatística, que a altura do bloco é fator preponderante nos valores das tensões nodais inferior e superior.

Delalibera \& Giongo (2004 - b) simularam blocos com três estacas em linha. Os blocos tinham as mesmas propriedades geométricas, variando ângulo de inclinação das bielas de compressão, as rigidezes (EI) dos blocos e o tipo de solo de apoio para as estacas. Por meio de estudo estatístico, os pesquisadores obtiveram vinte e sete combinações para serem simuladas.

Utilizando o critério ANOVA (analise de variância), os pesquisadores concluíram que a rigidez do bloco e a representação do solo como contínuo, tem importância relevante na distribuição de força nas cabeças das estacas e em situações onde pode-se desprezar o atrito lateral na interface estaca-solo o principal fator que influi na distribuição de força nas cabeças das estacas é o ângulo de inclinação da biela de compressão.

Os autores também constataram que os blocos considerados rígidos (maior altura) apresentam melhores resultados quanto à distribuição de força nas cabeças das estacas e que o método proposto por Moraes (1976), onde não existe diferença entre os tipos de solo, pode resultar em valores diferentes para as reações nas estacas.

Munhoz et al. (2004 - a) com o objetivo de contribuir para o estudo de critérios de projeto, analisaram numericamente, via Métodos dos Elementos Finitos, blocos sobre duas estacas, submetidos à ação de força centrada e considerando o comportamento dos materiais de elástico linear. Os resultados de interesse foram as tensões em suas direções principais. Os resultados obtidos foram comparados com os modelos analíticos empregados no dimensionamento. Os autores verificaram que existe grande variabilidade nos resultados.

Em Munhoz et al. (2004 - b) foram analisados numéricamente três blocos sobre quatro estacas, variando a altura, com o objetivo de verificar a influência da rigidez de bloco em estaqueamento paralelos com ações verticais excêntricas. Foram levadas em consideração as não linearidades física do material e a geométrica do elemento estrutural e também a aderência perfeita entre o concreto e as barras de aço. Para o concreto utilizou-se o critério de ruptura "Concrete" existente no programa ANSYS ${ }^{\circledR}$ e para o aço adotou-se o comportamento elastoplástico perfeito.

Os autores concluíram que nos blocos com menor altura (menor rigidez) as fis- 
suras foram mais intensas, o método da superposição dos efeitos é conservativo e que o modelo numérico apresentou valores de forças menores nas cabeças das estacas, pois a redistribuição de força foi influenciada pela rigidez do bloco.

Por meio de simulação numérica Munhoz et al. (2005) analisaram o comportamento de blocos quadrados sobre cinco estacas, sendo uma estaca em cada vértice e uma estaca central. Os pesquisadores concluíram que para se terem as mesmas reações em todas as estacas o bloco precisaria ter grande rigidez (grande altura), o que inviabilizaria economicamente sua construção. Com alturas mais elevadas o bloco passaria a se comportar como viga parede.

Portanto, os pesquisadores concluíram que a utilização de blocos sobre cinco estacas, com uma central, não é a forma mais adequada.

\subsection{Pesquisa com ênfase experimental e numérica}

Delalibela (2006) em seu trabalho realizou análise experimental e numérica em blocos sobre duas estacas submetidos à ação de força centrada e excêntrica. O autor, primeiramente, desenvolveu uma análise numérica tridimensional de blocos levando em consideração as não linearidades física do material e geométrica do elemento, fissuração do concreto e a influência das armaduras no comportamento do elemento.

Com a análise numérica feita por Delalibela (2006), foi possível perceber o comportamento e a forma geométrica das bielas de compressão e concluir que a geometria dos modelos difere das usualmente sugerida por vários autores.

Após uma primeira análise numérica computacional o autor, com o objetivo de otimizar o número de variáveis investigada experimentalmente, realizou uma análise estatística utilizando o critério ANOVA (analise de variância), e constatou que as variáveis preponderantes que influenciam o comportamento do bloco são: ângulo de inclinação da biela de compressão, a área da seção transversal do pilar e a posição da força de compressão.

Na parte experimental foram realizados ensaios em 14 blocos com o fim principal de observar a geometria das bielas de compressão, e também a análise da eficiência dos ganchos das barras de aço que compõem os tirantes. Nessa análise foi possível observar a diferença entre blocos submetidos à ação de força centrada e excêntrica. Verificou-se também que os ganchos podem ser omitidos sem prejuízo da segurança estrutural dos 
blocos.

Após a análise experimental, foi realizada a modelagem computacional de todos os blocos. O objetivo principal da análise foi analisar os fluxo das tensões principais de compressão e comparar os resultados com os obtidos nos ensaios.

Em função dos resultados obtidos por meio das análises experimental e numérica desenvolveram-se modelos de bielas e tirantes aplicados a blocos sobre duas estacas. 


\section{CAPÍTUlo}

\section{Projeto de Blocos}

\subsection{Considerações iniciais}

Neste capítulo é apresentada uma revisão bibliográfica a respeito dos critérios de projetos e métodos para o dimensionamento de blocos sobre várias estacas.

Inicialmente são apresentados os elementos gerais para o dimensionamento de bloco como por exemplo a distância entre estacas e a altura do bloco. Também são apresentadas algumas recomendações normativas e algumas recomendações dos principais autores. Salientando que os principais autores remetem ao cálculo de sapatas isoladas, adotando o método das seções de referência para o cálculo do dimensionamento de blocos sobre várias estacas.

Em seguida é apresentado um processo de determinação das ações nas estacas para blocos apoiados por muitas estacas. Outros métodos o têm como base, a exemplo do CEB-FIP (1970), Guerrin (1972), Moraes (1976), Alonso (1983), Pfeil (1983), Calavera (1991), entre outros autores consagrados.

Por último é apresentado detalhadamente o processo do boletim n ${ }^{\circ} 73$ do CEBFIP (1970).

\subsection{Procedimentos gerais de projeto}

Um das primeiras decisões tomada pelo projetista quando do dimensionamento de bloco é o tipo de estaca a ser usada. Em seguida conhecendo-se as ações atuantes no pilar pode-se determinar o número de estacas por pilar.

Sabendo o número de estacas necessárias para o pilar, faz-se a distribuição geométrica em planta de modo que, sempre que possível, obtenham-se blocos com volumes menores. É recomendado que o centro do estaqueamento coincida com o centro do pilar, sempre 
respeitando os valores mínimos para os espaçamentos entre eixos de estacas, distância das faces do bloco aos eixos das estacas mais próximas e altura do bloco.

Obedecendo a essas recomendações as dimensões do bloco são minimizadas e obtém-se conseqüentemente blocos rígidos. No entanto se essas dimensões mínimas não forem atendidas o bloco deixa de ser classificado como rígido passando a ser classificado como flexível e tendo seu comportamento semelhante às vigas de concreto armado.

A NBR 6118:2003 sugere que o valor de espaçamento entre eixos de estacas deva estar compreendido entre 2,5 vezes a 3 vezes o diâmetro da estaca, porém, alguns autores adotam 2,5 vezes o diâmetro no caso de estacas pré-moldadas e 3,0 vezes para estacas moldadas "in loco", para ambos os casos esse valor não deve ser inferior a $60 \mathrm{~cm}$. A norma considera também como sendo bloco rígido quando se verifica a expressão a seguir, considerando o mesmo critério usado para sapatas rígidas.

$$
\mathrm{h} \geq \frac{\left(\mathrm{a}-\mathrm{a}_{\mathrm{p}}\right)}{3}
$$

sendo:

h: altura do bloco;

a: dimensão do bloco em uma determinada direção;

$\mathrm{a}_{\mathrm{p}}$ : dimensão do pilar na mesma direção.

Com relação a distância do eixo da estaca até a face do bloco alguns projetistas e autores, como por exemplo Alonso (1983), adotam que a distância mínima deve ser de $15 \mathrm{~cm}$ somado a meio diâmetro da estaca.

Montoya et al. (2000) indicam que deve ser adotado para espaçamento entre estacas a distância de duas vezes seu diâmetro ou 1,75 vez a sua diagonal no caso de seção quadrada e não menor que $75 \mathrm{~cm}$. Quanto a classificação do bloco entre rígido e flexível o autor usa as mesmas especificações da norma EHE (2001) que classifica como sendo rígido quando a relação $l_{c} \leq 2 h$, onde $l_{c}$ é a distância entre a face do pilar ao eixo da estaca mais afastada, for atendida, caso contrário, o bloco dever ser classificado como sendo flexível. Para a distância do eixo da estaca até a face do bloco o autor sugere que o valor da distância entre qualquer ponto do perímetro da estaca até a borda do bloco não deva ser inferior ao raio da estaca sobre dois, nem a $25 \mathrm{~cm}$. Em relação ao valor do embutimento da estaca no bloco o autor considera recomendações práticas que esteja 
compreendido entre os valores de $10 \mathrm{~cm}$ e $15 \mathrm{~cm}$, podendo variar dependendo do tipo de estaca.

Calavera (1991) sugere que a distância entre as estacas deve estar entre duas vezes a três vezes o seu diâmetro. O autor ainda sugere que a distância do eixo da estaca até a face do bloco não seja inferior ao raio da estaca e nem a $25 \mathrm{~cm}$, tomando-se essa distância entre qualquer ponto do perímetro da estaca até a borda do bloco. Entre a ligação da estaca com o bloco o autor sugere que o valor do embutimento não seja menor que $10 \mathrm{~cm}$ e não mais que $15 \mathrm{~cm}$.

\subsection{Cálculo das ações nas estacas}

É um procedimento que determina a ação em cada estaca separadamente, que é útil em outros métodos de dimensionamento do elemento bloco. Para fazer o cálculo das reações nas estacas, primeiramente precisa-se levar em consideração algumas hipóteses básicas. As estacas devem ser paralelas e verticais, como é chamado no meio técnico, estaqueamento paralelo, estacas iguais, do mesmo tipo, e o bloco é considerado como sendo infinitamente rígido e as reações das estacas proporcionais aos respectivos deslocamentos (na direção do eixo da estaca), todas as estacas têm o mesmo comprimento e, por fim, desprezam-se as pressões de apoio do bloco no terreno.

Esse procedimento também é conhecido como método da superposição que, em resumo, consiste na soma separada de cada efeito, da ação vertical oriunda do pilar, e dos momentos nas duas direções, se existirem, como pode ser visto na figura 3.1.

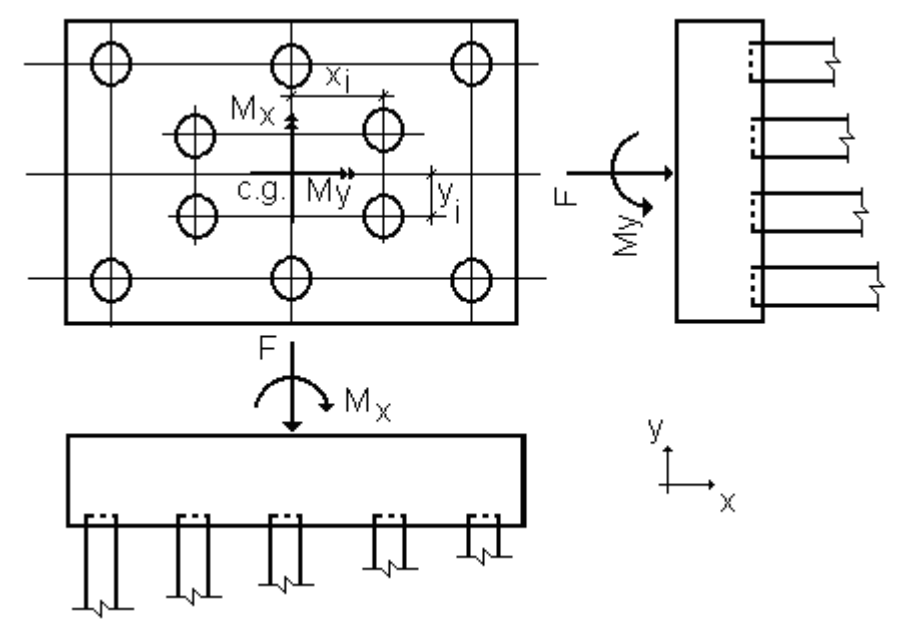

Figura 3.1: Método da Superposição (Alonso, 1983) 
Para que seja válido o procedimento, os eixos x e y devem ser os eixos principais de inércia. Logo a força resultante $\mathrm{R}_{i}$ em uma estaca genérica $i$ com coordenadas $\left(\mathrm{x}_{i}, \mathrm{y}_{i}\right)$ é dada pela seguinte expressão:

$$
\mathrm{R}_{\mathrm{i}}=\frac{\mathrm{F}}{\mathrm{n}_{\mathrm{e}}} \pm \frac{\mathrm{M}_{\mathrm{x}} \mathrm{x}_{\mathrm{i}}}{\sum \mathrm{x}_{\mathrm{i}}^{2}} \pm \frac{\mathrm{M}_{\mathrm{y}} \mathrm{y}_{\mathrm{i}}}{\sum \mathrm{y}_{\mathrm{i}}^{2}}
$$

sendo $\mathrm{F}$ a força vertical atuante, $\mathrm{n}_{e}$ o número de estacas e $\mathrm{M}_{x}$ e $\mathrm{M}_{y}$ os momentos atuantes em torno do eixo $\mathrm{x}$ e y respectivamente.

Os sinais a serem considerados na expressão 3.2 são positivos conforme a orientação ilustrada na figura 3.1 .

A solução é por tentativa, pois só são aceitas reações nas estacas no máximo igual à força admissível de compressão e tração. Esse método nada mais é do que aplicar a fórmula de flexão composta da Resistência dos Materiais, visto que as hipóteses são as mesmas.

\subsection{Processo do Boletim $\mathrm{n}^{\circ} 73$ do CEB-FIP (1970)}

Os métodos de cálculo e dimensionamento do CEB-FIP (1970) consideram os blocos como sendo rígidos, e indicam verificações de seguranças por meio de seções de referências.

Para que o bloco seja classificado como rígido, a distância entre a face do pilar ao eixo da estaca mais afastada " $l_{c}$ " deve ser menor do que uma vez e meia a altura do bloco "h", e não maior do que a metade da altura "h". Conforme pode ser visto na figura 3.2 , ou seja:

$$
h / 2 \leq l_{c} \leq 1,5 h
$$

A altura do bloco pode variar, da face do pilar a extremidade do bloco, desde que em todas as seções a resistência à força cortante seja satisfeita, e os cobrimentos de ancoragem sejam suficientes. 


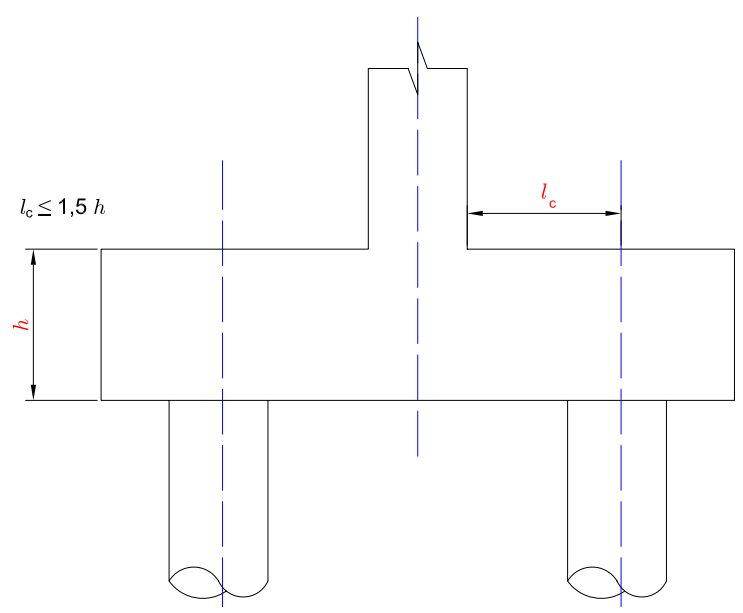

Figura 3.2: Relação entre as distâncias

\subsubsection{Dimensionamento da armadura inferior}

Para o cálculo da armadura inferior do bloco é necessário primeiramente localizar uma seção de referência. O cálculo da armadura é baseado nessa seção, que é chamada de seção $S_{1}$. A seção de referência $S_{1}$ do bloco é a seção plana e normal à superfície do bloco situado entre a face do pilar e seu eixo, e a uma distância de 0,15a da face do pilar, sendo "a" a dimensão do pilar na direção perpendicular a seção $S_{1}$ considerada (figura 3.3).

A altura útil da seção $S_{1}$ é igual à altura útil da seção paralela a $S_{1}$, e situada na face do pilar, salvo se essa altura excede 1,5 vez a distância " $l_{c}$ " $\left(d \leq 1,5 l_{c}\right)$ medida perpendicular a esta seção. A distância " $l_{c}$ " refere-se à estaca mais afastada da face do pilar (figura 3.3).

A área de armadura da seção transversal é calculada com base no momento fletor obtido para a seção $\mathrm{S}_{1}$, considerando o dimensionamento como sendo à flexão simples. $\mathrm{O}$ momento fletor relativo a seção $\mathrm{S}_{1}$ é o momento que leva em conta as reações das estacas atuando no bloco limitado pela seção $\mathrm{S}_{1}$, ou seja, o produto da reação das estacas e a distâncias dessa a seção de referência $S_{1}$.

\subsubsection{Disposição da armadura inferior}

As barras da armadura inferior de tração necessária para equilibrar o momento fletor podem ser distribuídas em malha (figura 3.4a), ou em faixas sobre as estacas, no caso em que as estacas são dispostas segundo os vértices de um polígono regular centrado em relação ao eixo do pilar (figura 3.4b), ou por faixas entre estacas (figura 3.4c) 


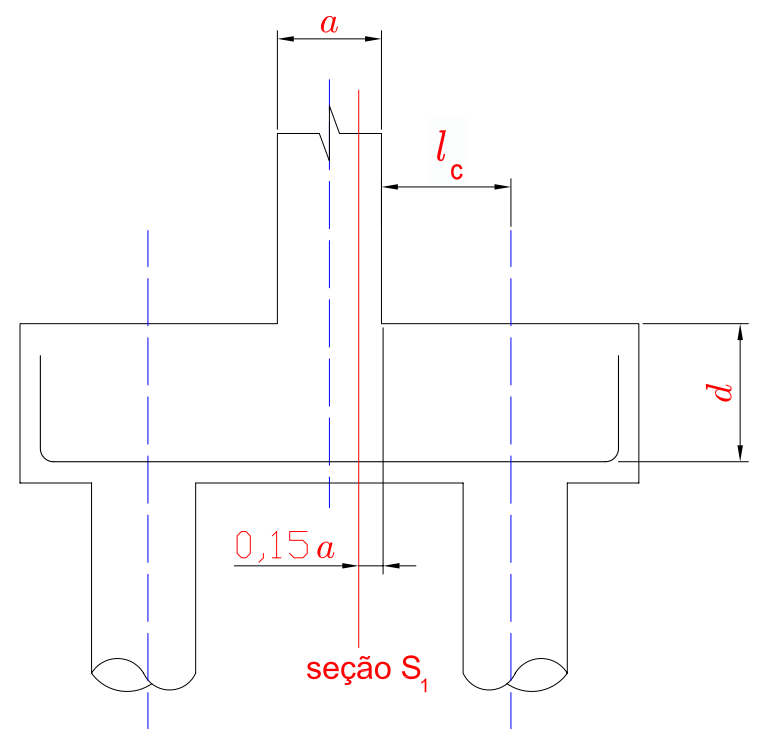

Figura 3.3: Seção de Referência $\mathrm{S}_{1}$

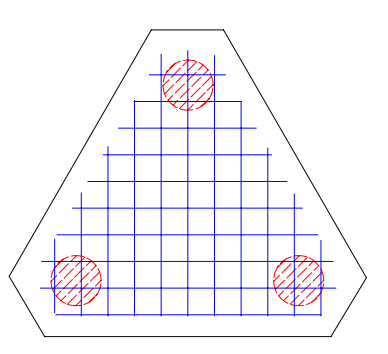

(a)

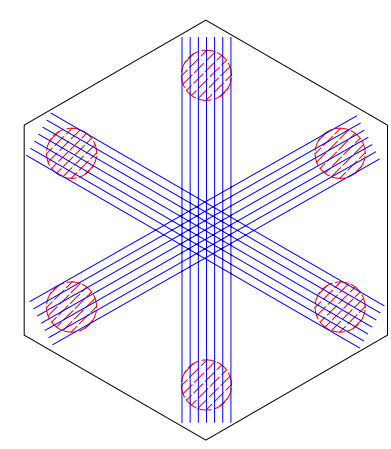

(b)

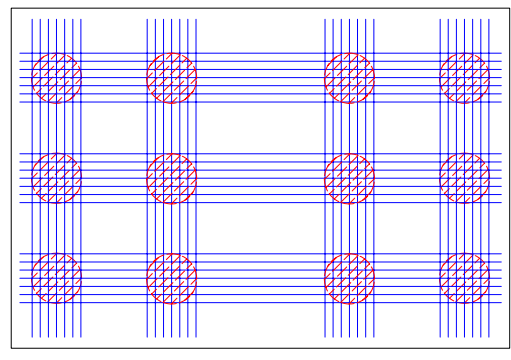

(c)

Figura 3.4: Disposições das Armaduras

As armaduras devem ser dispostas em todos os casos de maneira que sejam satisfeitas as condições de ancoragem além das estacas periféricas. Pode-se considerar ancorada quando a armadura inferior que atravessa a superfície cilíndrica axial sobre a estaca ser equilibrada por uma força correspondente a $80 \%$ da reação da estaca. Apenas as barras dentro da faixa podem ser considerada, sendo a faixa igual a 3 vezes o diâmetro da estaca. Como pode ser visto na figura 3.5.

\subsubsection{Condição de aderência das barras da armadura principal}

A consideração da aderência das barras da armadura principal é feita por meio seguinte expressão: 


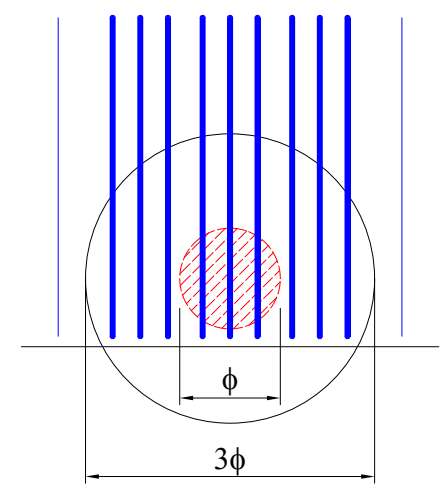

Figura 3.5: Condições de ancoragem

$$
V_{\mathrm{d} 1} \leq 0,9 \cdot \mathrm{d} \cdot \mathrm{n} \cdot \pi \cdot \phi \cdot \mathrm{f}_{\mathrm{bd}}
$$

Sendo:

n: número de barras por unidade de largura;

$\phi$ : diâmetro da barra de aço;

d: altura útil da seção S1;

$\mathrm{f}_{b d}$ : resistência de aderência de cálculo entre armadura e concreto na ancoragem de armaduras passivas, definida pela expressão 3.5 , conforme NBR 6118:2003, deve ser:

$$
\mathrm{f}_{\mathrm{bd}}=\eta_{1} \cdot \eta_{2} \cdot \eta_{3} \cdot \mathrm{f}_{\mathrm{ctd}}
$$

Em que:

$\eta_{1}=1,0$ barras lisas (CA-25);

$\eta_{1}=1,4$ barras entalhadas (CA-60);

$\eta_{1}=2,25$ barras nervuradas $(\mathrm{CA}-50) ;$

$\eta_{2}=1,0$ situação de boa aderência;

$\eta_{2}=0,7$ situação de má aderência;

$\eta_{3}=1,0$ para $<32 \mathrm{~mm} ;$

$\eta_{3}=\frac{132-\phi}{100}$ para $\phi \geq 32 \mathrm{~mm} ;$ 
Sendo $\phi$ é o diâmetro da barra, em milímetros.

A resistência à tração de cálculo do concreto é igual a:

$$
\mathrm{f}_{\mathrm{ctd}}=\frac{\mathrm{f}_{\mathrm{ctk}, \text { inf }}}{\gamma_{\mathrm{c}}} ; \mathrm{f}_{\mathrm{ctk}, \text { inf }}=0,7 \cdot \mathrm{f}_{\mathrm{ctm}} \quad \text { e } \mathrm{f}_{\mathrm{ctm}}=0,3 \cdot \mathrm{f}_{\mathrm{ck}}^{2 / 3}
$$

Com $\mathrm{f}_{c k}$ expresso em megapascal.

\subsubsection{Resistência à força cortante}

A verificação da resistência à força cortante é feita em uma seção de referência, chamada de $\mathrm{S}_{2}$, paralela a face do pilar e perpendicular a superfície inferior do bloco. A seção de referência $\mathrm{S}_{2}$ dista da face do pilar um comprimento igual à metade da altura útil do bloco (figura 3.6a). No caso de algumas estacas ficarem situadas a uma distância da face do pilar inferior a metade da altura útil "d" $(d / 2)$, a seção de referência $\mathrm{S}_{2}$ passa a ser localizada junto a face do pilar, como pode ser visto na figura $3.6 \mathrm{~b}$.

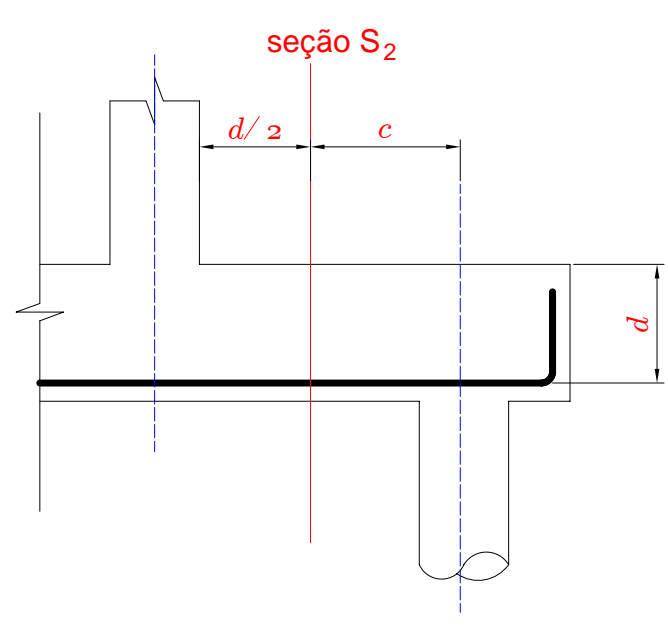

(a)

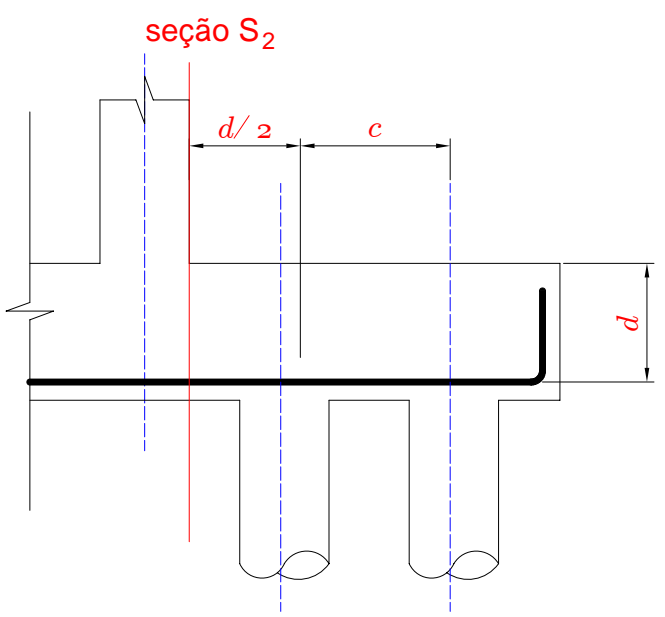

(b)

Figura 3.6: Seção de Referência $\mathrm{S}_{2}$

Para o dimensionamento, a força cortante de cálculo $\mathrm{V}_{d}$ é igual a componente normal à superfície de apoio da resultante das forças aplicadas sobre a parte limitada pela seção de referência $S_{2}$.

Na figura 3.7 pode-se ver que a largura da seção de referência $\mathrm{S}_{2}$ é a soma das dimensões do pilar medida segundo a horizontal e a altura útil do bloco, conforme a seguinte expressão: 


$$
\mathrm{b}_{2}=\mathrm{b}+\mathrm{d}
$$

sendo:

b a dimensão do pilar medido na horizontal paralela a seção; e

d a altura útil da seção $S_{2}$.

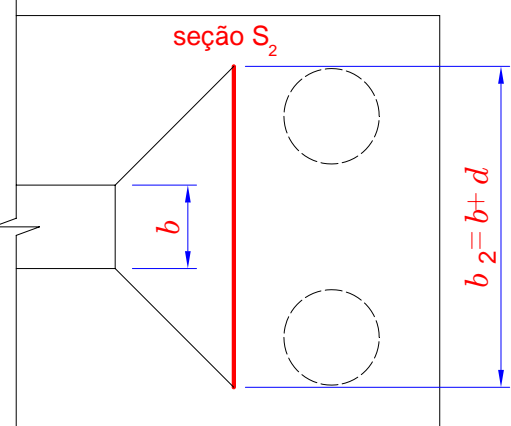

Figura 3.7: Largura da seção de referência $S_{2}$

A altura útil " $\mathrm{d}_{2}$ " da seção de referência $\mathrm{S}_{2}$ é igual a altura medida na própria seção considerada. Se a altura exceder 1,5 vez a distância " $l_{c 2}$ ", que é a medida entre a seção $\mathrm{S}_{2}$ ao eixo da estaca mais afastada, a altura útil " $\mathrm{d}_{2}$ " será limitada a esse valor:

$$
d_{2} \leq 1,5 l_{c 2}
$$

Logo a força cortante de referência $V_{d}$ na seção de referência $S_{2}$, deve ser inferior ou no mínimo igual a força cortante limite dada pela expressão:

$$
\mathrm{V}_{\mathrm{d}, \lim }=\frac{0,25}{\gamma_{\mathrm{c}}} \cdot\left(1-\frac{\mathrm{l}_{\mathrm{c}}}{5 \mathrm{~d}}\right) \cdot \mathrm{b}_{2} \cdot \mathrm{d}_{2} \cdot \sqrt{\mathrm{f}_{\mathrm{ck}}}
$$

Sendo $l_{c}$ a distância a partir do eixo da estaca mais afastada até a seção de referência $\mathrm{S}_{2}$; d é a altura da seção; $\mathrm{b}_{2}$ é a largura da seção de referência $\mathrm{S}_{2}$ e $\mathrm{d}_{2}$ é a altura útil da seção $\mathrm{S}_{2}$.

\subsubsection{Resistência local à força cortante}

Precisa ser verificada a resistência à força cortante em todas as seções do bloco onde as propriedades geométrica e a localização das estacas possam provocar circunstâncias 
desfavoráveis. A figura 3.8 indica uma das seções a ser verificadas, onde a força cortante que solicita a seção é igual à reação da estaca de canto.

A seção $\mathrm{S}_{2}^{\prime}$ fica situada a uma distância da face da estaca igual à metade da altura útil $\mathrm{d}_{1}$ do bloco, medida junto à face da estaca. A largura $\mathrm{b}_{2}^{\prime}$ é igual a altura $\mathrm{d}_{1}$ somada a largura da estaca $\left(b_{2}^{\prime}=\phi+d_{1}\right)$. E a altura $\mathrm{d}_{2}^{\prime}$ é a altura útil efetiva da seção $\mathrm{S}_{2}^{\prime}$.
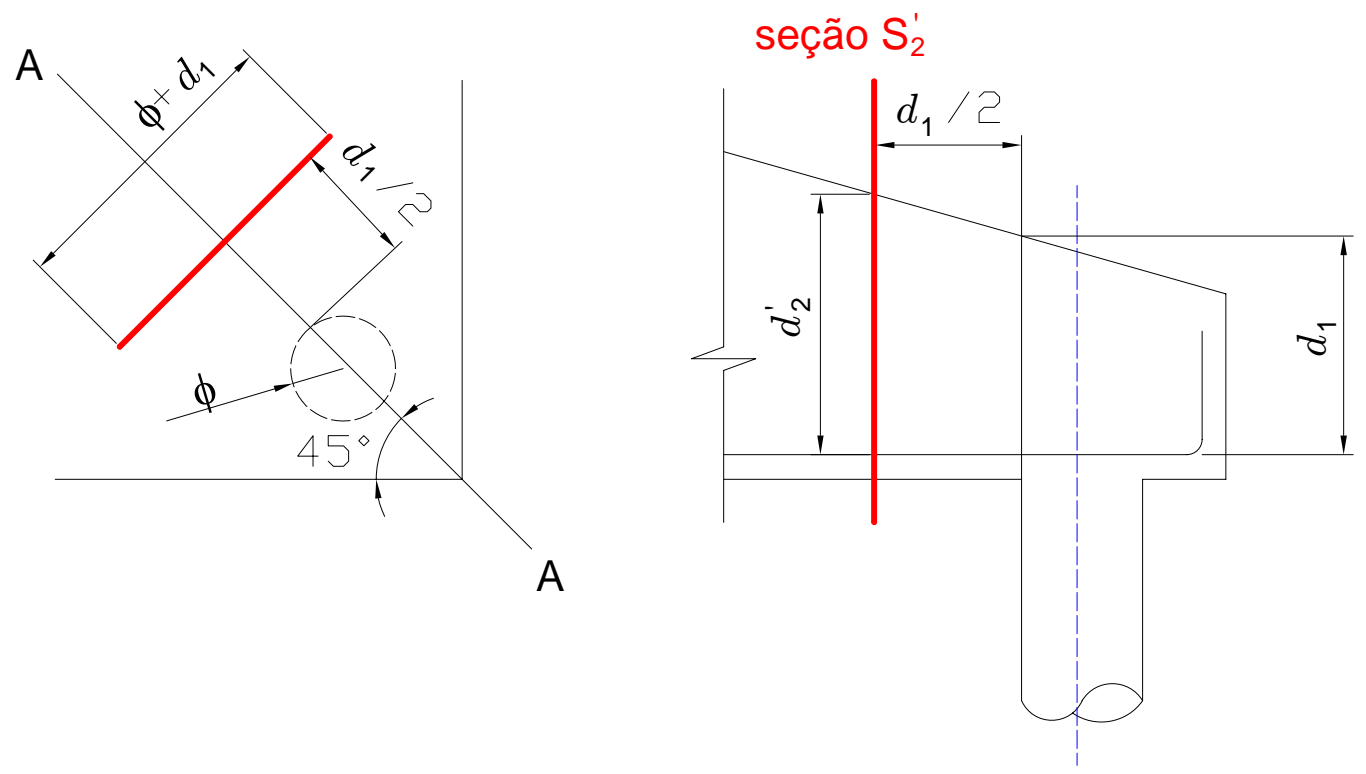

Corte AA

Figura 3.8: Seção de referência para o cálculo da força cortante

Portanto, a força cortante relativa a reação da estaca deve ser no máximo igual a resistência limite definida pela seguinte expressão:

$$
\mathrm{R}_{\mathrm{d}, \lim }=\frac{0,12}{\gamma_{\mathrm{c}}} \cdot \mathrm{b}_{2}^{\prime} \cdot \mathrm{d}_{2}^{\prime} \cdot \sqrt{\mathrm{f}_{\mathrm{ck}}}
$$




\section{Capítulo

\section{Aspectos da Modelagem}

Numérica

\subsection{Considerações iniciais}

Neste capítulo são apresentados os aspectos relacionados com a modelagem numérica. O programa e os elementos finitos são alguns, dentre outros, aspectos que se relacionam com a discretização e são apresentados neste capítulo.

As principais propriedades dos modelos utilizados nesse trabalho, a exemplo da aferição dos coeficientes, levaram em consideração os trabalhos anteriores, principalmente o desenvolvido por Delalibela (2006).

Toda a modelagem numérica deste trabalho foi elaborada considerando o programa para computador, baseado no Métodos dos Elementos Finitos (MEF), ANSYS ${ }^{\circledR}$ (ANalyser SYStem - ANSYS, Inc.) versão 9, referenciado apenas por Ansys.

\subsection{Elementos finitos utilizados}

O programa Ansys, em sua biblioteca interna de elementos finitos, disponibiliza um vasto arquivo de opções de elementos finitos com a finalidade de fornecer ao usuário condições para resolver problemas diversos da engenharia.

A escolha dos elementos finitos, para a discretização do modelo, foi baseada em alguns aspectos, como por exemplo, o número de graus de liberdade e principalmente na representatividade do material modelado.

A seguir são apresentados os elementos finitos utilizados e suas principais propriedades relevantes à modelagem em conjunto com as suas respectivas representações dos materiais modelados. 


\subsubsection{Solid65}

Para a modelagem do material concreto, foi utilizado o elemento solid65. É o elemento presente na biblioteca do Ansys como sendo o que melhor representa o comportamento do concreto, pois apresenta fissuração na tração e ruptura na compressão. Esse elemento possui oito nós, sendo cada nó com três graus de liberdade, translação nas direções x, y e z.

O elemento apresenta ainda deformações plásticas e armadura espalhada em forma de taxa ao longo do elemento. A fissuração ocorre quando a tensão principal de tração em qualquer direção atinge a tensão limite de ruptura. O esmagamento ocorre quando todas as tensões de compressão atingem o limite de ruptura.

Na figura 4.1 é apresentado o elemento solid65. Para maiores detalhes a respeito do elemento, consultar Ansys User's Manual (2004).

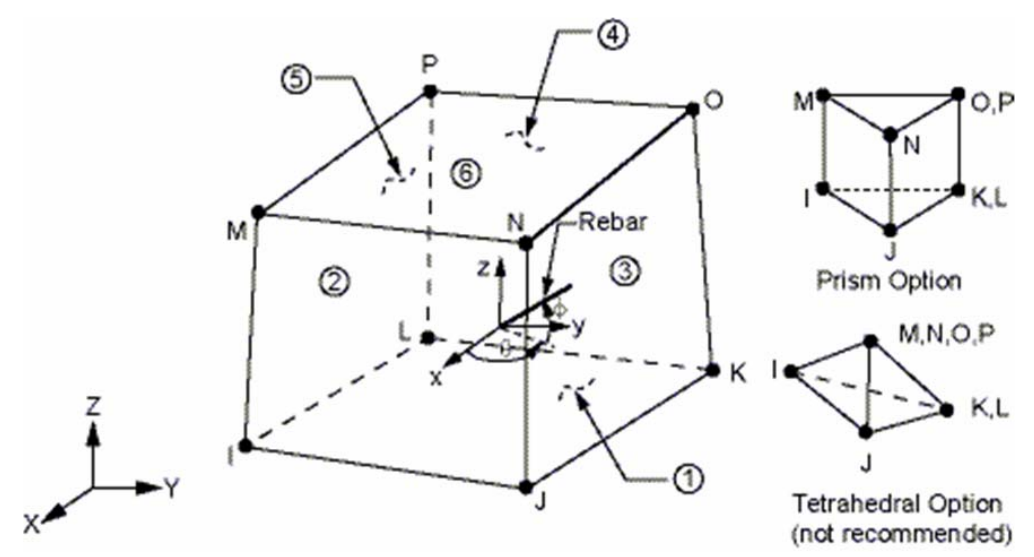

Figura 4.1: Elemento Solid65. (Fonte: Ansys User's Manual)

\subsubsection{Link8}

Para a modelagem das barras de aço da armadura foi utilizado o elemento finito link8 (figura 4.2). Esse elemento possui dois nós, sendo cada nó com três graus de liberdade, translação nas direções x, y e z.

A opção pela utilização desse elemento foi que as armaduras nos modelos eram discretas. Para maiores detalhes a respeito do elemento, consultar Ansys User's Manual (2004). 

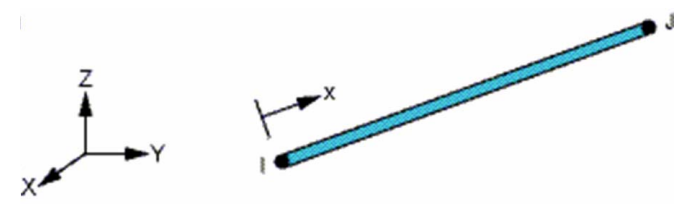

Figura 4.2: Elemento Link8. (Fonte: Ansys User's Manual)

\subsubsection{Solid45}

O elemento solid45 foi utilizado para modelar as placas de aço no topo do pilar e na base da estaca. Esse elemento possui oito nós, sendo três graus de liberdade cada nó, translação nas direções x, y e z. Na figura 4.3 pode ser visto o elemento. Para maiores detalhes a respeito do elemento, consultar Ansys User's Manual (2004).

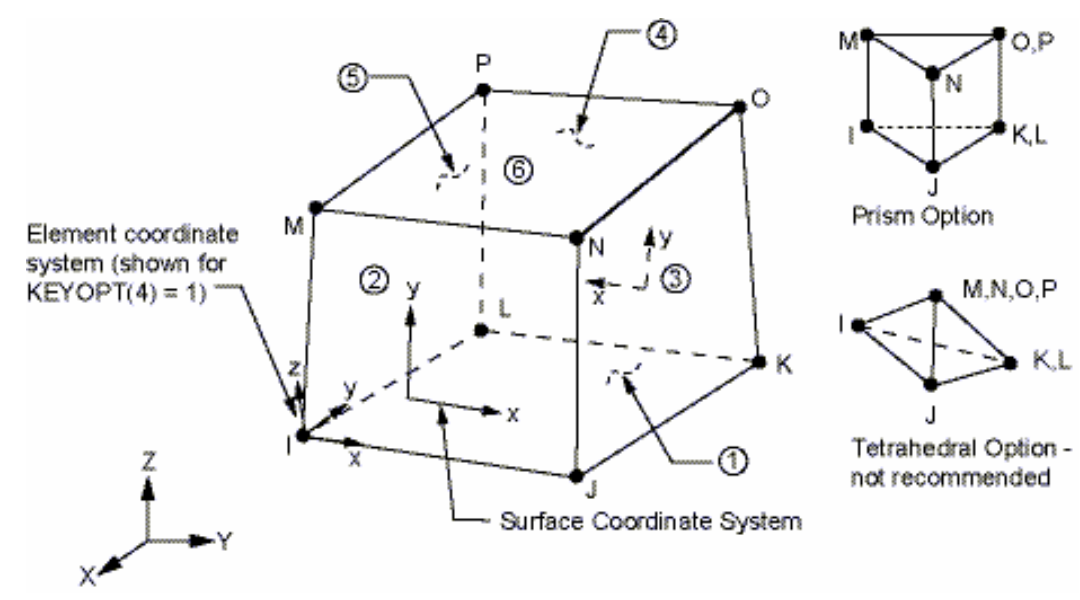

Figura 4.3: Elemento Solid45. (Fonte: Ansys User's Manual)

\subsubsection{Combin39}

Para a modelagem das molas foi utilizado o elemento combin39. É o elemento presente na biblioteca do programa Ansys que simula a mola com comportamento não linear em força vs. deslocamento (maiores detalhes podem ser visto adiante).

O elemento possui dois nós com seis graus de liberdade cada nó, sendo três de rotação (rotação nos eixos x, y e z) e três de translação (translação da direção em x, y e z).

Possui ainda, como umas de suas restrições, a necessidade de ser com nós coincidentes, ou seja, o nó inicial e o nó final do elemento finito tem a mesma posição, por isso não é possível visualiza-lo no modelo. Na figura 4.4 pode ser visto o elemento. Para 
maiores detalhes a respeito do elemento, consultar Ansys User's Manual (2004).

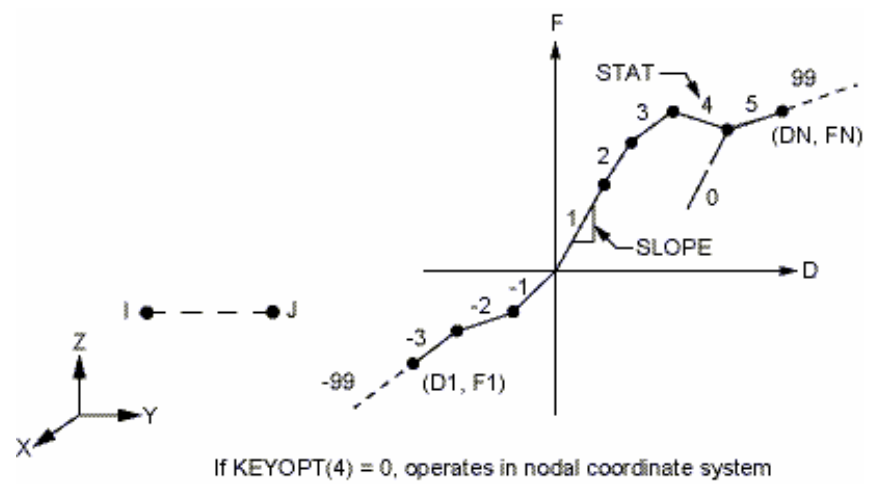

Figura 4.4: Elemento Combin39. (Fonte: Ansys User's Manual)

\subsection{Propriedades dos Materiais}

\subsubsection{Concreto}

O material concreto foi representado pelo elemento finito solid65. Esse elemento é o que melhor representa o comportamento do concreto entre os elementos presentes na biblioteca de elementos do programa Ansys. Alguns parâmetros precisam ser fornecidos ao programa para caracterizar o material concreto, como por exemplo: módulo de elasticidade longitudinal do concreto; resistência última do concreto à compressão e à tração; coeficiente de Poisson; coeficiente de transferência ao cisalhamento; entre outros.

O programa permite ainda o estabelecimento de uma relação entre a tensão e a deformação do material concreto, na figura 4.5 pode ser visto a curva tensão vs. deformação para um concreto de resistência à compressão de $25 \mathrm{MPa}$. Essa resistência à compressão foi utilizada em uma grande maioria dos modelos e está baseado em Desayi \& Krishman (1964).

Os parâmetros utilizados para as propriedades do material foram estabelecidos conforme a NBR 6118:2003. Na tabela 4.1 podem ser vistos esses parâmetros. Os coeficientes de transferência de cisalhamento foram adotados conforme Delalibera (2006).

Para representação do comportamento do material concreto na modelagem foi usado o critério de ruptura concrete disponível na biblioteca do programa Ansys, baseado no modelo de Willan-Warnke que permite simular a fissuração do concreto quando submetido a tensões de tração. 


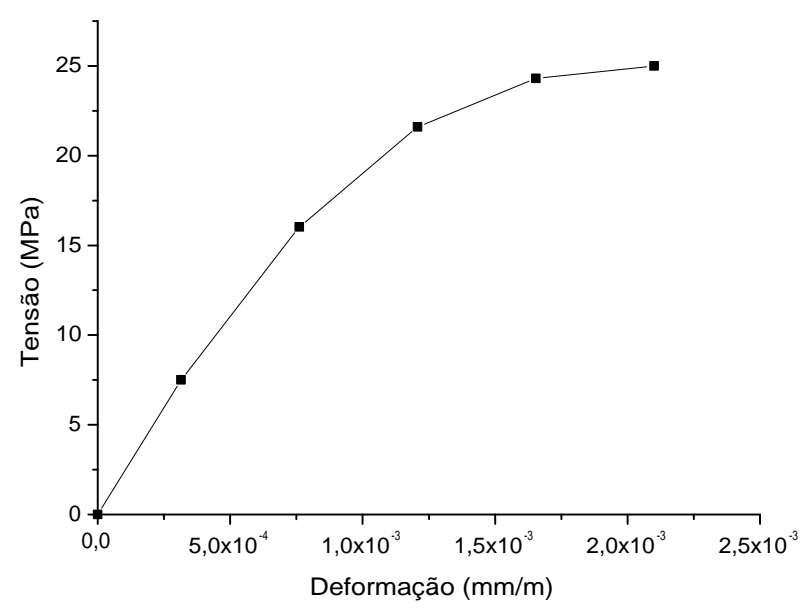

Figura 4.5: Curva Tensão vs. deformação do concreto Segundo Desayi \& Krishman (1964)

Tabela 4.1: Descrição dos parâmetros do material concreto

\begin{tabular}{cc}
\hline Módulo de Elasticidade Longitudinal $\left(\mathrm{E}_{c}\right)$ & $23800 \mathrm{MPa}$ \\
Coeficiente de Poisson $(\nu)$ & 0,2 \\
Resistência última à tração $\left(\mathrm{f}_{c t}\right)$ & $2,565 \mathrm{MPa}$ \\
Coeficiente de transferência de cisalhamento & 1 \\
\hline
\end{tabular}

\subsubsection{Aço}

\subsubsection{Barras das armaduras}

As barras das armaduras foram discretizadas pelo elemento link8, e para o material foi adotado o comportamento elasto-plástico perfeito segundo os critérios de von Mises, sendo representada por meio da curva tensão vs. deformação mostrada na figura 4.6 .

O módulo de elasticidade utilizado foi igual a $210.000 \mathrm{MPa}$, o coeficiente de Poisson igual a 0,3 e a resistência característica ao escoamento igual a $500 \mathrm{MPa}$.

\subsubsection{Placa no topo do pilar e na base da estaca}

Para o aço da placa no topo do pilar e da base da estaca foi utilizado um modelo linear com módulo de elasticidade longitudinal igual a 210.000 MPa e coeficiente de Poisson igual a 0,3. O elemento finito usado para discretizar foi o solid45.

A placa no topo do pilar tinha a finalidade de uniformizar as tensões provenientes 


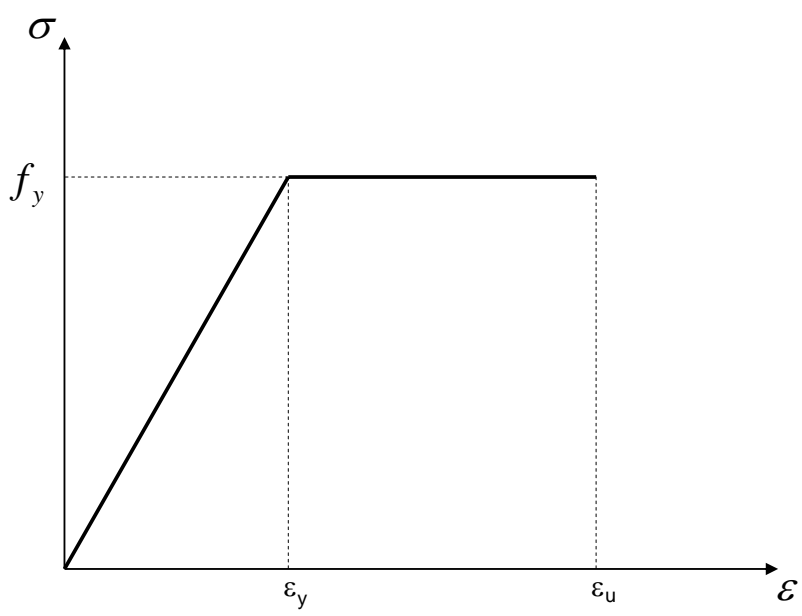

Figura 4.6: Curva tensão vs. deformação do aço das barras

das ações de força normal e momentos fletores. Foi adotada a placa, pois em testes realizados na ausência da mesma notou-se que o modelo não atingia a força estimada para o modelo. As forças nodais atuantes no topo do pilar atingiam a força de tração do concreto, fazendo com que a parte fissurada de concreto do modelo tivesse movimento de corpo rígido.

A placa na base da estaca tinha, também, a finalidade de uniformizar as tensões. Pois era necessária a uniformização das forças nodais naquele ponto para que as molas pudessem funcionar adequadamente. Os testes preliminares mostraram que, na ausência da placa, as forças nodais eram transferidas às molas de forma não uniforme, tornando assim difícil de controlar a força de ruptura das molas e, conseqüentemente, da estaca.

\subsubsection{Solo}

Para a modelagem do solo foi utilizado um elemento que simulava o comportamento de uma mola. O elemento finito utilizado foi o combin39, e foi utilizado esse elemento por se tratar de uma mola presente na biblioteca de elementos finitos do programa Ansys e que pode ser adotado o modelo constitutivo não linear. O comportamento da mola foi representado fisicamente por meio de valores de força vs. deslocamento, simulando o comportamento do solo por meio de ensaios de carga-recalque.

Os testes preliminares mostraram que o comportamento estrutural do bloco está diretamente relacionado com o tipo de solo e conseqüentemente com o tipo de mola adotado. Baseando-se em alguns testes foram adotados dois tipos padrões de solo: solo indeformável e solo deformável. 
O autor entende que qualquer outro tipo de solo estará compreendido entre esses dois tipos extremos de solo.

\subsubsection{Solo Indeformável}

O solo indeformável é o solo que representa o comportamento de estacas sendo apoiadas em rocha, ou seja, não há deslocamento axial com a aplicação de força na estaca decorrente da ruína do solo, mas sim da ruína na estaca (por hipótese).

Para representar o comportamento de estacas apoiadas em rocha foi adotado a restrição dos deslocamento na direção do eixo "z" dos nós inferiores da estaca.

\subsubsection{Solo Deformável}

Solo deformável é o solo onde o comportamento é considerado deslocável. Ou seja, é a representação do comportamento do conjunto estaca solo. Esse comportamento é representado por meio da curva carga recalque. Estão implícitos nesse comportamento alguns fatores como por exemplo o comprimento da estaca, o atrito lateral da estaca, a resistência de ponta, a deformação axial, entre outros. Com a aplicação da força o conjunto estaca solo se desloca axialmente provocando um recalque, como em um caso real. O comportamento do conjunto estaca solo foi modelado com a relação constitutiva elastoplástico multi-linear. Na figura 4.7 pode ser visto o comportamento da mola adotada.

Os valores adotados para o comportamento do solo foram indicados pela professora Miriam Gonçalves Miguel ${ }^{1}$ da FEC-Unicamp.

\subsection{Critérios adotados para a modelagem}

\subsubsection{Aplicação das ações}

A aplicação da força no bloco foi na forma de incrementos, isso se deve à consideração da não linearidade física dos materiais. O programa Ansys disponibiliza um procedimento denominado "Automatic Load Stepping", que controla os passos de força a serem aplicadas no processamento do modelo.

As ações aplicadas foram dividas em duas parcelas. A primeira, constituída em uma força axial aplicada em forma de pressão no topo do pilar, e, a segunda, na aplicação

\footnotetext{
${ }^{1}$ Informações obtidas por correspondência.
} 


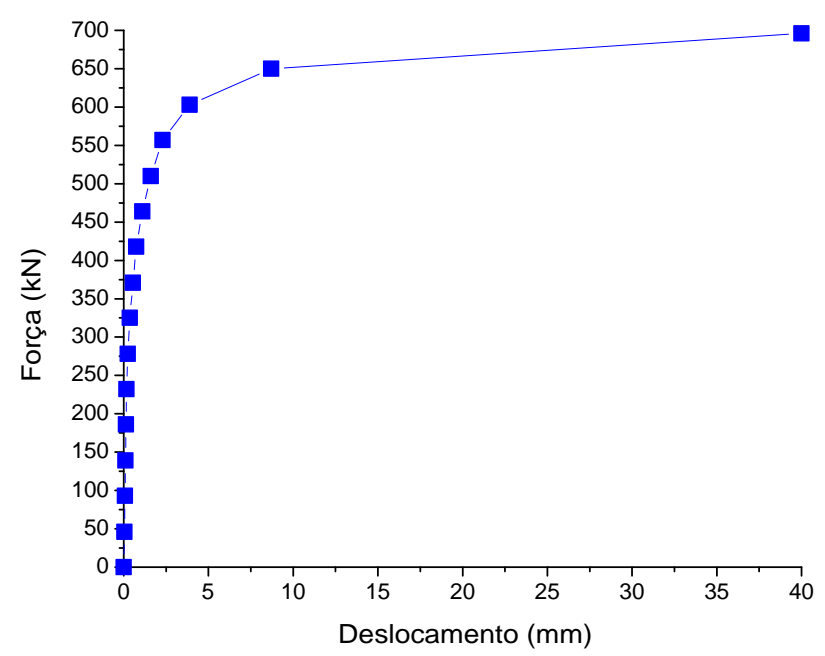

Figura 4.7: Comportamento da mola para solo deformável

dos momentos - se houvessem - como forma de forças nodais.

Na figura 4.8a pode ser visto um detalhe de como é representado pelo programa Ansys a força aplicada em forma de pressão para as forças axiais.

As ações de momento eram consideradas separadamente e, em seguida, somadas os valores das forças por nós. Primeiro era calculado a força aplicada em cada nó para um determinado momento em uma direção, e depois na outra direção, e em seguida somados os dois valores, ou seja, somavam-se os valores das forças relativas aos momentos em cada direção. Na figura $4.8 \mathrm{~b}$ pode ser visto com maiores detalhes a aplicação das forças por nós considerando os momentos.

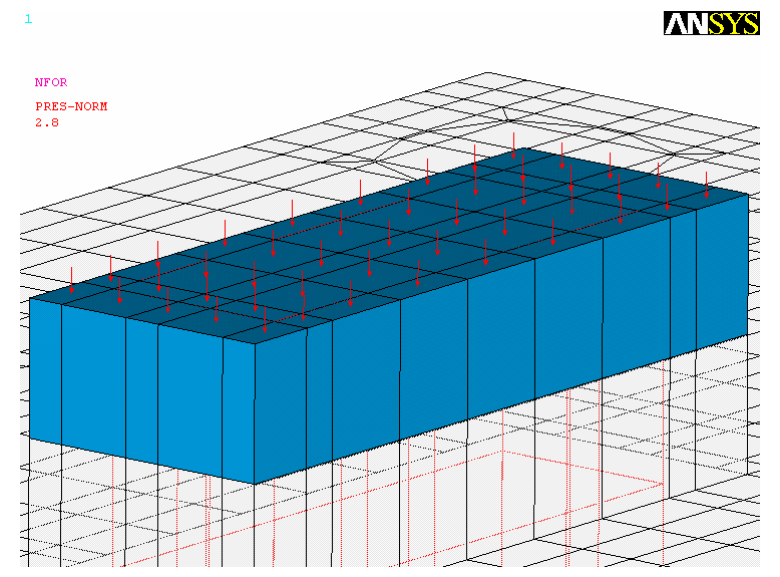

(a) Força axial em forma de pressão
MNSYS

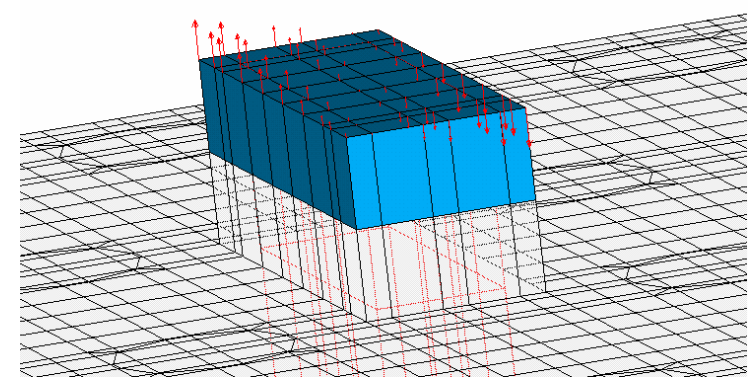

(b) Momentos aplicados nos nós

Figura 4.8: Força axial e momentos aplicados 


\subsubsection{Vinculações e restrições de apoio}

Os elementos finitos foram acoplados entre si por meio de nós coincidentes, exceto o elemento da mola, como pode ser visto no item descrito anteriormente (item 4.2.4), sendo uma de sua restrição trabalhar com nós coincidentes em termos de posição. Ou seja, a posição do nó inicial da mola era coincidente, em posição, com o nó final.

Não foi possível aplicar a simetria no modelo, sendo uma prática muito comum em análise numérica, pois era necessário analisar o comportamento estrutural do bloco com a interação simultânea das força vertical e dos momentos fletores.

A restrição do modelo se deu por meio dos nós dos elementos, restringindo seus graus de liberdade impedindo assim seus deslocamentos naquela direção.

Na direção global "z" foram restringidos os nós na base da estaca, com os nós pertencentes aos elementos da mola. Na figura 4.9(a) pode ser visto essa restrição. Visualmente essa figura também mostra a restrição na base da estaca sem a presença das molas, visto que o elemento de mola trabalha com mesma posição para nó inicial e final (nós coincidentes).

Para que fosse evitado o deslocamento de corpo rígido, durante o processamento do modelo, foram restringidos os nós externos da estaca, tanto os deslocamento na direção de "x" quanto na direção de "y". Na figura 4.9(b) são apresentados as restrições impostas ao modelo para que possa ser visualizado de forma mais clara essa restrição.

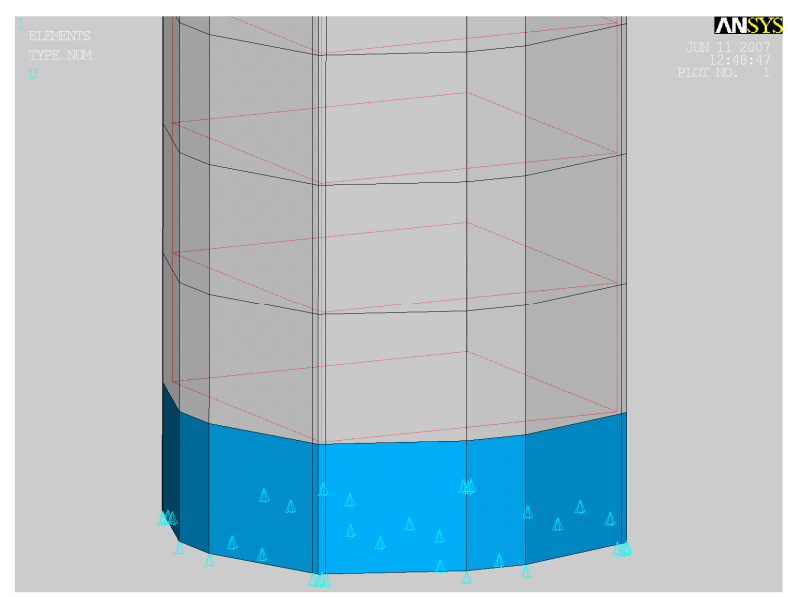

(a) Na direção global "z"

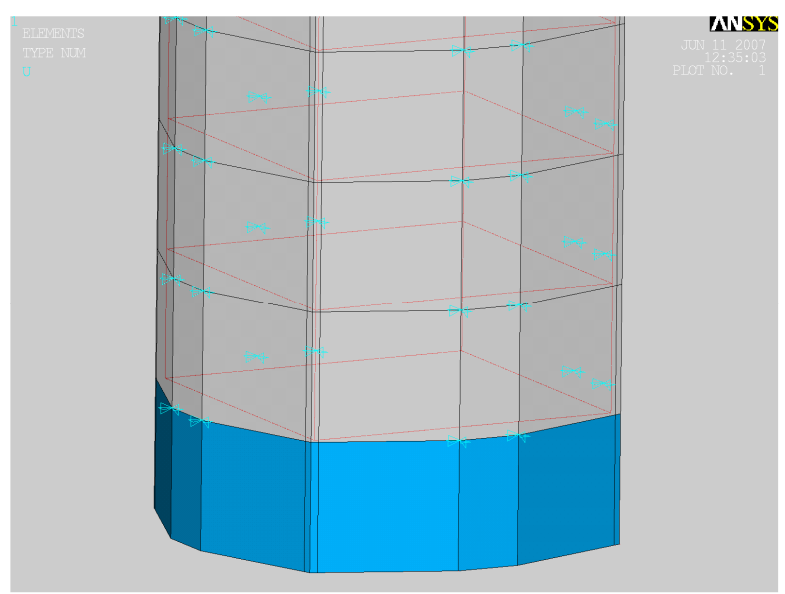

(b) Na direção global "x" e "y"

Figura 4.9: Restrições impostas ao modelo 


\subsubsection{Definição da malha de elementos finitos}

Os modelos desenvolvidos no programa Ansys são constituídos por quatro conjuntos de elementos quando simula bloco apoiado em solo deformável e três para bloco apoiado em rocha. Sendo o bloco de concreto, as armaduras de aço, as chapas de aço na base e no topo do pilar e as molas que representam o solo, quando existiam.

Cada conjunto de elemento foi discretizado separadamente, porém de modo a coincidir os nós de cada um na interface entre eles, possibilitando o acoplamento entre tais conjuntos por meio de seus nós.

O grau de refinamento da malha foi adotado levando-se em consideração o trabalho computacional e a confiabilidade do resultado.

A discretização do bloco de concreto teve como um dos fatores a disposição das barras de aço no bloco e a existência de estacas, visto que as estacas foram modeladas na forma circular.

A chapa de aço na base do bloco e no topo do pilar teve a sua discretização respeitando e acompanhando a discretização da malha do bloco, de forma a coincidir os nós dos dois grupos de elementos.

\subsubsection{Análise não linear}

Em virtude da não linearidade física dos materiais, a ação foi aplicada na estrutura de modo incremental. O programa automaticamente estabelece o incremento ou o decréscimo do passo de carga necessário para que o modelo convergisse. Esse recurso é chamado pelo programa Ansys de "Automatic Load Stepping".

O método utilizado para a resolução do sistema não-linear foi o de "Newton Raphson Full". Esse método é caracterizado pela atualização da matriz de rigidez tangente a cada iteração.

O critério de convergência utilizado foi estabelecido com base no vetor de resíduos de força, sendo satisfeito quando a norma deste vetor fosse menor ou igual ao valor de $5 \%$. Em testes realizados anteriormente foi constatado que esse critério foi o que melhor ajudou na convergência do modelo. Outros critérios e valores levaram a um acréscimo considerado no tempo de processamento ou até mesmo a não convergência do modelo.

Para maiores informações e detalhes dos processos e métodos citado acima, o 
autor sugere consultar o manual do Ansys (Ansys User's Manual - 2004). 


$\frac{\text { Сарі́tulo }}{\text { O Bloco e suas Propriedades }}$

\subsection{Considerações iniciais}

Este capítulo tem como objetivo fornecer informações referentes ao modelo bloco simulado numericamente, como suas propriedades geométricas, tipos de forças aplicadas, variação de altura do bloco, entre outras.

Os critérios da modelagem são descritos no capítulo 4. O modelo teve como variáveis a altura do bloco e o tipo de força aplicada. Em virtude ao grande número de blocos analisados e suas diferentes configurações, foi criado um script para auxiliar na construção do modelo numérico.

O script é uma seqüência de comandos, os quais são executados pelo Ansys permitindo gerar automaticamente o modelo desejado com suas diversas configurações. Um exemplo de script pode ser visto no apêndice A.

Esse sistema de modelagem por script permite que outros usuários do programa Ansys possam reproduzir o mesmo modelo em qualquer outro computador. Podendo assim, ser utilizados em pesquisas futuras dando continuidade a este trabalho, ou simplesmente por interesse neste procedimento de construção de modelos numéricos.

Os resultados da análise numérica de interesse concentraram na obtenção das reações nas estacas e no fluxo de tensões em suas direções principais.

De inicio, foram simulados alguns blocos variando a sua rigidez. Essa primeira tentativa de variação da rigidez foi escolhida como variável a resistência característica à compressão do concreto $\left(f_{c k}\right)$. Visto que esses resultados não foram satisfatórios do ponto de vista esperado, foram simulados blocos variando a rigidez considerando apenas a altura do bloco. 


\subsection{O Bloco}

O bloco proposto para a análise numérica tem dez estacas. A escolha desse tipo de bloco é justificada pelo fato que quadro das dez estacas estão próximo ao pilar. Há também, o interesse em estudar a influência de estacas nesse tipo de configuração. Embora o bloco tenha dupla simetria geométrica, com a aplicação das forças verticais e momentos o bloco passa a ser assimétrico.

A rotina de projeto de bloco sobre estacas utilizada para o dimensionamento do bloco foi baseado no processo do CEB-FIP (1970) publicado no Boletim de Informação 73, processo descrito anteriormente no item 3.4.

Em dois dos casos analisados, foram estudados blocos considerando a variação da resistência do material concreto. Em um dos casos foram analisados concretos de resistência à compressão de $20 \mathrm{MPa}, 25 \mathrm{MPa}, 30 \mathrm{MPa}$ e $45 \mathrm{MPa}$. No outro caso foram analisados concretos com resistência à compressão de $25 \mathrm{MPa}$ e $45 \mathrm{MPa}$. Para essas análises foram considerados tipos de vinculação das estacas: solo deformável e indeformável.

\subsubsection{Propriedades Geométricas}

Os blocos analisados possuem as mesmas dimensões geométricas em planta, variandose apenas as alturas e as forças aplicadas.

Para as dimensões laterais do bloco foram utilizadas dimensões iguais em todos os blocos com o valor de $360 \mathrm{~cm}$ x $260 \mathrm{~cm}$. O diâmetro da estaca foi igual para todas as estacas no valor de $35 \mathrm{~cm}$, e as dimensões do pilar foram de $90 \mathrm{~cm}$ x $30 \mathrm{~cm}$. Na figura 5.1 pode ser visto com maiores detalhes as dimensões do bloco em planta.

Outro detalhe importante que pode ser visto na figura 5.1 é com relação a numeração das estacas. Todas as estacas serão referenciadas por essa numeração apresentada.

A seguir é apresentado na figura 5.2 o modelo numérico tridimensional(3D) analisado. A figura mostrada do bloco em 3D foi retirada do programa Ansys.

\subsubsection{Altura do Bloco}

$\mathrm{Na}$ análise numérica foram simulados blocos com diferentes tipos de rigidez. Para ter uma variação na rigidez no bloco, foi considerada a variação da altura. A altura do 


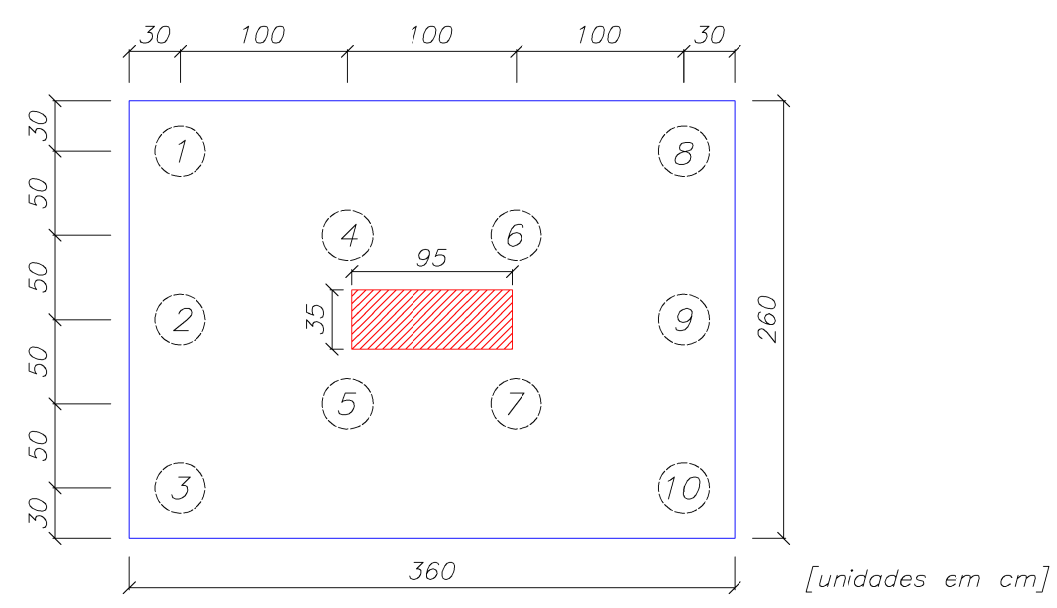

Figura 5.1: Propriedades geométrica do bloco

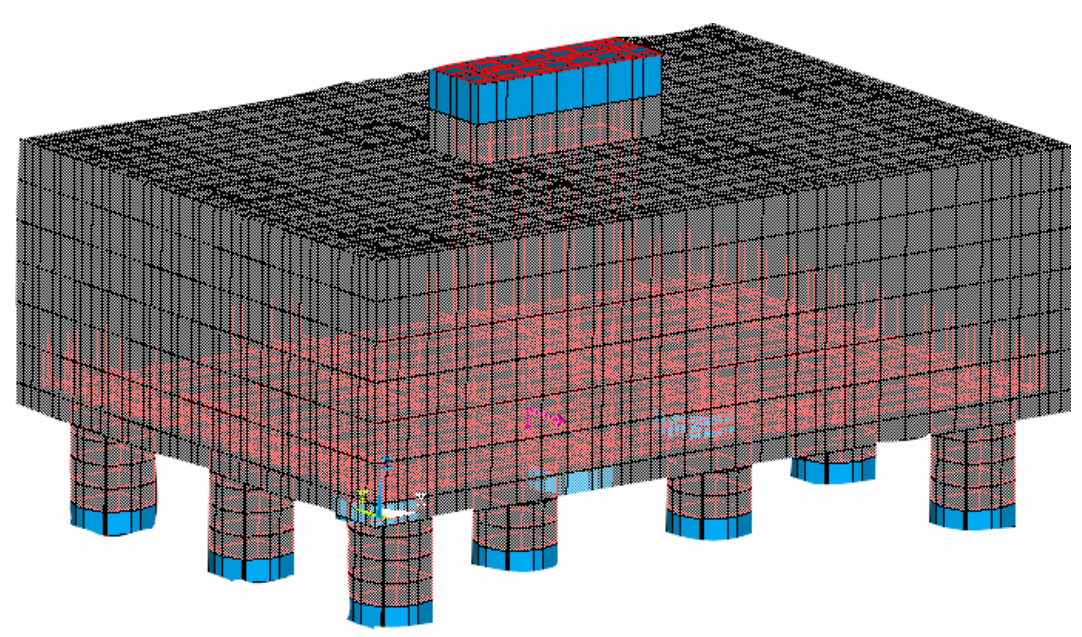

Figura 5.2: Bloco Tridimensional Analisado

bloco varia entre os valores de $80 \mathrm{~cm}, 115 \mathrm{~cm}$ e $200 \mathrm{~cm}$.

À partir desse ponto em diante os blocos serão referenciados de acordo com a sua altura, ou seja, no nome do bloco está vinculado a sua respectiva altura. Na tabela 5.1 são apresentadas as propriedades de cada bloco analisado com relação as suas alturas e seus respectivos nomes adotados.

\subsection{Casos de Forças Aplicadas}

Foram adotados quatro casos de ações aplicadas ao bloco. Chamando-se de Caso 1, Caso 2, Caso 3 e Caso 4. No Caso 1, apenas a ação de força vertical foi considerada. 
Tabela 5.1: Nome no bloco simulado e sua altura

\begin{tabular}{cc}
\hline Nome do bloco & Altura \\
\hline $\mathrm{h} 80$ & 80 \\
$\mathrm{~h} 115$ & 115 \\
$\mathrm{~h} 200$ & 200 \\
\hline
\end{tabular}

No Caso 2 além da força vertical foram consideradas as aplicações de momentos fletores nas duas direções (x e y), porém momentos fletores com baixa intensidade. No Caso 3, semelhante ao Caso 2, mas com maior intensidade em relação aos momentos fletores do Caso 2. Já no Caso 4, com a finalidade de se obter tração em uma das estacas, foram feitas as mesmas considerações que no Caso 3, mas com intensidade maior em relação aos momentos fletores. É valido lembrar que nos quatro casos analisados a força vertical foi sempre a mesma. Apenas foi alterada a intensidade dos momentos fletores.

Em todos os casos que havia momentos fletores, a estaca mais solicitada, de acordo com o método analítico apresentado no item 3.3, foi a de número 8. A estaca com a menor solicitação, de acordo com o mesmo item, foi a de número 3. No Caso 4 em que o objetivo era obter tração, a estaca foi a de número 3. Essa numeração pode ser vista na figura 5.1.

A força vertical considerada para a modelagem foi de $3000 \mathrm{kN}$, e o peso próprio do bloco está considerada neste valor. O momento na direção x foi de 600 kN.m, 960 kN.m e 1500 kN.m para os Casos 2, 3 e 4, respectivamente. Esses valores correspondem a $20 \mathrm{~cm}, 32 \mathrm{~cm}$ e $50 \mathrm{~cm}$ para os respectivos Caso 2, 3 e 4 em termos de excentricidade. Para momentos na direção y foi considerado os valores de 300 kN.m, 480 kN.m e 750 kN.m para os Casos 2, 3 e 4 respectivamente. A excentricidade para o Caso 2 foi de 10 $\mathrm{cm}$, para o Caso 3 de $16 \mathrm{~cm}$ e para o Caso 4 de $25 \mathrm{~cm}$.

Na tabela 5.2 é mostrado um resumo dos casos analisados. É possível também ver as características de cada caso, bem como as suas respectivas configurações.

Tabela 5.2: Quadro com os Casos analisados

\begin{tabular}{c|c|c|c|c|c}
\hline CASO & Força Vertical & M. na direção x & Exc. em x & M. na direção y & Exc. em y \\
\hline 1 & $F_{V}(3000 \mathrm{kN})$ & - & - & - & - \\
2 & $F_{V}(3000 \mathrm{kN})$ & $600 \mathrm{kN} . \mathrm{m}$ & $20 \mathrm{~cm}$ & $300 \mathrm{kN} . \mathrm{m}$ & $10 \mathrm{~cm}$ \\
3 & $F_{V}(3000 \mathrm{kN})$ & $960 \mathrm{kN} . \mathrm{m}$ & $32 \mathrm{~cm}$ & $480 \mathrm{kN} . \mathrm{m}$ & $16 \mathrm{~cm}$ \\
4 & $F_{V}(3000 \mathrm{kN})$ & $1500 \mathrm{kN} . \mathrm{m}$ & $50 \mathrm{~cm}$ & $750 \mathrm{kN} . \mathrm{m}$ & $25 \mathrm{~cm}$ \\
\hline
\end{tabular}

Nota: M. Momento; Exc. Excentricidade; 


\subsection{Modelos Adotados}

Foram analisados 32 modelos de bloco, submetidos à ação de força vertical, momentos fletores nas duas direções (x e y), com variação na altura do bloco e variação no tipo de vinculação da estaca com o solo. Apenas em alguns modelos foram variadas as propriedades do material concreto. Na tabela 5.3 pode ser visto todos os modelos dos blocos analisados e suas propriedades.

Tabela 5.3: Modelos analisados

\begin{tabular}{|c|c|c|c|}
\hline CASOS & Altura $(\mathrm{cm})$ & Tipo de vinculação (solo) & Concreto \\
\hline \multirow{3}{*}{1} & 80 & Indeformável & $25 \mathrm{MPa}$ \\
\hline & 115 & Indeformável & $20,25,30$ e $45 \mathrm{MPa}$ \\
\hline & 200 & Indeformável & $25 \mathrm{MPa}$ \\
\hline \multirow{3}{*}{2} & 80 & Indeformável & $25 \mathrm{MPa}$ \\
\hline & 115 & Indeformável & 25 e $45 \mathrm{MPa}$ \\
\hline & 200 & Indeformável & $25 \mathrm{MPa}$ \\
\hline \multirow{3}{*}{3} & 80 & Indeformável & $25 \mathrm{MPa}$ \\
\hline & 115 & Indeformável & $25 \mathrm{MPa}$ \\
\hline & 200 & Indeformável & $25 \mathrm{MPa}$ \\
\hline \multirow{3}{*}{4} & 80 & Indeformável & $25 \mathrm{MPa}$ \\
\hline & 115 & Indeformável & $25 \mathrm{MPa}$ \\
\hline & 200 & Deformável Indeformável & $25 \mathrm{MPa}$ \\
\hline
\end{tabular}

Em quase todos os modelos apresentados na tabela 5.3 a resistência característica do concreto à compressão $\left(f_{c k}\right)$ foi de $25 \mathrm{MPa}$, exceto nos casos 1 e 2 para altura de bloco de 115, onde foram analisados resistência do concreto à compressão de $20 \mathrm{MPa}, 25 \mathrm{MPa}$, $30 \mathrm{MPa}, 45 \mathrm{MPa}$. O módulo de elasticidade das barras de aço foi adotado igual a 210.000 MPa. Essas propriedades acima citado podem ser vistas com maiores detalhes no item 4.3.1 e 4.3.2.1 respectivamente.

\subsection{Verificações e Valores de Projeto}

A rotina de projeto de blocos sobre estacas empregado pelo meio técnico é a do CEB-FIP (1970), por meio das seções de referência. Para utilizar esse processo é preciso calcular as reações nas estacas e, para isso o meio técnico utiliza os critérios da Resistência dos Materiais. Essa rotina de dimensionamento foi realizada em todos os blocos aqui analisados. Maiores detalhes podem ser visto no item 3.3, onde se trata especificamente a respeito desse assunto. 


\subsubsection{Reação Nas Estacas}

Um dos resultados de interesse dessa análise foram as reações nas estacas. A tabela 5.4 mostra os vários casos analisados e as reações em cada estacas do bloco. Esses valores mostrado na tabela estão de acordo com o item 3.3, chamados a partir desse ponto de valores analíticos.

Tabela 5.4: Reações nas estacas (analítico)

\begin{tabular}{ccccccccccc}
\hline & \multicolumn{10}{c}{ Estacas - Reações $(\mathrm{kN})$} \\
\cline { 2 - 12 } Caso & 1 & 2 & 3 & 4 & 5 & 6 & 7 & 8 & 9 & 10 \\
\hline 1 & 300,0 & 300,0 & 300,0 & 300,0 & 300,0 & 300,0 & 300,0 & 300,0 & 300,0 & 300,0 \\
2 & 297,9 & 237,9 & 177,9 & 309,3 & 249,3 & 350,7 & 290,7 & 422,1 & 362,1 & 302,1 \\
3 & 296,7 & 200,7 & 104,7 & 314,9 & 218,9 & 381,1 & 285,1 & 495,3 & 399,3 & 303,3 \\
4 & 294,8 & 144,8 & $-5,2$ & 323,3 & 173,3 & 426,7 & 276,7 & 605,2 & 455,2 & 305,2 \\
\hline
\end{tabular}

Como pode ser visto da tabela 5.4 a estaca 3 do Caso 4 é a que está tracionada. Os momentos fletores para o Caso 4 foram aumentados propositalmente para que a estacas de número 3 estivesse tracionada.

Outro detalhe que dever ser chamado atenção, é quando aos valores das reações nas estacas de número 6 e 8. De acordo com o item 3.3 a estaca de número 8 é sempre a mais solicitada. A estaca de número 6 sempre fica na $3^{\circ}$ posição, exceto para o Caso 1.

\subsubsection{Armaduras e Verificações}

Todos os modelos dos blocos simulados foram utilizadas apenas as armaduras principais na face inferior do bloco, as armaduras do pilar e as armaduras nas estacas.

Na tabela 5.5 são mostradas as áreas de armaduras principais, calculadas e adotadas por meio das expressões utilizadas para cálculo de flexão de vigas. São também mostradas as verificações quanto as forças cortantes nas duas direções do bloco. Ambos estão de acordo com o CEB-FIP (1970). Esses são os valores usados na simulação numérica. 
Tabela 5.5: Valores de projetos

\begin{tabular}{cc|c|c|c|c}
\hline \multirow{2}{*}{ Casos } & Altura $(\mathrm{cm})$ & \multicolumn{2}{|c|}{ Armaduras Principais } & \multicolumn{2}{c}{ Forças } \\
\cline { 3 - 6 } & $A_{s, x}\left(\mathrm{~cm}^{2}\right)$ & $A_{s, y}\left(\mathrm{~cm}^{2}\right)$ & $V_{d x}$ & $V_{d y}$ \\
\hline \multirow{2}{*}{1} & 80 & 60,3 & 48,2 & não ok & ok \\
& 115 & 60,3 & 29,5 & ok & ok \\
& 200 & 60,3 & 29,5 & ok & ok \\
\hline \multirow{3}{*}{2} & 80 & 60,3 & 48,2 & não ok & ok \\
& 115 & 60,3 & 29,5 & ok & ok \\
& 200 & 60,3 & 29,5 & ok & ok \\
\hline \multirow{3}{*}{3} & 80 & 60,3 & 48,2 & não ok & ok \\
& 115 & 60,3 & 48,2 & ok & ok \\
& 200 & 60,3 & 48,2 & ok & ok \\
\hline \multirow{2}{*}{4} & 80 & 60,3 & 48,2 & não ok & ok \\
& 115 & 60,3 & 48,2 & ok & ok \\
& 200 & 60,3 & 48,2 & ok & ok \\
\hline
\end{tabular}

Pode-se observar que os blocos com altura de $115 \mathrm{~cm}$ e $200 \mathrm{~cm}$ passaram na verificação quanto a força cortante e apenas os blocos com altura de $80 \mathrm{~cm}$ não foram satisfeito quanto a força cortante. As três alturas consideradas para a análise permitem classificar os blocos como rígido (NBR 6118:2003). 


\section{Resultados e Análise dos}

\section{Resultados}

\subsection{Considerações iniciais}

Neste capítulo são apresentados os resultados das análises numéricas. Os principais resultados de interesse foram: as reações nas estacas e os fluxos das tensões principais de compressão sendo, portanto, possível fazer uma comparação entre os métodos analíticos e o método numérico. As reações nas estacas analisadas são referentes ao valor característico de projeto, ou seja, sem coeficiente de majoração.

Inicialmente são apresentados os resultados referentes ao Caso 1, em seguida para o Caso 2, Caso 3 e Caso 4 respectivamente.

No inicio do trabalho o bloco adotado como padrão para a simulação tinha altura de $115 \mathrm{~cm}$. No intuito de verificar o comportamento estrutural variando a rigidez do bloco optou-se por analisar posteriormente blocos com altura de $80 \mathrm{~cm}$. Em seguida com o mesmo propósito analisaram-se blocos com altura de $200 \mathrm{~cm}$.

Como já foi mencionado, foram simulados 32 blocos. No capítulo 5 são apresentados os resultados analíticos. A rotina de dimensionamento dos blocos está descrita no capítulo 3, mais especificamente nos item 3.3 e 3.4 . 


\subsection{Caso 1}

Neste item é analisada apenas o Caso 1. Para o Caso 1 considera-se apenas a força centrada.

Inicialmente foram feitas simulações em blocos variando a rigidez por meio da variação da resistência característica à compressão do concreto $\left(f_{c k}\right)$. Os resultados referentes a essas simulações são apresentados no apêndice B. Esses resultados mostraram que variando a resistência do concreto não houve uma mudança significativa no comportamento estrutural do bloco. Por esse motivo esses resultados serão apenas apresentados no apêndice.

Na tabela 6.1 são apresentadas as reações nas estacas para os dois tipos de vinculação das estacas para bloco com altura de $80 \mathrm{~cm}$. Vale lembrar que o bloco com altura de $80 \mathrm{~cm}$ não satisfaz a verificação quanto a resistência à força cortante, conforme o processo do CEB-FIP (1970). A biela de compressão referente as estacas centrais formaram ângulos de inclinação da biela de compressão igual a 46 graus. Esse valor corresponde a um grau acima do valor mínimo sugerido por Blévot \& Frémy (1967). Segundo a NBR 6118:2003 o bloco com essa altura considerada, ainda atende as exigências para a classificação de blocos como sendo rígidos. A comparação utilizada nesta tabela é feita em termos da relação entre a reação nas estacas do modelo numérico $\left(F_{k, n}\right)$ analisado e a reação das estacas do modelo analítico $\left(F_{k, a}\right)$.

Tabela 6.1: Reações nas estacas para o Caso 1 em bloco com altura de $80 \mathrm{~cm}$

\begin{tabular}{ccccccc}
\hline \multicolumn{7}{c}{ Caso $1 ; \mathrm{h}=80 \mathrm{~cm} ; 25 \mathrm{MPa}$} \\
\hline \multicolumn{5}{c}{ deformável } & \multicolumn{3}{c}{ Indeformável } \\
\hline & Modelo & Modelo & & Modelo & Modelo \\
Estacas & $F_{k, n}(\mathrm{kN})$ & $F_{k, a}(\mathrm{kN})$ & $F_{k, n} / F_{k, a}$ & $F_{k, n}(\mathrm{kN})$ & $F_{k, a}(\mathrm{kN})$ & $F_{k, n} / F_{k, a}$ \\
\hline 1 & 272,2 & 300 & 0,91 & 106,1 & 300 & 0,35 \\
2 & 283,5 & 300 & 0,94 & 171,1 & 300 & 0,57 \\
3 & 271,8 & 300 & 0,91 & 106,1 & 300 & 0,35 \\
4 & 336,0 & 300 & 1,12 & 558,4 & 300 & 1,86 \\
5 & 335,8 & 300 & 1,12 & 558,4 & 300 & 1,86 \\
6 & 336,0 & 300 & 1,12 & 558,4 & 300 & 1,86 \\
7 & 335,8 & 300 & 1,12 & 558,4 & 300 & 1,86 \\
8 & 272,6 & 300 & 0,91 & 106,1 & 300 & 0,35 \\
9 & 283,8 & 300 & 0,95 & 171,1 & 300 & 0,57 \\
10 & 272,1 & 300 & 0,91 & 106,1 & 300 & 0,35 \\
\hline
\end{tabular}

Observou-se que houve uma mudança no comportamento estrutural do bloco quando modificado o tipo de vinculação das estacas, ou seja, o tipo de solo considerado. 
Para vinculação das estacas do bloco com o solo do tipo deformável, houve uma "certa" uniformização na distribuição das reações nas estacas. Porém, quando o solo é do tipo indeformável há uma tendência maior das forças ficarem maiores nas estacas centrais, mais próxima ao pilar.

Em ambos os casos as estacas na região central, próxima ao pilar, foram as mais solicitadas. Para o solo do tipo deformável a diferença do modelo numérico para o modelo analítico foi de $12 \%$. Para solo do tipo indeformável a diferença foi de $86 \%$.

Essas diferenças nas reações das estacas para solo do tipo indeformável são bastante consideráveis, visto que o bloco ainda é considerado como rígido.

Na tabela 6.2 são apresentadas as reações nas estacas para os dois tipos de vinculação das estacas para bloco com altura de $115 \mathrm{~cm}$. Vale lembrar que o bloco com altura de $115 \mathrm{~cm}$ satisfez a verificação quanto a resistência à força cortante, conforme o processo do CEB-FIP (1970). A biela de compressão referente as estacas centrais formaram ângulos de inclinação da biela de compressão iguais a 56 graus. Esse valor corresponde a um grau acima do valor máximo sugerido por Blévot \& Frémy (1967).

Tabela 6.2: Reações nas estacas para o Caso 1 em bloco com altura de $115 \mathrm{~cm}$

\begin{tabular}{ccccccc}
\hline \multicolumn{5}{c}{ Caso $1 ; \mathrm{h}=115 \mathrm{~cm} ; 25 \mathrm{MPa}$} \\
\hline & Modelo & Modelo & \multicolumn{3}{c}{ Indeformável } \\
\hline & Numérico & Analítico & & Modelo & Modelórico & Analítico \\
Estacas & $F_{k, n}(\mathrm{kN})$ & $F_{k, a}(\mathrm{kN})$ & $F_{k, n} / F_{k, a}$ & $F_{k, n}(\mathrm{kN})$ & $F_{k, a}(\mathrm{kN})$ & $F_{k, n} / F_{k, a}$ \\
\hline 1 & 288,6 & 300 & 0,96 & 183,7 & 300 & 0,61 \\
2 & 292,8 & 300 & 0,98 & 222,2 & 300 & 0,74 \\
3 & 288,2 & 300 & 0,96 & 183,7 & 300 & 0,61 \\
4 & 315,0 & 300 & 1,05 & 455,2 & 300 & 1,52 \\
5 & 314,8 & 300 & 1,05 & 455,2 & 300 & 1,52 \\
6 & 315,0 & 300 & 1,05 & 455,2 & 300 & 1,52 \\
7 & 314,9 & 300 & 1,05 & 455,2 & 300 & 1,52 \\
8 & 288,9 & 300 & 0,96 & 183,7 & 300 & 0,61 \\
9 & 293,1 & 300 & 0,98 & 222,2 & 300 & 0,74 \\
10 & 288,5 & 300 & 0,96 & 183,7 & 300 & 0,61 \\
\hline
\end{tabular}

Para este bloco analisado observou-se que houve uma mudança no comportamento estrutural quando variado o tipo de vinculação das estacas, o solo, como já haviam mostrado os resultados para bloco com altura de $80 \mathrm{~cm}$ de altura. Com o aumento da rigidez do bloco, e para as vinculações das estacas do bloco com o solo do tipo deformável, as distribuições das reações nas estacas foram mais uniformes. Com o solo do tipo indeformável ainda há uma tendência das forças serem maiores nas estacas centrais, mais próximas ao pilar. 
Em ambos os casos as estacas na região central, próximas ao pilar, foram as mais solicitadas. Para solo do tipo deformável a diferença do modelo numérico para o modelo analítico foi de $5 \%$, e para solo do tipo indeformável a diferença foi de $52 \%$.

É possível perceber que com o aumento da rigidez do bloco o comportamento estrutural é modificado. Para rigidez maior a tendência é de que haja uma uniformização nas reações das estacas. Porém, a diferença na distribuição das reações nas estacas ainda continua elevada, principalmente quando o bloco está apoiado em solo indeformável.

Na tabela 6.3 são apresentadas as reações nas estacas para os dois tipos de vinculação das estacas para bloco com altura de $200 \mathrm{~cm}$. Vale lembrar que o bloco com altura de $200 \mathrm{~cm}$ satisfez a verificação quanto a resistência à força cortante, conforme o processo do CEB-FIP (1970). A biela de compressão referente as estacas centrais formaram ângulos de inclinação da biela de compressão iguais a 69 graus. Esse valor está bem acima dos valores sugeridos por Blévot \& Frémy (1967). Esse bloco foi simulado para verificar a influência da rigidez do bloco na distribuição das reações das estacas, conforme foi constatado em outros blocos com altura menores.

Tabela 6.3: Reações nas estacas para o Caso 1 em bloco com altura de $200 \mathrm{~cm}$

\begin{tabular}{|c|c|c|c|c|c|c|}
\hline \multicolumn{7}{|c|}{ Caso $1 ; \mathrm{h}=200 \mathrm{~cm} ; 25 \mathrm{MPa}$} \\
\hline & \multicolumn{3}{|c|}{ deformável } & \multicolumn{3}{|c|}{ Indeformável } \\
\hline & Modelo & Modelo & & Modelo & Modelo & \\
\hline & Numérico & Analítico & & Numérico & Analítico & \\
\hline Estacas & $F_{k, n}(\mathrm{kN})$ & $F_{k, a}(\mathrm{kN})$ & $F_{k, n} / F_{k, a}$ & $F_{k, n}(\mathrm{kN})$ & $F_{k, a}(\mathrm{kN})$ & $F_{k, n} / F_{k, a}$ \\
\hline 1 & 296,1 & 300 & 0,99 & 258,7 & 300 & 0,86 \\
\hline 2 & 297,5 & 300 & 0,99 & 274,8 & 300 & 0,92 \\
\hline 3 & 295,7 & 300 & 0,99 & 258,8 & 300 & 0,86 \\
\hline 4 & 305,0 & 300 & 1,02 & 353,8 & 300 & 1,18 \\
\hline 5 & 304,8 & 300 & 1,02 & 353,8 & 300 & 1,18 \\
\hline 6 & 305,1 & 300 & 1,02 & 353,8 & 300 & 1,18 \\
\hline 7 & 304,9 & 300 & 1,02 & 353,8 & 300 & 1,18 \\
\hline 8 & 296,4 & 300 & 0,99 & 258,8 & 300 & 0,86 \\
\hline 9 & 297,8 & 300 & 0,99 & 274,8 & 300 & 0,92 \\
\hline 10 & 296,0 & 300 & 0,99 & 258,8 & 300 & 0,86 \\
\hline
\end{tabular}

Conforme já havia observado em blocos com alturas menores o comportamento estrutural quando modificado o tipo de vinculação das estacas foi alterado, como já mostrado pelos resultados dos blocos de $80 \mathrm{~cm}$ e $115 \mathrm{~cm}$ de altura. Com o aumento da rigidez do bloco, e para vinculação das estacas do bloco com o solo do tipo deformável, a distribuição das reações nas estacas foi ainda mais uniforme. Com o solo do tipo indeformável ainda há uma tendência das forças ficarem maiores junto as estacas centrais, mais próximas do pilar, porém esse valor foi bastante reduzido. 
Novamente em ambos os casos as estacas na região central, próximas ao pilar, foram as mais solicitadas. Para solo do tipo deformável a diferença do modelo numérico para o modelo analítico foi de apenas $2 \%$, e para solo do tipo indeformável a diferença foi de 18\%. Para solo indeformável a queda foi bastante expressiva, principalmente quando se comparam com outros blocos.

Portanto, depois de analisar as três tabelas apresentadas percebe-se que o comportamento estrutural do bloco é fortemente influenciado pelo tipo de vinculação das estacas e pela rigidez do bloco. Com o aumento da rigidez do bloco as distribuições das reações nas estacas demonstraram um comportamento com tendência de uniformização. Nos três blocos analisados o comportamento foi semelhante quando comparado o tipo de vinculação das estacas. Para blocos com estacas apoiadas em solo deformável a tendência das reações nas estacas é ficarem iguais. Em blocos com estacas apoiadas em solo indeformável a tendência é que haja uma pequena uniformização, e as forças ficarem maiores nas estacas mais próximas do pilar. Isso mostra que para blocos com estacas apoiadas em solo indeformável é necessário ter maior altura para que haja uma efetiva uniformização, fazendo com que o elemento estrutural deixe de se comportar como bloco e passe a ter comportamento análogo a de uma viga parede.

Para que fique claro o que foi tido é apresentado na figura 6.1 um gráfico comparando as alturas dos blocos versus a relação entre a força obtida numericamente e a força calculada analiticamente. Foi tomada como exemplo a estaca de número 4, pois todas as outras estacas próxima da região central são de mesmo valor.

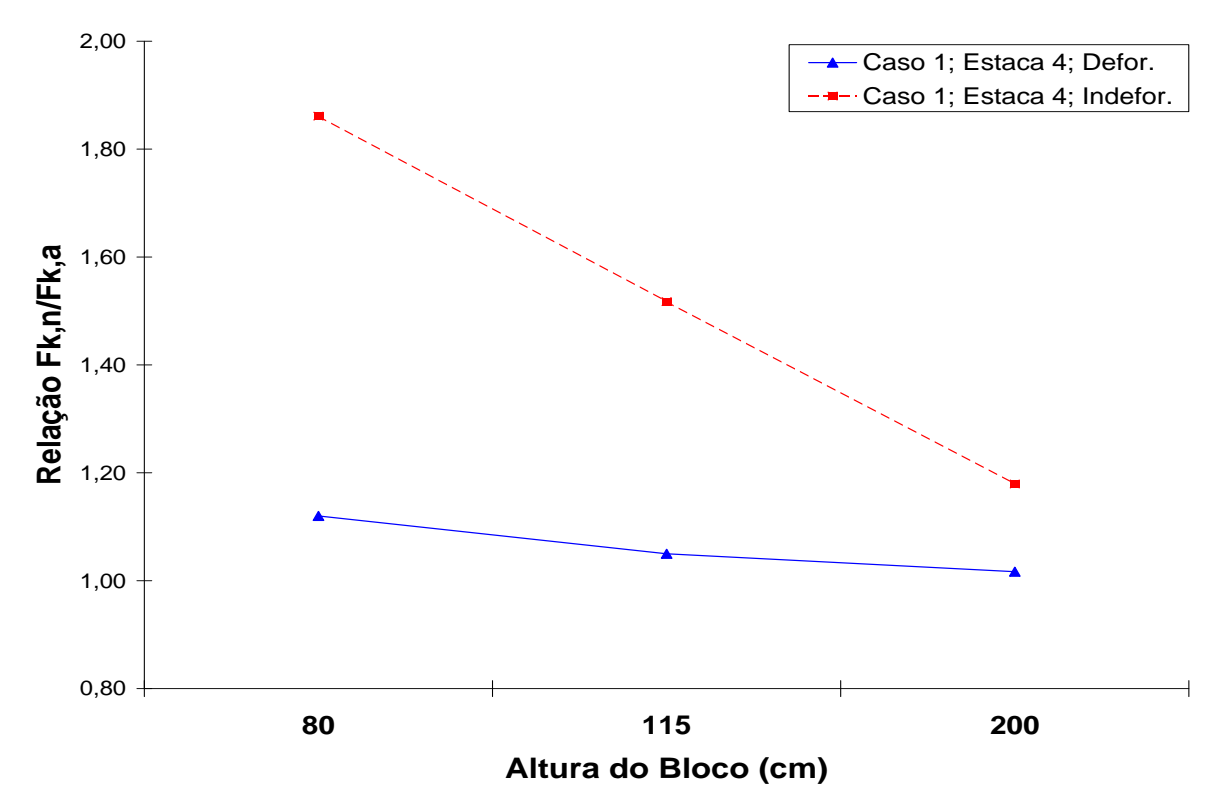

Figura 6.1: Comparação entre as alturas para estaca 4 do Caso 1 
Na figura 6.1 é possível visualizar as linhas para solo deformável (linha contínua) e para solo indeformável (linha pontilhada). As duas linhas com o aumento da altura do bloco tendem ao valor da unidade. Isso mostra que com o aumento da altura as reações nas estacas tendem a se aproximar dos valores analíticos.

Na figura 6.2 é apresentado um gráfico comparando as alturas dos blocos. Nessa figura é tomada como exemplo a estaca de número 1. As estacas de número 3, 8 e 10 são de mesmo valor.

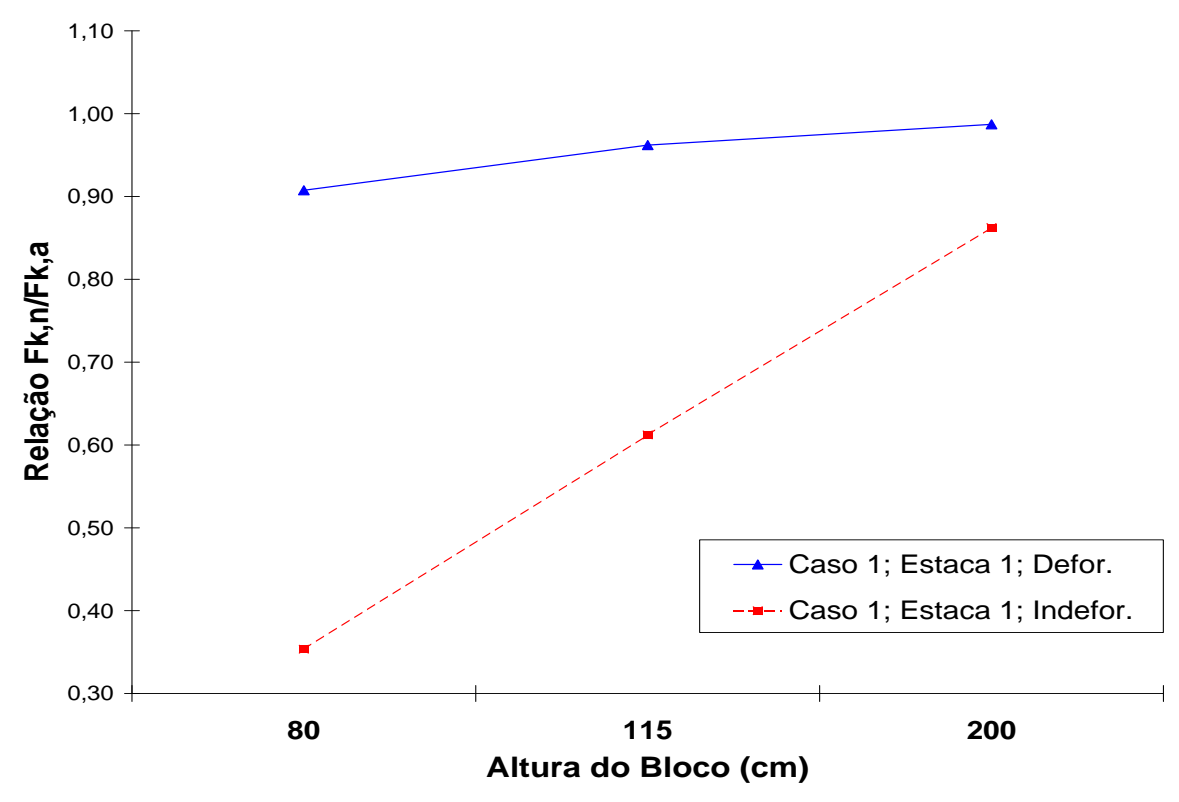

Figura 6.2: Comparação entre as alturas para estaca 1 do Caso 1

Na figura 6.2 é possível visualizar as linhas para solo deformável (linha contínua) e para solo indeformável (linha pontilhada). As duas linhas com o aumento da altura do bloco tendem ao valor da unidade. Assim como no caso da figura anterior, com o aumento da altura as reações nas estacas tendem a se aproximar dos valores analíticos. 
Na figura 6.3 é apresentado um gráfico, igual as duas anteriores, comparando as alturas dos blocos. Nessa figura é tomada como exemplo a estaca de número 2. A estaca de número 9 é do mesmo valor.

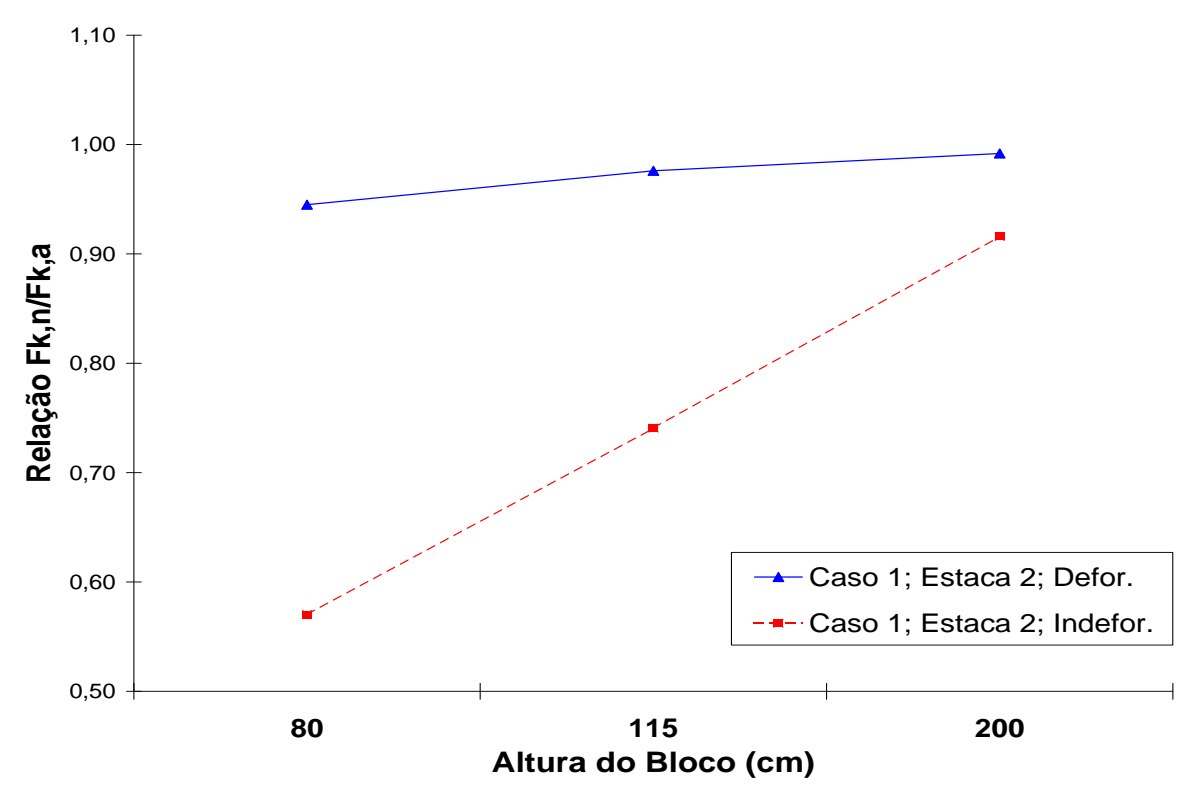

Figura 6.3: Comparação entre as alturas para estaca 2 do Caso 1

Na figura 6.3 é possível visualizar as linhas para solo deformável (linha contínua) e para solo indeformável (linha pontilhada). O mesmo comportamento presentes nas duas figuras mostradas anteriormente indica que com o aumento da altura do bloco as reações nas estacas tendem a se aproximar dos valores analíticos.

São apresentadas a seguir figuras que representam a relação entre as reações nas estacas versus o acréscimo de ações aplicadas ao bloco simulado numericamente. Esse acréscimo de ação é uma relação da ação atuante no bloco pela ação de projeto. Quando a relação for igual a unidade, significa que as ações atuantes no modelo simulado numericamente são iguais as ações consideradas em projeto. 
Na figura 6.4 são apresentadas as relações entre as reações nas estacas para bloco com altura de $80 \mathrm{~cm}$ e estacas apoiadas em solo deformável.

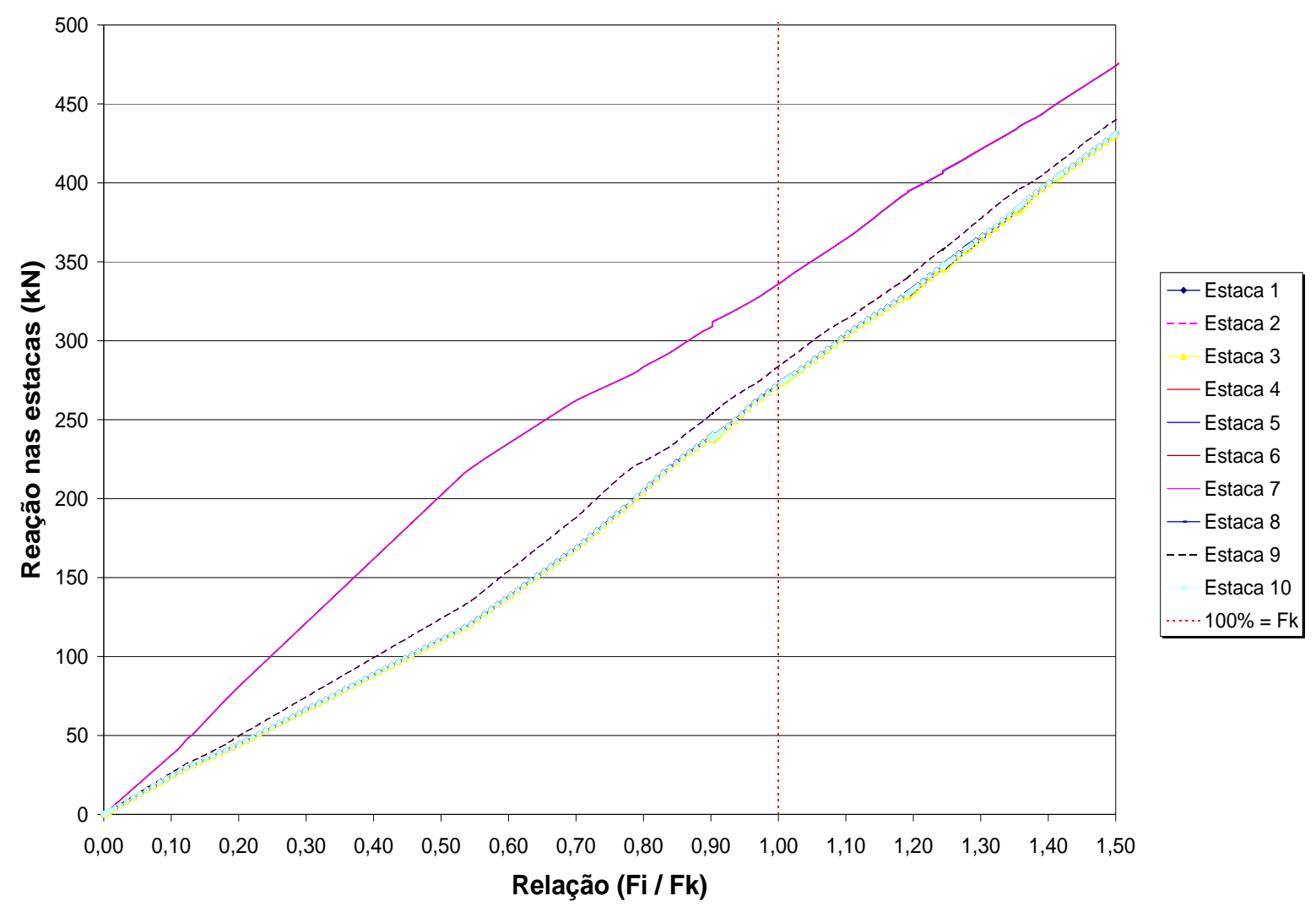

Figura 6.4: Reações nas estacas ao longo da aplicação das ações para bloco com altura de $80 \mathrm{~cm}$ e solo deformável

Por meio da figura 6.4 percebe-se que as reações nas estacas centrais inicialmente tem um comportamento de bloco com estacas apoiadas em solo indeformável, próxima da relação $F_{i} / F_{k}$ igual a 0,50 há uma mudança no comportamento. Para este caso as estacas mais solicitadas foram as de número 4, 5, 6 e 7 com $336 \mathrm{kN}$ ficando $12 \%$ acima do valor calculado analiticamente. 
Na figura 6.5 são apresentadas as relações entre as reações nas estacas para bloco com altura de $115 \mathrm{~cm}$ e estacas apoiadas em solo deformável.

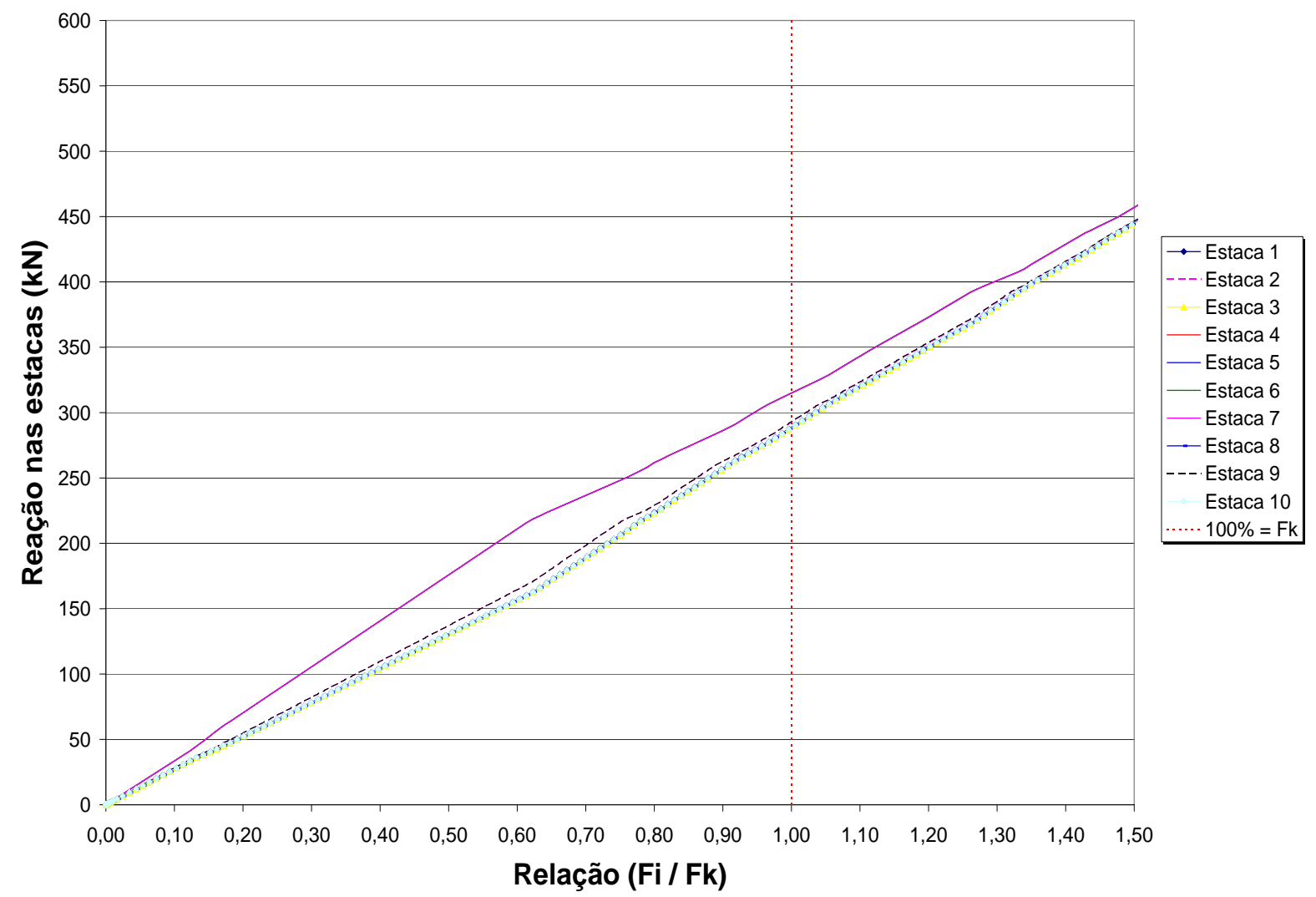

Figura 6.5: Reações nas estacas ao longo da aplicação das ações para bloco com altura de $115 \mathrm{~cm}$ e solo deformável

Por meio da figura 6.5 percebe-se que o comportamento das reações nas estacas foi análogo ao de bloco com altura de $80 \mathrm{~cm}$, onde as estacas nas regiões centrais foram as mais solicitadas e tiveram inicialmente um comportamento de bloco com estacas apoiadas em solo indeformável. Próxima da relação $F_{i} / F_{k}$ igual a 0,60 há uma mudança no comportamento. Para este caso a estacas mais solicitada foram as centrais que atingiram 315 $\mathrm{kN}$ ficando $5 \%$ acima do valor calculado analiticamente. Percebe-se também que há uma uniformização da distribuição das reações nas estacas comparadas a bloco com altura de altura de $80 \mathrm{~cm}$. 
Na figura 6.6 são apresentadas as relações entre as reações nas estacas para bloco com altura de $200 \mathrm{~cm}$ e estacas apoiadas em solo deformável.

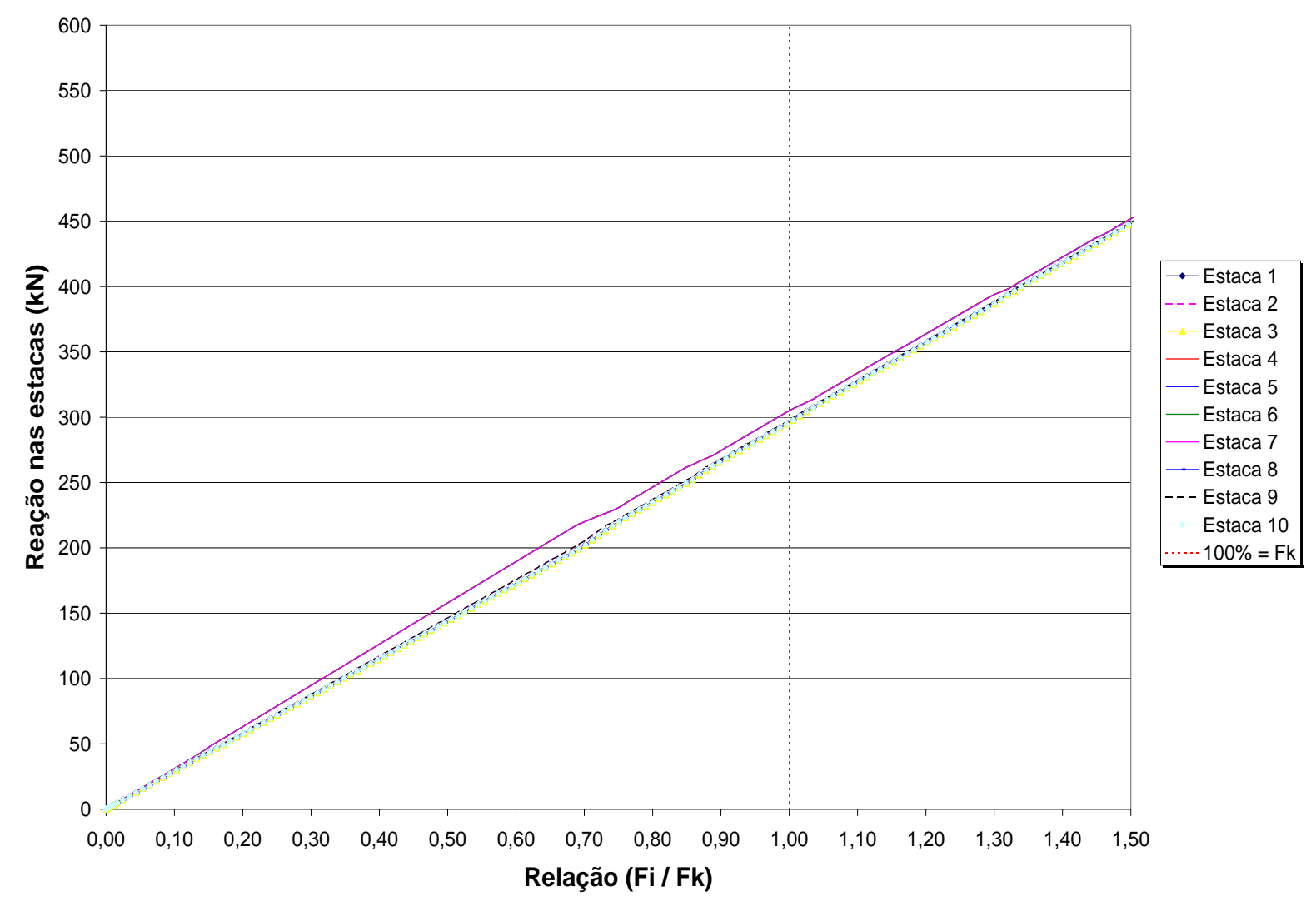

Figura 6.6: Reações nas estacas ao longo da aplicação das ações para bloco com altura de $200 \mathrm{~cm}$ e solo deformável

Por meio da figura 6.6 percebe-se que a uniformização nas reações das estacas para este caso foi bem maior quando comparado com blocos de altura de $80 \mathrm{~cm}$ e $115 \mathrm{~cm}$. Pode-se afirmar que as reações em todas as estacas foram iguais visto que a diferença é de apenas 3\%. As estacas na região central do bloco foram as mais solicitadas e ficaram apenas $2 \%$ acima do valor calculado analiticamente. As outras estacas ficaram apenas a $1 \%$ menores do valor calculado.

Esses gráficos apresentados mostram que para blocos com estacas apoiadas em solo deformável há uma "certa" redistribuição das reações nas estacas. Em simulações realizadas com um tipo de solo fictício onde foram adotadas molas mais deslocáveis, as reações nas estacas mostraram uma uniformização ainda maior, muito próxima ao gráfico do bloco com altura de $200 \mathrm{~cm}$. Em nenhum dos casos analisados aqui as estacas apresentaram ruína. 
Na figura 6.7 são apresentadas as relações entre as reações nas estacas para bloco com altura de $80 \mathrm{~cm}$ e estacas apoiadas em solo indeformável.

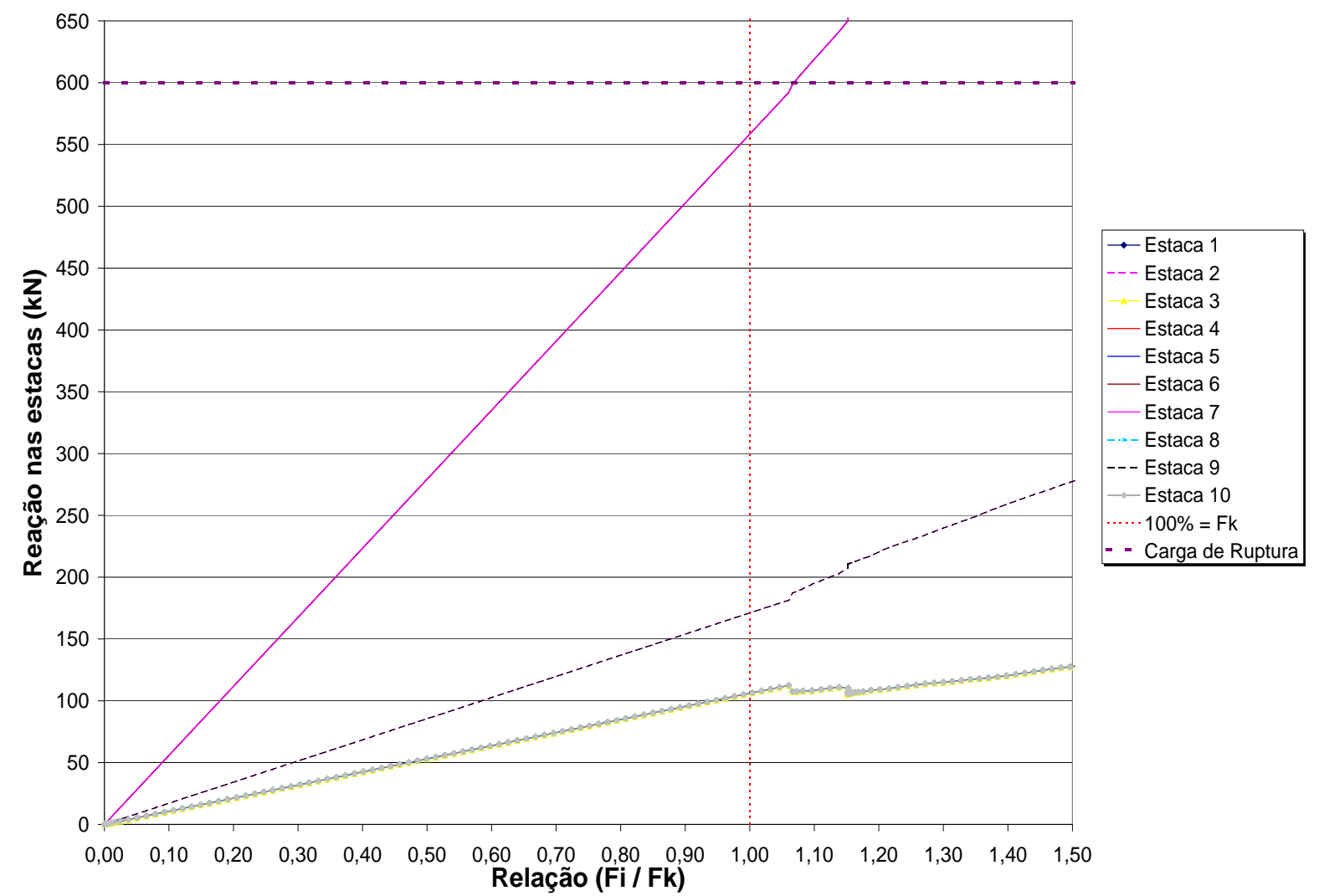

Figura 6.7: Reações nas estacas ao longo da aplicação das ações para bloco com altura de $80 \mathrm{~cm}$ e solo indeformável

Por meio da figura 6.7 percebe-se que o comportamento do bloco mudou muito quando comparado com o bloco sobre estacas apoiadas em solo deformável. Houve uma grande variabilidade nos valores das reações nas estacas, principalmente para as estacas na região central do bloco. Essas estacas foram as mais solicitadas e atingiram o valor de $558,4 \mathrm{kN}$ para relação $F_{i} / F_{k}$ igual a unidade. Esse valor corresponde a $86 \%$ acima do valor calculado analiticamente. O valor de ruína da estaca que é de $600 \mathrm{kN}$ foi atingido para uma relação $F_{i} / F_{k}$ próxima de 1,1 . 
Na figura 6.8 são apresentadas as relações entre as reações nas estacas para bloco com altura de $115 \mathrm{~cm}$ e estacas apoiadas em solo indeformável.

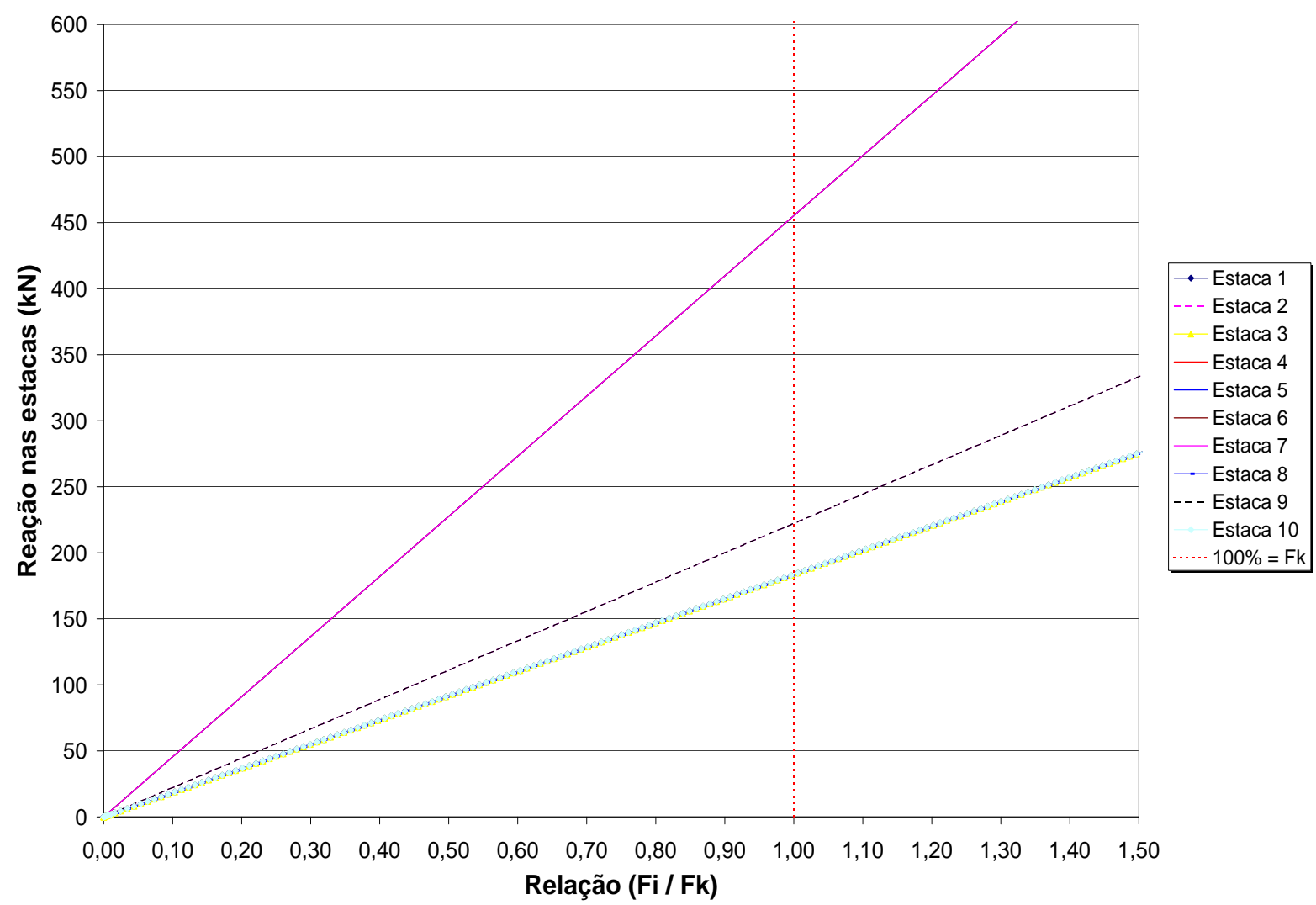

Figura 6.8: Reações nas estacas ao longo da aplicação das ações para bloco com altura de $115 \mathrm{~cm}$ e solo indeformável

Por meio da figura 6.8 percebe-se que o comportamento do bloco se assemelha ao do bloco com altura de $80 \mathrm{~cm}$ com mesmo tipo de solo. A variação nos valores das reações nas estacas foi menor. As estacas centrais, novamente, foram as mais solicitadas. Para a relação $F_{i} / F_{k}$ igual a unidade a reação nas estacas foi de $455,2 \mathrm{kN}$, esse valor corresponde a $52 \%$ acima do valor esperando analiticamente. O valor de ruína foi atingido para a relação $F_{i} / F_{k}$ próxima de 1,3 . 
Na figura 6.9 são apresentadas as relações entre as reações nas estacas para bloco com altura de $200 \mathrm{~cm}$ e estacas apoiadas em solo indeformável.

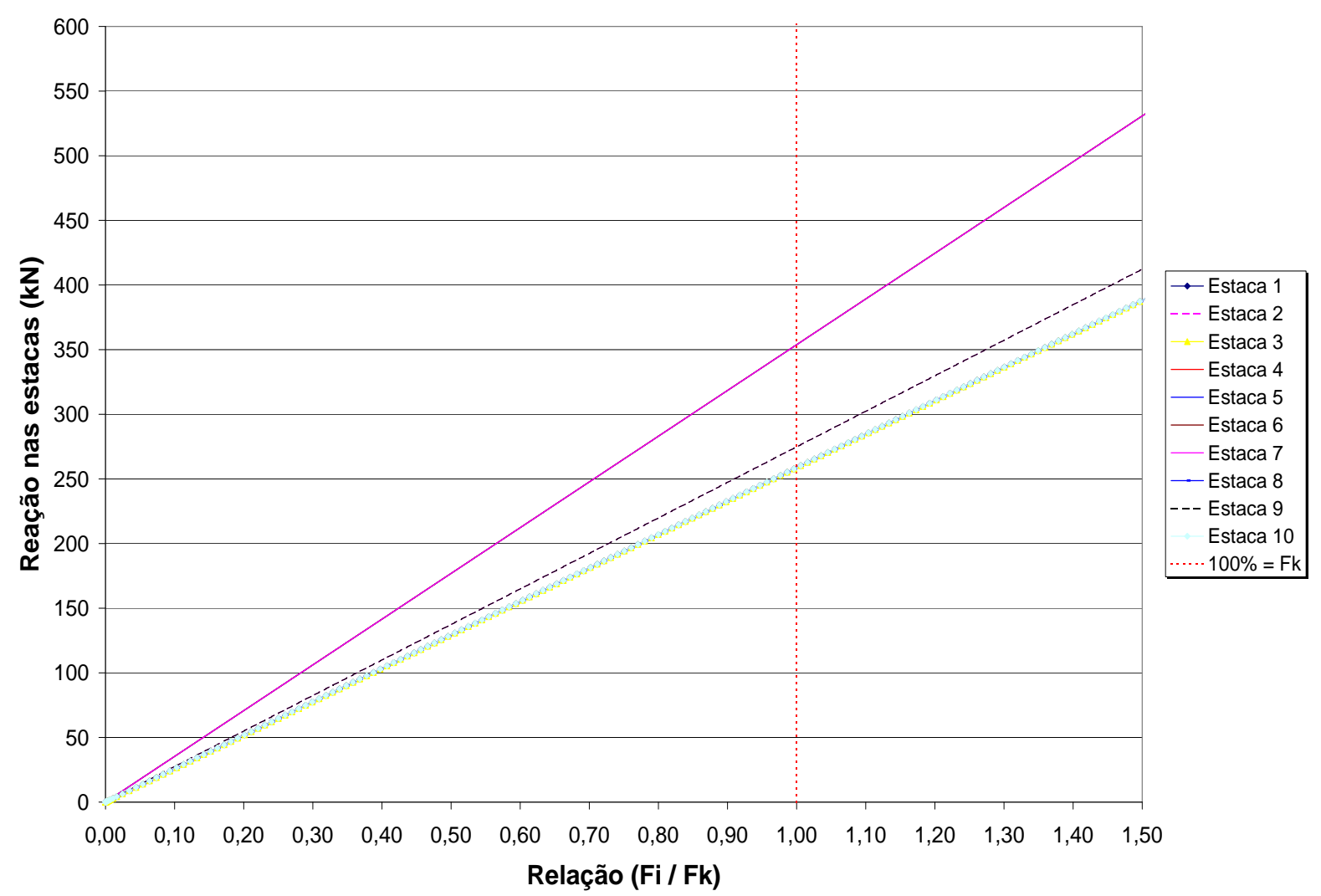

Figura 6.9: Reações nas estacas ao longo da aplicação das ações para bloco com altura de $200 \mathrm{~cm}$ e solo indeformável

Por meio da figura 6.9 percebe-se que o comportamento do bloco se assemelha aos de alturas de $80 \mathrm{~cm}$ e $115 \mathrm{~cm}$, porém com uma distribuição na reação das estacas mais uniforme. As estacas centrais, como já ocorreu para os outros dois casos, foi a mais solicitada chegando ao valor de $353,8 \mathrm{kN}$. Esse valor corresponde a $18 \%$ acima do valor calculado analiticamente. O valor de ruína foi atingido para a relação $F_{i} / F_{k}$ próxima de 1,7, muito acima da carga de projeto.

No entanto, com o aumento da rigidez do bloco as diferenças das reações nas estacas diminuiu. Essa situação de blocos com estacas apoiadas em solo indeformável mostra ser a mais crítica delas, principalmente quando se comparam os mesmos resultados com outro tipo de solo. Neste caso as estacas centrais, as mais comprimidas, não atingiriam a força de ruptura da estaca. 
A figura 6.10 apresenta as tensões principais de compressão na seção transversal do bloco ao longo de sua altura para bloco com altura de $80 \mathrm{~cm}$, e vinculação das estacas para solo do tipo deformável. No item $d$ é possível ver as alturas adotadas.

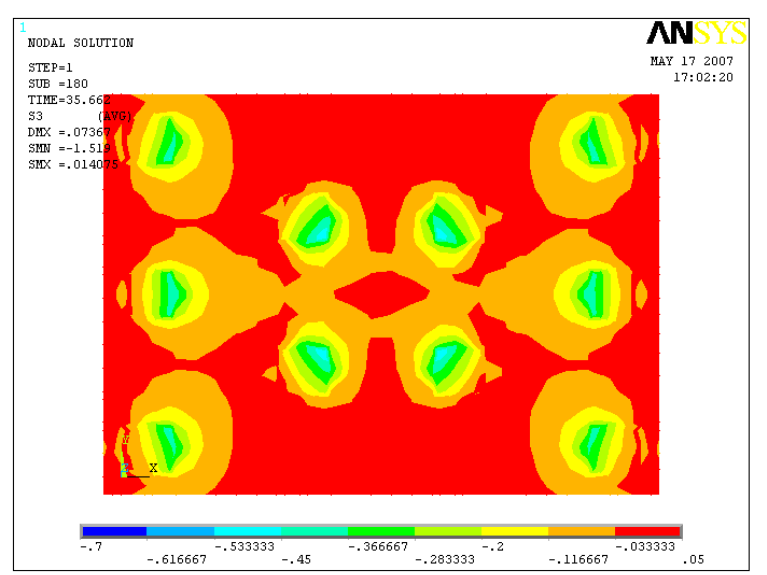

(a) $10 \mathrm{~cm}$

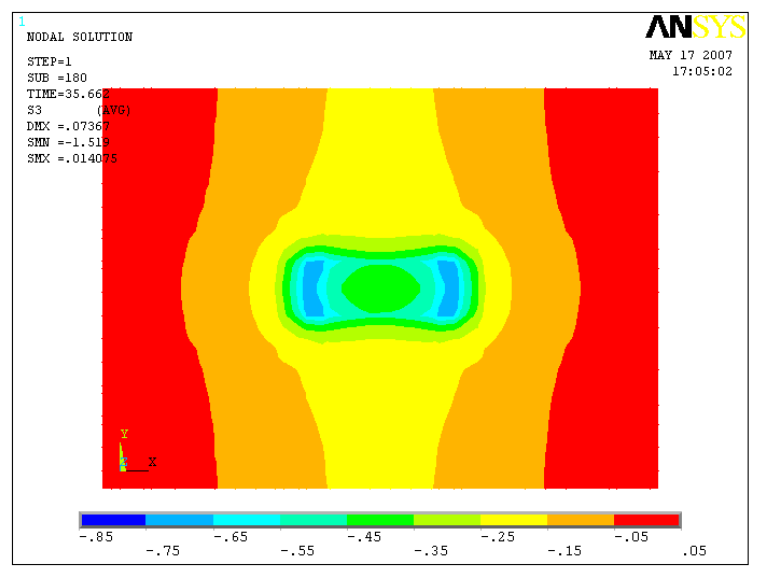

(c) $70 \mathrm{~cm}$

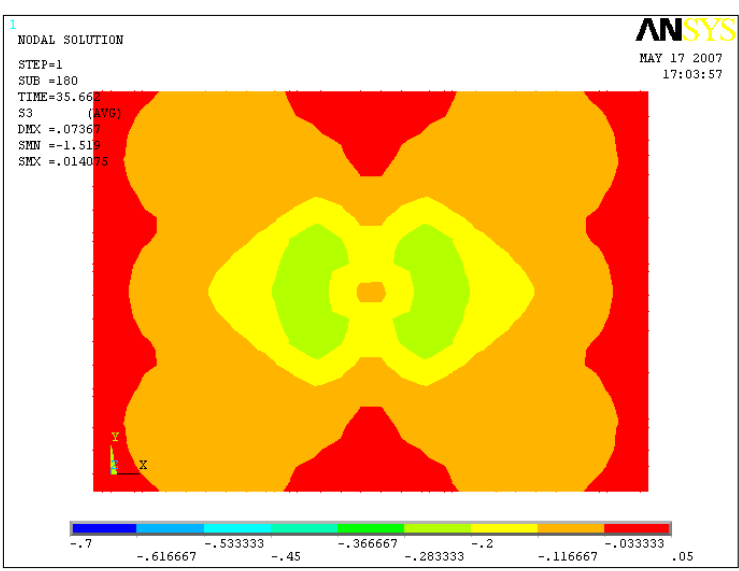

(b) $40 \mathrm{~cm}$

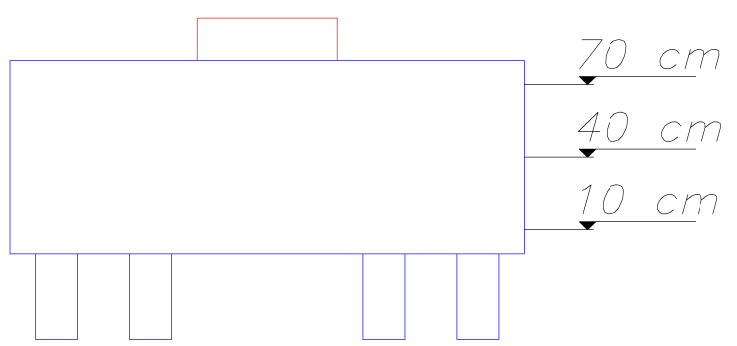

(d) alturas

Figura 6.10: Campos de tensão de compressão - bloco com altura de $80 \mathrm{~cm}$ para solo deformável - valores em $\mathrm{kN} / \mathrm{cm}^{2}$

Por meio da figura 6.10 pode se observar: as tensões junto a cabeça da estaca para uma altura de $10 \mathrm{~cm}$ (a); tensões no bloco a meia altura (b); e tensões próxima ao pilar (c). É possível visualizar a formação dos campos de tensões ao longo da altura do bloco. Percebe-se que nesse caso as tensões junto a cabeça da estaca (a) são próximas para todas as estacas, no entanto, as estacas centrais próxima ao pilar tem uma pequena região com tensões um pouco mais elevada, mostrando que as forças tendem a migrar para elas. Nessa região a tensão de compressão foi de 5,33 MPa. Na região próxima ao pilar, item (c), a tensão de compressão foi de 7,5 MPa. 
A figura 6.11 apresenta as tensões principais de compressão na seção transversal do bloco ao longo de sua altura para bloco com altura de $80 \mathrm{~cm}$, e vinculação das estacas para solo do tipo indeformável.

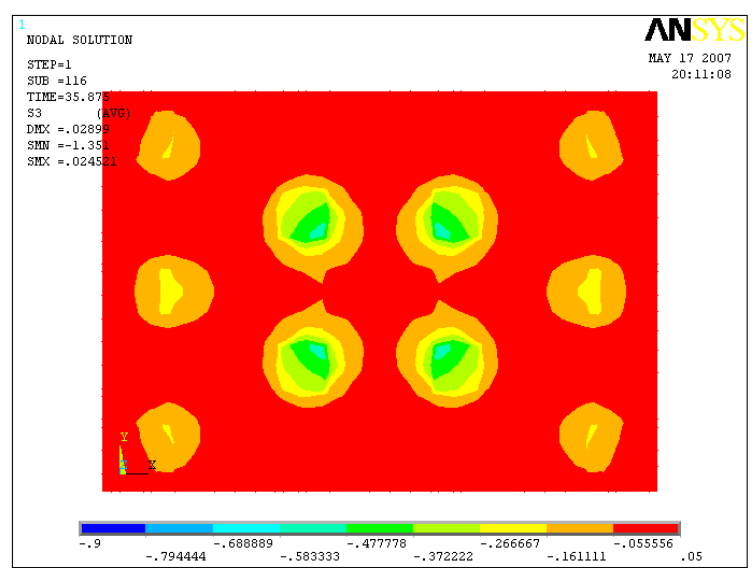

(a) $10 \mathrm{~cm}$

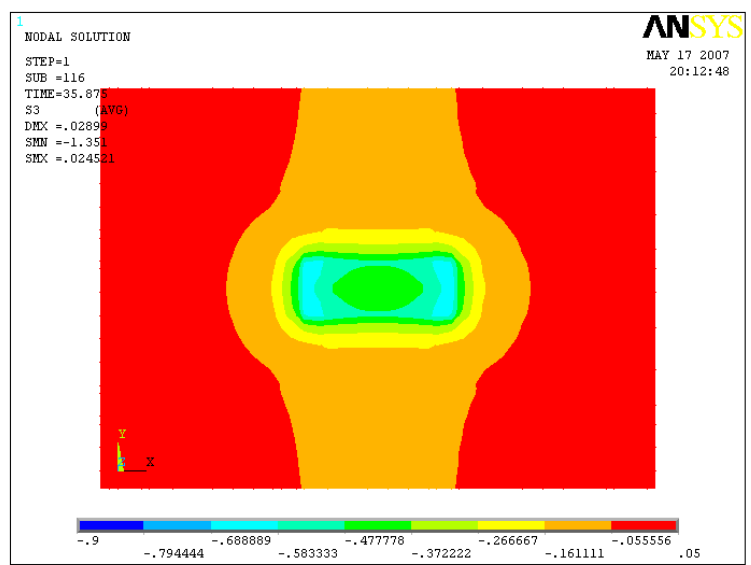

(c) $70 \mathrm{~cm}$

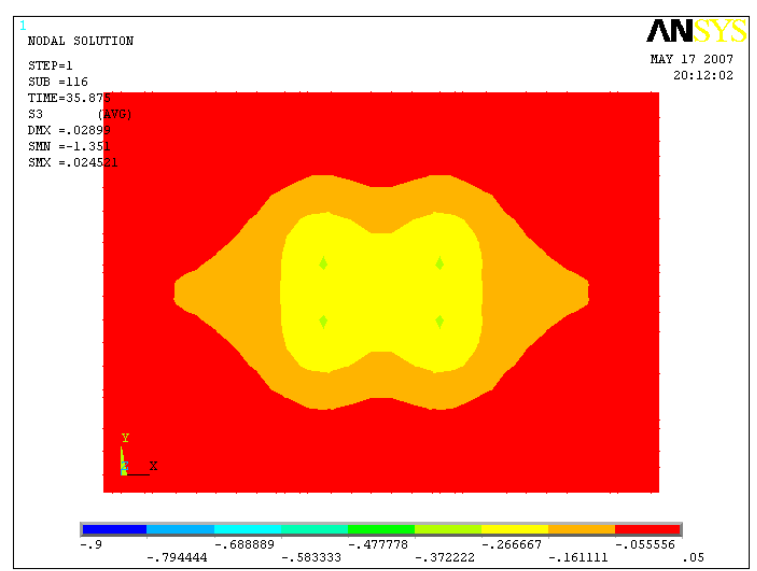

(b) $40 \mathrm{~cm}$

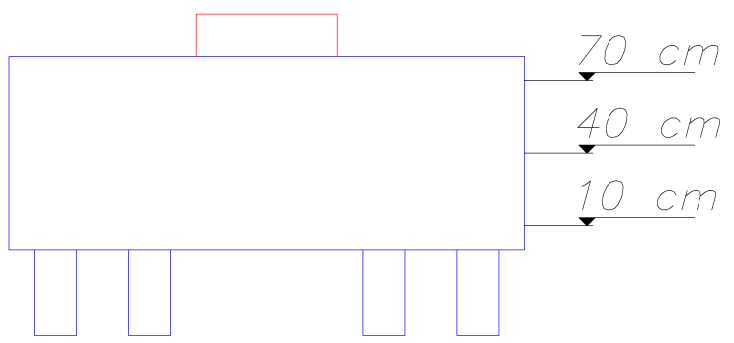

(d) alturas

Figura 6.11: Campos de tensão de compressão - bloco com altura de $80 \mathrm{~cm}$ para solo indeformável - valores em $\mathrm{kN} / \mathrm{cm}^{2}$

Conforme a figura 6.11 pode se observar que nesse caso as tensões de compressão junto a cabeça da estaca (a) não são mais próximas entre as estacas, como ocorreu para estacas apoiadas em solo deformável. Isso mostra, mais uma vez, que as forças tendem a migrar para as estacas centrais mais próximas ao pilar. A tensão de compressão nessa região foi de 5,83 MPa. Para a região próxima ao pilar mostrada no item (c) a tensão de compressão foi de 6,89 MPa. 
Na figura 6.12 são apresentadas as tensões principais de compressão na seção transversal do bloco ao longo de sua altura para bloco com altura de $115 \mathrm{~cm}$, e vinculação das estacas para solo do tipo deformável.

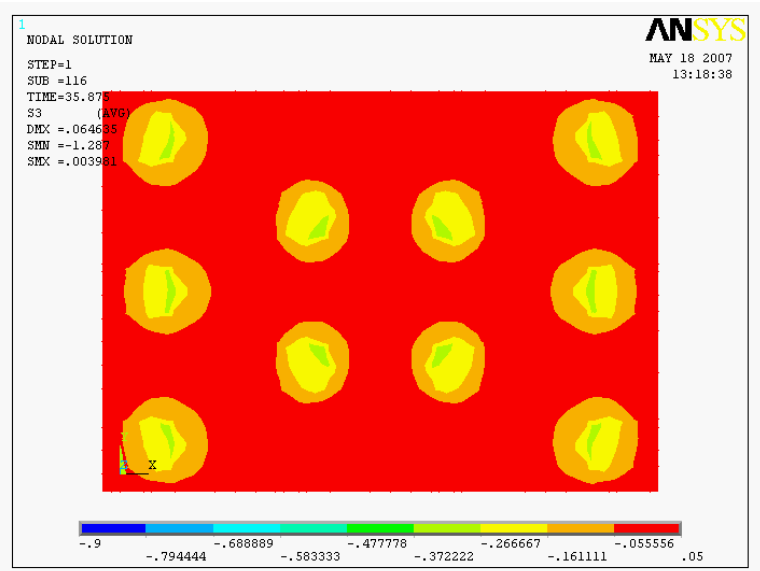

(a) $10 \mathrm{~cm}$

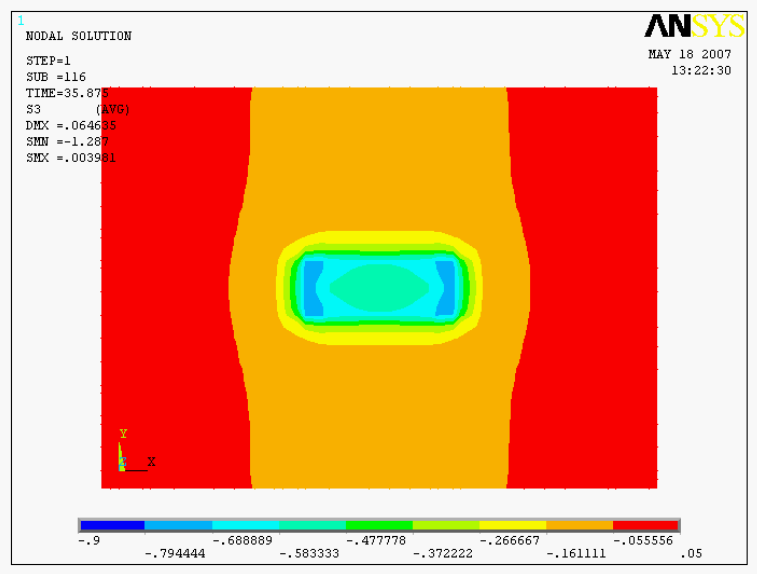

(c) $110 \mathrm{~cm}$

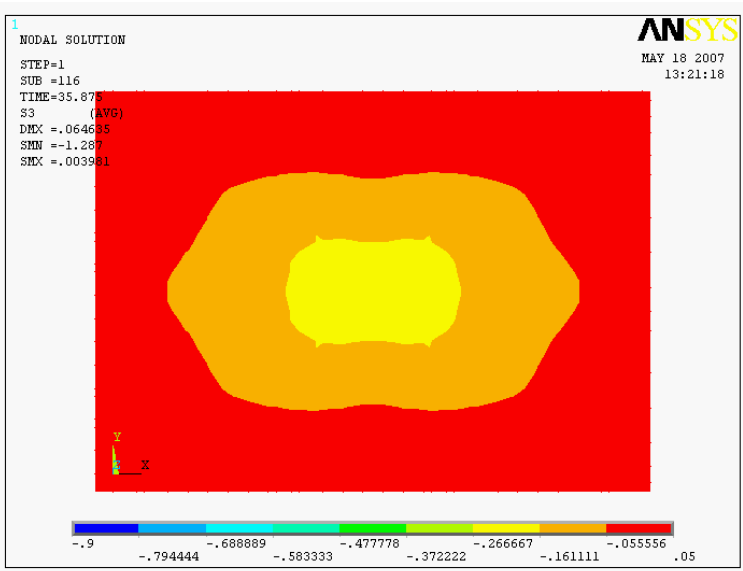

(b) $60 \mathrm{~cm}$

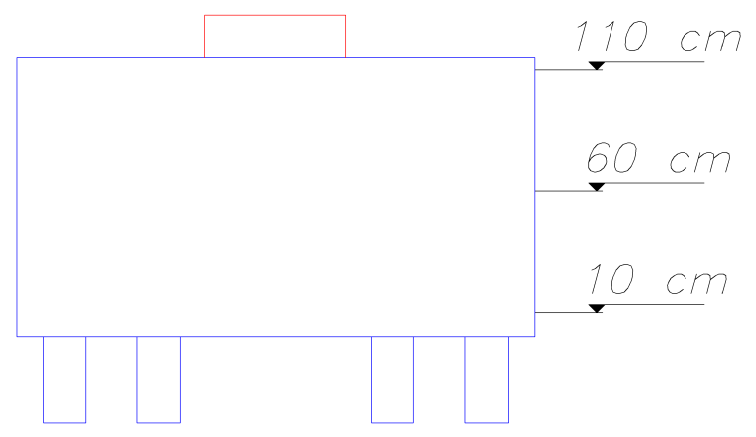

(d) alturas

Figura 6.12: Campos de tensão de compressão - bloco com altura de $115 \mathrm{~cm}$ para solo deformável - valores em $\mathrm{kN} / \mathrm{cm}^{2}$

Na figura 6.12 pode se observar que as tensões de compressão junto a cabeça da estaca (a) são próximas entre as estacas, como ocorreu para blocos de altura de $80 \mathrm{~cm}$ e estacas apoiadas em solo deformável. A tensão de compressão na cabeça das estacas foi de 3,72 MPa e para a região próxima ao pilar (item c) foi de 7,94 MPa. 
Na figura 6.13 são apresentadas as tensões principais de compressão na seção transversal do bloco ao longo de sua altura para bloco com altura de $115 \mathrm{~cm}$, e vinculação das estacas para solo do tipo indeformável.

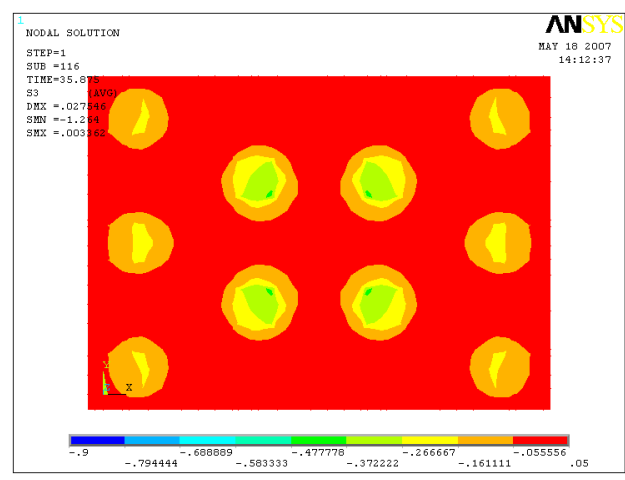

(a) $10 \mathrm{~cm}$

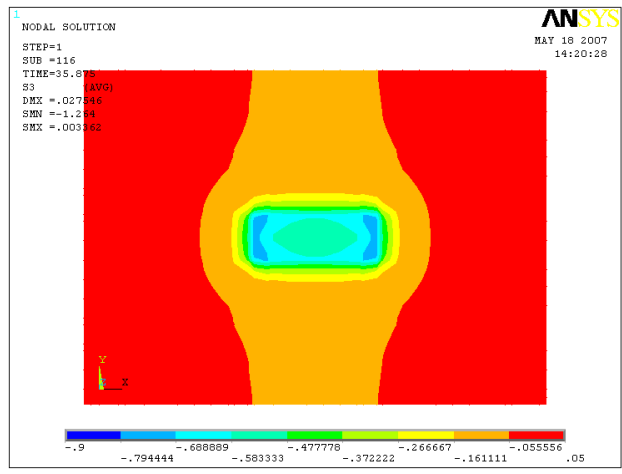

(c) $110 \mathrm{~cm}$

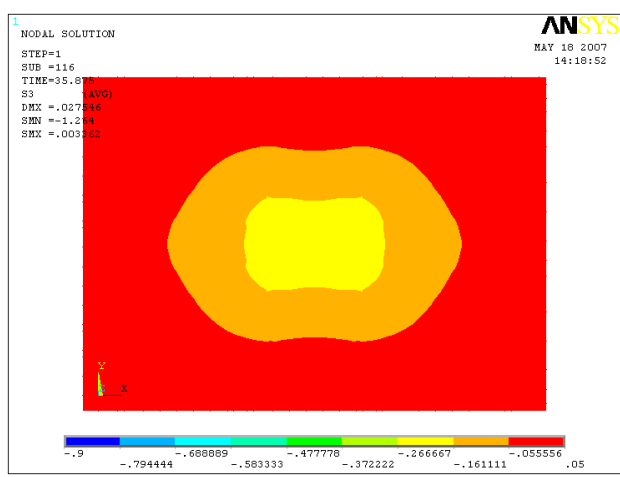

(b) $60 \mathrm{~cm}$

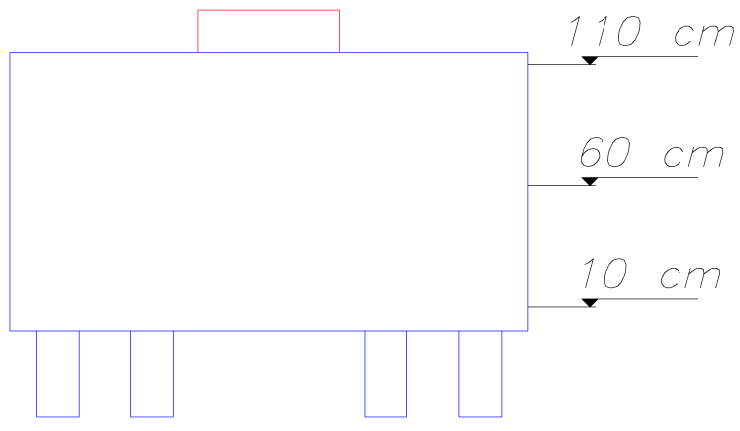

(d) alturas

Figura 6.13: Campos de tensão de compressão - bloco com altura de $115 \mathrm{~cm}$ para solo indeformável - valores em $\mathrm{kN} / \mathrm{cm}^{2}$

Conforme a figura 6.13 pode se observar que nesse caso as tensões de compressão junto a cabeça da estaca (a) são maiores para a região central. A tensão de compressão nessa região foi de 4,78 MPa. Para a região próxima ao pilar mostrada no item (c) da mesma figura a tensão de compressão foi de 7,94 MPa. A região central sendo a mais comprimida mostra, mais uma vez, que para esse tipo de solo (indeformável) as forças tentem a migrar para as estacas centrais mais próximas do pilar. 
Na figura 6.14 são apresentadas as tensões principais de compressão na seção transversal do bloco ao longo de sua altura para bloco com altura de $200 \mathrm{~cm}$, e vinculação das estacas para solo do tipo deformável.

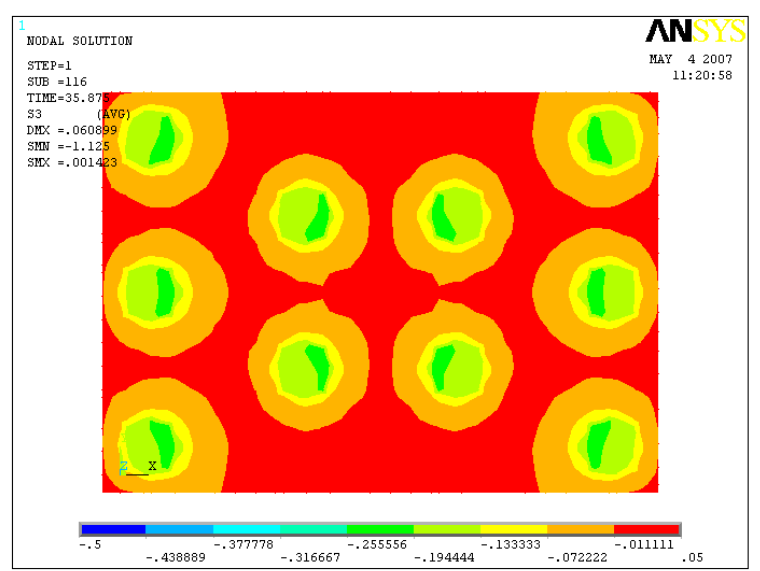

(a) $10 \mathrm{~cm}$

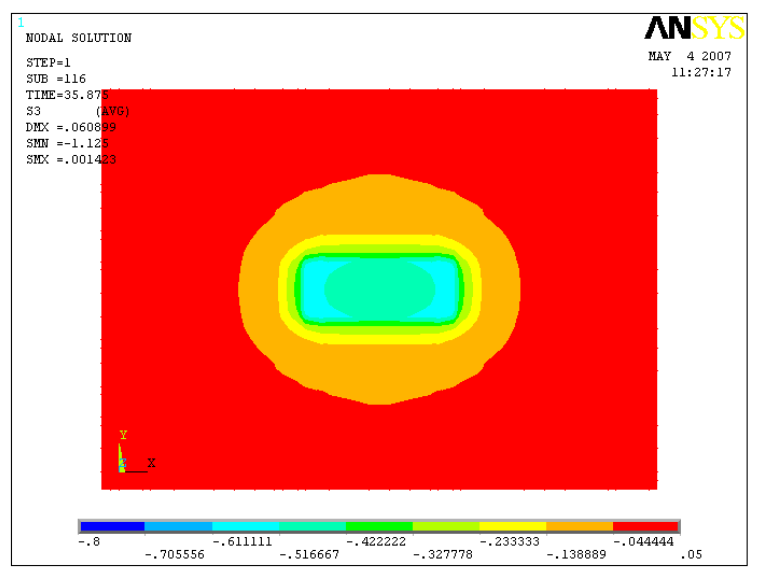

(c) $190 \mathrm{~cm}$

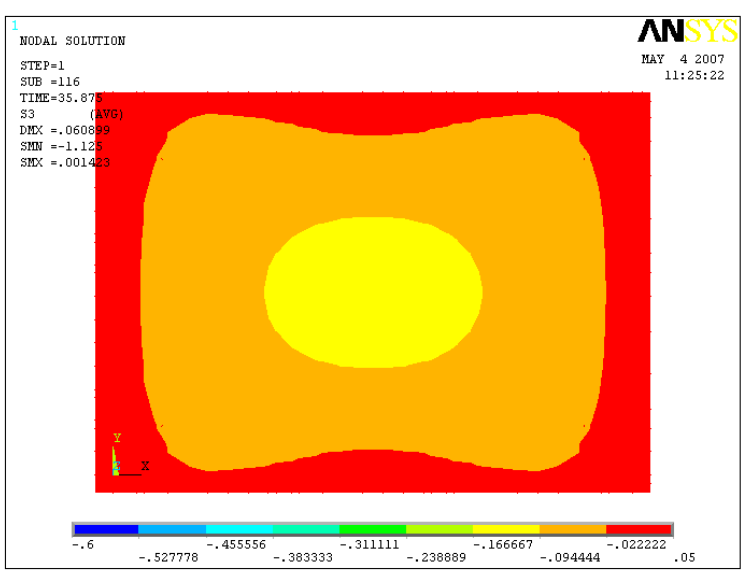

(b) $120 \mathrm{~cm}$

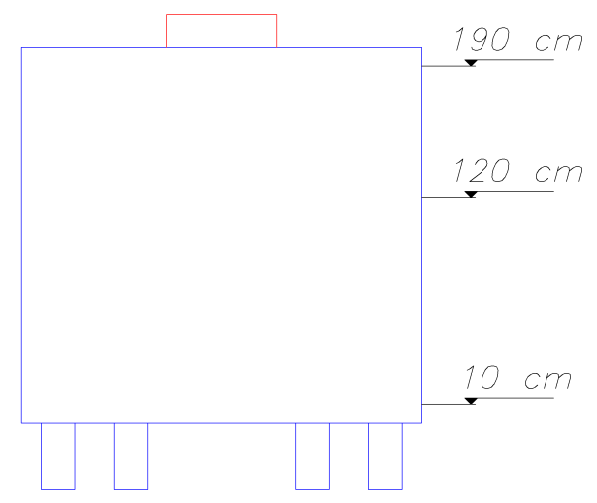

(d) alturas

Figura 6.14: Campos de tensão de compressão - bloco com altura de $200 \mathrm{~cm}$ para solo deformável - valores $\mathrm{em} \mathrm{kN} / \mathrm{cm}^{2}$

Na figura 6.14 pode se observar que as tensões de compressão junto a cabeça da estaca (a) são próximas, isso ocorreu de igual modo para blocos de altura de $80 \mathrm{~cm}$ e 115 cm com estacas apoiadas no mesmo tipo de solo (deformável). A tensão de compressão foi de 2,56 MPa para a região na cabeça das estacas, item (a). Outro detalhe que pode ser visto na figura é que as tensões na cabeça da estacas não são uniforme. Mesmo com o aumentando a rigidez do bloco, e considerando o solo deformável, essas tensões permanecem excêntrica. A tensão de compressão próxima a região do pilar mostrado no item (c) foi de 6,11 MPa. 
Na figura 6.15 são apresentadas as tensões principais de compressão na seção transversal do bloco ao longo de sua altura para bloco com altura de $200 \mathrm{~cm}$, e vinculação das estacas para solo do tipo indeformável.

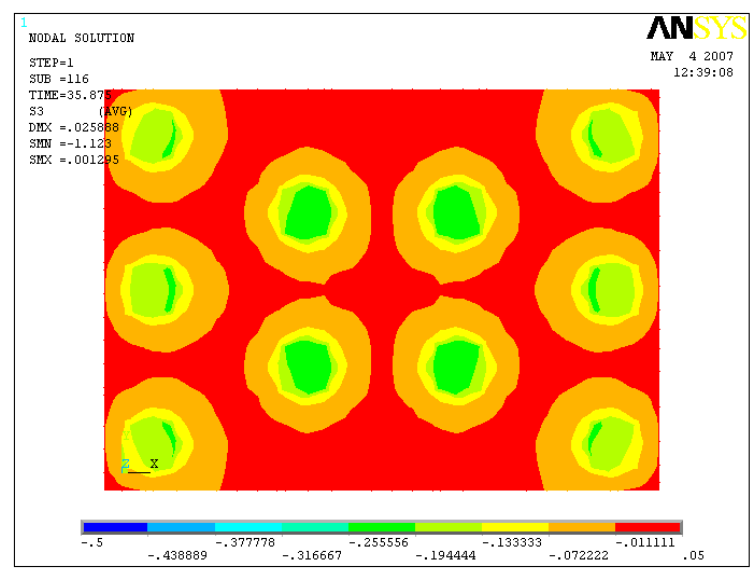

(a) $10 \mathrm{~cm}$

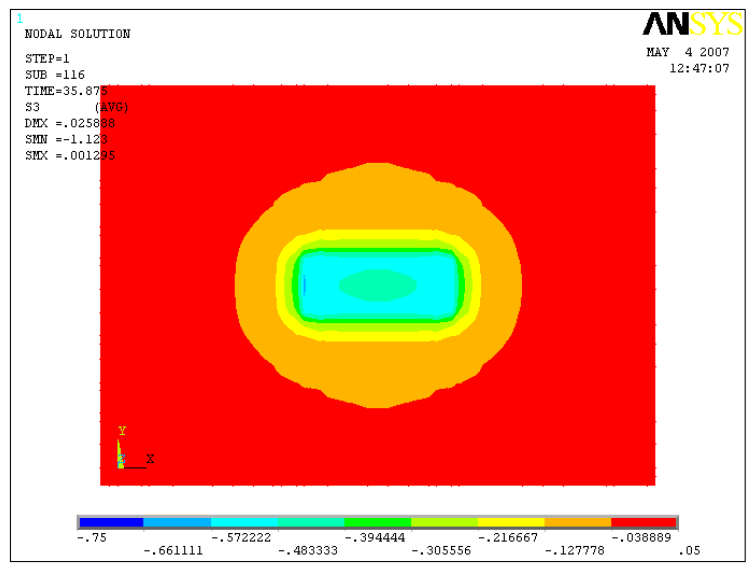

(c) $190 \mathrm{~cm}$

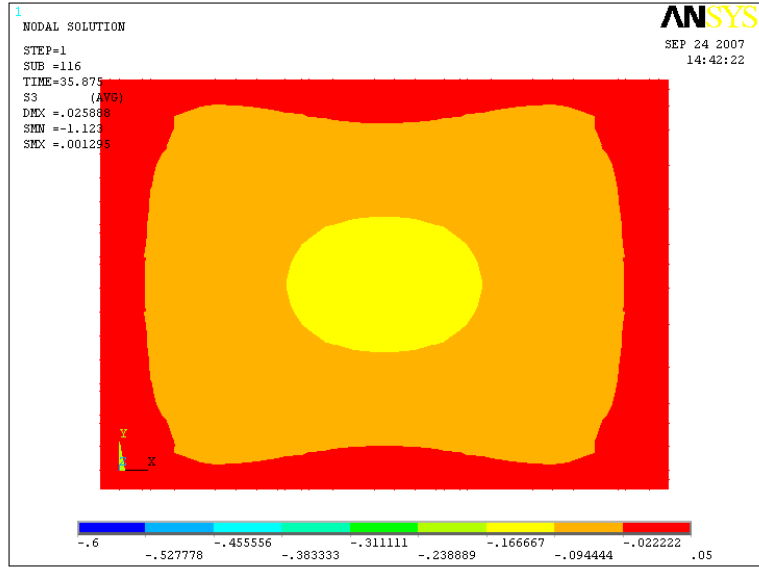

(b) $110 \mathrm{~cm}$

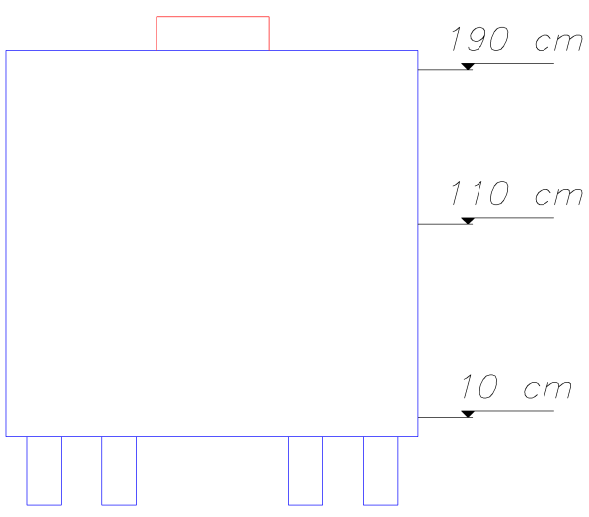

(d) alturas

Figura 6.15: Campos de tensão de compressão - bloco com altura de $200 \mathrm{~cm}$ para solo indeformável - valores em $\mathrm{kN} / \mathrm{cm}^{2}$

Conforme a figura 6.15 pode se observar que nesse caso as tensões de compressão junto a cabeça da estaca (a) são menores quando comparado com as tensões para bloco com altura de $80 \mathrm{~cm}$ e $115 \mathrm{~cm}$ de altura com estacas apoiadas em solo indeformável. Para este caso as tensões de compressão na cabeça das estacas chegaram em 2,56 MPa. Na região próxima ao pilar, item (c), a tensão de compressão foi de 5,72 MPa. 


\subsection{Caso 2}

Neste item é analisada apenas o Caso 2. Para este Caso são consideradas a força centrada e os momentos fletores nas duas direções.

Para este caso a variação da rigidez, em relação a resistência característica à compressão do concreto $\left(f_{c k}\right)$, se deu apenas para blocos com altura de $115 \mathrm{~cm}$. Os resultados para esse bloco mostraram que o comportamento estrutural não varia significativamente com o aumento da resistência do concreto. Portanto, pelo mesmo motivo apresentado para o Caso 1, os resultados são apenas apresentados no apêndice B.

Na tabela 6.4 são apresentadas as reações nas estacas para os dois tipos de vinculação das estacas para bloco com altura de $80 \mathrm{~cm}$. Vale lembrar que o bloco com altura de $80 \mathrm{~cm}$ não satisfez a verificação quanto a resistência à força cortante, conforme o processo do CEB-FIP (1970).

Tabela 6.4: Reações nas estacas para o Caso 2 em bloco com altura de $80 \mathrm{~cm}$

\begin{tabular}{ccccccc}
\hline \multicolumn{5}{c}{ Caso $2 ; \mathrm{h}=80 \mathrm{~cm} ; 25 \mathrm{MPa}$} \\
\hline \multicolumn{5}{c}{ deformável } & \multicolumn{5}{c}{ Indeformável } \\
\hline & Modelo & Modelo & \multicolumn{5}{c}{ Modelo } & Modelo \\
Estacas & $F_{k, n}(\mathrm{kN})$ & $F_{k, a}(\mathrm{kN})$ & $F_{k, n} / F_{k, a}$ & $F_{k, n}(\mathrm{kN})$ & $F_{k, a}(\mathrm{kN})$ & $F_{k, n} / F_{k, a}$ \\
\hline 1 & 273,0 & 297,9 & 0,92 & 98,2 & 297,9 & 0,33 \\
2 & 237,9 & 237,9 & 1,00 & 107,3 & 237,9 & 0,45 \\
3 & 120,8 & 177,9 & 0,68 & 19,0 & 177,9 & 0,11 \\
4 & 347,1 & 309,3 & 1,12 & 554,4 & 309,3 & 1,79 \\
5 & 313,0 & 249,3 & 1,26 & 413,0 & 249,3 & 1,66 \\
6 & 378,4 & 350,7 & 1,08 & 716,3 & 350,7 & 2,04 \\
7 & 346,3 & 290,7 & 1,19 & 578,9 & 290,7 & 1,99 \\
8 & 353,0 & 422,1 & 0,84 & 169,3 & 422,1 & 0,40 \\
9 & 336,2 & 362,1 & 0,93 & 245,8 & 362,1 & 0,68 \\
10 & 293,9 & 302,1 & 0,97 & 97,6 & 302,1 & 0,32 \\
\hline
\end{tabular}

Observou-se que houve uma mudança no comportamento estrutural do bloco quanto ao tipo de vinculação das estacas e o tipo de ação aplicada. Para vinculação das estacas do bloco com o solo do tipo deformável, não houve uma uniformização na distribuição das reações nas estacas, como tinha ocorrido para o mesmo bloco para o Caso 1. Houve uma pequena variação quando se compara a relação entre o modelo numérico e o modelo analítico para solo do tipo deformável. Quando se comparam os mesmos resultados para blocos com estacas apoiadas em solo do tipo indeformável essa relação é bem maior, chegando a mais de $100 \%$ para estaca de número 6. Quando o solo é do tipo indeformável percebe-se que houve uma grande variação dos valores. No entanto, 
percebe-se que ainda há uma tendência das forças de maior intensidade ocorrerem nas estacas centrais, mais próximas ao pilar nos dois casos, conforme ocorrem nos modelos anteriores.

Para solo do tipo deformável a diferença do modelo numérico para o modelo analítico chegou a $32 \%$ para a estaca de número 3 e a $26 \%$ para estacas de número 5 . Para solo do tipo indeformável a diferença chegou a $89 \%$ para estaca de número 3 e a $104 \%$ para estaca de número 6.

Nos dois casos analisados esperava-se que a estaca de número 8 fosse a mais solicitada, porém nos dois casos analisados a estaca de número 6 é a que foi a mais solicitada.

Na tabela 6.5 são apresentadas as reações nas estacas para os dois tipos de vinculação das estacas no caso de bloco com a altura de $115 \mathrm{~cm}$. Vale lembrar que o bloco com altura de $115 \mathrm{~cm}$ satisfez a verificação quanto a resistência à força cortante, conforme o processo do CEB-FIP (1970).

Tabela 6.5: Reações nas estacas para o Caso 2 em bloco com altura de $115 \mathrm{~cm}$

\begin{tabular}{ccccccc}
\hline \multicolumn{7}{c}{ Caso $4 ; \mathrm{h}=115 \mathrm{~cm} ; 25 \mathrm{MPa}$} \\
\hline & Modelo & Modelo & & Modelo & Modelo \\
Estacas & $F_{k, n}(\mathrm{kN})$ & $F_{k, a}(\mathrm{kN})$ & $F_{k, n} / F_{k, a}$ & $F_{k, n}(\mathrm{kN})$ & $F_{k, a}(\mathrm{kN})$ & $F_{k, n} / F_{k, a}$ \\
\hline 1 & 289,1 & 297,9 & 0,97 & 181,0 & 297,9 & 0,61 \\
2 & 247,5 & 237,9 & 1,04 & 156,9 & 237,9 & 0,66 \\
3 & 143,8 & 177,9 & 0,81 & 85,7 & 177,9 & 0,48 \\
4 & 326,0 & 309,3 & 1,05 & 454,7 & 309,3 & 1,47 \\
5 & 291,3 & 249,3 & 1,17 & 363,2 & 249,3 & 1,46 \\
6 & 353,9 & 350,7 & 1,01 & 547,5 & 350,7 & 1,56 \\
7 & 323,4 & 290,7 & 1,11 & 453,0 & 290,7 & 1,56 \\
8 & 367,8 & 422,1 & 0,87 & 284,8 & 422,1 & 0,67 \\
9 & 344,7 & 362,1 & 0,95 & 287,4 & 362,1 & 0,79 \\
10 & 312,0 & 302,1 & 1,03 & 185,6 & 302,1 & 0,61 \\
\hline
\end{tabular}

Como já vem mostrando os resultados anteriores o comportamento estrutural do bloco sofre mudança dependendo do tipo de vinculação das estacas e do tipo de ação aplicada. Com o aumento da rigidez do bloco e para a vinculação das estacas do bloco com o solo do tipo deformável, a distribuição das reações nas estacas foi um pouco mais uniforme comparando com os mesmos resultados com o bloco de altura de $80 \mathrm{~cm}$. Com o solo do tipo indeformável ainda há uma tendência maior das forças serem maiores nas estacas centrais, mais próximas ao pilar, porém houve uma maior uniformização quando comparado a bloco com altura de $80 \mathrm{~cm}$. 
Para solo do tipo deformável a diferença do modelo numérico para o modelo analítico chegou a $19 \%$ para a estaca de número 3 e a $17 \%$ para estacas de número 5 . Para solo do tipo indeformável a diferença chegou a $52 \%$ para estaca de número 3 e a $56 \%$ para estacas de número 6 e 7. Comparando esses dados a bloco com altura de $80 \mathrm{~cm}$ percebe-se que houve uma redução nessa relação.

Novamente nesses dois casos analisados esperava-se que a estaca de número 8 fosse a mais solicitada, porém a estaca de número 6 foi a mais solicitada.

Na tabela 6.6 são apresentadas as reações nas estacas para os dois tipos de vinculação das estacas para bloco com altura de $200 \mathrm{~cm}$. Vale lembrar que o bloco com altura de $200 \mathrm{~cm}$ satisfez a verificação quanto a resistência à força cortante, conforme o processo do CEB-FIP (1970).

Tabela 6.6: Reações nas estacas para o Caso 2 em bloco com altura de $200 \mathrm{~cm}$

\begin{tabular}{|c|c|c|c|c|c|c|}
\hline \multicolumn{7}{|c|}{ Caso $2 ; \mathrm{h}=200 \mathrm{~cm} ; 25 \mathrm{MPa}$} \\
\hline & \multicolumn{3}{|c|}{ deformável } & \multicolumn{3}{|c|}{ Indeformável } \\
\hline & Modelo & Modelo & & Modelo & Modelo & \\
\hline & Numérico & Analítico & & Numérico & Analítico & \\
\hline Estacas & $F_{k, n}(\mathrm{kN})$ & $F_{k, a}(\mathrm{kN})$ & $F_{k, n} / F_{k, a}$ & $F_{k, n}(\mathrm{kN})$ & $F_{k, a}(\mathrm{kN})$ & $F_{k, n} / F_{k, a}$ \\
\hline 1 & 296,1 & 297,9 & 0,99 & 254,8 & 297,9 & 0,86 \\
\hline 2 & 252,9 & 237,9 & 1,06 & 211,7 & 237,9 & 0,89 \\
\hline 3 & 153,6 & 177,9 & 0,86 & 146,7 & 177,9 & 0,82 \\
\hline 4 & 317,0 & 309,3 & 1,02 & 361,6 & 309,3 & 1,17 \\
\hline 5 & 279,8 & 249,3 & 1,12 & 293,9 & 249,3 & 1,18 \\
\hline 6 & 343,5 & 350,7 & 0,98 & 413,2 & 350,7 & 1,18 \\
\hline 7 & 314,2 & 290,7 & 1,08 & 345,1 & 290,7 & 1,19 \\
\hline 8 & 374,1 & 422,1 & 0,89 & 372,1 & 422,1 & 0,88 \\
\hline 9 & 349,2 & 362,1 & 0,96 & 338,0 & 362,1 & 0,93 \\
\hline 10 & 319,2 & 302,1 & 1,06 & 262,7 & 302,1 & 0,87 \\
\hline
\end{tabular}

Percebe-se por meio da tabela 6.6 que o comportamento estrutural do bloco sofre mudança dependendo do tipo de vinculação das estacas e do tipo de ação aplicada. Com o aumento da rigidez do bloco, e para vinculação das estacas do bloco com o solo do tipo deformável, a distribuição das reações nas estacas foi um pouco mais uniforme comparado com os mesmos resultados para bloco com altura de $80 \mathrm{~cm}$ e $115 \mathrm{~cm}$. Com o solo do tipo indeformável ainda há uma tendência maior das forças serem maiores nas estacas centrais, mais próxima ao pilar, porém houve ainda uma maior uniformização quando comparado a bloco com altura de $80 \mathrm{~cm}$ e $115 \mathrm{~cm}$.

Para solo do tipo deformável a diferença do modelo numérico para o modelo analítico chegou a $14 \%$ para a estaca de número 3 e a $12 \%$ para estacas de número 5 . Para solo do tipo indeformável a diferença chegou a $18 \%$ para estaca de número 3 e a 
19\% para estacas de número 7. Comparando esses dados a bloco com altura de $80 \mathrm{~cm} \mathrm{e}$ $115 \mathrm{~cm}$ percebe-se que houve uma redução nessa relação quando é aumentado a rigidez do bloco.

Para este caso analisado esperava-se que a estaca de número 8 fosse a mais solicitada, porém isso apenas foi confirmado para blocos com estacas apoiadas em solo do tipo deformável, para bloco com estaca apoiada em solo do tipo indeformável a estaca de número 6 foi a mais solicitada.

Portanto, depois de analisar as três tabelas apresentadas percebe-se que o comportamento estrutural do bloco é fortemente influenciado pelo tipo de vinculação das estacas e pela rigidez do bloco. Para todos os blocos analisados esperava-se que a estaca de número 8 fosse a mais solicitada, porém isso apenas foi confirmado para bloco com altura de $200 \mathrm{~cm}$ com estacas apoiadas em solo do tipo deformável, nos outros casos a estaca de número 6 é a que foi a mais solicitada. Para esse caso, com o aumento da rigidez do bloco as distribuições das reações nas estacas demonstraram um comportamento com tendência de uniformização, assim como ocorreu com o Caso 1. Esses resultados mostram que o método de dimensionamento tem grande mudança pelo fato de não considerar a interação do solo.

Para que fique mais claro são apresentadas nas figuras a seguir gráficos comparando os resultados para todas as estacas. A comparação é feita relacionando a altura do bloco versus a relação entre a força obtida numericamente e a força calculada analiticamente. Nos gráficos as linhas contínua representam estacas apoiadas em solo do tipo deformável e as linhas tracejada solo do tipo indeformável.

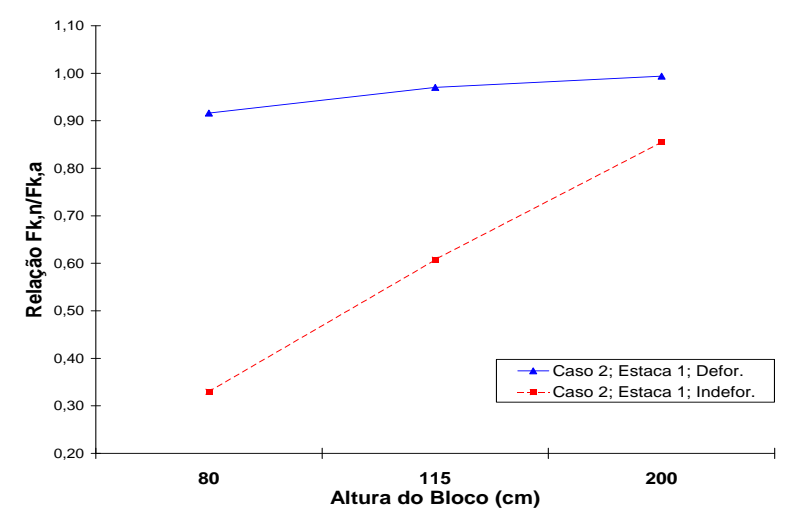

(a) estaca 1

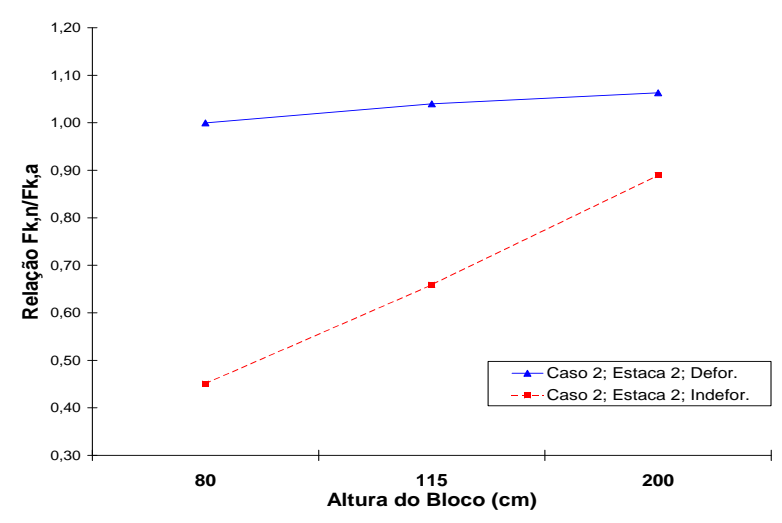

(b) estaca 2

Figura 6.16: Comparação entre as alturas para estacas 1 e 2 do Caso 2 
Percebe-se na figura 6.16 que o comportamento das estacas de número 1 e 2 foi o mesmo, ou seja, com o aumento da altura do bloco essas estacas tendem a ser mais próximo do modelo analítico. Em ambos os casos as estacas apoiadas em solo do tipo indeformável esse comportamento foi mais acentuado.

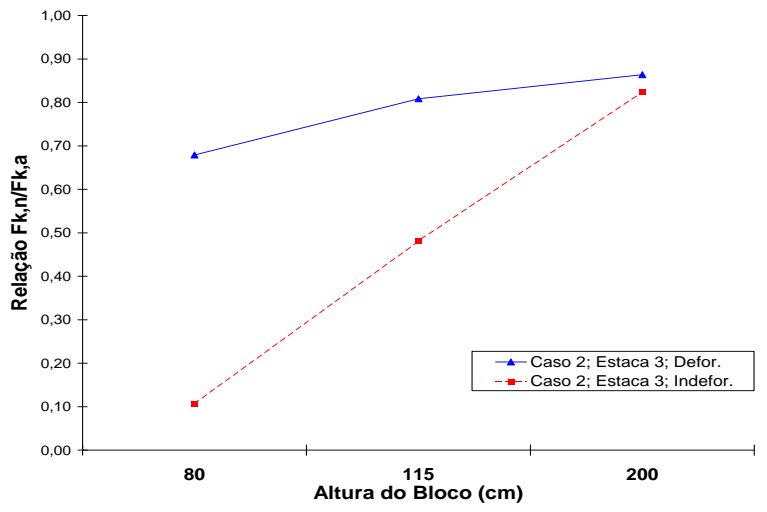

(a) estaca 3

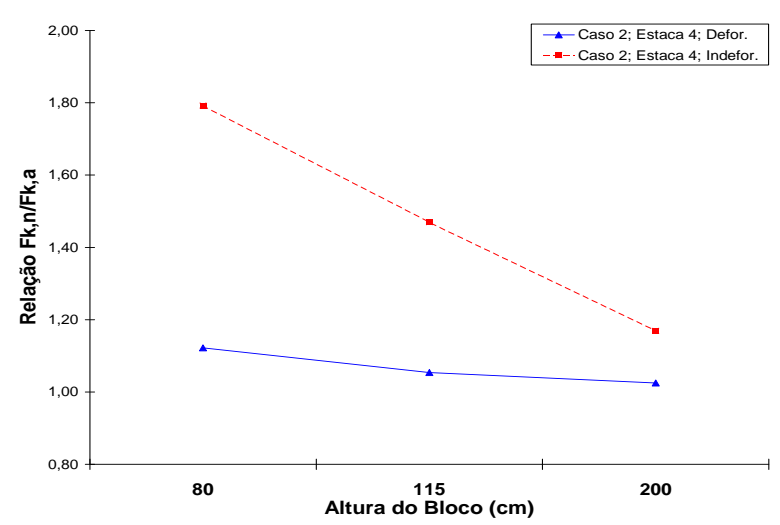

(b) estaca 4

Figura 6.17: Comparação entre as alturas para estacas 3 e 4 do Caso 2

Na figura 6.17 percebe-se que a estaca de número 3 teve o mesmo comportamento que as estacas de número 1 e 2 . Na estaca de número 4 houve uma mudança, porém o comportamento foi o mesmo, onde aumentando a altura do bloco as reações nas estacas tendem aos valores analíticos.

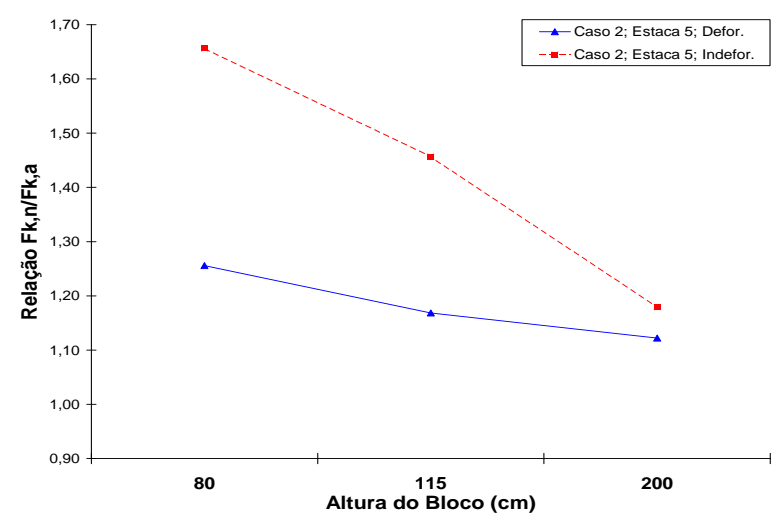

(a) estaca 5

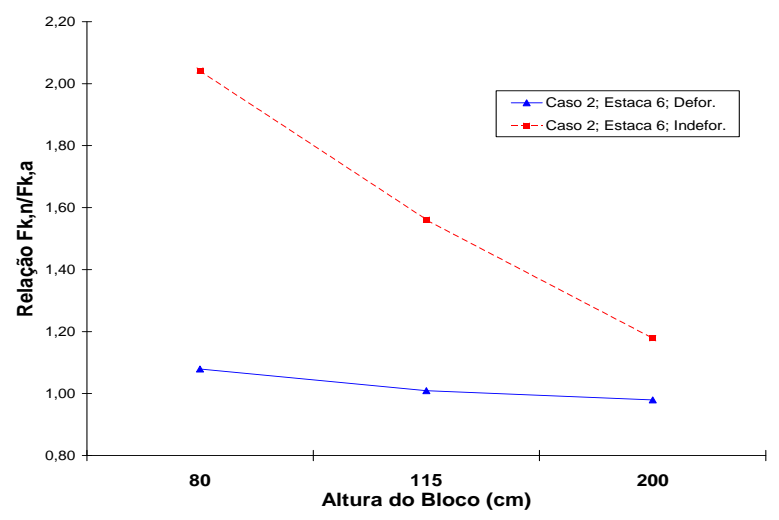

(b) estaca 6

Figura 6.18: Comparação entre as alturas para estacas 5 e 6 do Caso 2 


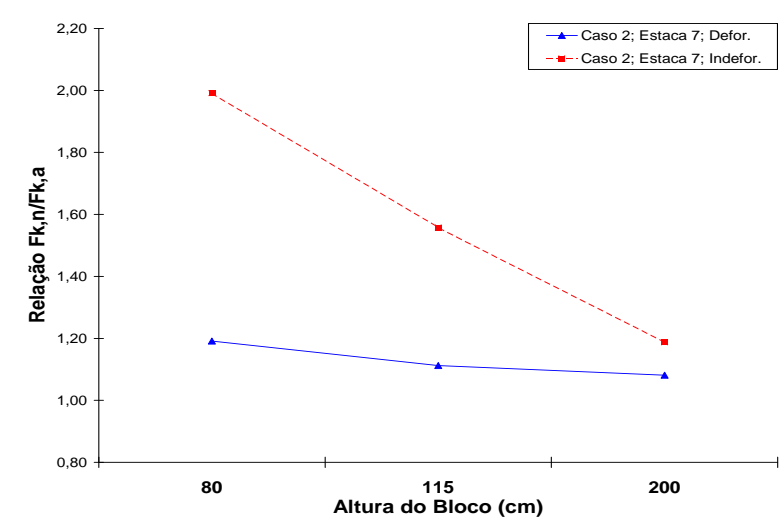

(a) estaca 7

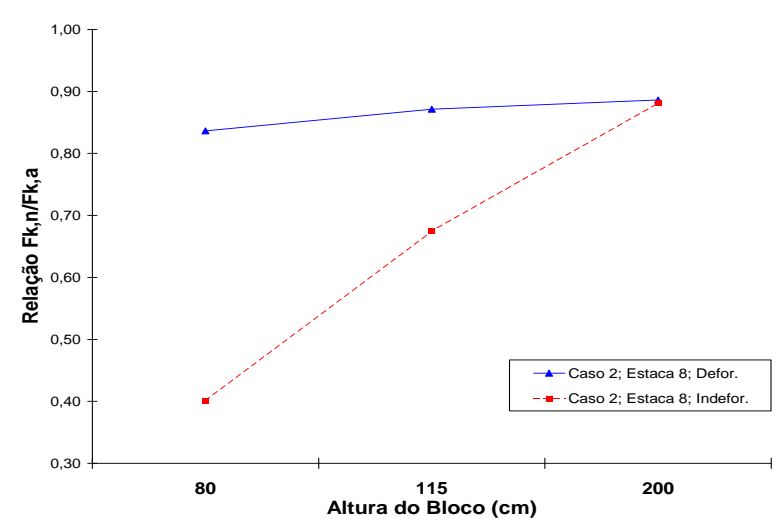

(b) estaca 8

Figura 6.19: Comparação entre as alturas para estacas 7 e 8 do Caso 2

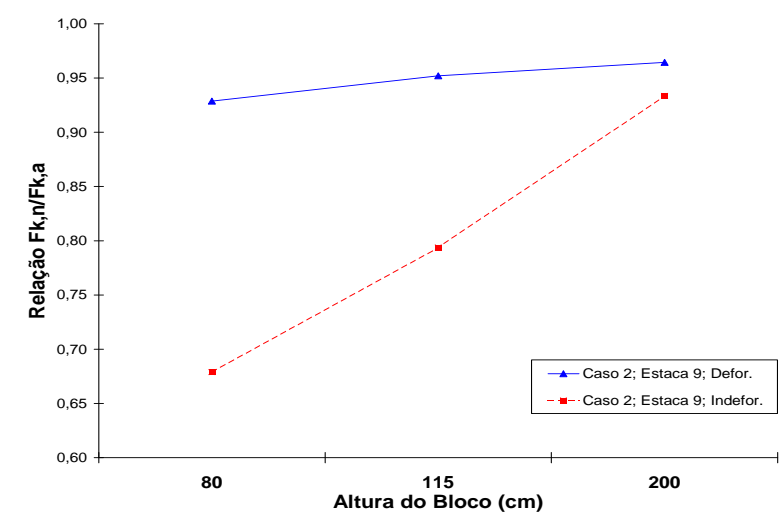

(a) estaca 9

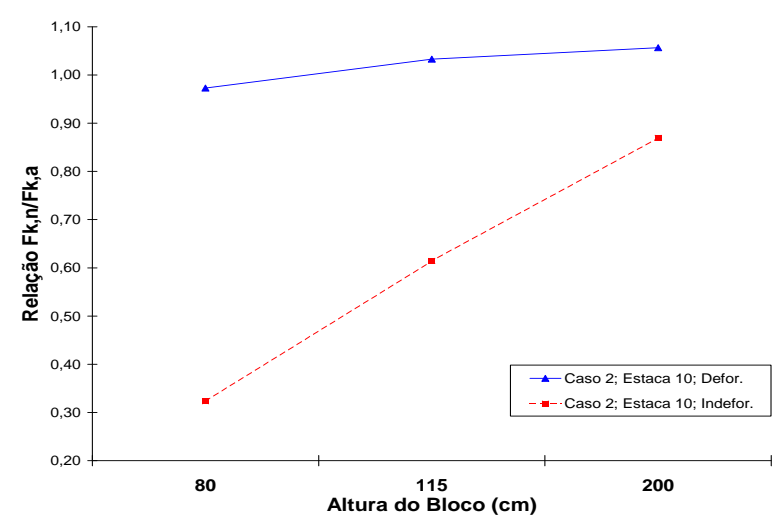

(b) estaca 10

Figura 6.20: Comparação entre as alturas para estacas 9 e 10 do Caso 2

É possível perceber nas figuras 6.18, 6.19 e 6.20 que o comportamento foi sempre o mesmo, com o aumento da altura do bloco as reações nas estacas tendem aos valores analíticos e a diferença, entre o tipo de solo considerado, diminui e fica mais próxima uma da outra. Percebe-se que há dois tipos de comportamento quando se comparam os gráficos. Os gráficos das estacas na região central tem um comportamento diferente das estacas nas extremidades. Os gráficos das estacas da região central tem um comportamento descendente, já os gráficos das estacas externas tem um comportamento ascendente. 
A seguir são apresentadas figuras que representam a relação entre as reações nas estacas versus o acréscimo de ações aplicadas ao bloco simulado numericamente. Primeiramente são apresentados gráficos de blocos com estacas apoiadas em solo do tipo deformável e em seguida para solo do tipo indeformável.

Na figura 6.21 são apresentadas as relações entre as reações nas estacas para bloco com altura de $80 \mathrm{~cm}$ e estacas apoiadas em solo deformável.

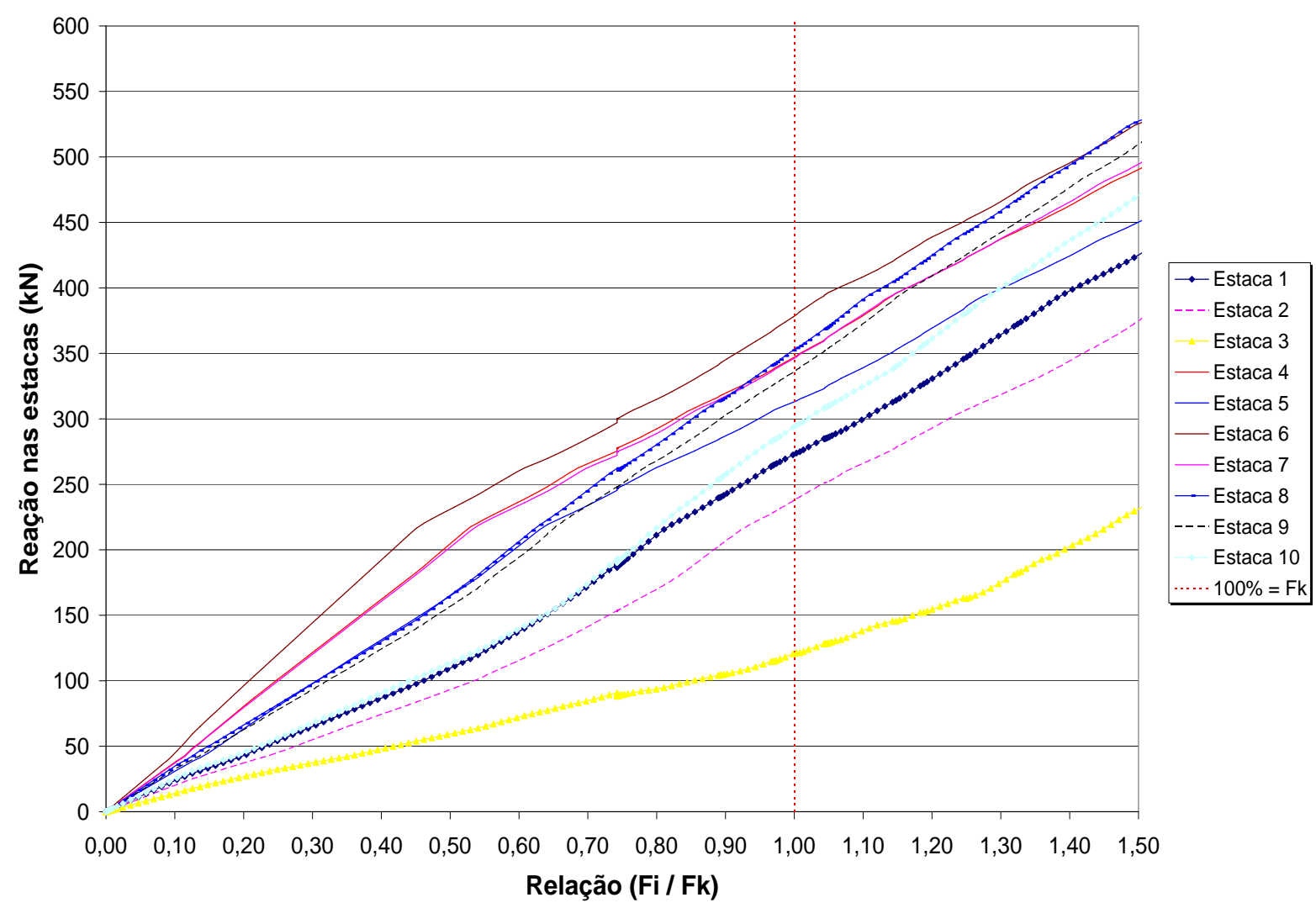

Figura 6.21: Reações nas estacas ao longo da aplicação das ações para bloco com altura de $80 \mathrm{~cm}$ e solo deformável

Por meio da figura 6.21 percebe-se que as reações nas estacas centrais inicialmente tem um comportamento de bloco com estacas apoiadas em solo indeformável. Próxima da relação $F_{i} / F_{k}$ igual a 0,40 há uma mudança no comportamento. Para este caso a estacas mais solicitada foi a de número 6 ficando $8 \%$ acima do valor calculado analiticamente. 
Na figura 6.22 são apresentadas as relações entre as reações nas estacas para bloco com altura de $115 \mathrm{~cm}$ e estacas apoiadas em solo deformável.

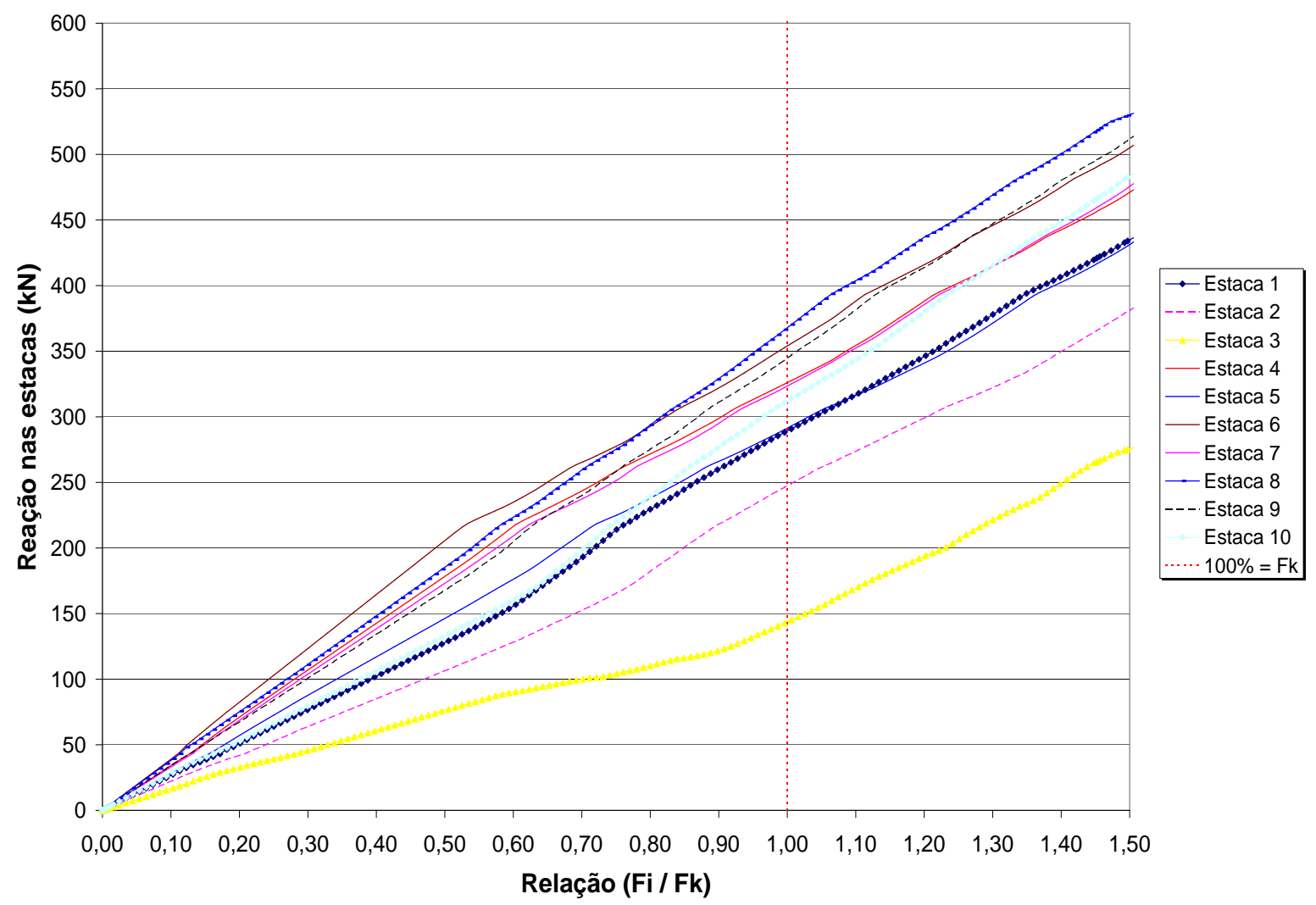

Figura 6.22: Reações nas estacas ao longo da aplicação das ações para bloco com altura de $115 \mathrm{~cm}$ e solo deformável

Por meio da figura 6.22 percebe-se que apenas a estaca de número 6 tem inicialmente comportamento de bloco com estacas apoiadas em solo indeformável, e próxima da relação $F_{i} / F_{k}$ igual a 0,50 há uma mudança no seu comportamento. Percebe-se também que inicialmente que essa era a estacas mais solicitada e próxima da relação $F_{i} / F_{k}$ igual a 0,80 a estaca de número 8 passa a ser a mais solicitada. Para este caso a estacas mais solicitada foi a de número 8 ficando $13 \%$ abaixo do valor calculado analiticamente. 
Na figura 6.23 são apresentadas as relações entre as reações nas estacas para bloco com altura de $200 \mathrm{~cm}$ e estacas apoiadas em solo deformável.

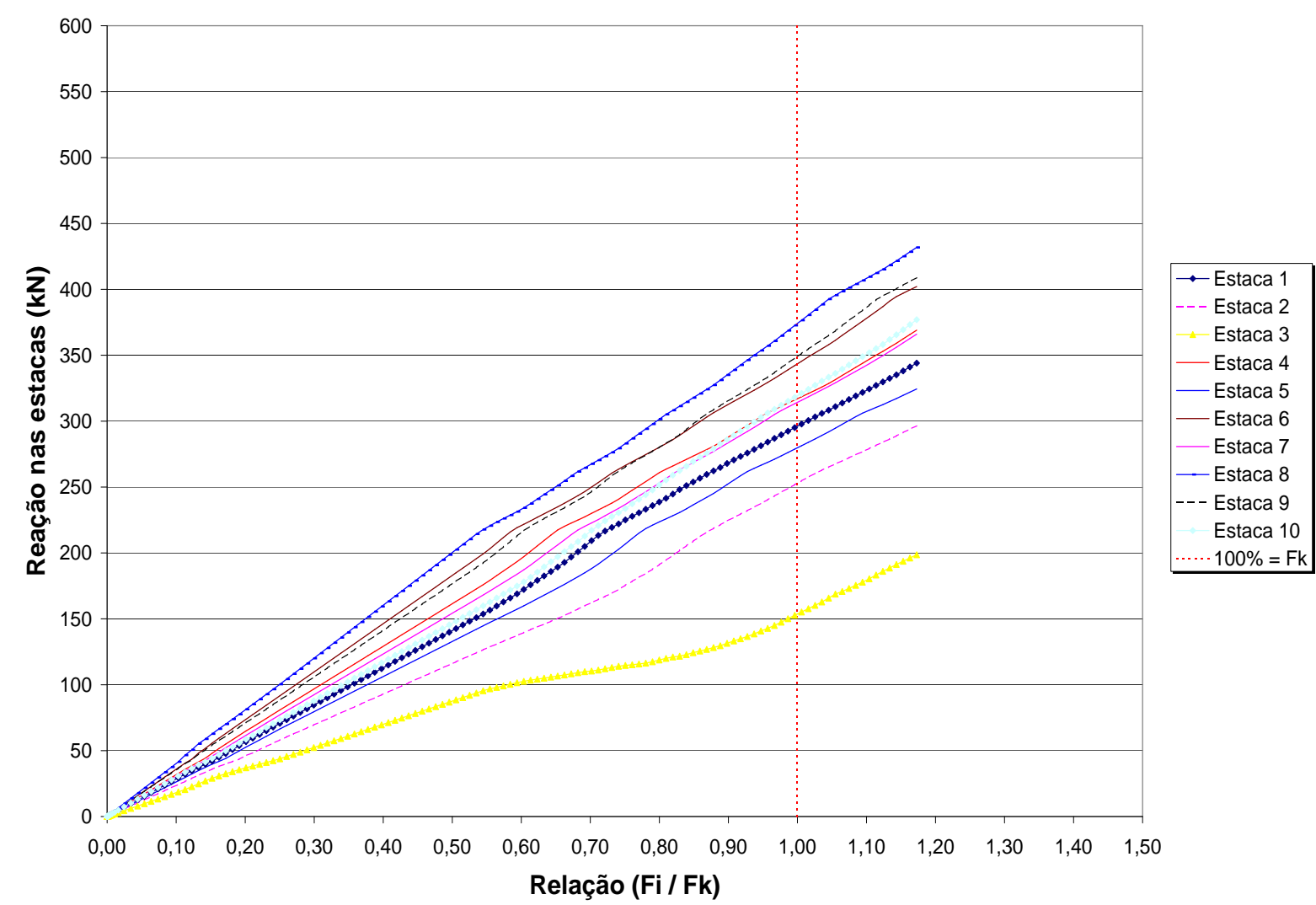

Figura 6.23: Reações nas estacas ao longo da aplicação das ações para bloco com altura de $200 \mathrm{~cm}$ e solo deformável

Por meio da figura 6.23 percebe-se que há uma uniformização na distribuição das reações nas estacas. Apenas a estaca de número 3 que fica um pouco fora desse comportamento. Ao longo de todo a aplicação da força a estaca de número 8 foi a mais solicitada, ficando $11 \%$ abaixo do valor calculado analiticamente para a relação $F_{i} / F_{k}$ igual a unidade, que é o valor de projeto.

Nas três figuras apresentada percebe-se que o comportamento do bloco é influenciado pelo tipo de vinculação da estaca (solo). Conforme as figuras apresentadas nenhuma das estacas apresentaram ruptura. 
Na figura 6.24 são apresentadas as relações entre as reações nas estacas para bloco com altura de $80 \mathrm{~cm}$ e estacas apoiadas em solo indeformável.

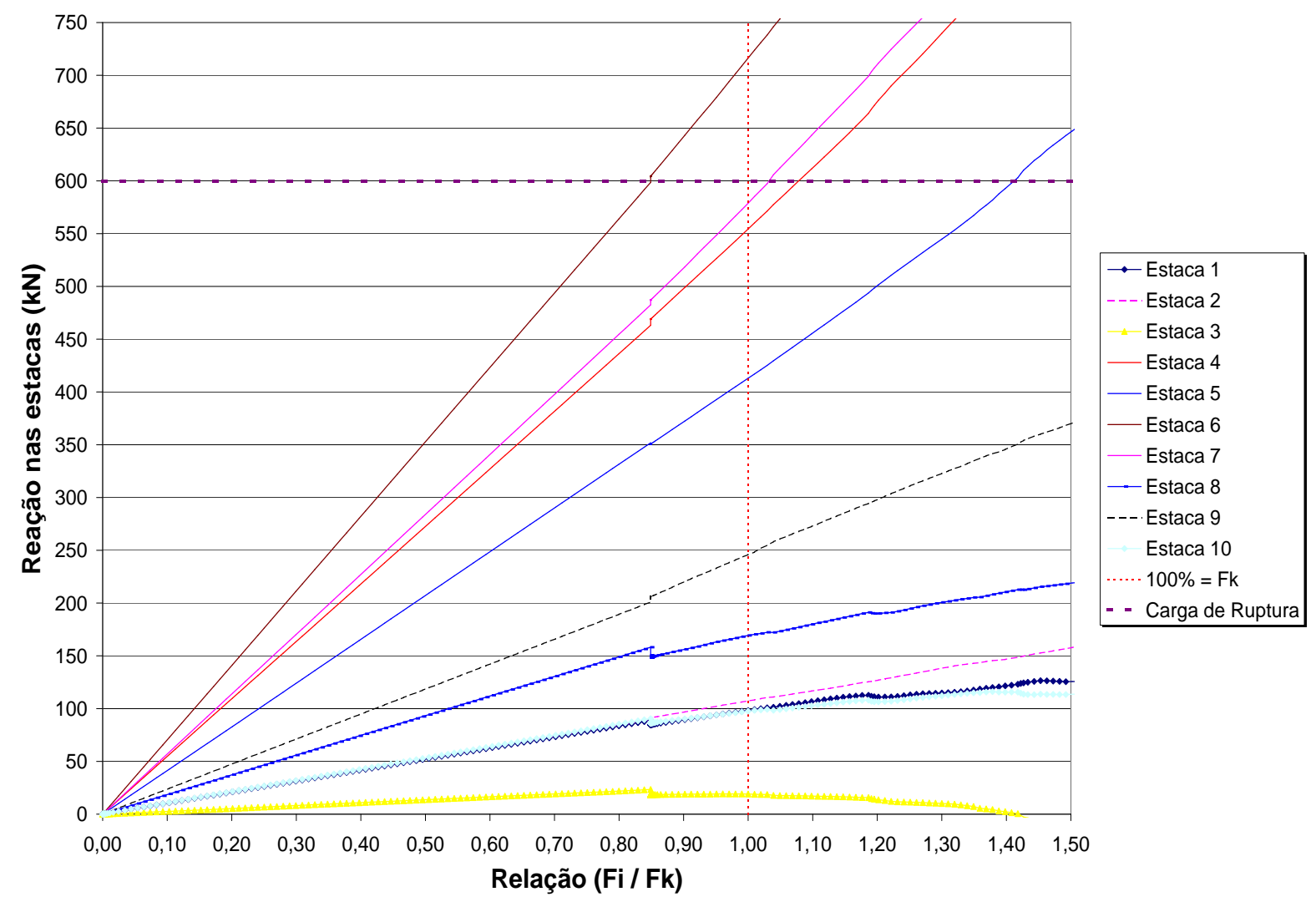

Figura 6.24: Reações nas estacas ao longo da aplicação das ações para bloco com altura de $80 \mathrm{~cm}$ e solo indeformável

Por meio da figura 6.24 percebe-se que o comportamento do bloco mudou muito quando comparado com o bloco sobre estacas apoiadas em solo deformável. Houve uma grande variabilidade nos valores das reações nas estacas. A estaca de número 6 foi a mais solicitada e atingiu o valor de $716,3 \mathrm{kN}$ para relação $F_{i} / F_{k}$ igual a unidade muito acima do valor de ruína da estaca que é de $600 \mathrm{kN}$, que ficou próxima da relação $F_{i} / F_{k}$ de 0,85 . Esse valor corresponde a $104 \%$ acima do valor calculado analiticamente. 
Na figura 6.25 são apresentadas as relações entre as reações nas estacas para bloco com altura de $115 \mathrm{~cm}$ e estacas apoiadas em solo indeformável.

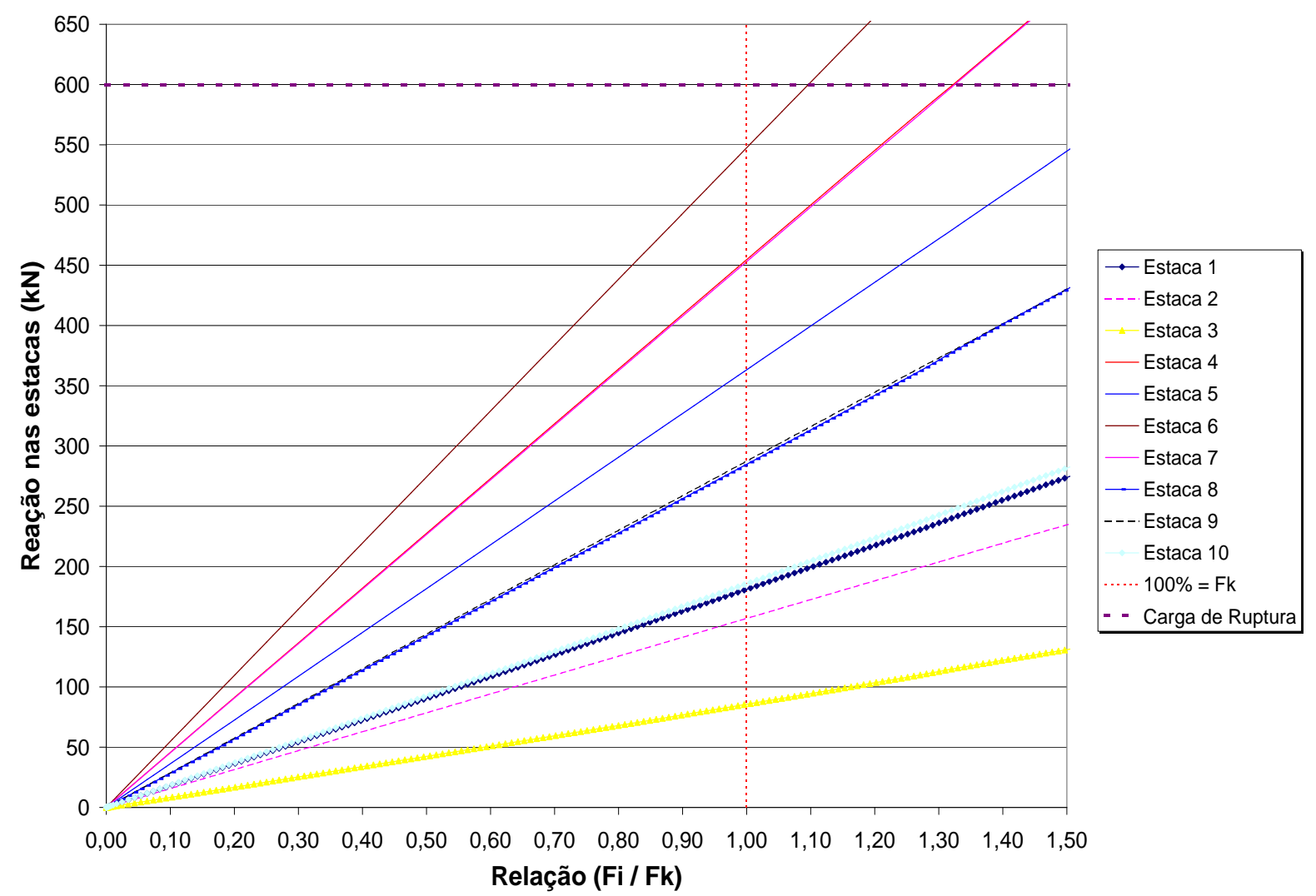

Figura 6.25: Reações nas estacas ao longo da aplicação das ações para bloco com altura de $115 \mathrm{~cm}$ e solo indeformável

Por meio da figura 6.25 percebe-se que o comportamento do bloco se assemelha ao do bloco com altura de $80 \mathrm{~cm}$ com mesmo tipo de solo. A variação nos valores das reações nas estacas foi menor. A estaca de número 6, novamente, foi a mais solicitada. Para a relação $F_{i} / F_{k}$ igual a unidade a reação na estaca de número 6 foi de $547,5 \mathrm{kN}$, esse valor corresponde a $56 \%$ acima do valor esperando analiticamente. O valor de ruína foi atingido para a relação $F_{i} / F_{k}$ próxima de 1,1 . 
Na figura 6.26 são apresentadas as relações entre as reações nas estacas para bloco com altura de $200 \mathrm{~cm}$ e estacas apoiadas em solo indeformável.

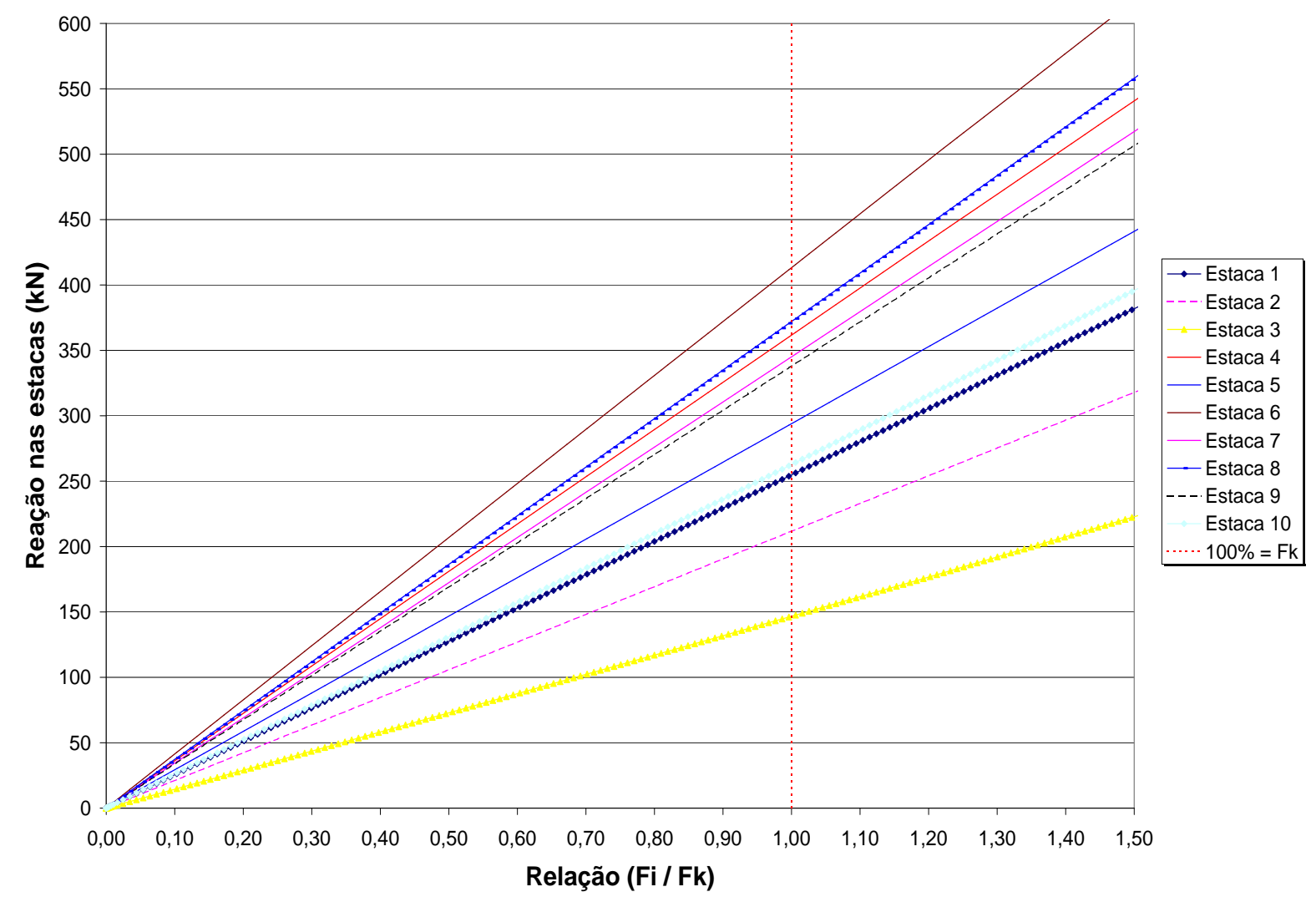

Figura 6.26: Reações nas estacas ao longo da aplicação das ações para bloco com altura de $200 \mathrm{~cm}$ e solo indeformável

Por meio da figura 6.26 percebe-se que o comportamento do bloco se assemelha ao do bloco com altura de $80 \mathrm{~cm}$ e $115 \mathrm{~cm}$, porém com uma distribuição na reação das estacas mais uniforme. A estaca de número 6, como já ocorreu para os outros dois casos, foi a mais solicitada chegando ao valor de 413,2 $\mathrm{kN}$. Esse valor corresponde a $18 \%$ acima do valor calculado analiticamente. $O$ valor de ruína foi atingido para a relação $F_{i} / F_{k}$ próxima de 1,5 .

Com relação $F_{i} / F_{k}$ igual a unidade, que é o valor de projeto, verifica-se por meio das figuras $6.24,6.25$ e 6.26 que o valor de ruína da estaca ocorreu antes para bloco com altura de $80 \mathrm{~cm}$, e depois para blocos com altura de $115 \mathrm{~cm}$ e $200 \mathrm{~cm}$. 
Serão apresentadas 6 figuras que mostram as tensões principais de compressão na seção transversal do bloco ao longo de sua altura.

A figura 6.27 apresenta as tensões principais de compressão na seção transversal do bloco ao longo de sua altura para blocos com altura de $80 \mathrm{~cm}$, e vinculação das estacas para solo do tipo deformável.

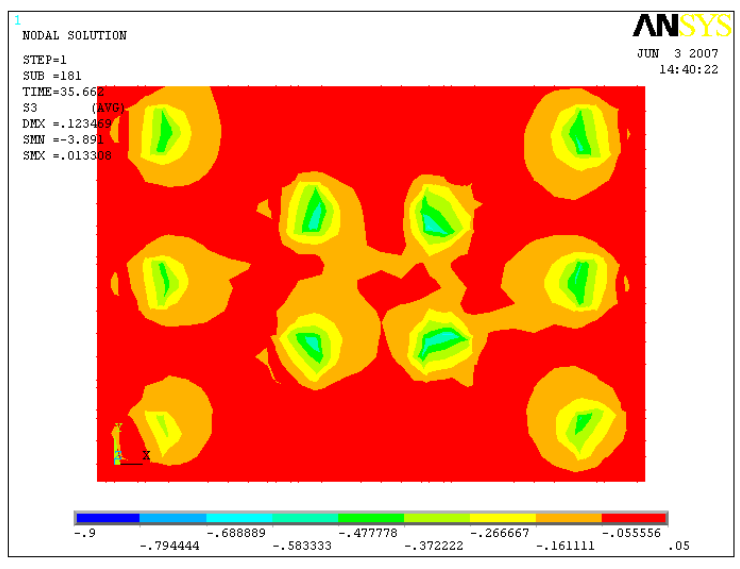

(a) $10 \mathrm{~cm}$

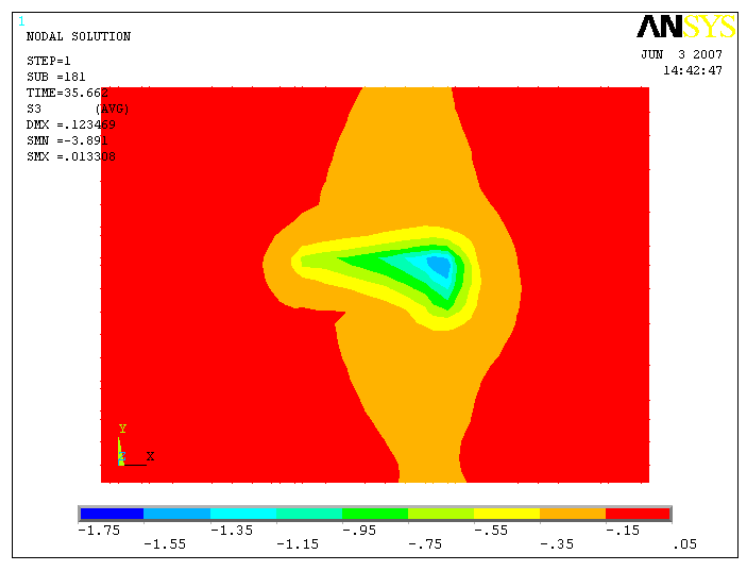

(c) $70 \mathrm{~cm}$

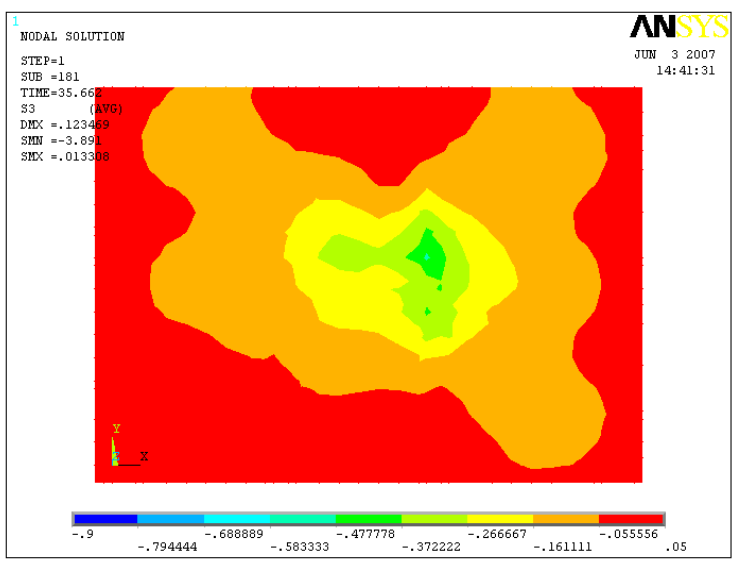

(b) $40 \mathrm{~cm}$

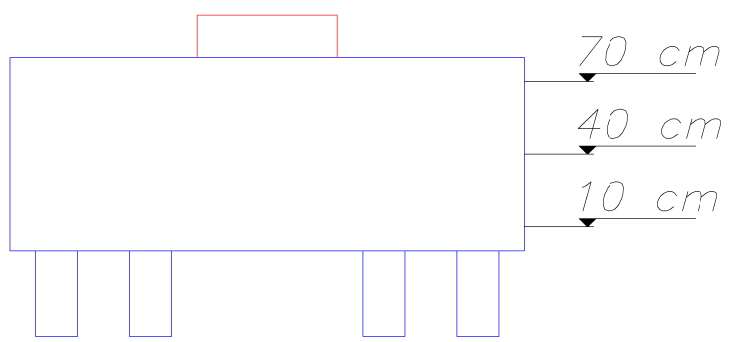

(d) alturas

Figura 6.27: Campos de tensão de compressão - bloco com altura de $80 \mathrm{~cm}$ para solo deformável - valores em $\mathrm{kN} / \mathrm{cm}^{2}$

Por meio da figura 6.27 pode se observar: as tensões junto a cabeça da estaca para uma altura de $10 \mathrm{~cm}$ (a); tensões no bloco a meia altura (b); e tensões próxima ao pilar (c). É possível visualizar a formação dos campos de tensões ao longo da altura do bloco. Percebe-se que nesse caso as tensões junto a cabeça da estaca (a) são maiores na região central onde estão as estacas mais próxima do pilar. Isso mostra que as forças tendem a migrar para as estacas na região central. A tensão nessa região atingiu 5,8 MPa. Na região próxima ao pilar, item (c), a tensão foi de 15,5 MPa. 
A figura 6.28 apresenta as tensões principais de compressão na seção transversal do bloco ao longo de sua altura para bloco com altura de $80 \mathrm{~cm}$, e vinculação das estacas para solo do tipo indeformável.

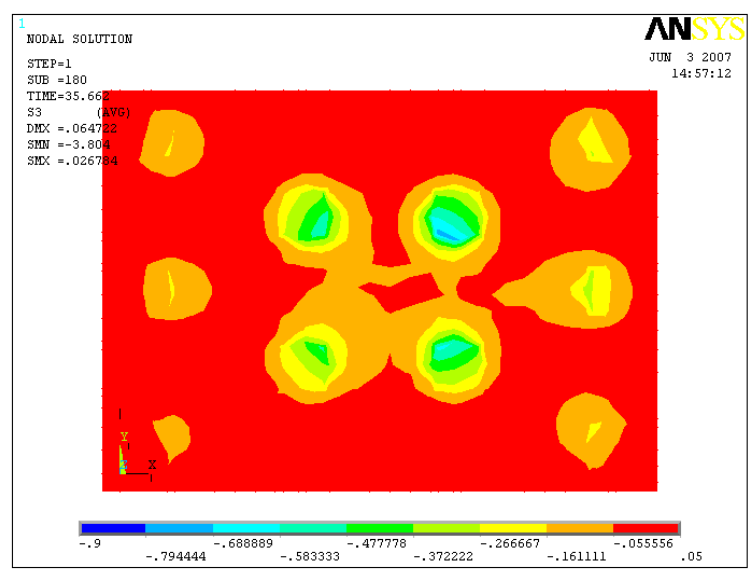

(a) $10 \mathrm{~cm}$

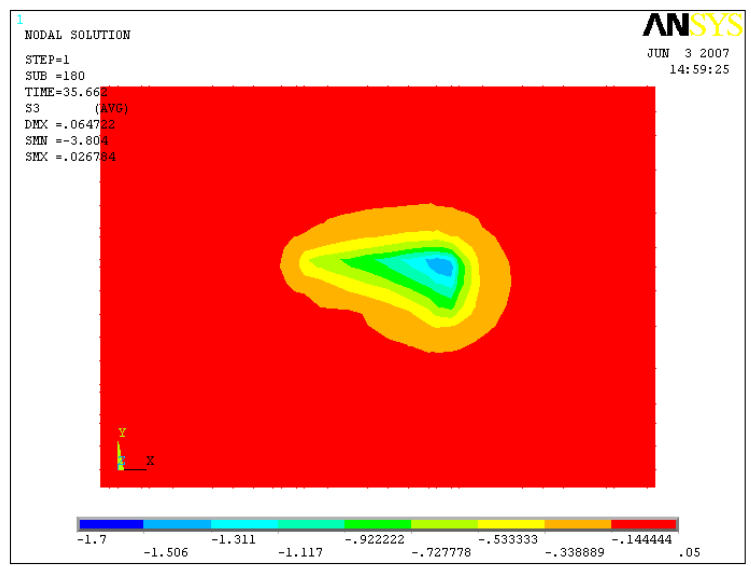

(c) $70 \mathrm{~cm}$

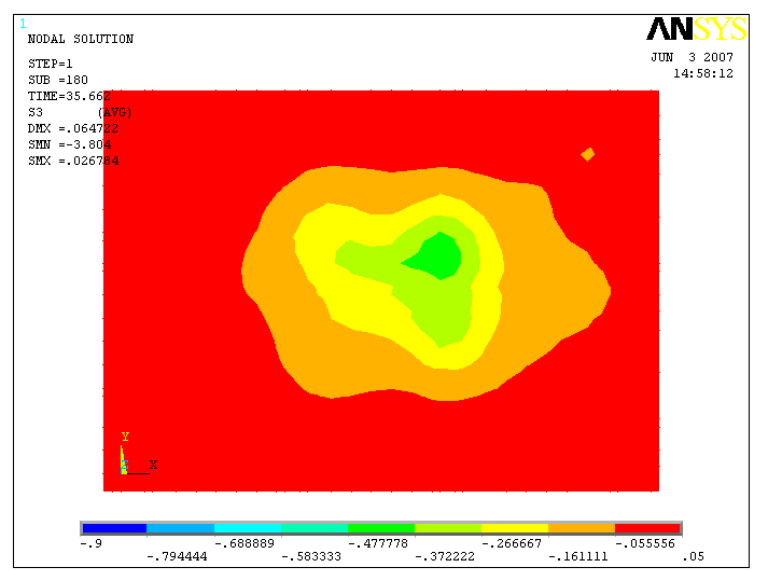

(b) $40 \mathrm{~cm}$

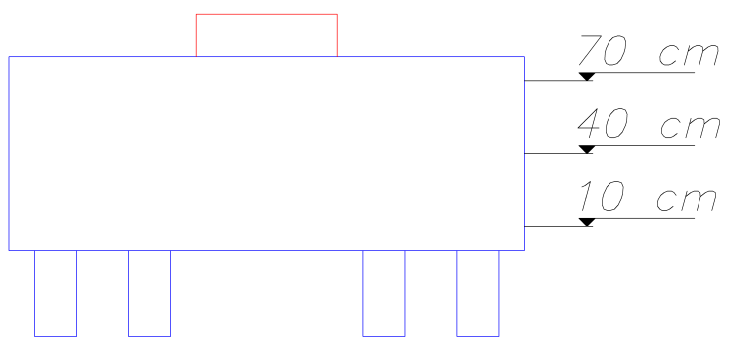

(d) alturas

Figura 6.28: Campos de tensão de compressão - bloco com altura de $80 \mathrm{~cm}$ para solo indeformável - valores em $\mathrm{kN} / \mathrm{cm}^{2}$

Conforme a figura 6.28 pode se observar que nesse caso as tensões de compressão junto a cabeça da estaca (a) são maiores quando comparadas com as tensões para o mesmo bloco com estacas apoiadas em solo deformável. A região central do bloco junto a cabeça das estacas foi a região mais comprimida, e a estaca de numero 6 teve tensões que chegaram a 7,9 MPa. Por meio dessa figura é possível perceber que, mais uma vez, as forças tendem a migrar para as estacas centrais mais próximas ao pilar. Na região próxima ao pilar, item (c), a tensão foi de $15 \mathrm{MPa}$. 
A figura 6.29 apresenta as tensões principais de compressão na seção transversal do bloco ao longo de sua altura para blocos com altura de $115 \mathrm{~cm}$, e vinculação das estacas para solo do tipo deformável.

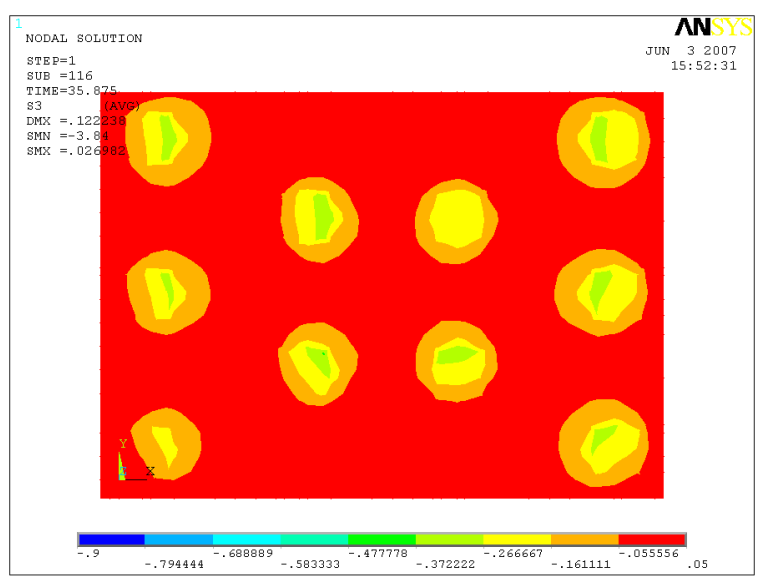

(a) $10 \mathrm{~cm}$

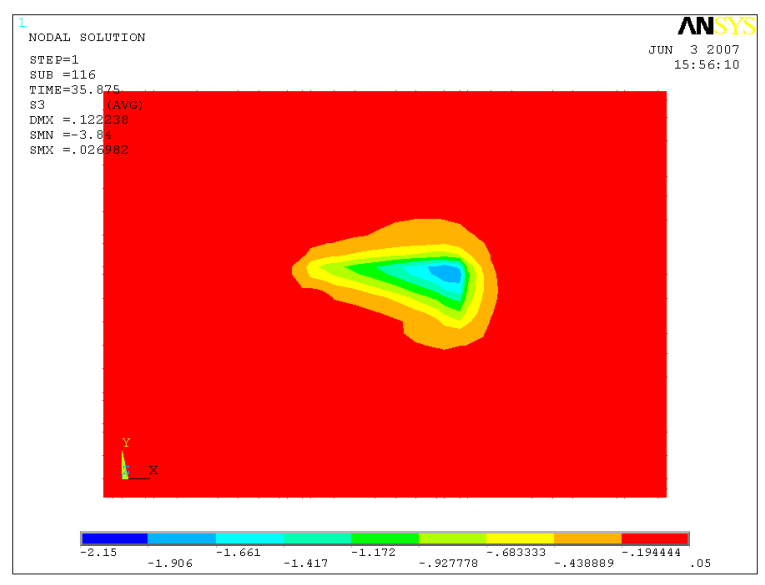

(c) $110 \mathrm{~cm}$

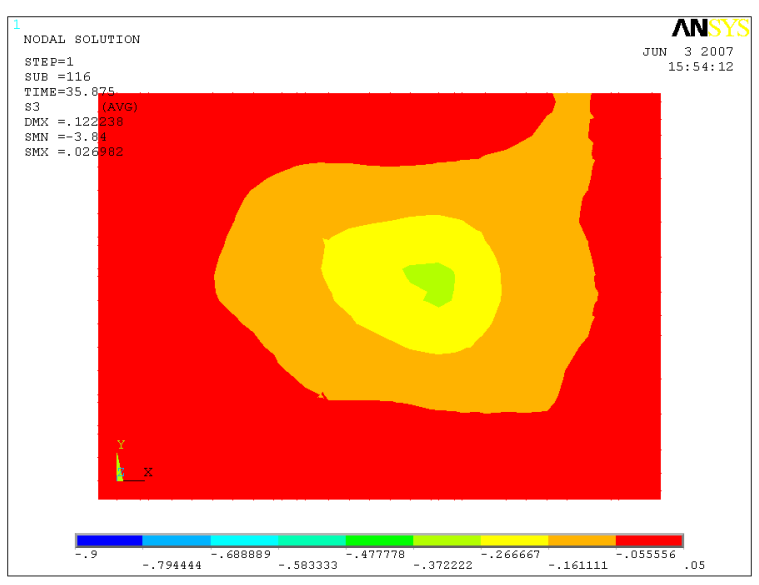

(b) $60 \mathrm{~cm}$

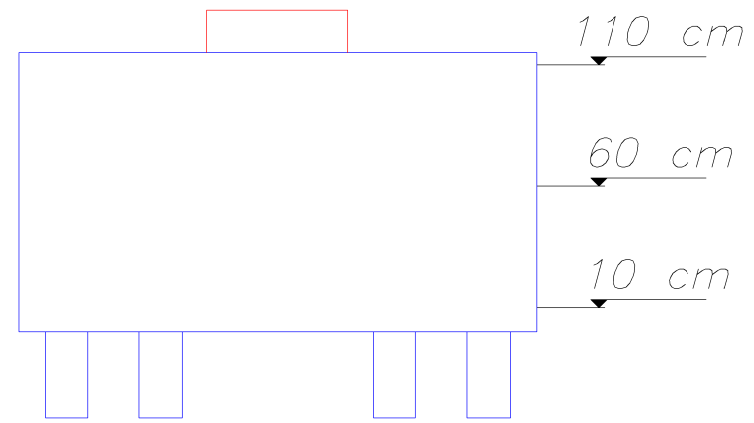

(d) alturas

Figura 6.29: Campos de tensão de compressão - bloco com altura de $115 \mathrm{~cm}$ para solo deformável - valores em $\mathrm{kN} / \mathrm{cm}^{2}$

Conforme a figura 6.29 pode se observar que nesse caso as tensões de compressão junto a cabeça da estaca (a) são menores quando comparadas com as tensões para bloco com altura de $80 \mathrm{~cm}$ com estacas apoiadas em solo deformável. Para este caso as tensões de compressão na cabeça da estaca chegaram em 4,78 MPa. Nessa caso apenas as estacas de número 3 e 6 não chegaram a este valor. Na região próxima ao pilar, item (c), a tensão foi de 19,06 MPa. 
A figura 6.30 apresenta as tensões principais de compressão na seção transversal do bloco ao longo de sua altura para bloco com altura de $115 \mathrm{~cm}$, e vinculação das estacas para solo do tipo indeformável.

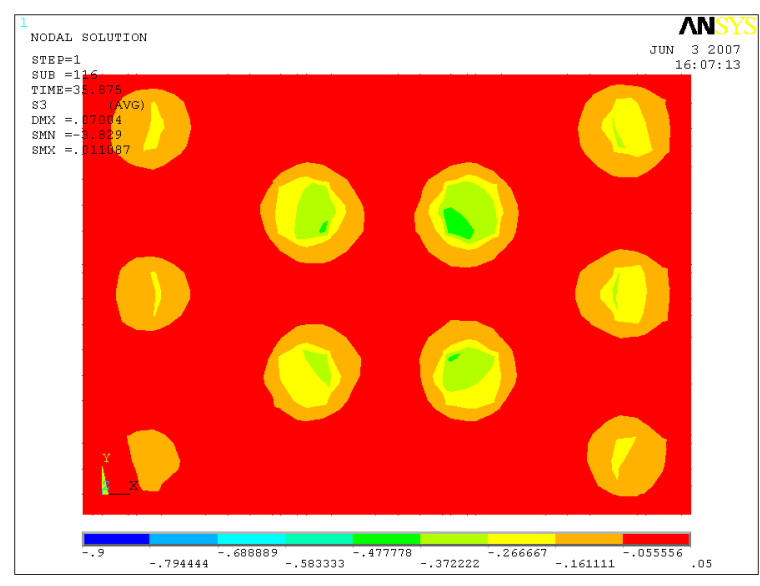

(a) $10 \mathrm{~cm}$

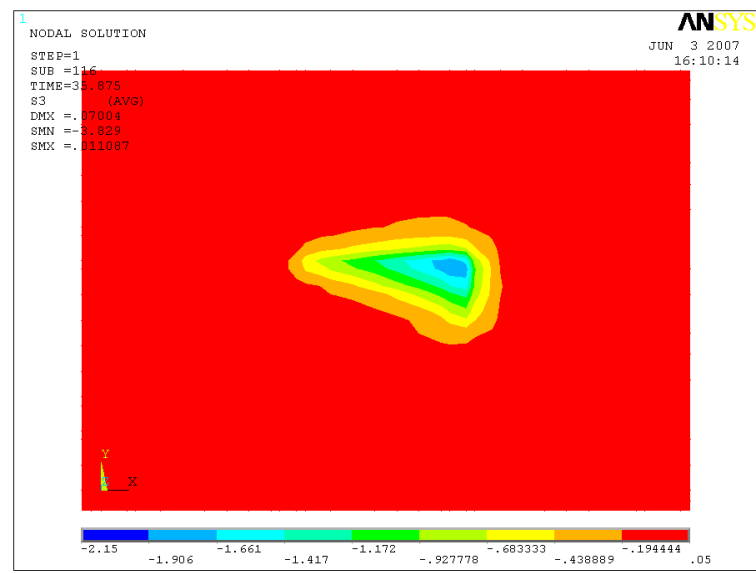

(c) $110 \mathrm{~cm}$

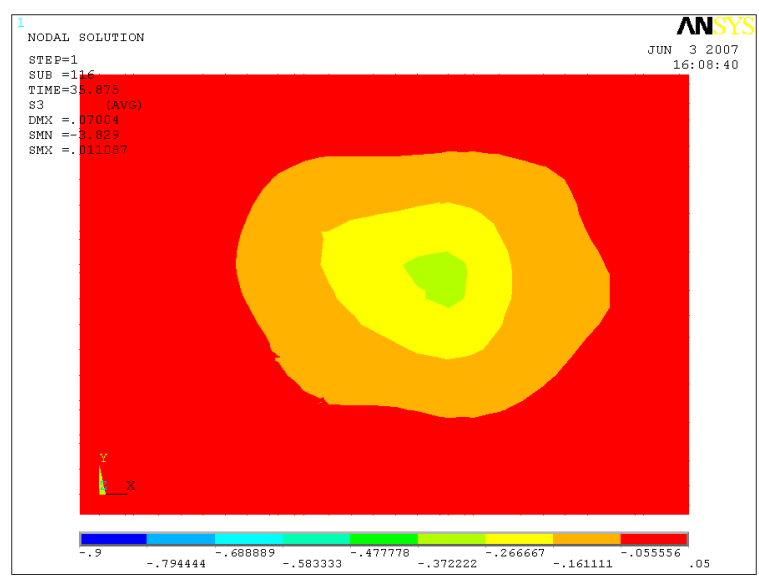

(b) $60 \mathrm{~cm}$

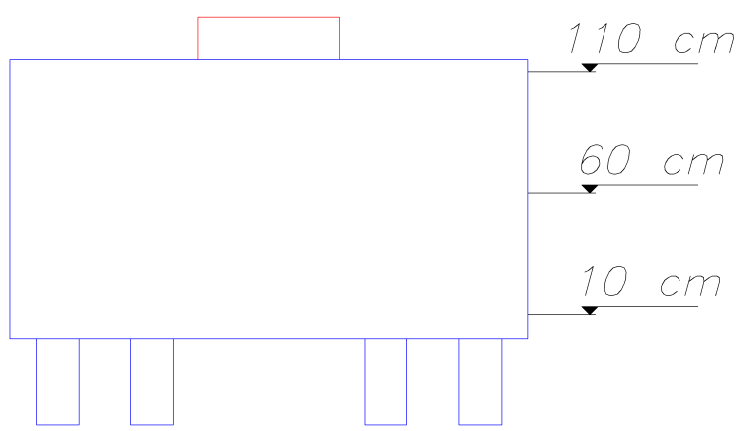

(d) alturas

Figura 6.30: Campos de tensão de compressão - bloco com altura de $115 \mathrm{~cm}$ para solo indeformável - valores em $\mathrm{kN} / \mathrm{cm}^{2}$

Conforme a figura 6.30 pode se observar que nesse caso as tensões de compressão junto a cabeça da estaca (a) são menores quando comparadas com as tensões para bloco com altura de $80 \mathrm{~cm}$ com estacas apoiada em solo indeformável. Para este caso as tensões de compressão na cabeça da estaca chegaram em 4,78 MPa. Novamente as tensões migraram para a região central do bloco e a estaca de número 6 foi a estacas que teve as tensões maiores. Na região próxima ao pilar, item (c), a tensão foi de 19,06 MPa. 
A figura 6.31 apresenta as tensões principais de compressão na seção transversal do bloco ao longo de sua altura para bloco com altura de $200 \mathrm{~cm}$, e vinculação das estacas para solo do tipo deformável.

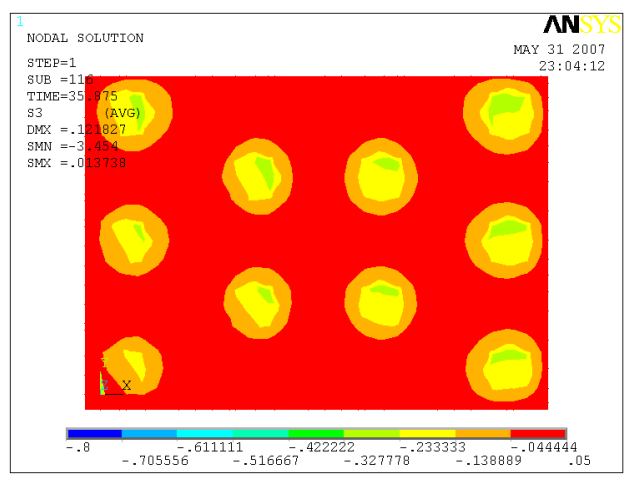

(a) $10 \mathrm{~cm}$

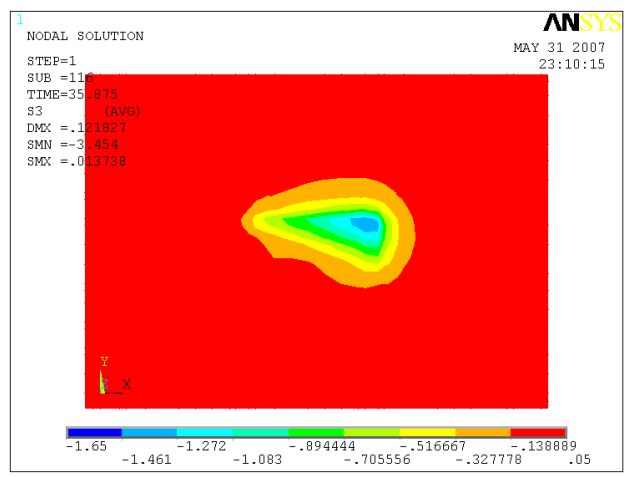

(c) $190 \mathrm{~cm}$

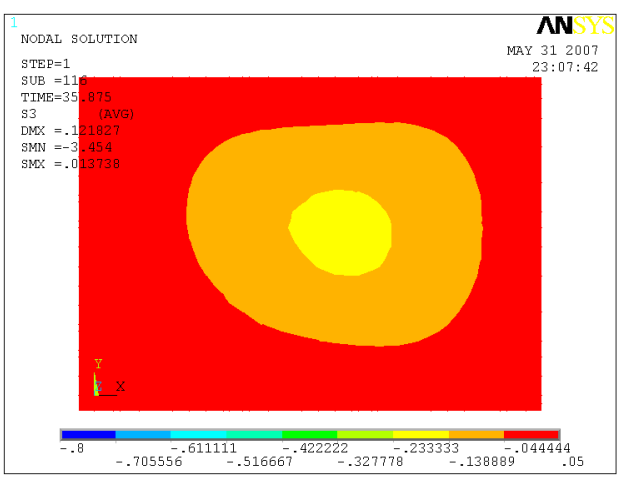

(b) $120 \mathrm{~cm}$

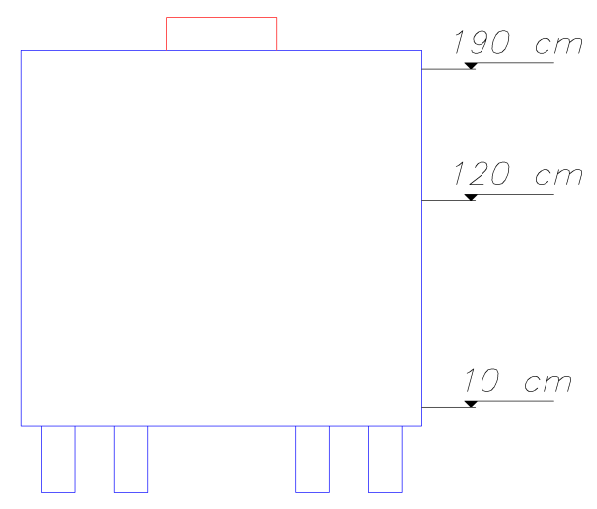

(d) alturas

Figura 6.31: Campos de tensão de compressão - bloco com altura de $200 \mathrm{~cm}$ para solo deformável - valores em $\mathrm{kN} / \mathrm{cm}^{2}$

Conforme a figura 6.31 pode se observar que nesse caso as tensões de compressão junto a cabeça da estaca (a) são menores quando comparadas com as tensões para blocos de altura de $80 \mathrm{~cm}$ e $115 \mathrm{~cm}$ com estacas apoiadas em solo deformável. Para este caso as tensões de compressão na cabeça da estaca chegaram em 3,28 MPa. Na região próxima ao pilar, item (c), a tensão foi de 14,6 MPa. Nas duas regiões a tensão de compressão diminuiu com o aumento da rigidez do bloco. 
A figura 6.32 apresenta as tensões principais de compressão na seção transversal do bloco ao longo de sua altura para bloco com altura de $200 \mathrm{~cm}$, e vinculação das estacas para solo do tipo indeformável.

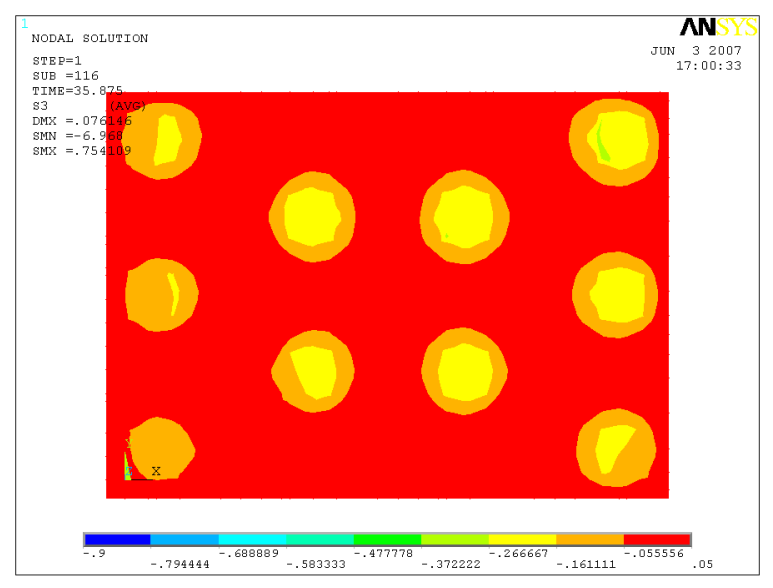

(a) $10 \mathrm{~cm}$

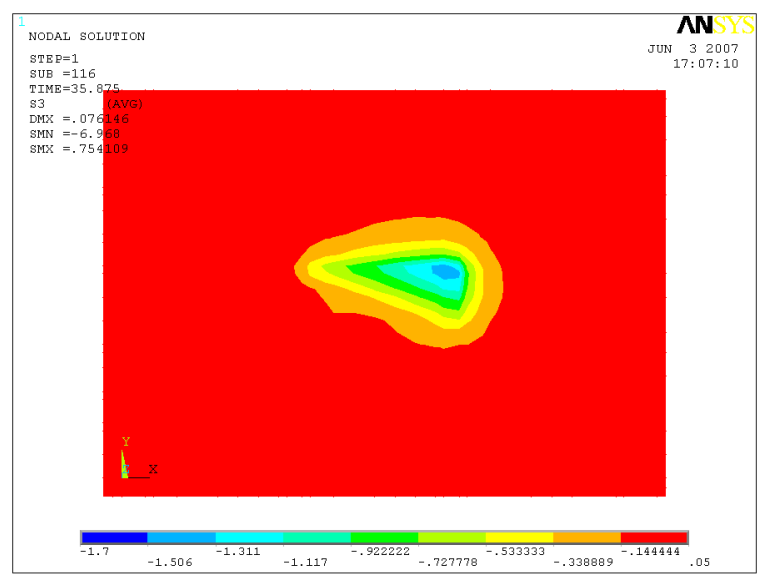

(c) $190 \mathrm{~cm}$

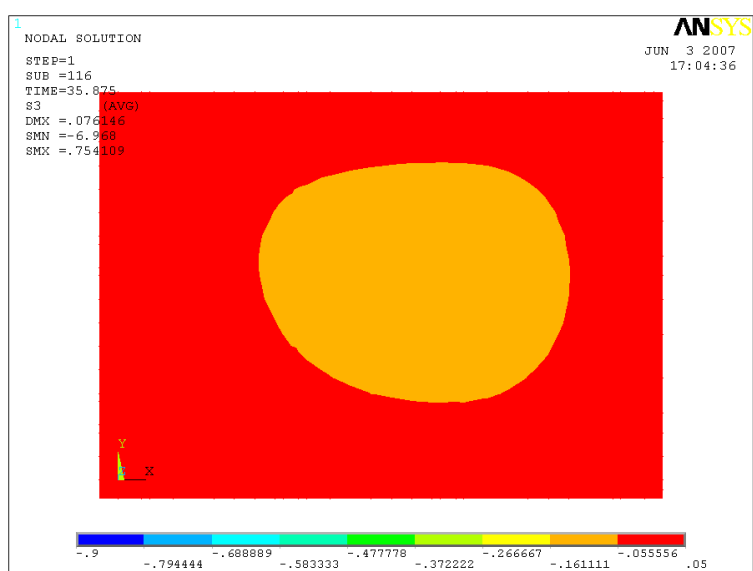

(b) $110 \mathrm{~cm}$

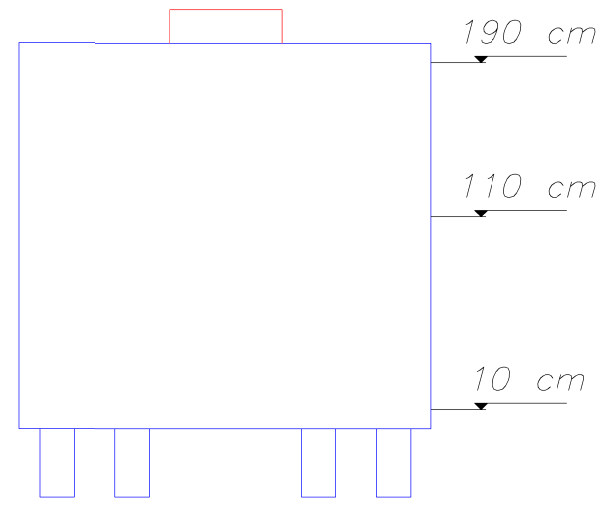

(d) alturas

Figura 6.32: Campos de tensão de compressão - bloco com altura de $200 \mathrm{~cm}$ para solo indeformável - valores em $\mathrm{kN} / \mathrm{cm}^{2}$

Conforme a figura 6.32 pode se observar que nesse caso as tensões de compressão junto a cabeça da estaca (a) são menores quando comparadas com as tensões para bloco com altura de $80 \mathrm{~cm}$ e $115 \mathrm{~cm}$ com estacas apoiadas em solo indeformável. Para este caso as tensões de compressão na cabeça da estaca chegaram em 2,67 MPa. Na região próxima ao pilar, item (c), a tensão foi de 15,06 MPa. Percebe-se que a estaca de número 3 é a menos solicitada, esse resultado já era o calculado. 


\subsection{Caso 3}

Neste item é analisada apenas o Caso 3. Para este Caso são consideradas a força centrada e os momentos fletores nas duas direções. Para o Caso 3 foram aumentados os valores de momentos fletores comparados ao Caso 2.

Para este caso não houve a variação da rigidez com relação a resistência característica à compressão do concreto $\left(f_{c k}\right)$.

Na tabela 6.7 são apresentadas as reações nas estacas para os dois tipos de vinculação das estacas para bloco com altura de $80 \mathrm{~cm}$. Vale lembrar que o bloco com altura de $80 \mathrm{~cm}$ não satisfez a verificação quanto a resistência à força cortante, conforme o processo do CEB-FIP (1970).

Tabela 6.7: Reações nas estacas para o Caso 3 em bloco com altura de $80 \mathrm{~cm}$

\begin{tabular}{ccccccc}
\hline \multicolumn{7}{c}{ Caso $3 ; \mathrm{h}=80 \mathrm{~cm} ; 25 \mathrm{MPa}$} \\
\hline \multicolumn{5}{c}{ deformável } & \multicolumn{5}{c}{ Indeformável } \\
\hline & Modelo & Modelo & & Nodelo & Modelo \\
Estacas & $F_{k, n}(\mathrm{kN})$ & $F_{k, a}(\mathrm{kN})$ & $F_{k, n} / F_{k, a}$ & $F_{k, n}(\mathrm{kN})$ & $F_{k, a}(\mathrm{kN})$ & $F_{k, n} / F_{k, a}$ \\
\hline 1 & 278,0 & 296,7 & 0,94 & 93,8 & 296,7 & 0,32 \\
2 & 196,5 & 200,7 & 0,98 & 63,2 & 200,7 & 0,31 \\
3 & 26,8 & 104,7 & 0,26 & $-10,7$ & 104,7 & $-0,10$ \\
4 & 361,4 & 314,9 & 1,15 & 544,4 & 314,9 & 1,73 \\
5 & 301,7 & 218,9 & 1,38 & 300,2 & 218,9 & 1,37 \\
6 & 406,1 & 381,1 & 1,07 & 830,8 & 381,1 & 2,18 \\
7 & 357,7 & 285,1 & 1,25 & 585,0 & 285,1 & 2,05 \\
8 & 396,1 & 495,3 & 0,80 & 210,5 & 495,3 & 0,43 \\
9 & 367,9 & 399,3 & 0,92 & 285,9 & 399,3 & 0,72 \\
10 & 307,4 & 303,3 & 1,01 & 96,8 & 303,3 & 0,32 \\
\hline
\end{tabular}

Por meio da tabela 6.7 percebe-se que o comportamento estrutural do bloco quando variou o tipo de vinculação das estacas e o tipo de ação aplicada mudou. Para vinculação das estacas do bloco com o solo do tipo deformável, percebe-se que houve pouca diferença comparado com os resultados do Caso 2, exceto para a estaca de número 3. Os resultados mostram que não houve uma uniformização na distribuição das reações nas estacas, como tinha ocorrido com mesmo bloco para o Caso 1. Quando se comparam os mesmos resultados da relação entre o modelo numérico e o modelo analítico os resultados para blocos com estacas apoiadas em solo do tipo deformável é bem maior. Para bloco com estacas apoiadas em solo do tipo indeformável essa relação chega a 118\% para estaca de número 6. Conforme ocorreu nos outros Casos, quando o solo é do tipo indeformável percebe-se que há uma grande variação dos valores. No entanto, percebe-se que ainda há 
uma tendência das forças serem maiores nas estacas centrais, mais próximas ao pilar.

Para solo do tipo deformável a diferença do modelo numérico para o modelo analítico chegou a $74 \%$ para a estaca de número 3 e a $38 \%$ para estacas de número 5 . Para solo do tipo indeformável a diferença foi bem maior chegando a ter tração para estaca de número 3 e a $118 \%$ para estaca de número 6 .

Nos dois casos analisados esperava-se que a estaca de número 8 fosse a mais solicitada, porém nos dois casos analisados a estaca de número 6 é a que foi a mais solicitada. Esse comportamento também ocorreu para o Caso 2.

Na tabela 6.8 são apresentadas as reações nas estacas para os dois tipos de vinculação das estacas para bloco com altura de $115 \mathrm{~cm}$. Vale lembrar que o bloco com altura de $115 \mathrm{~cm}$ satisfez a verificação quanto a resistência à força cortante, conforme o processo do CEB-FIP (1970).

Tabela 6.8: Reações nas estacas para o Caso 3 em bloco com altura de $115 \mathrm{~cm}$

\begin{tabular}{ccccccc}
\hline \multicolumn{7}{c}{ Caso $4 ; \mathrm{h}=115 \mathrm{~cm} ; 25 \mathrm{MPa}$} \\
\hline & Modelo & Modelo & \multicolumn{3}{c}{ Indeformável } \\
\hline & Numérico & Analítico & & Modelo & Modelo \\
Estacas & $F_{k, n}(\mathrm{kN})$ & $F_{k, a}(\mathrm{kN})$ & $F_{k, n} / F_{k, a}$ & $F_{k, n}(\mathrm{kN})$ & $F_{k, a}(\mathrm{kN})$ & $F_{k, n} / F_{k, a}$ \\
\hline 1 & 293,7 & 296,7 & 0,99 & 182,2 & 296,7 & 0,61 \\
2 & 220,7 & 200,7 & 1,10 & 116,8 & 200,7 & 0,58 \\
3 & 43,1 & 104,7 & 0,41 & 60,0 & 104,7 & 0,57 \\
4 & 335,8 & 314,9 & 1,07 & 441,5 & 314,9 & 1,40 \\
5 & 282,7 & 218,9 & 1,29 & 297,7 & 218,9 & 1,36 \\
6 & 379,1 & 381,1 & 0,99 & 599,5 & 381,1 & 1,57 \\
7 & 333,8 & 285,1 & 1,17 & 442,5 & 285,1 & 1,55 \\
8 & 405,0 & 495,3 & 0,82 & 358,5 & 495,3 & 0,72 \\
9 & 376,0 & 399,3 & 0,94 & 325,7 & 399,3 & 0,82 \\
10 & 329,7 & 303,3 & 1,09 & 191,0 & 303,3 & 0,63 \\
\hline
\end{tabular}

Percebe-se que o comportamento estrutural do bloco com altura de $115 \mathrm{~cm}$ se assemelha a bloco com altura de $80 \mathrm{~cm}$. A relação entre o modelo numérico e o modelo analítico entre os dois blocos mantiveram quase que as mesmas ordem de grandeza, sendo um pouco mais distribuída para bloco com altura de $115 \mathrm{~cm}$. Com o aumento da rigidez do bloco, e para vinculação das estacas do bloco com o solo do tipo deformável, a distribuição das reações nas estacas foram um pouco mais uniforme comparado com os mesmos resultados para bloco com altura de $80 \mathrm{~cm}$. Com o solo do tipo indeformável ainda há uma tendência das forças serem maiores nas estacas centrais, mais próxima ao pilar, porém houve uma maior uniformização quando comparado a bloco com altura de $80 \mathrm{~cm}$. 
Para solo do tipo deformável a diferença do modelo numérico para o modelo analítico chegou a 39\% para a estaca de número 3 e a $29 \%$ para estacas de número 5. Para solo do tipo indeformável a diferença chegou a $43 \%$ para estaca de número 3 e a $57 \%$ para estacas de número 6. Comparando esses dados a bloco com altura de $80 \mathrm{~cm}$ percebe-se que houve uma redução nessa relação.

Conforme os resultados analíticos esperava-se, nos dois casos, que a estaca de número 8 fosse a mais solicitada. Para bloco com estacas apoiadas em solo do tipo deformável esse resultado foi confirmado, porém para bloco com estacas apoiadas em solo do tipo indeformável a estaca de número 6 foi a mais solicitada, conforme ocorreu para o caso 2.

Na tabela 6.9 são apresentadas as reações nas estacas para os dois tipos de vinculação das estacas para bloco com altura de $200 \mathrm{~cm}$. Vale lembrar que o bloco com altura de $200 \mathrm{~cm}$ satisfez a verificação quanto a resistência à força cortante, conforme o processo do CEB-FIP (1970).

Tabela 6.9: Reações nas estacas para o Caso 3 em bloco com altura de $200 \mathrm{~cm}$

\begin{tabular}{ccccccc}
\hline \multicolumn{7}{c}{ Caso $4 ; \mathrm{h}=200 \mathrm{~cm} ; 25 \mathrm{MPa}$} \\
\hline \multicolumn{5}{c}{ deformável } & \multicolumn{5}{c}{ Indeformável } \\
\hline & Modelo & Modelo & \multicolumn{5}{c}{ Modelo } & Modelo \\
Estacas & $F_{k, n}(\mathrm{kN})$ & $F_{k, a}(\mathrm{kN})$ & $F_{k, n} / F_{k, a}$ & $F_{k, n}(\mathrm{kN})$ & $F_{k, a}(\mathrm{kN})$ & $F_{k, n} / F_{k, a}$ \\
\hline 1 & 301,3 & 296,7 & 1,02 & 251,8 & 296,7 & 0,85 \\
2 & 228,9 & 200,7 & 1,14 & 174,2 & 200,7 & 0,87 \\
3 & 47,7 & 104,7 & 0,46 & 86,7 & 104,7 & 0,83 \\
4 & 328,0 & 314,9 & 1,04 & 361,5 & 314,9 & 1,15 \\
5 & 275,0 & 218,9 & 1,26 & 255,0 & 218,9 & 1,16 \\
6 & 367,8 & 381,1 & 0,97 & 446,6 & 381,1 & 1,17 \\
7 & 325,7 & 285,1 & 1,14 & 336,5 & 285,1 & 1,18 \\
8 & 407,4 & 495,3 & 0,82 & 444,7 & 495,3 & 0,90 \\
9 & 379,7 & 399,3 & 0,95 & 376,5 & 399,3 & 0,94 \\
10 & 338,2 & 303,3 & 1,12 & 266,3 & 303,3 & 0,88 \\
\hline
\end{tabular}

Percebe-se que o comportamento estrutural do bloco com altura de $200 \mathrm{~cm}$ se assemelha com os blocos de alturas de $80 \mathrm{~cm}$ e $115 \mathrm{~cm}$. A relação entre o modelo numérico e o modelo analítico entre os três blocos analisados mantiveram quase que as mesmas ordens de grandezas, sendo um pouco mais distribuída para o bloco com altura de 200 cm. Com o aumento da rigidez do bloco, e para vinculação das estacas do bloco com o solo do tipo deformável, a distribuição das reações nas estacas foram um pouco mais uniforme comparado com os mesmos resultados para bloco com altura de $80 \mathrm{~cm}$ e $115 \mathrm{~cm}$. Com o solo do tipo indeformável ainda há uma tendência das forças serem maiores nas 
estacas centrais, mais próximas ao pilar, porém houve uma maior uniformização quando comparado a bloco com altura de $80 \mathrm{~cm}$ e $115 \mathrm{~cm}$.

Para solo do tipo deformável a diferença do modelo numérico para o modelo analítico chegou a $54 \%$ para a estaca de número 3 e a $26 \%$ para estacas de número 5 . Para solo do tipo indeformável a diferença chegou a 17\% para estaca de número 3 e a $18 \%$ para estacas de número 7.

Conforme os resultados analíticos esperava-se, nos dois casos, que a estaca de número 8 fosse a mais solicitada. Para bloco com estacas apoiadas em solo do tipo deformável esse resultado foi confirmado, porém para bloco com estacas apoiadas em solo do tipo indeformável a estaca de número 6 foi a mais solicitada, embora essa diferença tenha sido pequena, pode-se afirmar que as duas foram as mais solicitadas.

Analisando as três tabelas apresentadas percebe-se que o comportamento estrutural do bloco é fortemente influenciado pelo tipo de vinculação das estacas e pela rigidez do bloco. Para todos os blocos analisados esperava-se que a estacas de número 8 fosse a mais solicitada, porém isso apenas foi confirmado em alguns bloco, nos outros casos a estaca de número 6 é a que foi a mais solicitada. Para esse caso com o aumento da rigidez do bloco as distribuições das reações nas estacas demonstraram um comportamento com tendência de uniformização, assim como ocorreu com o Caso 1 e Caso 2.

Para que fique mais claro são apresentadas nas figuras a seguir gráficos comparando os resultados para todas as estacas. A comparação é feita relacionando a altura do bloco versus a relação entre a força obtida numericamente e a força calculada analiticamente. Nos gráficos as linhas contínua representam estacas apoiadas em solo do tipo deformável e as linhas tracejada solo do tipo indeformável.

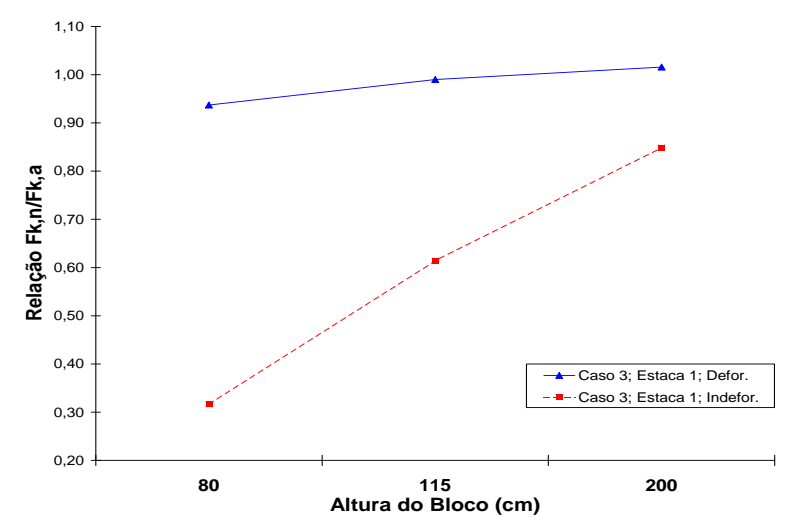

(a) estaca 1

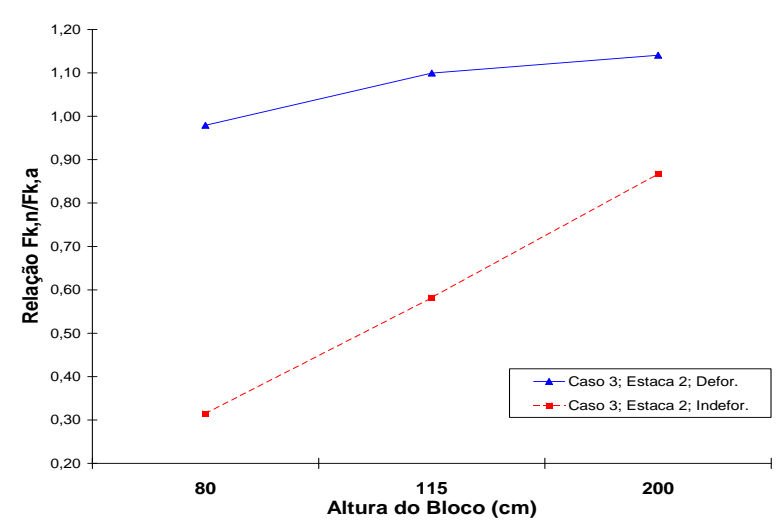

(b) estaca 2

Figura 6.33: Comparação entre as alturas para estacas 1 e 2 do Caso 3 
Percebe-se na figura 6.33 que o comportamento das estacas de número 1 e 2 foi o mesmo, ou seja, com o aumento da altura do bloco essas estacas tendem a ser mais próximo do modelo analítico. Esse comportamento também ocorreu para o Caso 2 com as mesmas estacas.

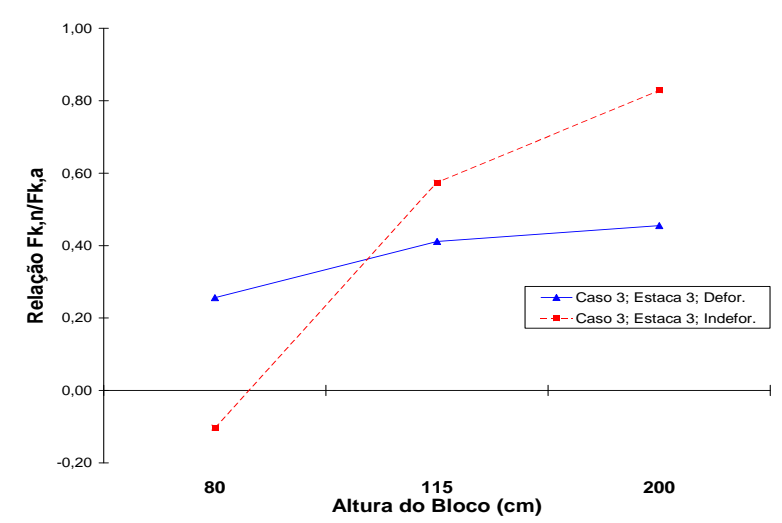

(a) estaca 3

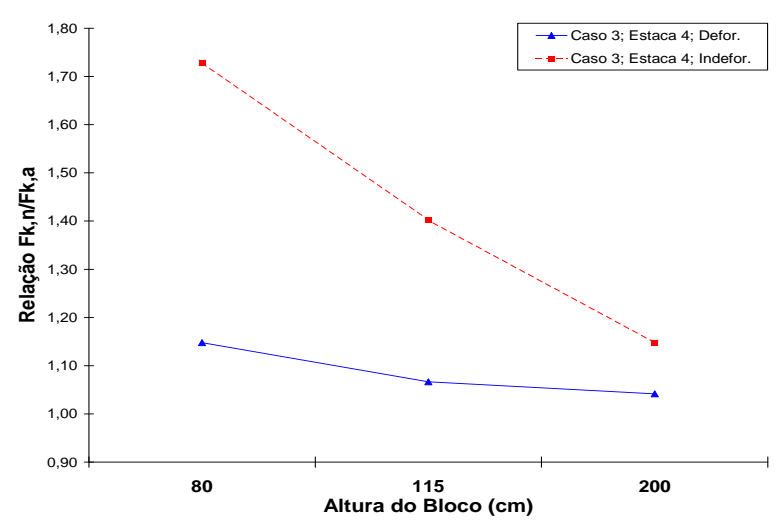

(b) estaca 4

Figura 6.34: Comparação entre as alturas para estacas 3 e 4 do Caso 3

Na figura 6.34 o gráfico da estaca de número 4 manteve o comportamento típico. No entanto, a estaca de número 3 teve um comportamento totalmente diferente, embora tenha sido crescente com o aumento da altura do bloco.

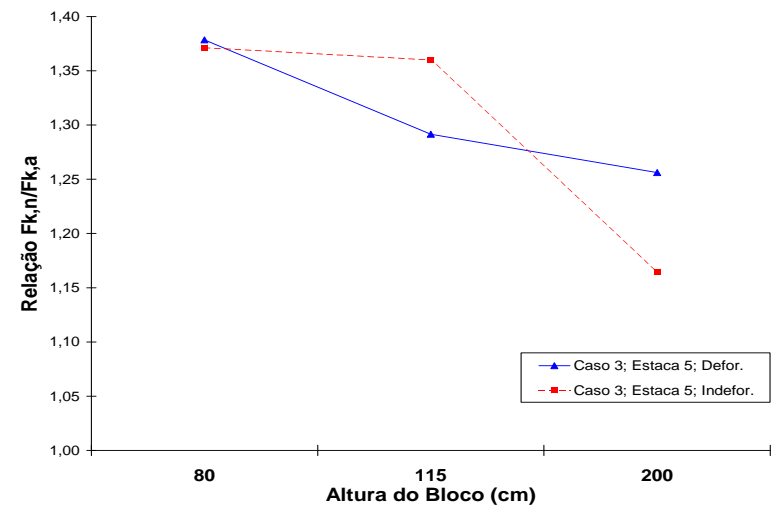

(a) estaca 5

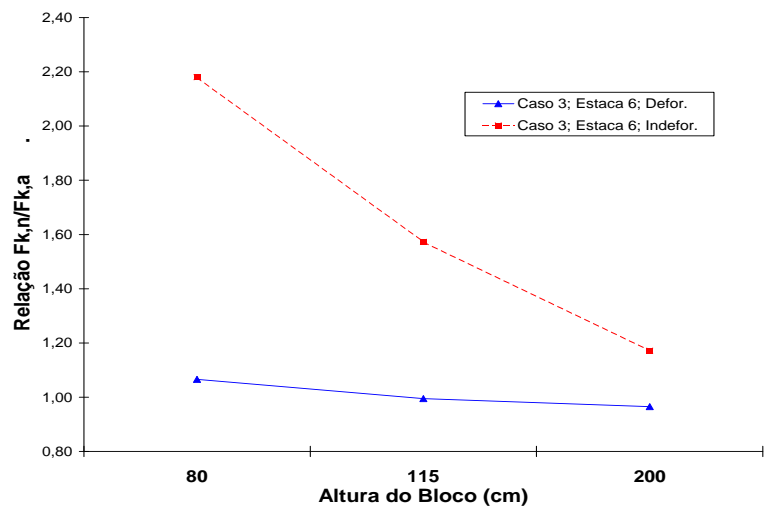

(b) estaca 6

Figura 6.35: Comparação entre as alturas para estacas 5 e 6 do Caso 3

Na figura 6.35 a estaca de número 6 manteve o comportamento típico mostrado anteriormente. No entanto, a estaca de número 5 teve um comportamento diferente das anteriores, embora tenha sido crescente com o aumento da altura do bloco. 


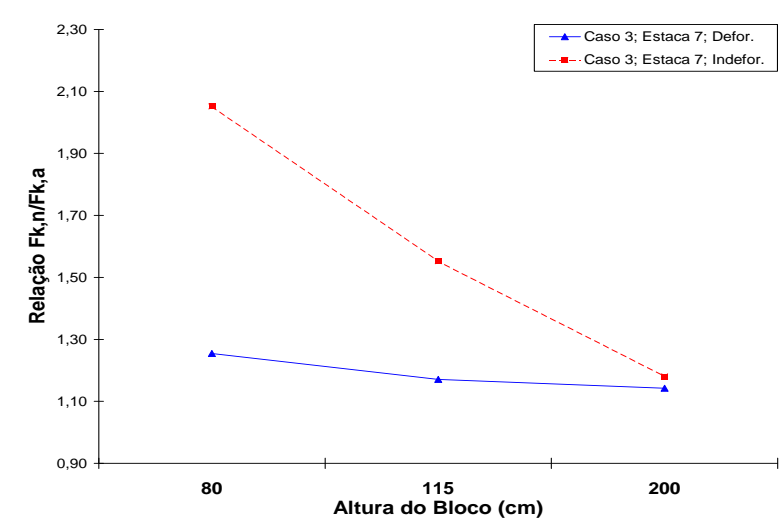

(a) estaca 7

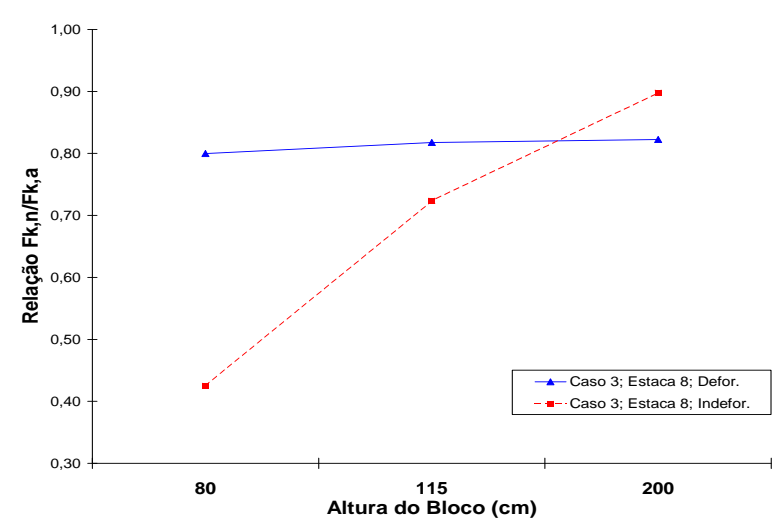

(b) estaca 8

Figura 6.36: Comparação entre as alturas para estacas 7 e 8 do Caso 3

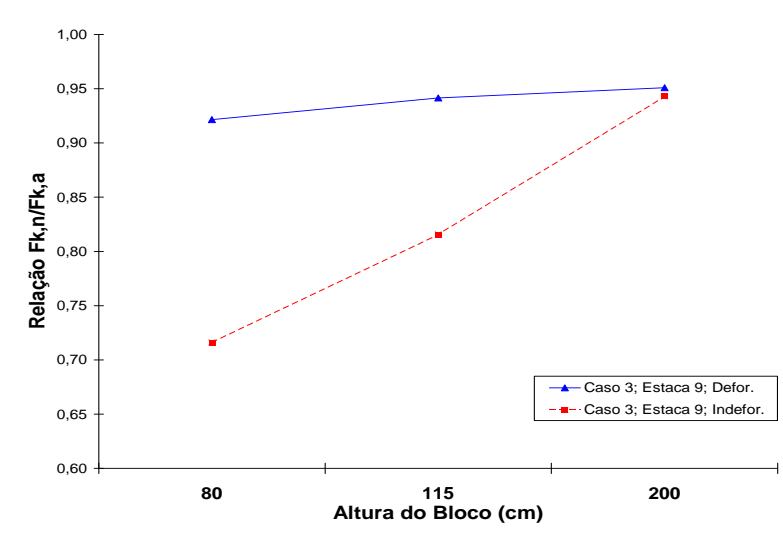

(a) estaca 9

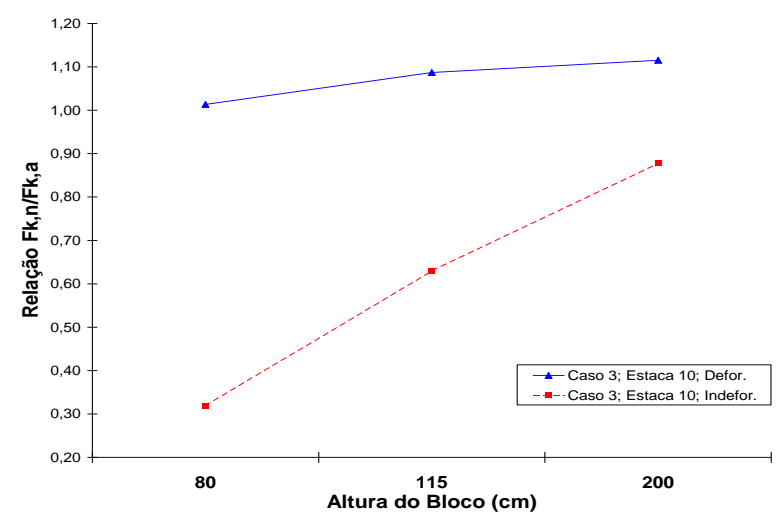

(b) estaca 10

Figura 6.37: Comparação entre as alturas para estacas 9 e 10 do Caso 3

Nas figuras 6.36 e 6.37 percebe-se que o comportamento foi sempre o mesmo, com o aumento da altura do bloco as reações nas estacas tendem aos valores analíticos e a diferença, entre o tipo de solo considerado, diminui e fica mais próxima uma da outra. Apenas a estaca de número 8 que houve uma inversão para blocos com altura de 200 $\mathrm{cm}$. Como já havia ocorrido para o Caso 2 há dois tipos de comportamento quando se comparam os gráficos. Os gráficos das estacas da região central tem um comportamento descendente, já os gráficos das estacas externas tem um comportamento ascendente. 
A seguir são apresentadas figuras que representam a relação entre as reações nas estacas versus o acréscimo de ações aplicado ao bloco simulado numericamente. Primeiramente são apresentados gráficos de blocos com estacas apoiadas em solo do tipo deformável e em seguida para solo do tipo indeformável.

Na figura 6.38 são apresentadas as relações entre as reações nas estacas para bloco com altura de $80 \mathrm{~cm}$ e estacas apoiadas em solo deformável.

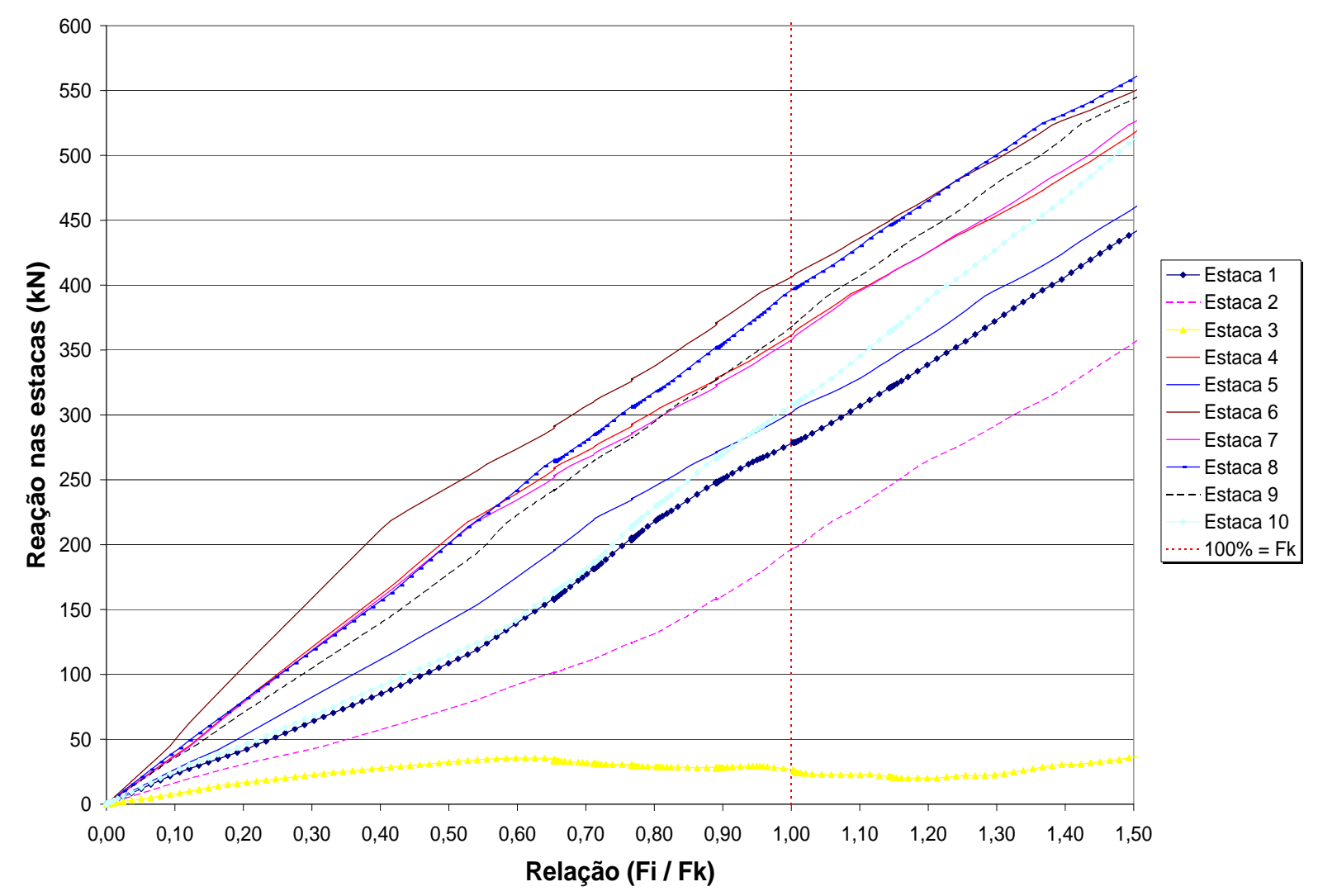

Figura 6.38: Reações nas estacas ao longo da aplicação das ações para bloco com altura de $80 \mathrm{~cm}$ e solo deformável

Por meio da figura 6.38 percebe-se que as reações na estaca de número 6 inicialmente tem um comportamento de bloco com estacas apoiadas em solo indeformável, e próxima da relação $F_{i} / F_{k}$ igual a 0,40 há uma mudança no seu comportamento. Para este caso a estacas mais solicitada em toda a análise foi a de número 6 ficando $7 \%$ acima do valor calculado analiticamente para a relação $F_{i} / F_{k}$ igual a unidade. No entanto, a estaca de número 3 foi a menos solicitada em toda a análise. Nesse caso nenhuma estaca chegou a força de ruptura. 
Na figura 6.39 são apresentadas as relações entre as reações nas estacas para bloco com altura de $115 \mathrm{~cm}$ e estacas apoiadas em solo deformável.

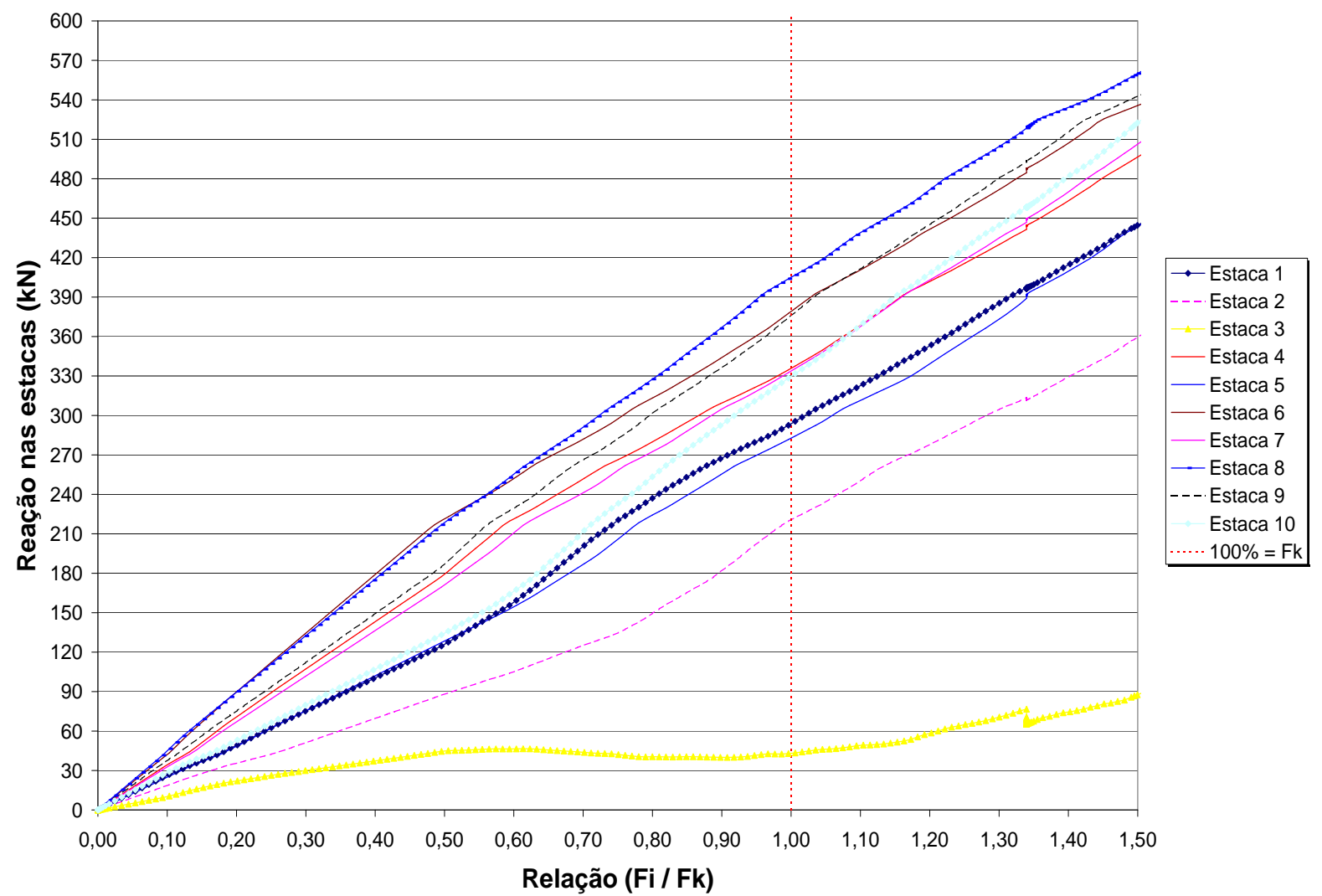

Figura 6.39: Reações nas estacas ao longo da aplicação das ações para bloco com altura de $115 \mathrm{~cm}$ e solo deformável

Por meio da figura 6.39 percebe-se o comportamento nas reações nas estacas foram semelhante ao bloco com altura de $80 \mathrm{~cm}$. Inicialmente as estacas de número $6 \mathrm{e}$ 8 tem praticamente a mesma força e próxima da relação $F_{i} / F_{k}$ igual a 0,6 a estaca de número 8 passa a ser a mais solicitada. Para a relação de $F_{i} / F_{k}$ igual a unidade a estaca de número 8 está $18 \%$ abaixo do valor calculado analiticamente. Novamente a estaca de número 3 é a menos solicitada. Nesse caso nenhuma estaca chegou a força de ruptura. 
Na figura 6.40 são apresentadas as relações entre as reações nas estacas para bloco com altura de $200 \mathrm{~cm}$ e estacas apoiadas em solo deformável.

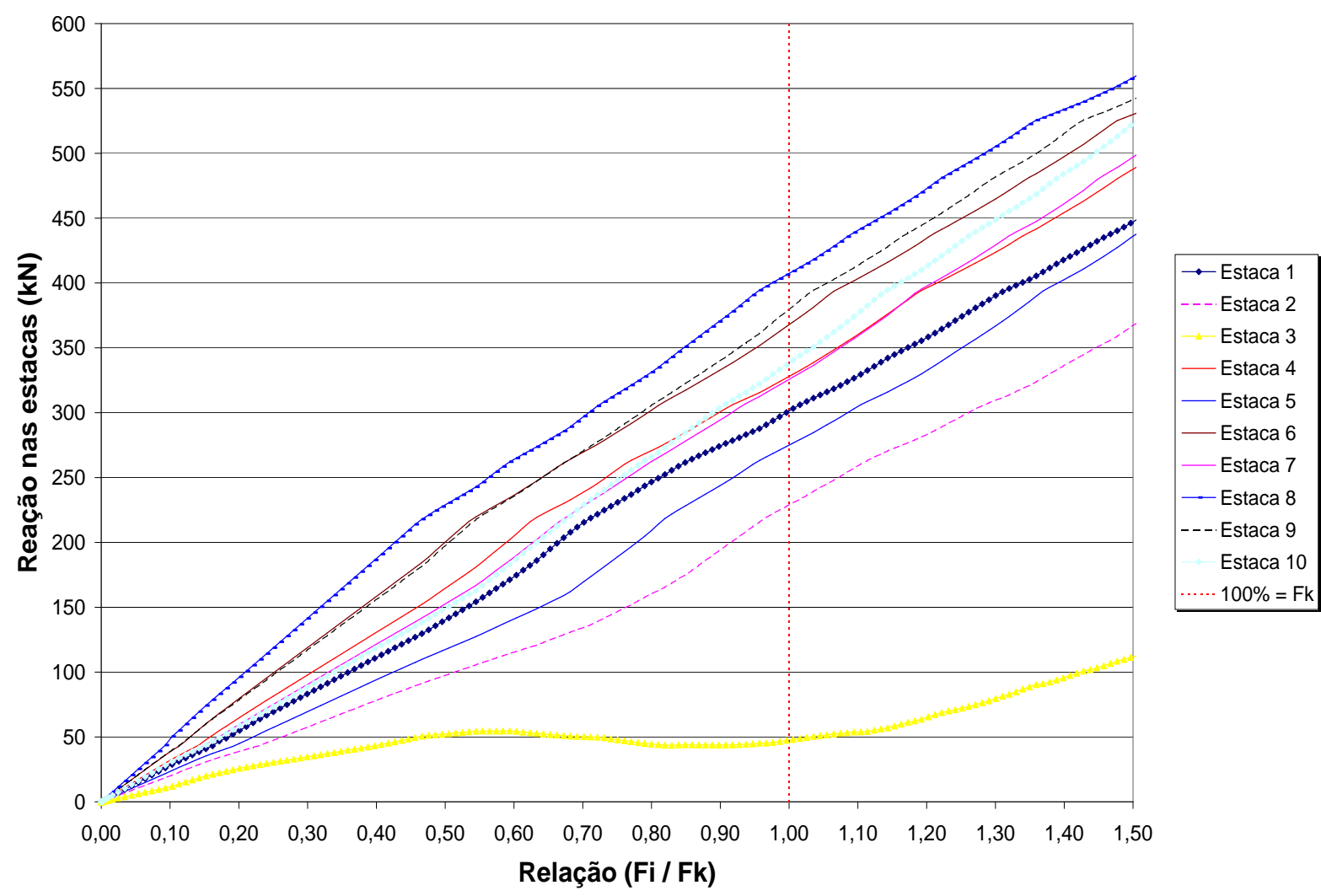

Figura 6.40: Reações nas estacas ao longo da aplicação das ações para bloco com altura de $200 \mathrm{~cm}$ e solo deformável

Na figura 6.40 percebe-se que o comportamento das reações nas estacas mantevese o mesmo para bloco com altura de $80 \mathrm{~cm}$ e $115 \mathrm{~cm}$. Para este caso a estaca que foi mais solicitada desde o inicio da aplicação das forças foi a de número 8. Para a relação $F_{i} / F_{k}$ igual a unidade a estaca de número 8 ficou $18 \%$ abaixo do valor calculado analiticamente. Apenas a estaca de número 3 que ficou um pouco deslocada das demais, porém seu comportamento ficou levemente acima comparado com os outros dois casos. Nesse caso nenhuma estaca chegou a força de ruptura. 
Na figura 6.41 são apresentadas as relações entre as reações nas estacas para bloco com altura de $80 \mathrm{~cm}$ e estacas apoiadas em solo indeformável.

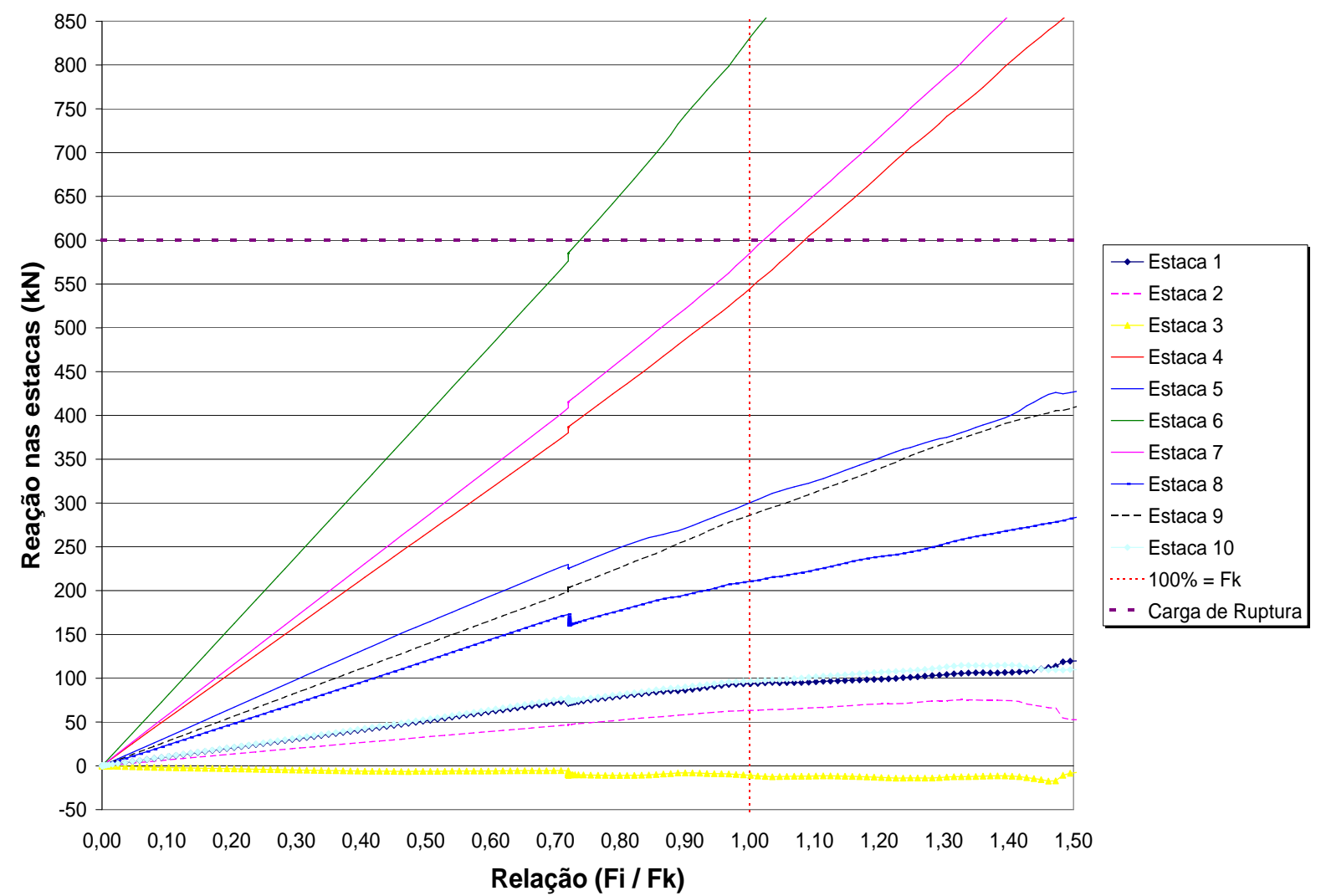

Figura 6.41: Reações nas estacas ao longo da aplicação das ações para bloco com altura de $80 \mathrm{~cm}$ e solo indeformável

Por meio da figura 6.41 percebe-se que o comportamento do bloco mudou muito quando comparado com bloco sobre estacas apoiadas em solo deformável. Houve uma grande variabilidade nos valores das reações nas estacas. A estaca de número 6 foi a mais solicitada ao longo de toda a análise e atingiu o valor de $830,8 \mathrm{kN}$ para relação $F_{i} / F_{k}$ igual a unidade, muito acima do valor de ruína da estaca que é de $600 \mathrm{kN}$, que ficou próxima da relação $F_{i} / F_{k}$ de 0,7 . Esse valor corresponde a $118 \%$ acima do valor calculado analiticamente. A estaca de número 3 foi tracionada ao longo de toda a análise. 
Na figura 6.42 são apresentadas as relações entre as reações nas estacas para bloco com altura de $115 \mathrm{~cm}$ e estacas apoiadas em solo indeformável.

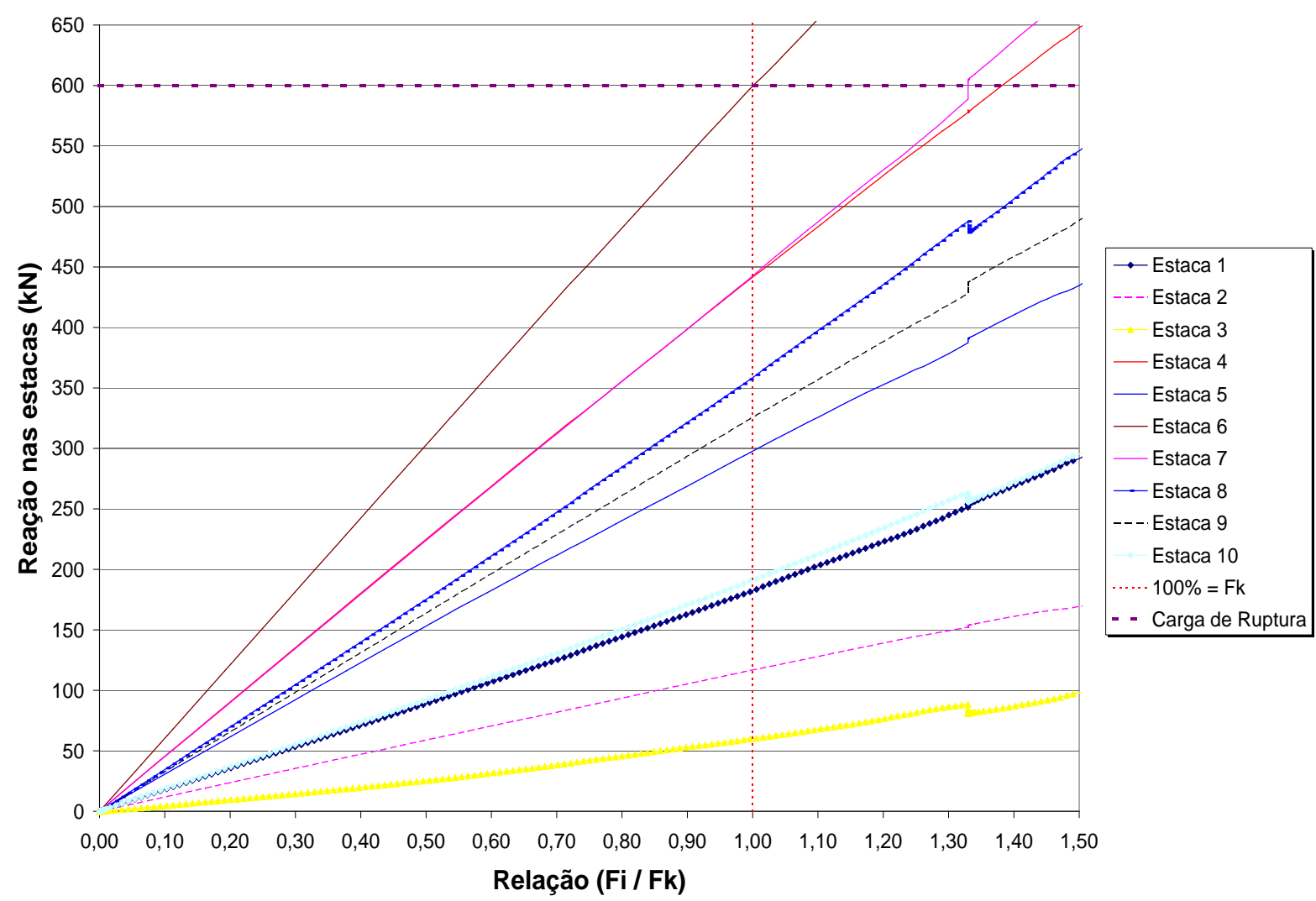

Figura 6.42: Reações nas estacas ao longo da aplicação das ações para bloco com altura de $115 \mathrm{~cm}$ e solo indeformável

Por meio da figura 6.42 percebe-se que o comportamento do bloco se assemelha ao do bloco com altura de $80 \mathrm{~cm}$ com mesmo tipo de solo. As variações nos valores das reações nas estacas, foram comparados com os do bloco de altura menor. A estaca de número 6, novamente, foi a mais solicitada ao longo de toda a análise. Para a relação $F_{i} / F_{k}$ igual a unidade a reação na estaca de número 6 foi de $599,5 \mathrm{kN}$ praticamente igual ao valor de ruína da estaca. Esse valor corresponde a $57 \%$ acima do valor calculado analiticamente. Percebe-se, também, que a estaca de número 3 não foi tracionada como tinha ocorrido para bloco com altura de $80 \mathrm{~cm}$. 
Na figura 6.43 são apresentadas as relações entre as reações nas estacas para bloco com altura de $200 \mathrm{~cm}$ e estacas apoiadas em solo indeformável.

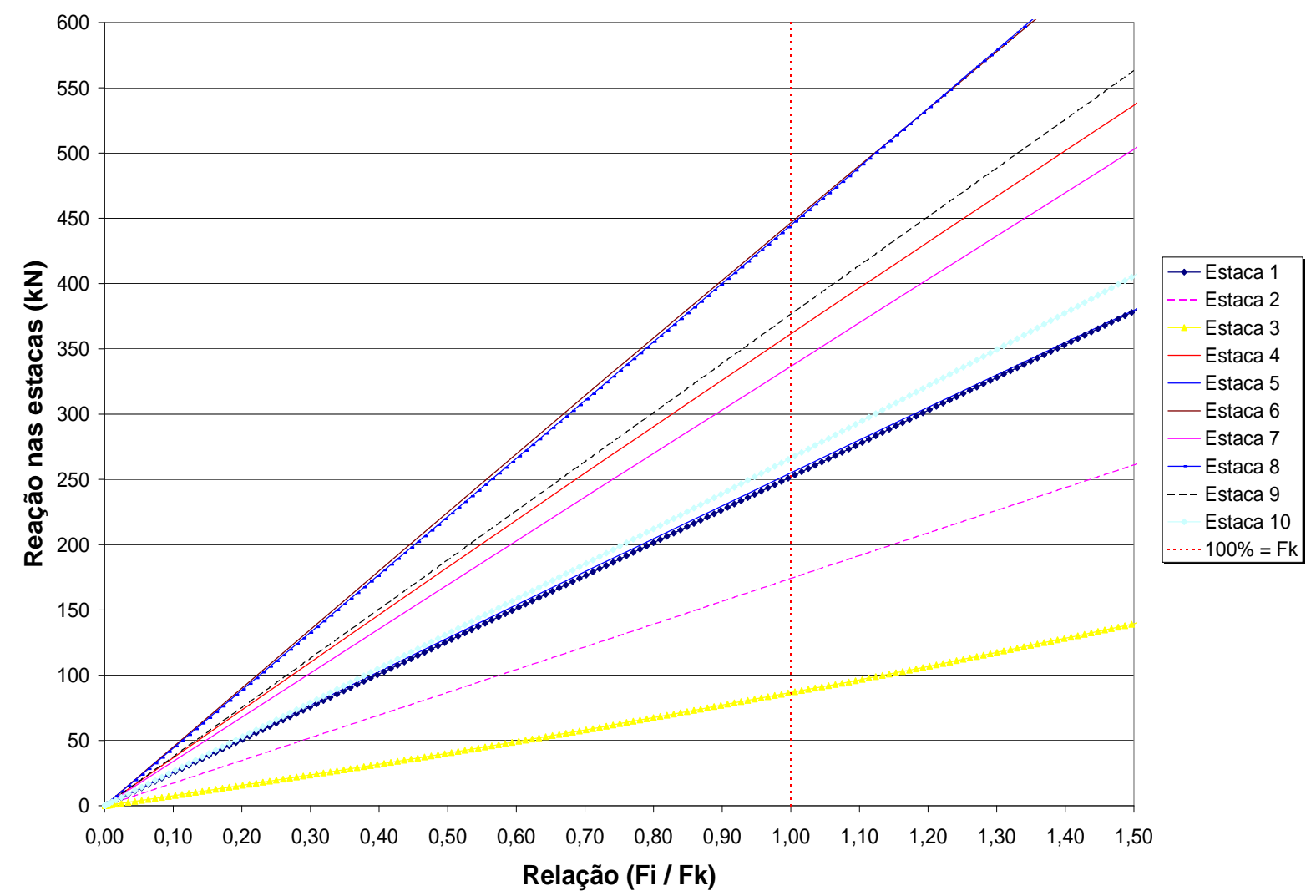

Figura 6.43: Reações nas estacas ao longo da aplicação das ações para bloco com altura de $200 \mathrm{~cm}$ e solo indeformável

Por meio da figura 6.43 percebe-se que o comportamento do bloco se assemelha ao do bloco com altura de $80 \mathrm{~cm}$ e $115 \mathrm{~cm}$, porém com uma distribuição na reação das estacas mais uniforme. A estaca de número 6 e 8 tiveram praticamente o mesmo valor da força ao longo de toda a análise. Ambas atingiram a ruptura próximo da relação $F_{i} / F_{k}$ de 1,40 . Para a relação $F_{i} / F_{k}$ igual a unidade a estaca de número 6 teve a reação de 446,6 $\mathrm{kN}$ ficando $17 \%$ acima do valor calculado analiticamente e a estaca de número 8 teve praticamente o mesmo valor da reação ficando $10 \%$ abaixo do valor calculado analiticamente. Para este caso a estaca de número 3 não foi tracionada ao longo da análise. 
Serão apresentadas 6 figuras que mostram as tensões principais de compressão na seção transversal do bloco ao longo de sua altura.

A figura 6.44 apresenta as tensões principais de compressão na seção transversal do bloco ao longo de sua altura para bloco com altura de $80 \mathrm{~cm}$, e vinculação das estacas para solo do tipo deformável.

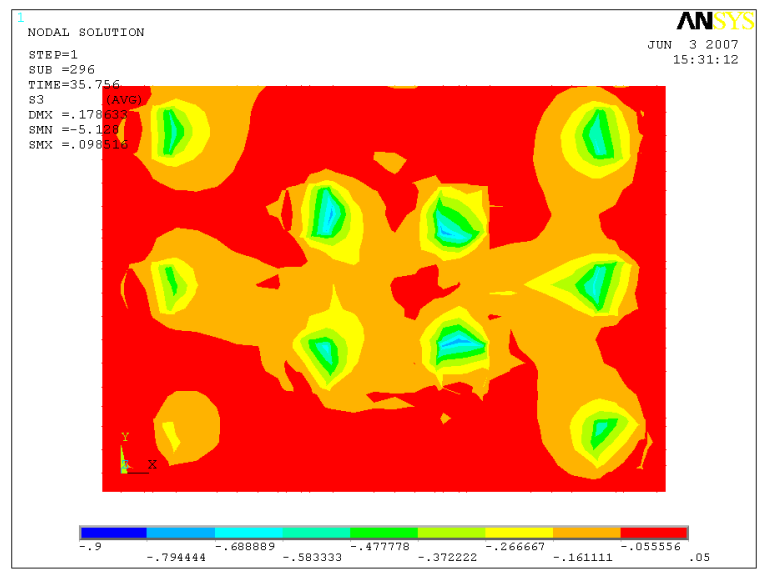

(a) $10 \mathrm{~cm}$

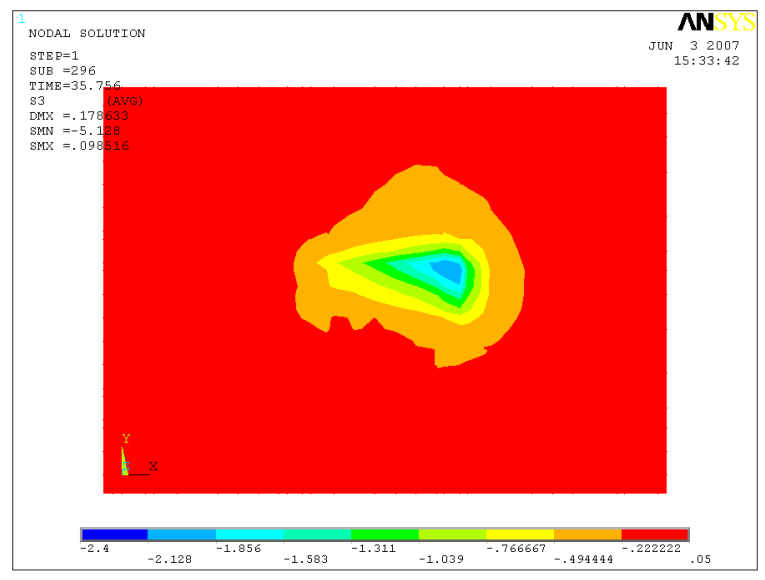

(c) $70 \mathrm{~cm}$

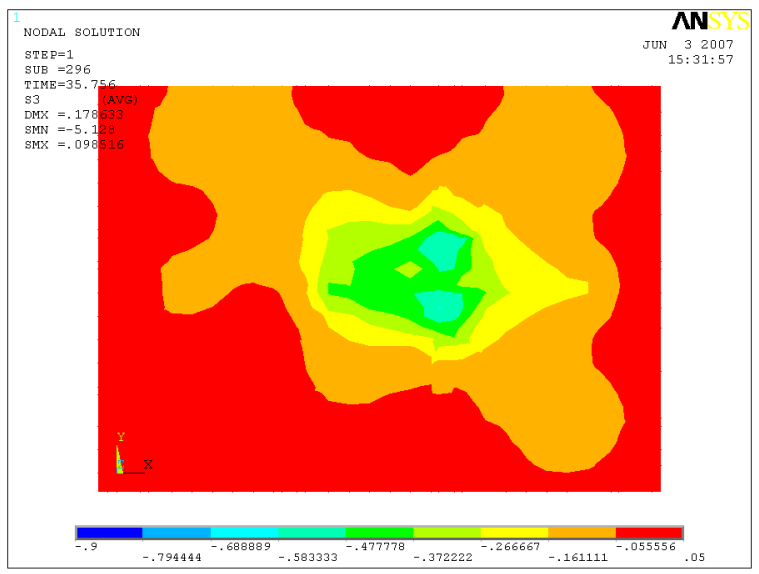

(b) $40 \mathrm{~cm}$

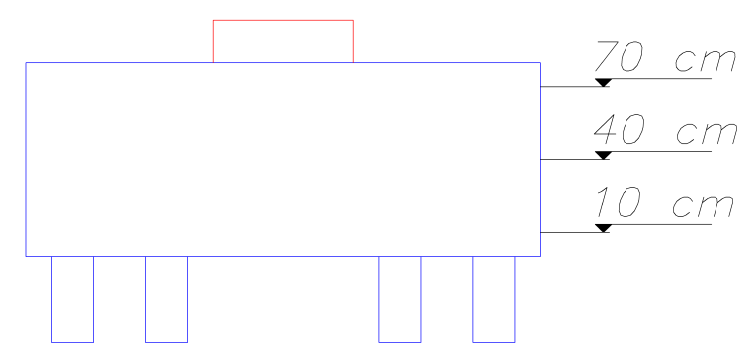

(d) alturas

Figura 6.44: Campos de tensão de compressão - bloco com altura de $80 \mathrm{~cm}$ para solo deformável - valores em $\mathrm{kN} / \mathrm{cm}^{2}$

Por meio da figura 6.44 pode se observar: as tensões junto a cabeça da estaca para uma altura de $10 \mathrm{~cm}$ (a); tensões no bloco a meia altura (b); e tensões próximas ao pilar (c). Percebe-se que nesse caso as tensões junto a cabeça da estaca (a) são maiores na região central onde estão as estacas mais próximas do pilar, como vem ocorrendo com outros modelos analisados. Isso mostra que as forças tendem a migrar para as estacas na região central. A tensão nessa região atingiu 7,9 MPa. Na região próxima ao pilar, item 
(c), a tensão foi de 21,28 MPa.

A figura 6.45 apresenta as tensões principais de compressão na seção transversal do bloco ao longo de sua altura para bloco com altura de $80 \mathrm{~cm}$, e vinculação das estacas para solo do tipo indeformável.

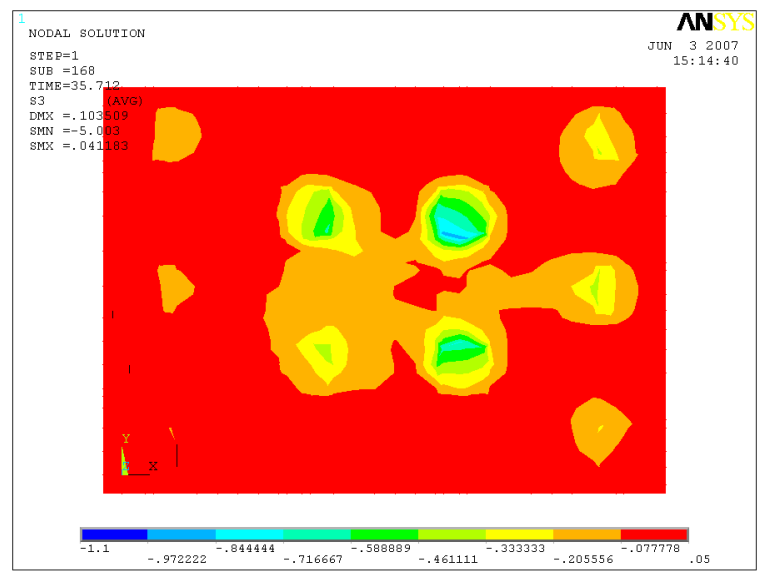

(a) $10 \mathrm{~cm}$

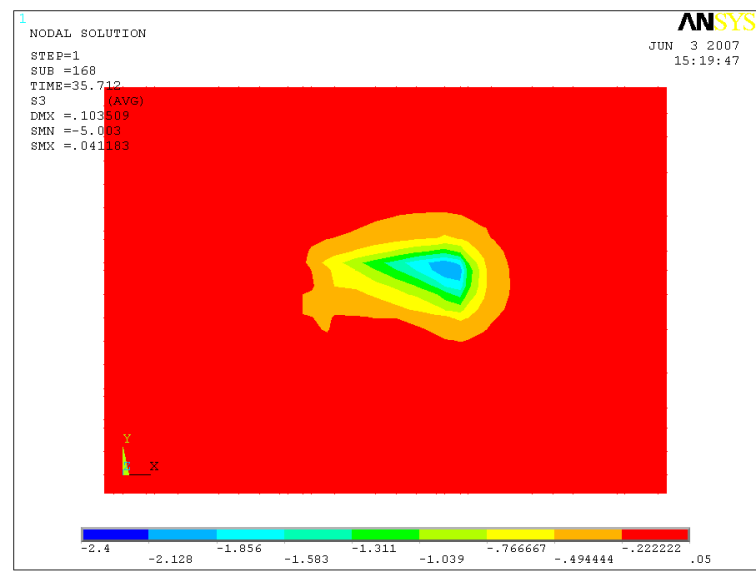

(c) $70 \mathrm{~cm}$

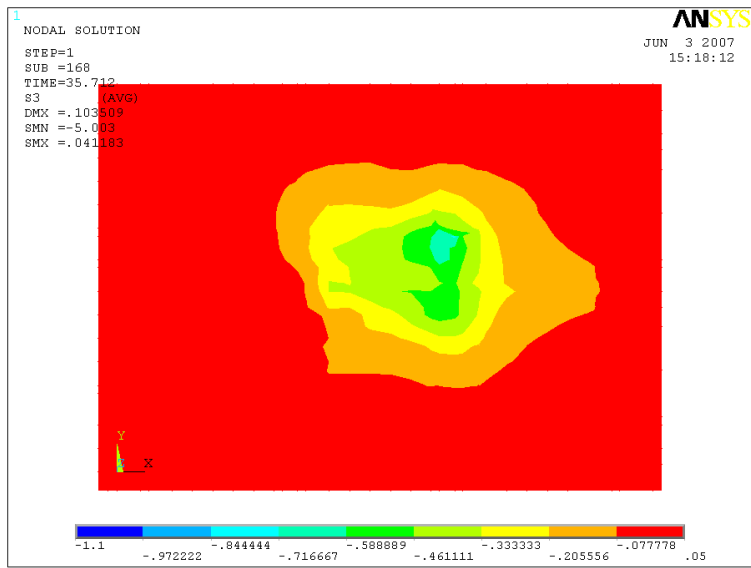

(b) $40 \mathrm{~cm}$

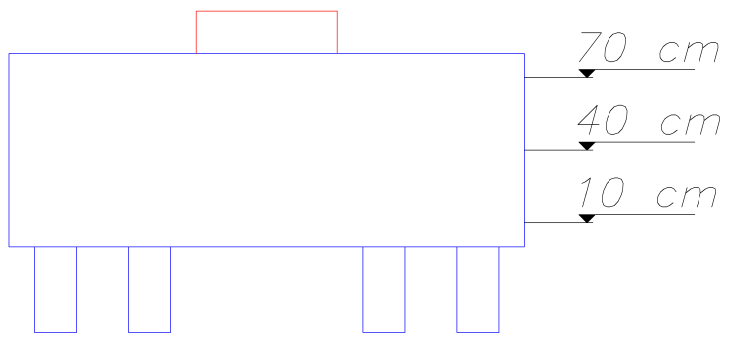

(d) alturas

Figura 6.45: Campos de tensão de compressão - bloco com altura de $80 \mathrm{~cm}$ para solo indeformável - valores em $\mathrm{kN} / \mathrm{cm}^{2}$

Conforme a figura 6.45 pode se observar que nesse caso as tensões de compressão junto a cabeça da estaca (a) são maiores quando comparado com as tensões para o mesmo bloco com estacas apoiadas em solo deformável. A região central do bloco junto a cabeça das estacas foi a região mais comprimida, e a estaca de numero 6 teve tensões que chegaram a 9,7 MPa. Por meio dessa figura é possível perceber que, mais uma vez, as forças tendem a migrar para as estacas centrais mais próximas ao pilar. Na região próxima ao pilar, item (c), a tensão foi de $21 \mathrm{MPa}$. 
A figura 6.46 apresenta as tensões principais de compressão na seção transversal do bloco ao longo de sua altura para bloco com altura de $115 \mathrm{~cm}$, e vinculação das estacas para solo do tipo deformável.

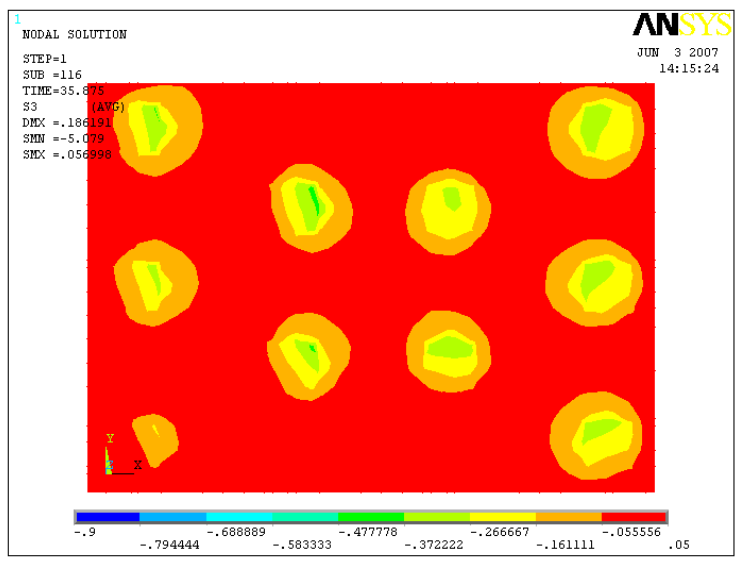

(a) $10 \mathrm{~cm}$

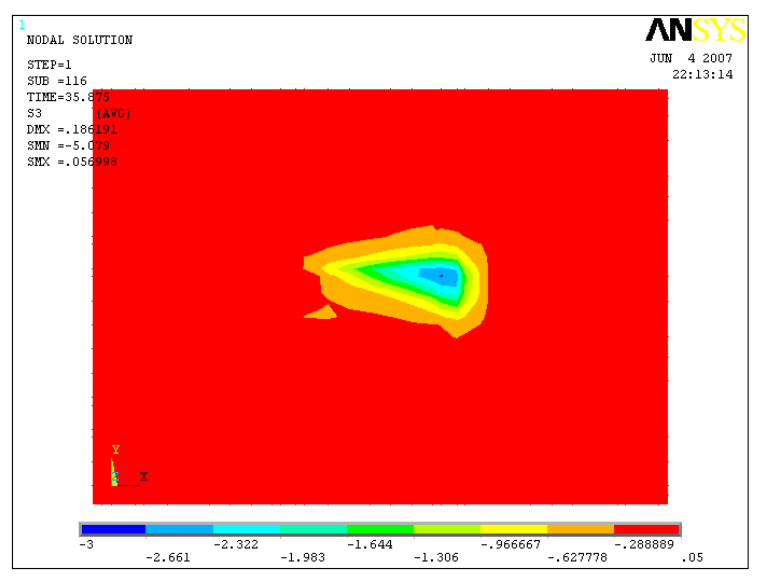

(c) $110 \mathrm{~cm}$

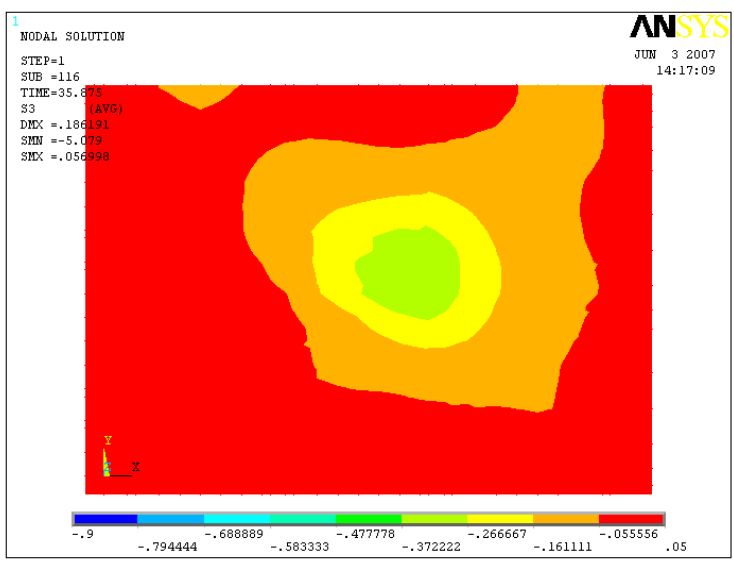

(b) $60 \mathrm{~cm}$

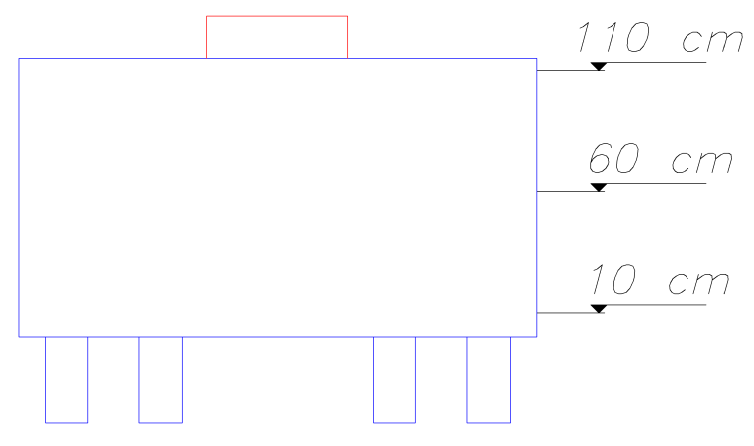

(d) alturas

Figura 6.46: Campos de tensão de compressão - bloco com altura de $115 \mathrm{~cm}$ para solo deformável - valores em $\mathrm{kN} / \mathrm{cm}^{2}$

Conforme a figura 6.46 pode se observar que nesse caso as tensões de compressão junto a cabeça da estaca (a) são menores quando comparado com as tensões para bloco com altura de $80 \mathrm{~cm}$ com estacas apoiadas em solo deformável. Para este caso as tensões de compressão na cabeça da estaca chegaram em 4,78 MPa. Nesse caso apenas as estacas de número 3 e 6 não chegaram a este valor, como já tinha ocorrido para o Caso 2. Na região próxima ao pilar, item (c), a tensão foi de 26,6 MPa. 
A figura 6.47 apresenta as tensões principais de compressão na seção transversal do bloco ao longo de sua altura para bloco com altura de $115 \mathrm{~cm}$, e vinculação das estacas para solo do tipo indeformável.

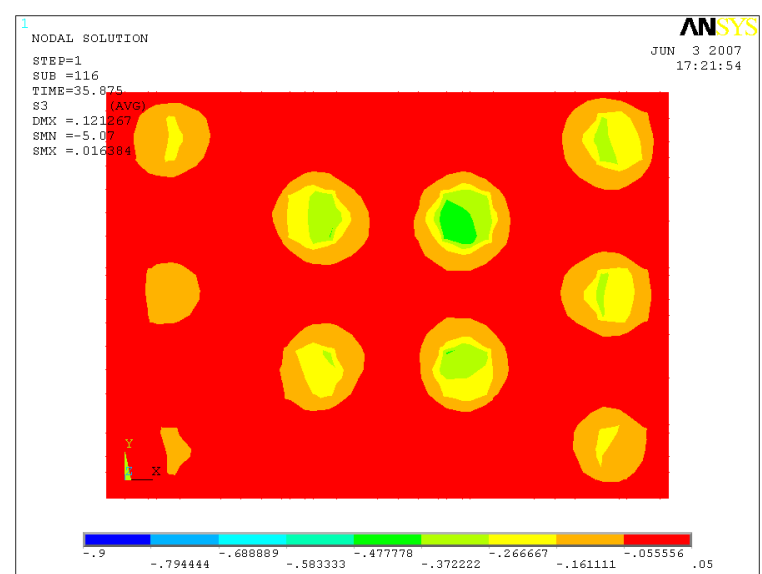

(a) $10 \mathrm{~cm}$

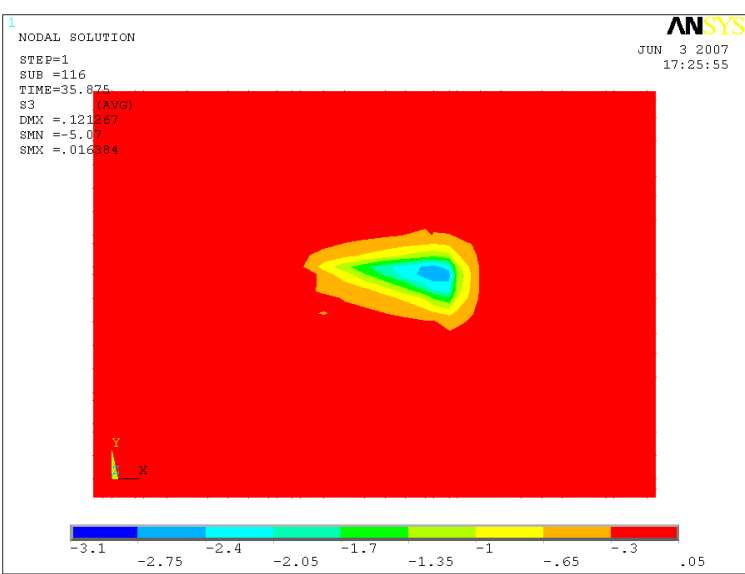

(c) $110 \mathrm{~cm}$

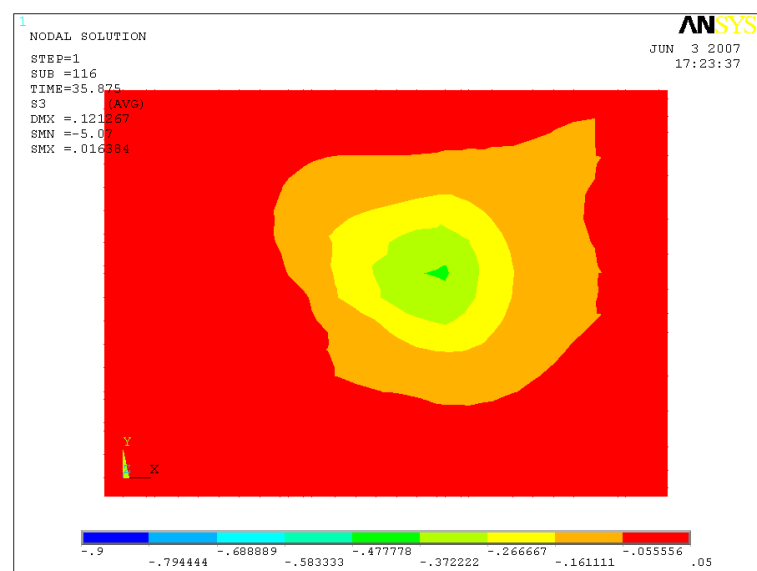

(b) $60 \mathrm{~cm}$

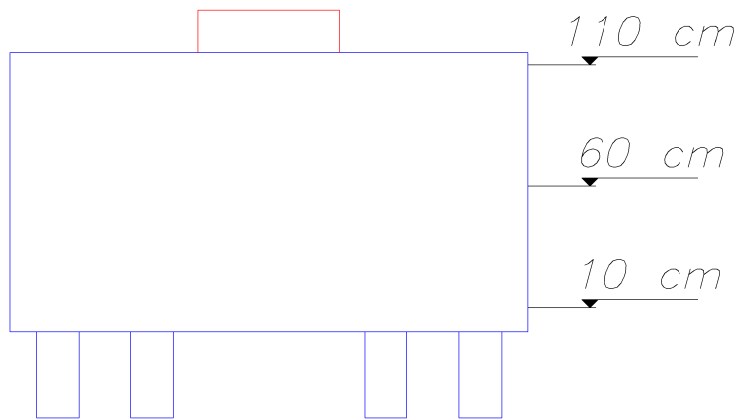

(d) alturas

Figura 6.47: Campos de tensão de compressão - bloco com altura de $115 \mathrm{~cm}$ para solo indeformável - valores em $\mathrm{kN} / \mathrm{cm}^{2}$

Conforme a figura 6.47 pode se observar que nesse caso as tensões de compressão junto a cabeça da estaca (a) são menores quando comparado com as tensões para bloco com altura de $80 \mathrm{~cm}$ com estacas apoiadas em solo indeformável. Para este caso as tensões de compressão na cabeça da estaca chegaram em 4,78 MPa. Na região próxima ao pilar, item (c), a tensão foi de 27,5 MPa. 
A figura 6.48 apresenta as tensões principais de compressão na seção transversal do bloco ao longo de sua altura para bloco com altura de $200 \mathrm{~cm}$, e vinculação das estacas para solo do tipo deformável.

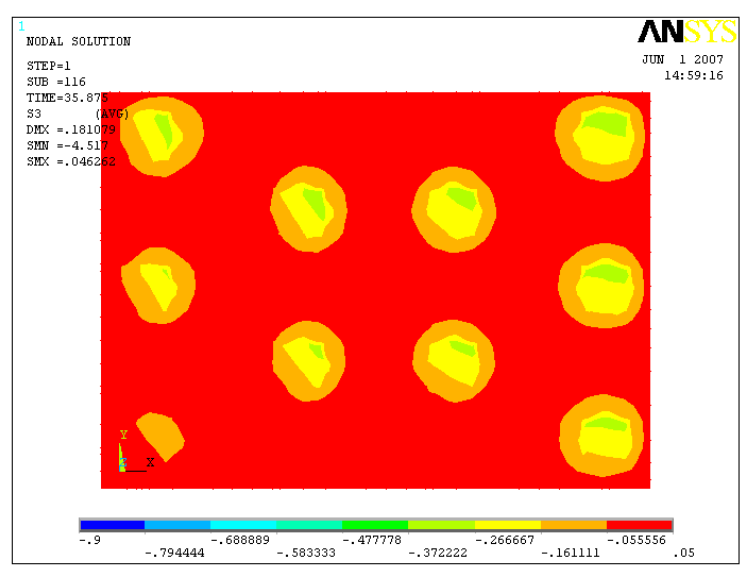

(a) $10 \mathrm{~cm}$

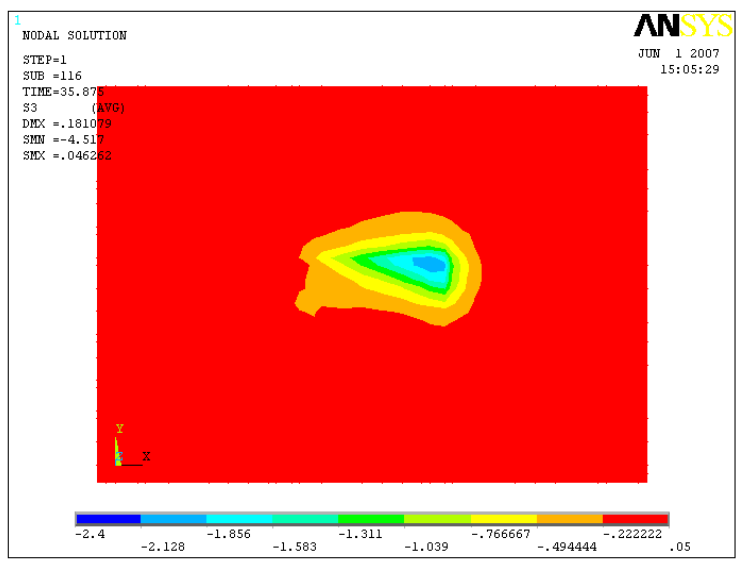

(c) $190 \mathrm{~cm}$

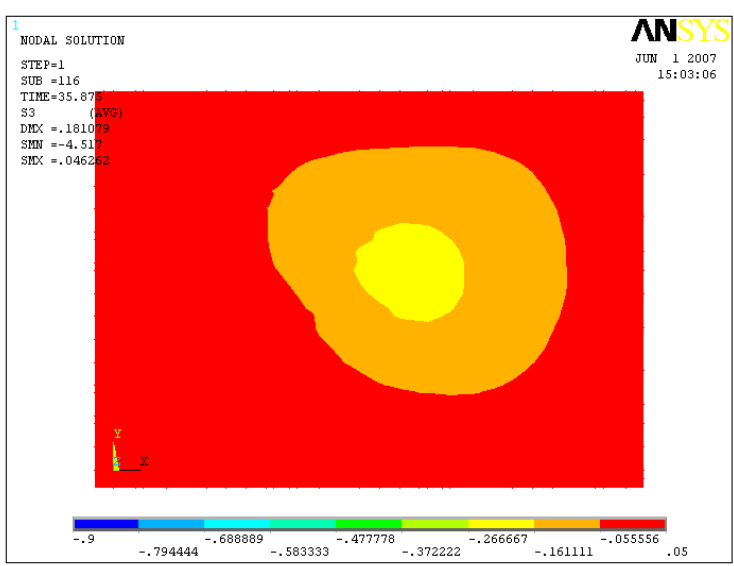

(b) $120 \mathrm{~cm}$

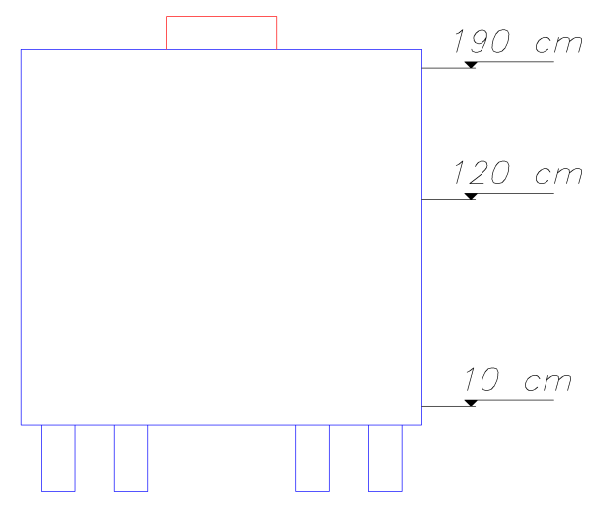

(d) alturas

Figura 6.48: Campos de tensão de compressão - bloco com altura de $200 \mathrm{~cm}$ para solo deformável - valores em $\mathrm{kN} / \mathrm{cm}^{2}$

Conforme a figura 6.48 pode se observar que nesse caso as tensões de compressão junto a cabeça da estaca (a) são menores quando comparado com as tensões para bloco com alturas de $80 \mathrm{~cm}$ e $115 \mathrm{~cm}$ com estacas apoiadas em solo deformável. Para este caso as tensões de compressão na cabeça da estaca chegaram em 3,72 MPa. Na região próxima ao pilar, item (c), a tensão foi de 21,28 MPa. 
A figura 6.49 apresenta as tensões principais de compressão na seção transversal do bloco ao longo de sua altura para bloco com altura de $200 \mathrm{~cm}$, e vinculação das estacas para solo do tipo indeformável.

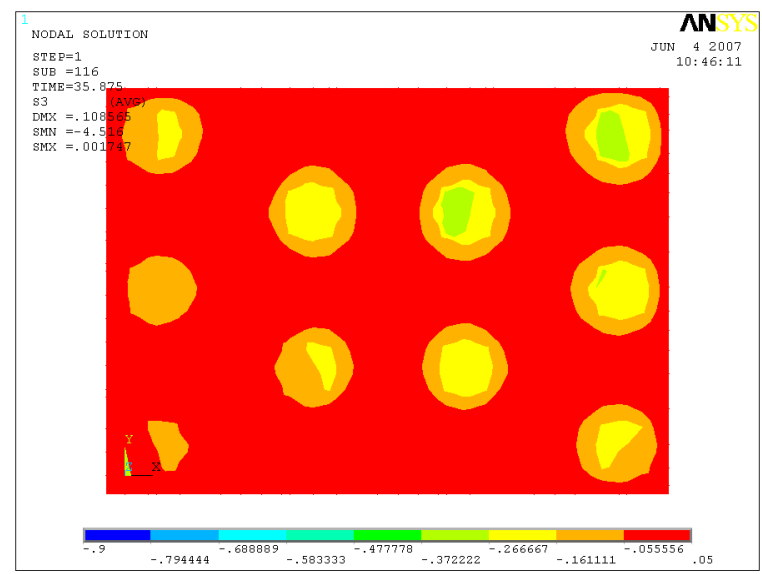

(a) $10 \mathrm{~cm}$

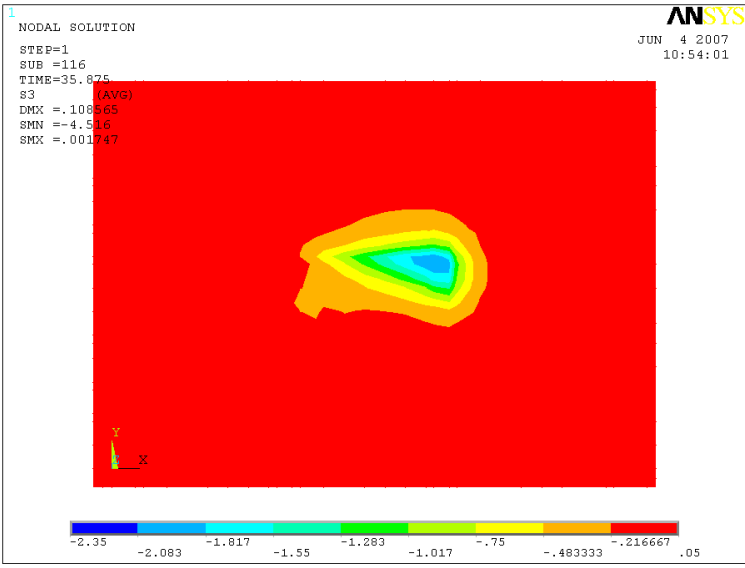

(c) $190 \mathrm{~cm}$

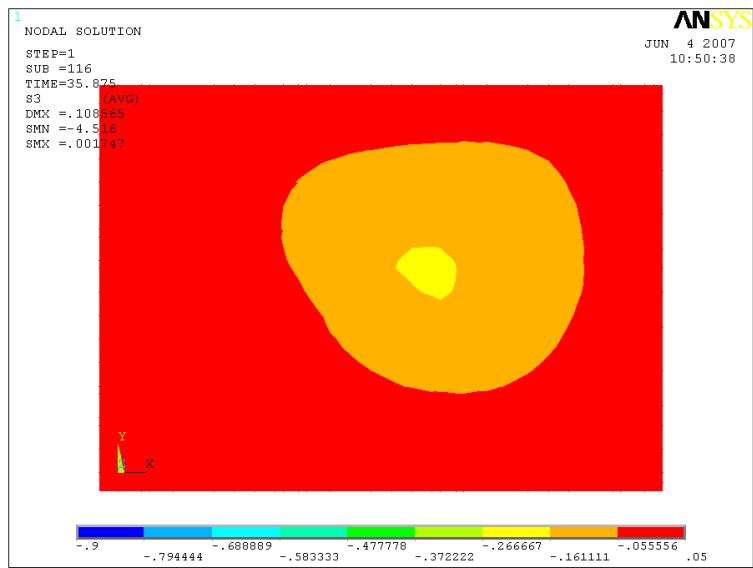

(b) $110 \mathrm{~cm}$

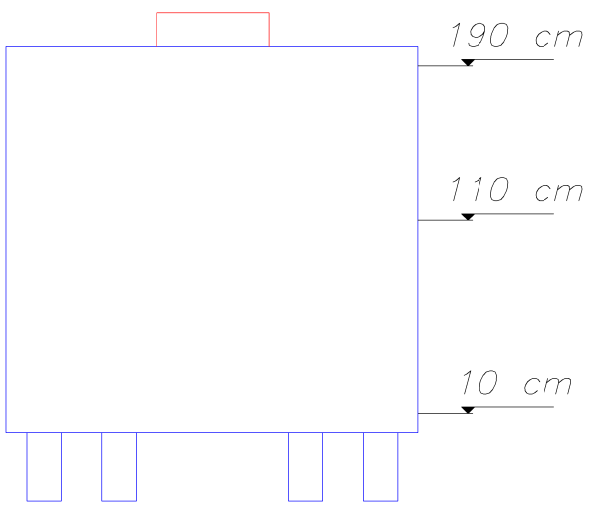

(d) alturas

Figura 6.49: Campos de tensão de compressão - bloco com altura de $200 \mathrm{~cm}$ para solo indeformável - valores em $\mathrm{kN} / \mathrm{cm}^{2}$

Conforme a figura 6.49 pode se observar que nesse caso as tensões de compressão junto a cabeça da estaca (a) são menores quando comparado com as tensões para bloco com altura de $80 \mathrm{~cm}$ e $115 \mathrm{~cm}$ com estacas apoiadas em solo deformável. Para este caso as tensões de compressão na cabeça da estaca chegaram em 3,72 MPa. Na região próxima ao pilar, item (c), a tensão foi de 20,8 MPa. 


\subsection{Caso 4}

Neste item é analisada apenas o Caso 4. Para este Caso são consideradas a força centrada e os momentos fletores nas duas direções. Para o Caso 4 foram aumentados os valores de momentos fletores comparados ao Caso 2 e 3. Neste Caso espera-se que uma das estacas (estaca de número 3) tenha tração.

Para este caso não houve a variação da rigidez com relação a resistência característica à compressão do concreto $\left(f_{c k}\right)$.

Na tabela 6.10 são apresentadas as reações nas estacas para os dois tipos de vinculação das estacas para bloco com altura de $80 \mathrm{~cm}$. Vale lembrar que o bloco com altura de $80 \mathrm{~cm}$ não satisfez a verificação quanto a resistência à força cortante, conforme o processo do CEB-FIP (1970).

Tabela 6.10: Reações nas estacas para o Caso 4 em bloco com altura de $80 \mathrm{~cm}$

\begin{tabular}{ccccccc}
\hline \multicolumn{7}{c}{ Caso $4 ; \mathrm{h}=80 \mathrm{~cm} ; 25 \mathrm{MPa}$} \\
\hline & Modelo & Modelo & \multicolumn{5}{c}{ Indeformável } \\
\hline & Numérico & Analítico & \multicolumn{5}{c}{ Nodelo } & Modelo \\
Estacas & $F_{k, n}(\mathrm{kN})$ & $F_{k, a}(\mathrm{kN})$ & $F_{k, n} / F_{k, a}$ & $F_{k, n}(\mathrm{kN})$ & $F_{k, a}(\mathrm{kN})$ & $F_{k, n} / F_{k, a}$ \\
\hline 1 & 302,9 & 294,8 & 1,03 & 91,3 & 294,8 & 0,31 \\
2 & 101,2 & 144,8 & 0,70 & $-22,4$ & 144,8 & $-0,15$ \\
3 & $-104,5$ & $-5,2$ & 20,22 & $-22,0$ & $-5,2$ & 4,25 \\
4 & 395,6 & 323,3 & 1,22 & 537,2 & 323,3 & 1,66 \\
5 & 272,6 & 173,3 & 1,57 & 69,8 & 173,3 & 0,40 \\
6 & 448,7 & 426,7 & 1,05 & 1056,8 & 426,7 & 2,48 \\
7 & 385,6 & 276,7 & 1,39 & 592,8 & 276,7 & 2,14 \\
8 & 449,6 & 605,2 & 0,74 & 253,0 & 605,2 & 0,42 \\
9 & 416,8 & 455,2 & 0,92 & 342,2 & 455,2 & 0,75 \\
10 & 331,2 & 305,2 & 1,09 & 101,0 & 305,2 & 0,33 \\
\hline
\end{tabular}

Como pode ser visto na tabela 6.10 percebe-se que o comportamento estrutural do bloco é dependente do tipo de vinculação das estacas e o tipo de ação aplicada. Esse comportamento já vinha ocorrendo com outros blocos. Os resultados mostram que não houve uma uniformização na distribuição das reações nas estacas para os dois tipo de solo adotado. Quando se compara os mesmos resultados da relação entre o modelo numérico e o modelo analítico os resultados para blocos com estacas apoiadas em solo do tipo deformável é bem maior. Conforme ocorreu nos outros Casos, quando o solo é do tipo indeformável percebe-se que há uma grande variação dos valores. Percebe-se também que neste Caso o comportamento estrutural do bloco é diferente dos anteriores, pois as estacas na região central não foram as mais solicitadas. 
Para solo do tipo deformável a diferença do modelo numérico para o modelo analítico chegou a 57\% para a estaca de número 5. Para solo do tipo indeformável a diferença foi bem maior chegando a a $148 \%$ para estaca de número 6 .

Nos dois casos analisados esperava-se que a estaca de número 8 fosse a mais solicitada, porém para bloco com estaca apoiada em solo do tipo indeformável a estaca de número 6 foi a mais solicitada. E para bloco com estacas apoiadas em solo do tipo deformável a diferença foi muito pequena para as estacas de número 6 e 8 .

Na tabela 6.11 são apresentadas as reações nas estacas para os dois tipos de vinculação das estacas para bloco com altura de $115 \mathrm{~cm}$. Vale lembrar que o bloco com altura de $115 \mathrm{~cm}$ satisfez a verificação quanto a resistência à força cortante, conforme o processo do CEB-FIP (1970).

Tabela 6.11: Reações nas estacas para o Caso 4 em bloco com altura de $115 \mathrm{~cm}$

\begin{tabular}{ccccccc}
\hline \multicolumn{7}{c}{ Caso $4 ; \mathrm{h}=115 \mathrm{~cm} ; 25 \mathrm{MPa}$} \\
\hline & Modelo & Modelo & \multicolumn{3}{c}{ Indeformável } \\
\hline & Numérico & Analítico & Modelo & Modelo \\
Estacas & $F_{k, n}(\mathrm{kN})$ & $F_{k, a}(\mathrm{kN})$ & $F_{k, n} / F_{k, a}$ & $F_{k, n}(\mathrm{kN})$ & $F_{k, a}(\mathrm{kN})$ & $F_{k, n} / F_{k, a}$ \\
\hline 1 & 315,1 & 294,8 & 1,07 & 180,3 & 294,8 & 0,61 \\
2 & 137,3 & 144,8 & 0,95 & 53,8 & 144,8 & 0,37 \\
3 & $-89,5$ & $-5,2$ & 17,31 & $-7,5$ & $-5,2$ & 1,45 \\
4 & 365,9 & 323,3 & 1,13 & 434,8 & 323,3 & 1,35 \\
5 & 262,6 & 173,3 & 1,52 & 156,5 & 173,3 & 0,90 \\
6 & 421,0 & 426,7 & 0,99 & 723,7 & 426,7 & 1,70 \\
7 & 354,7 & 276,7 & 1,28 & 427,0 & 276,7 & 1,54 \\
8 & 454,4 & 605,2 & 0,75 & 446,8 & 605,2 & 0,74 \\
9 & 419,5 & 455,2 & 0,92 & 383,3 & 455,2 & 0,84 \\
10 & 358,3 & 305,2 & 1,17 & 201,0 & 305,2 & 0,66 \\
\hline
\end{tabular}

Percebe-se que o comportamento estrutural do bloco com altura de $115 \mathrm{~cm}$ se assemelha a bloco com altura de $80 \mathrm{~cm}$. A relação entre o modelo numérico e o modelo analítico entre os dois blocos mantiveram quase que as mesmas ordens de grandezas, sendo um pouco mais distribuída para bloco com altura de $115 \mathrm{~cm}$. Com o aumento da rigidez do bloco, e para vinculação das estacas do bloco com o solo do tipo deformável, a distribuição das reações nas estacas foram um pouco mais uniforme comparado com os mesmos resultados para bloco com altura de $80 \mathrm{~cm}$. Com o solo do tipo indeformável ainda há uma tendência das forças serem maiores nas estacas centrais, mais próxima ao pilar, porém houve uma maior uniformização quando comparado a bloco com altura de $80 \mathrm{~cm}$.

Para solo do tipo deformável a diferença do modelo numérico para o modelo 
analítico chegou a 52\% para estacas de número 5. Para solo do tipo indeformável a diferença chegou a $70 \%$ para estacas de número 6 .

Conforme os resultados analíticos esperava-se, nos dois casos, que a estaca de número 8 fosse a mais solicitada. Para bloco com estacas apoiadas em solo do tipo deformável esse resultado foi confirmado, porém para bloco com estacas apoiadas em solo do tipo indeformável a estaca de número 6 foi a mais solicitada, conforme ocorreu para o caso 2 e 3 .

Na tabela 6.12 são apresentadas as reações nas estacas para os dois tipos de vinculação das estacas para bloco com altura de $200 \mathrm{~cm}$. Vale lembrar que o bloco com altura de $200 \mathrm{~cm}$ satisfez a verificação quanto a resistência à força cortante, conforme o processo do CEB-FIP (1970).

Tabela 6.12: Reações nas estacas para o Caso 4 em bloco com altura de $200 \mathrm{~cm}$

\begin{tabular}{ccccccc}
\hline \multicolumn{7}{c}{ Caso $4 ; \mathrm{h}=200 \mathrm{~cm} ; 25 \mathrm{MPa}$} \\
\hline \multicolumn{5}{c}{ deformável } & \multicolumn{5}{c}{ Indeformável } \\
\hline & Modelo & Modelo & \multicolumn{5}{c}{ Modelo } & Modelo \\
Estacas & $F_{k, n}(\mathrm{kN})$ & $F_{k, a}(\mathrm{kN})$ & $F_{k, n} / F_{k, a}$ & $F_{k, n}(\mathrm{kN})$ & $F_{k, a}(\mathrm{kN})$ & $F_{k, n} / F_{k, a}$ \\
\hline 1 & 317,7 & 294,8 & 1,08 & 252,0 & 294,8 & 0,85 \\
2 & 150,8 & 144,8 & 1,04 & 116,7 & 144,8 & 0,81 \\
3 & $-78,3$ & $-5,2$ & 15,15 & 10,5 & $-5,2$ & $-2,04$ \\
4 & 353,1 & 323,3 & 1,09 & 352,9 & 323,3 & 1,09 \\
5 & 259,7 & 173,3 & 1,50 & 186,3 & 173,3 & 1,08 \\
6 & 407,7 & 426,7 & 0,96 & 492,8 & 426,7 & 1,15 \\
7 & 345,5 & 276,7 & 1,25 & 316,6 & 276,7 & 1,14 \\
8 & 454,3 & 605,2 & 0,75 & 560,9 & 605,2 & 0,93 \\
9 & 420,5 & 455,2 & 0,92 & 433,5 & 455,2 & 0,95 \\
10 & 368,5 & 305,2 & 1,21 & 277,5 & 305,2 & 0,91 \\
\hline
\end{tabular}

Como pode ser visto na tabela 6.12 o comportamento estrutural do bloco tem influência pelo tipo de vinculação das estacas e também pela sua rigidez. O comportamento estrutural do bloco com altura de $200 \mathrm{~cm}$ se assemelha a bloco com altura de $80 \mathrm{~cm}$ e 115 cm. A distribuição na reação das estacas foram mais uniforme para os dois solos quando compara com os mesmos resultados com blocos de altura de $80 \mathrm{~cm}$ e $115 \mathrm{~cm}$. Percebe-se que a estaca de número 3 para solo do tipo deformável foi solicitada por uma reação bem maior de tração do que se esperava conforme valores analíticos.

Para solo do tipo deformável a diferença do modelo numérico para o modelo analítico chegou a 50\% para estacas de número 5. Para solo do tipo indeformável a diferença chegou a $15 \%$ para estacas de número 7 .

Para os dois casos analisados a estaca de número 8 foi a mais solicitada. Esse 
resultado já era esperado conforme os valores analíticos.

Analisando as três tabelas apresentadas percebe-se que o comportamento estrutural do bloco é fortemente influenciado pelo tipo de vinculação das estacas e pela rigidez do bloco. Para todos os blocos analisados esperava-se que a estacas de número 8 fosse a mais solicitada, porém isso apenas foi confirmado em alguns bloco, nos outros casos a estaca de número 6 é a que foi a mais solicitada. Esse comportamento já foi verificado em análises com outros tipos de Casos. Para esse caso com o aumento da rigidez do bloco as distribuições das reações nas estacas demonstraram um comportamento com tendência de uniformização, assim como ocorreu com o Caso 1,2 e 3.

Para que fique mais claro são apresentadas nas figuras a seguir gráficos comparando os resultados para todas as estacas. A comparação é feita relacionando a altura do bloco versus a relação entre a força obtida numericamente e a força calculada analiticamente. Nos gráficos as linhas contínua representam estacas apoiadas em solo do tipo deformável e as linhas tracejada solo do tipo indeformável.

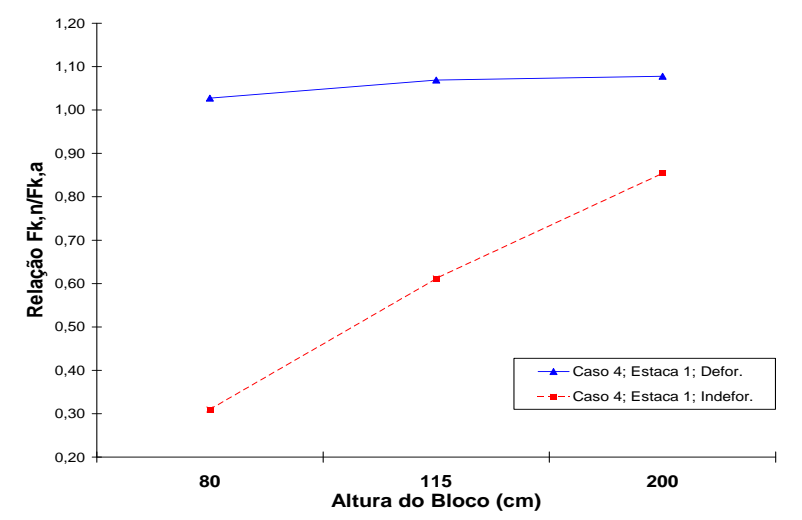

(a) estaca 1

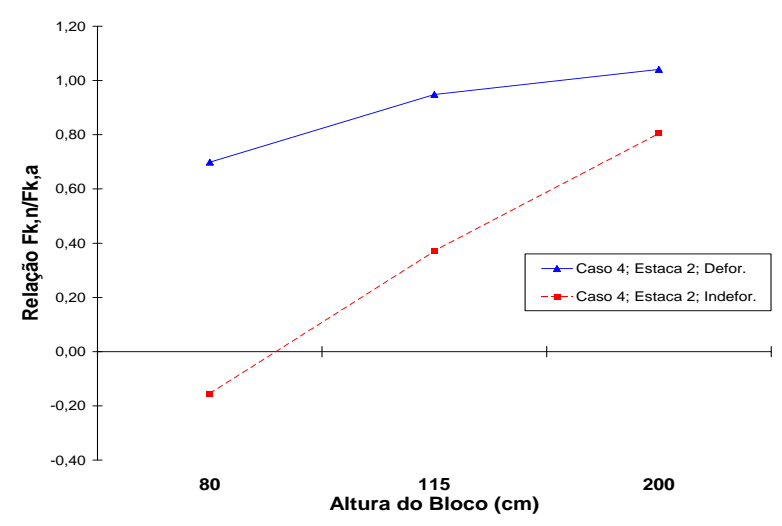

(b) estaca 2

Figura 6.50: Comparação entre as alturas para estacas 1 e 2 do Caso 4

Percebe-se na figura 6.50 que o comportamento das estacas de número 1 e 2 foi o mesmo, ou seja, com o aumento da altura do bloco essas estacas tendem a ser mais próximo do modelo analítico. Esse comportamento também ocorreu para o Caso 2 com as mesmas estacas. 


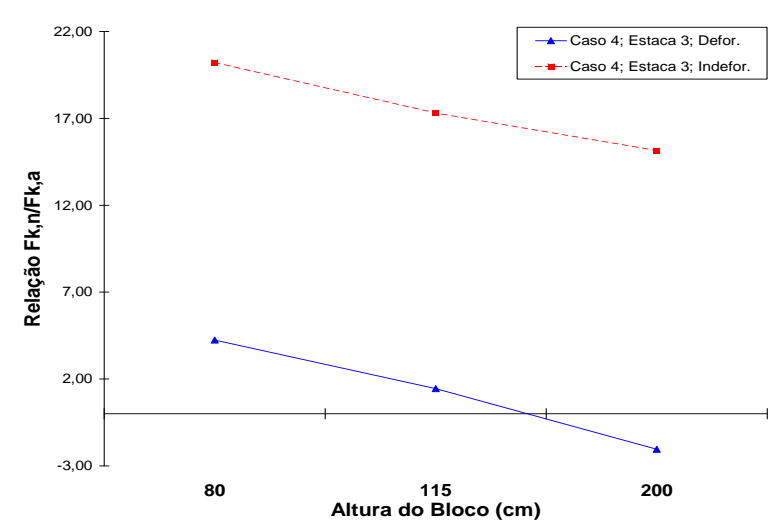

(a) estaca 3

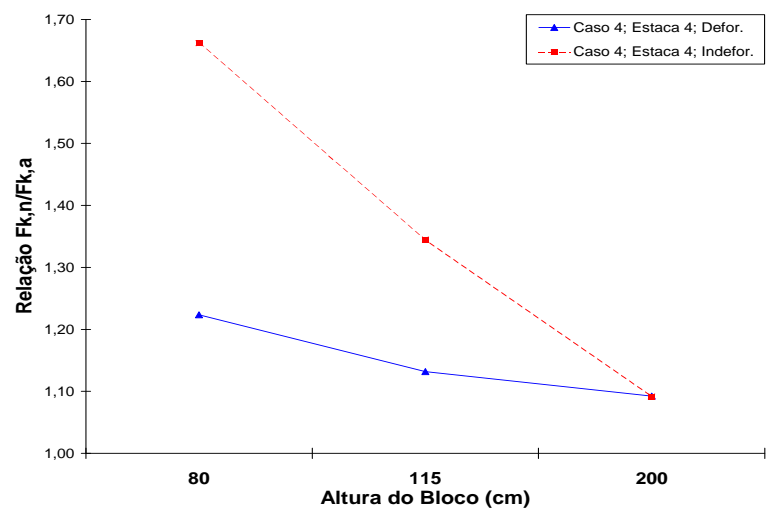

(b) estaca 4

Figura 6.51: Comparação entre as alturas para estacas 3 e 4 do Caso 4

Na figura 6.51 o gráfico da estaca de número 4 manteve o comportamento típico. No entanto, a estaca de número 3 teve um comportamento totalmente diferente do que havia ocorrendo com outros blocos.

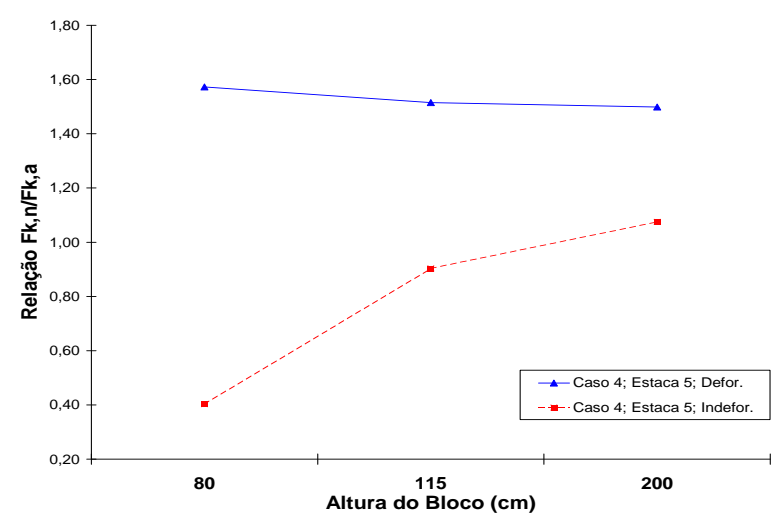

(a) estaca 5

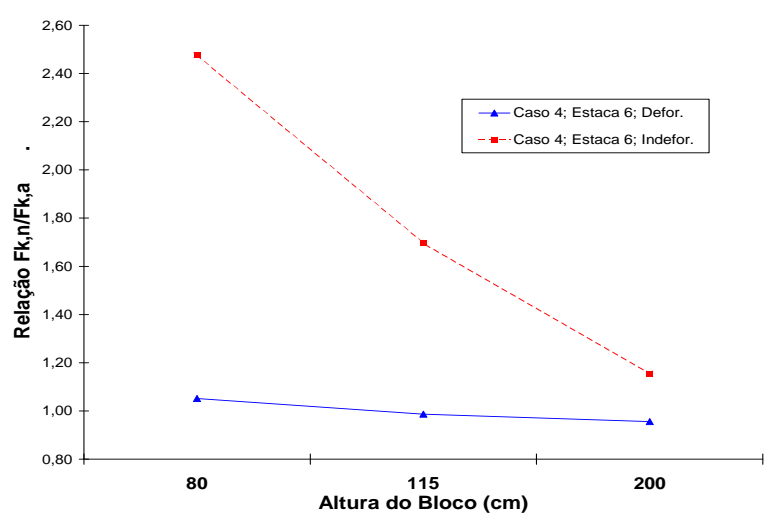

(b) estaca 6

Figura 6.52: Comparação entre as alturas para estacas 5 e 6 do Caso 4

Na figura 6.52 a estaca de número 6 manteve o comportamento típico mostrado anteriormente. No entanto, a estaca de número 5 teve um comportamento diferente das anteriores. 


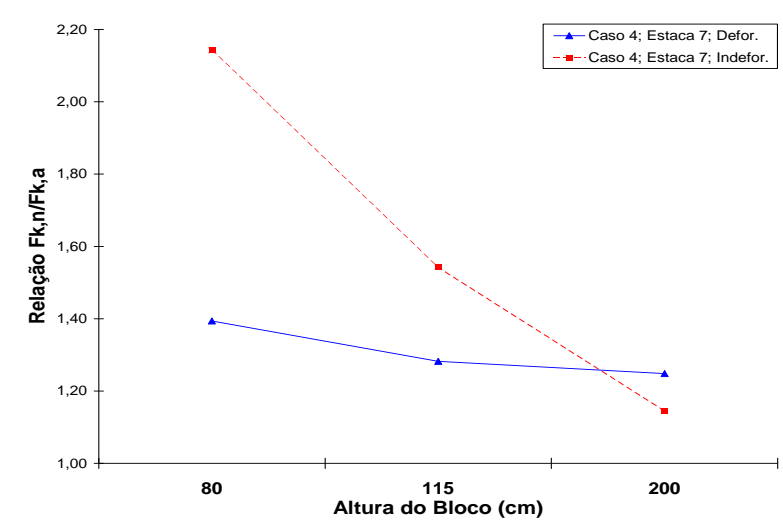

(a) estaca 7

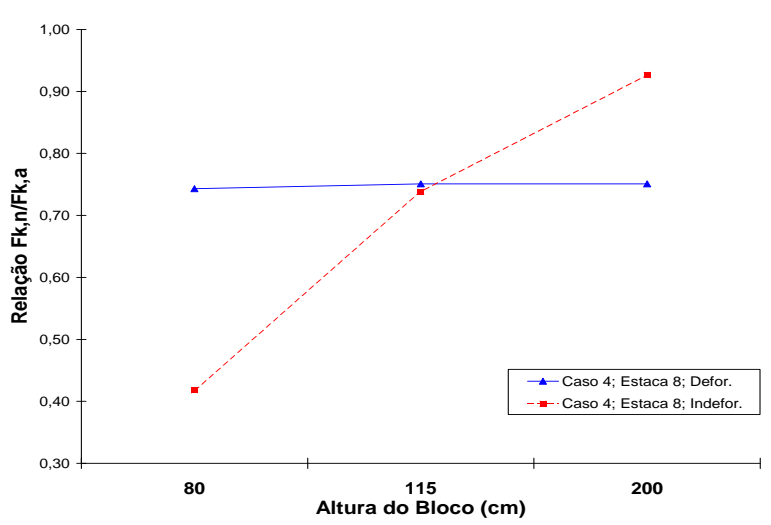

(b) estaca 8

Figura 6.53: Comparação entre as alturas para estacas 7 e 8 do Caso 4

Na figura 6.53 a estaca de número 7 manteve o comportamento típico mostrado anteriormente, porém com uma inversão para bloco com altura de $200 \mathrm{~cm}$, esse comportamento ocorreu para o Caso 3, mas sem a inversão. Para a estaca de número 8 o comportamento foi o mesmo que o Caso 3, no entanto, apenas aumentou a diferença.

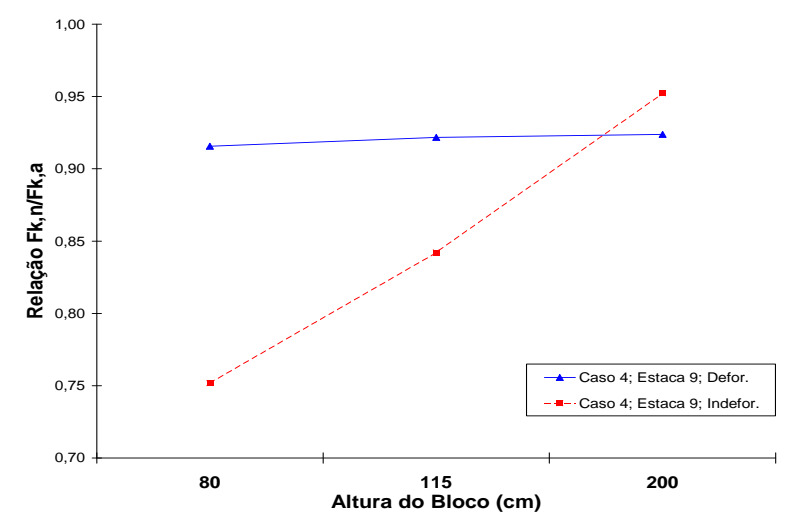

(a) estaca 9

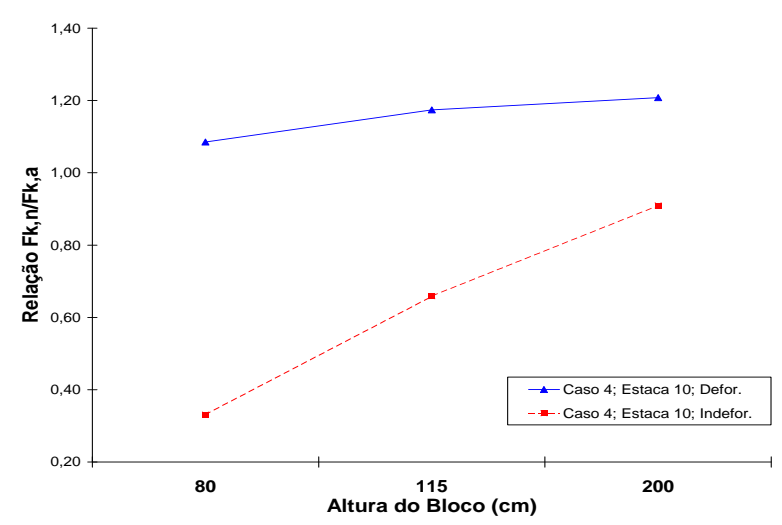

(b) estaca 10

Figura 6.54: Comparação entre as alturas para estacas 9 e 10 do Caso 4

Na figura 6.54 percebe-se que o comportamento foi o mesmo, para os três Casos. Apenas a estaca de número 9 que houve uma inversão para blocos com altura de $200 \mathrm{~cm}$. 
A seguir são apresentadas figuras que representam a relação entre as reações nas estacas versus o acréscimo de ações aplicado ao bloco simulado numericamente. Primeiramente são apresentados gráficos de blocos com estacas apoiadas em solo do tipo deformável e em seguida para solo do tipo indeformável.

Na figura 6.55 são apresentadas as relações entre as reações nas estacas para bloco com altura de $80 \mathrm{~cm}$ e estacas apoiadas em solo deformável.

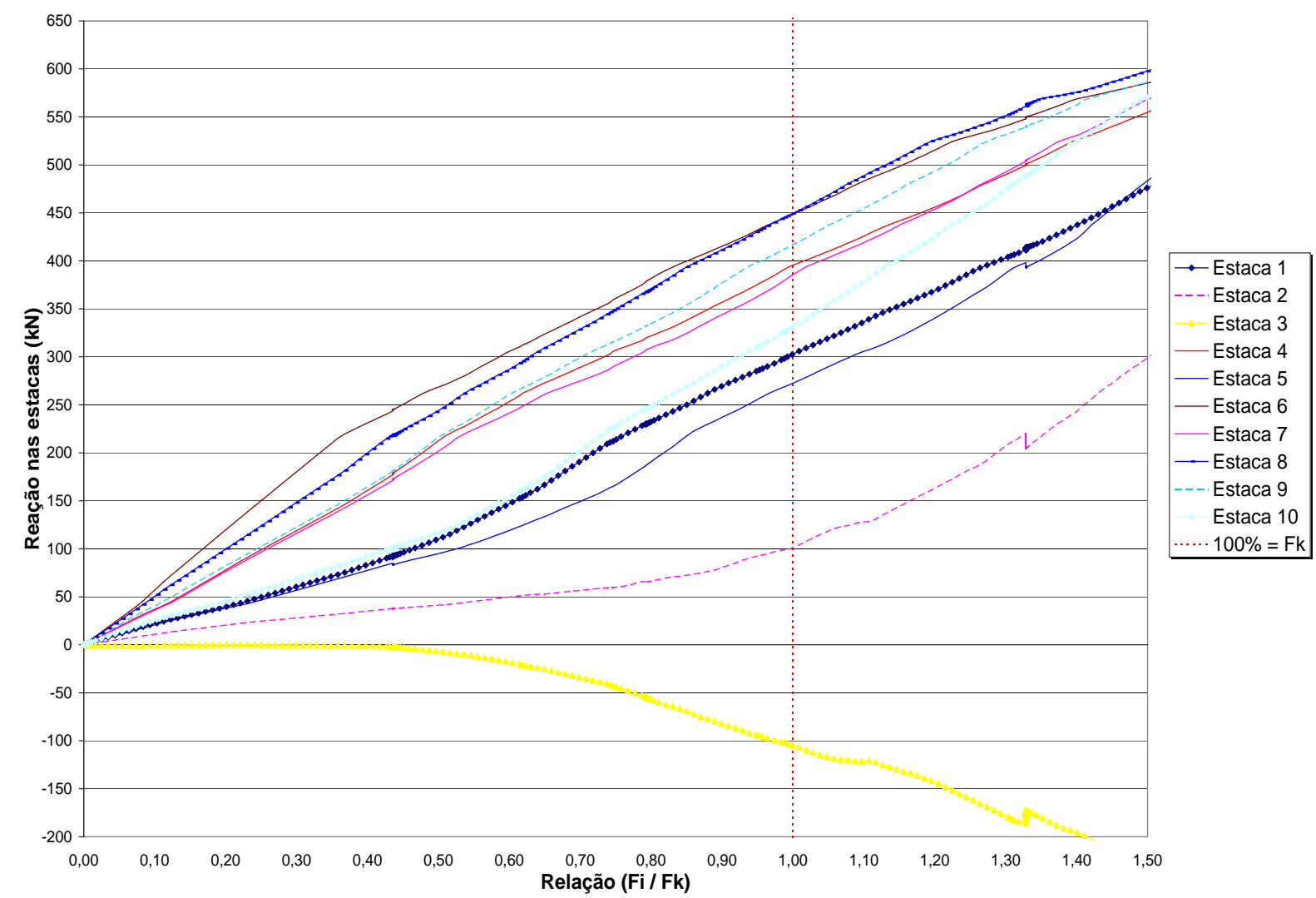

Figura 6.55: Reações nas estacas ao longo da aplicação das ações para bloco com altura de $80 \mathrm{~cm}$ e solo deformável

Por meio da figura 6.55 percebe-se que as reações na estaca de número 6 inicialmente tem um comportamento de bloco com estacas apoiadas em solo indeformável, e próxima da relação $F_{i} / F_{k}$ igual a 0,35 há uma mudança no seu comportamento. Para este caso a estacas mais solicitada na fase inicial foi a de número 6, e quando a relação $F_{i} / F_{k}$ foi igual a unidade a estaca de número 8 tinha praticamente a mesma reação com 448,7 kN e 449,6 kN respectivamente. Para a estaca de número 6 a relação foi $5 \%$ acima do valor calculado analiticamente e para a estaca de número 8,26\% abaixo. 
Na figura 6.56 são apresentadas as relações entre as reações nas estacas para bloco com altura de $115 \mathrm{~cm}$ e estacas apoiadas em solo deformável.

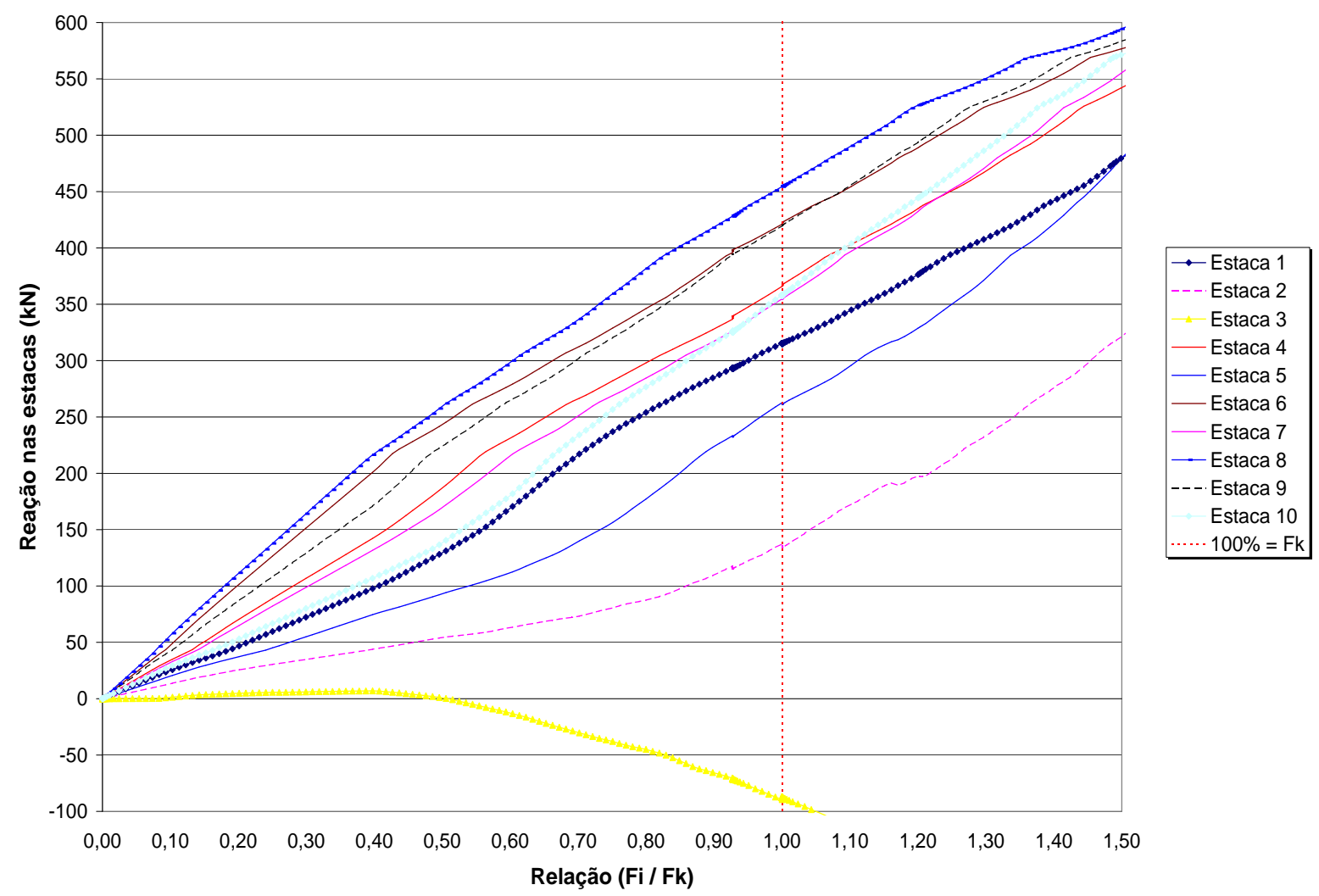

Figura 6.56: Reações nas estacas ao longo da aplicação das ações para bloco com altura de $115 \mathrm{~cm}$ e solo deformável

Por meio da figura 6.56 percebe-se que o comportamento das reações nas estacas foram semelhante ao bloco com altura de $80 \mathrm{~cm}$. Ao longo de toda a análise a estaca de número 8 foi a mais solicitada e atingiu o valor de reação igual a $454,4 \mathrm{kN}$ para a relação $F_{i} / F_{k}$ igual a unidade. Para esta relação a estaca de número 8 está $25 \%$ acima do valor calculado analiticamente. A estaca de número 3 onde se esperava que houvesse tração de $5,2 \mathrm{kN}$ chegou a atingir $89,5 \mathrm{kN}$, muito acima do calculado. 
Na figura 6.57 são apresentadas as relações entre as reações nas estacas para bloco com altura de $200 \mathrm{~cm}$ e estacas apoiadas em solo deformável.

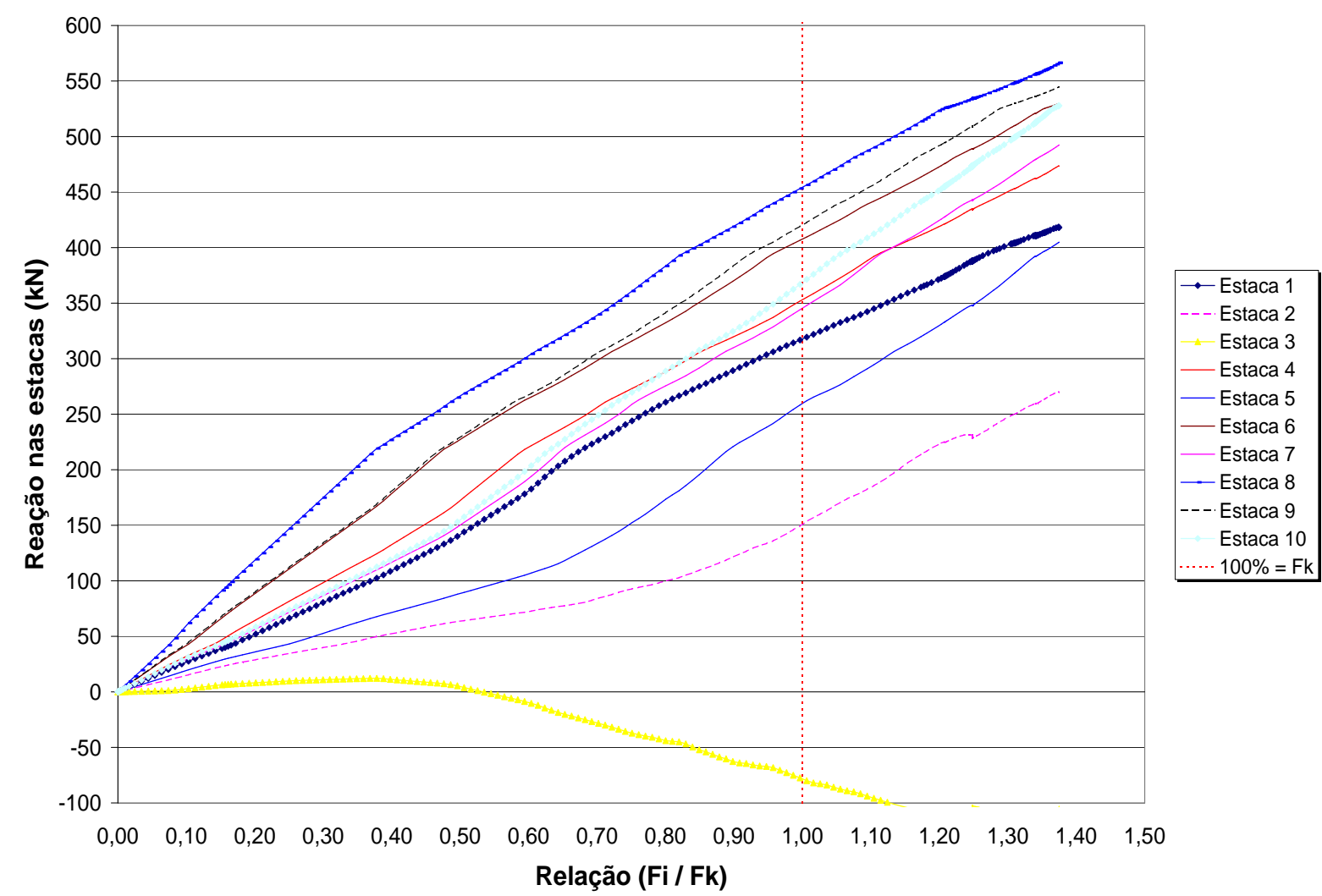

Figura 6.57: Reações nas estacas ao longo da aplicação das ações para bloco com altura de $200 \mathrm{~cm}$ e solo deformável

Na figura 6.57 percebe-se que o comportamento das reações nas estacas mantevese o mesmo para bloco com altura de $80 \mathrm{~cm}$ e $115 \mathrm{~cm}$. Para este caso a estaca que mais foi solicitada desde o inicio da aplicação das forças foi a de número 8. Para a relação $F_{i} / F_{k}$ igual a unidade a estaca ficou $25 \%$ abaixo do valor calculado analiticamente. Apenas a estaca de número 3 que teve um comportamento de compressão inicialmente, e próximo da relação $F_{i} / F_{k}$ de 0,4 teve seu comportamento alterado chegando a tração para relação igual a unidade. 
Na figura 6.58 são apresentadas as relações entre as reações nas estacas para bloco com altura de $80 \mathrm{~cm}$ e estacas apoiadas em solo indeformável.

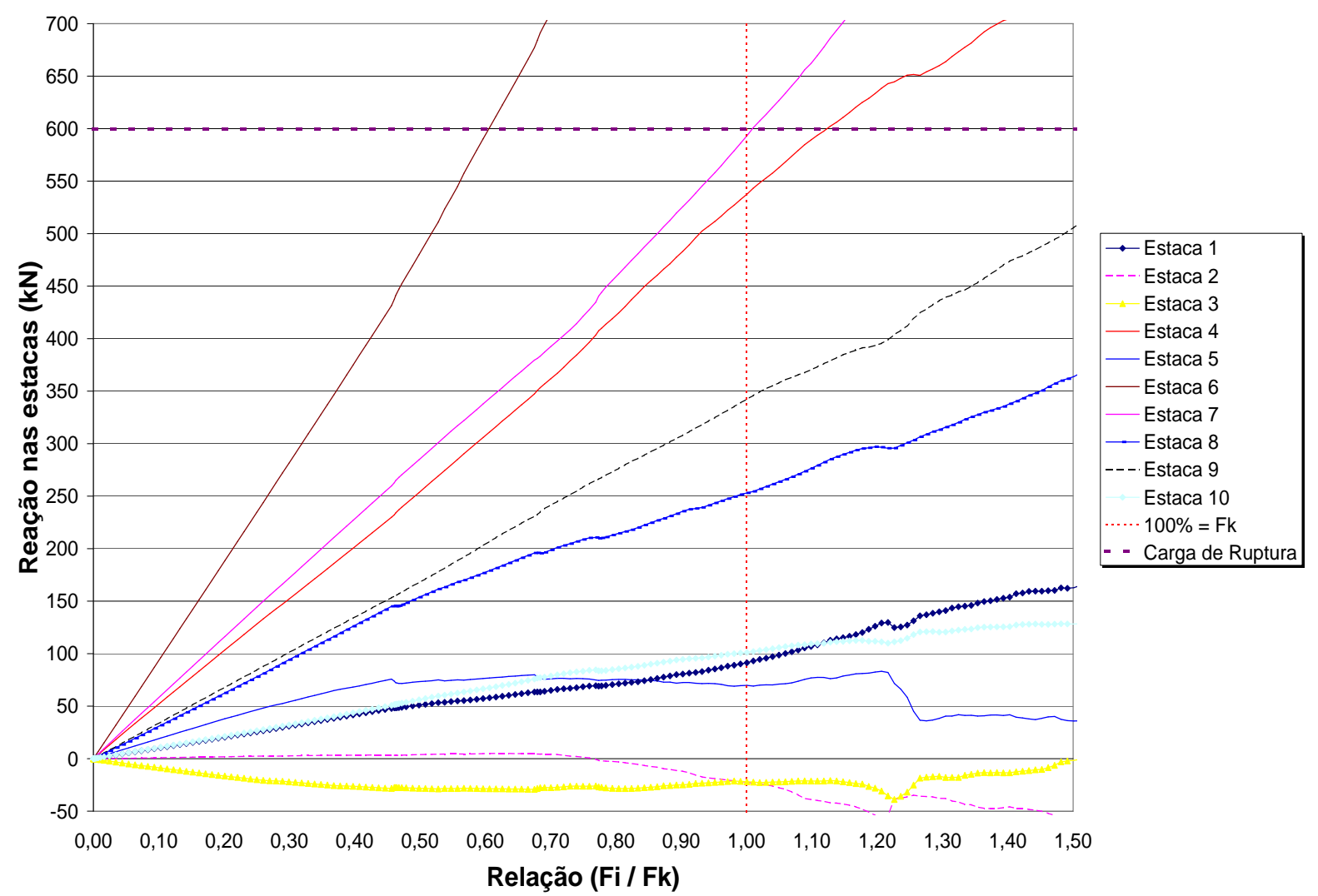

Figura 6.58: Reações nas estacas ao longo da aplicação das ações para bloco com altura de $80 \mathrm{~cm}$ e solo indeformável

Por meio da figura 6.58 percebe-se que o comportamento do bloco mudou muito quando comparado com o bloco sobre estacas apoiadas em solo deformável. Houve uma grande variabilidade nos valores das reações nas estacas. A estaca de número 6 foi a mais solicitada ao longo de toda a análise e atingiu o valor de $1056,8 \mathrm{kN}$ para relação $F_{i} / F_{k}$ igual a unidade, muito acima do valor de ruína da estaca que é de $600 \mathrm{kN}$, que ficou próxima da relação $F_{i} / F_{k}$ de 0,6 . Esse valor corresponde a $148 \%$ acima do valor calculado analiticamente. A estaca de número 3 foi tracionada ao longo de toda a análise. 
Na figura 6.59 são apresentadas as relações entre as reações nas estacas para bloco com altura de $115 \mathrm{~cm}$ e estacas apoiadas em solo indeformável.

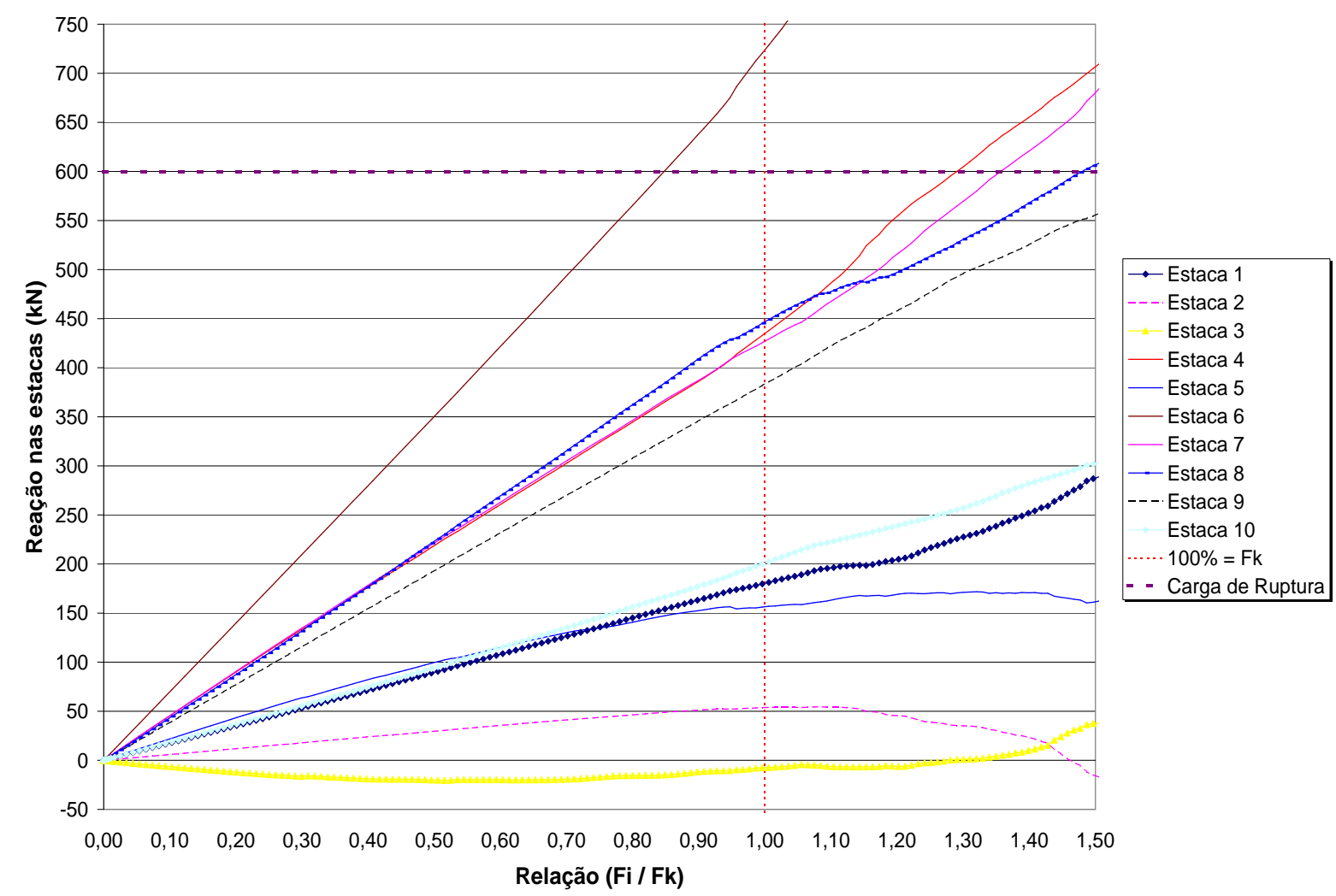

Figura 6.59: Reações nas estacas ao longo da aplicação das ações para bloco com altura de $115 \mathrm{~cm}$ e solo indeformável

Por meio da figura 6.59 percebe-se que o comportamento do bloco se assemelha ao do bloco com altura de $80 \mathrm{~cm}$ com mesmo tipo de solo. A variação nos valores das reações nas estacas, comparado a bloco dde altura menor, foi menor. A estaca de número 6 , novamente, foi a mais solicitada ao longo de toda a análise. Para a relação $F_{i} / F_{k}$ igual a unidade a reação na estaca de número 6 foi de 723,7 kN. Esse valor corresponde a 70\% acima do valor esperando analiticamente. Percebe-se também, que a estaca de número 3 foi tracionada boa parte na análise. 
Na figura 6.60 são apresentadas as relações entre as reações nas estacas para bloco com altura de $200 \mathrm{~cm}$ e estacas apoiadas em solo indeformável.

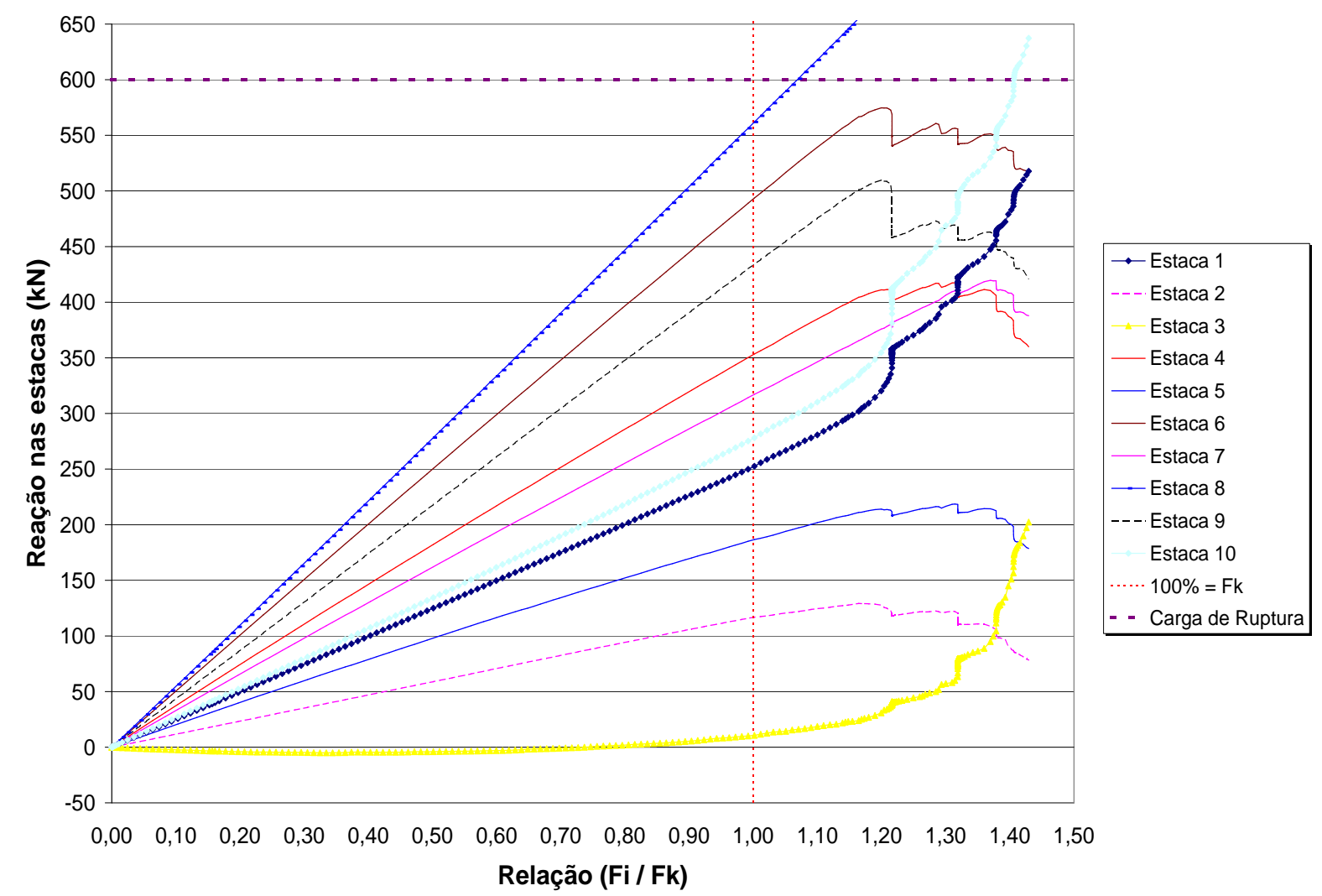

Figura 6.60: Reações nas estacas ao longo da aplicação das ações para bloco com altura de $200 \mathrm{~cm}$ e solo indeformável

Por meio da figura 6.60 percebe-se que o comportamento do bloco se assemelha ao do bloco com altura de $80 \mathrm{~cm}$ e $115 \mathrm{~cm}$, porém a estaca mais solicitada ao longo de toda a análise foi a de número 8. Esse comportamento é diferente das outras análises com blocos de altura $80 \mathrm{~cm}$ e $115 \mathrm{~cm}$ onde a estaca de número 6 foi a mais solicitada. Para a relação $F_{i} / F_{k}$ igual a unidade a estaca de número 8 foi solicitada por $560,9 \mathrm{kN}$, ficando $7 \%$ abaixo do valor esperando analiticamente. 
Serão apresentadas 6 figuras que mostram as tensões principais de compressão na seção transversal do bloco ao longo de sua altura.

A figura 6.61 apresenta as tensões principais de compressão na seção transversal do bloco ao longo de sua altura para bloco com altura de $80 \mathrm{~cm}$, e vinculação das estacas para solo do tipo deformável.

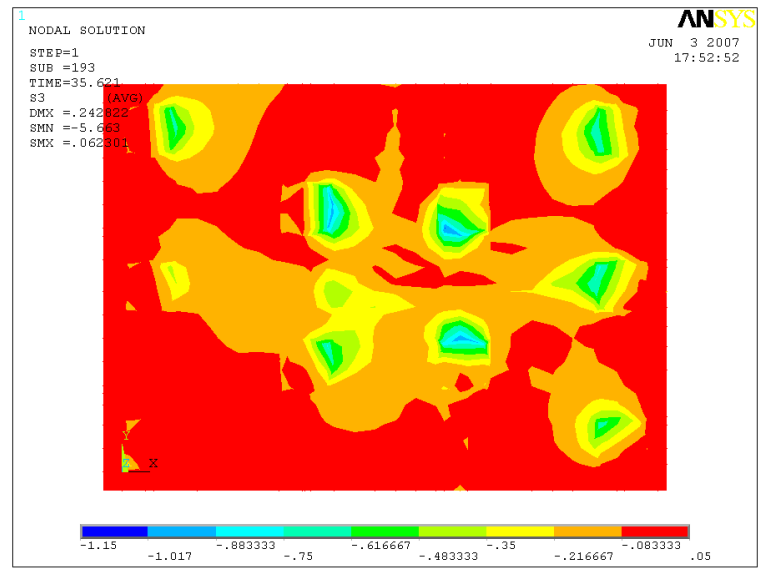

(a) $10 \mathrm{~cm}$

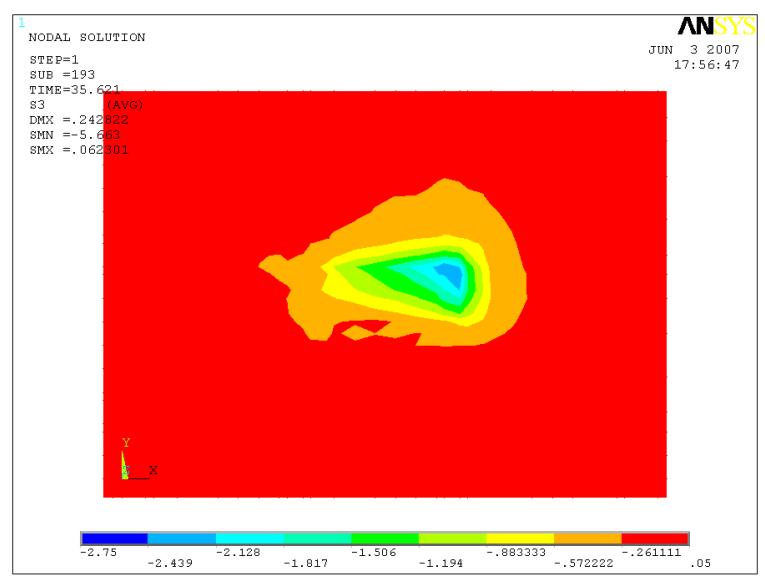

(c) $70 \mathrm{~cm}$

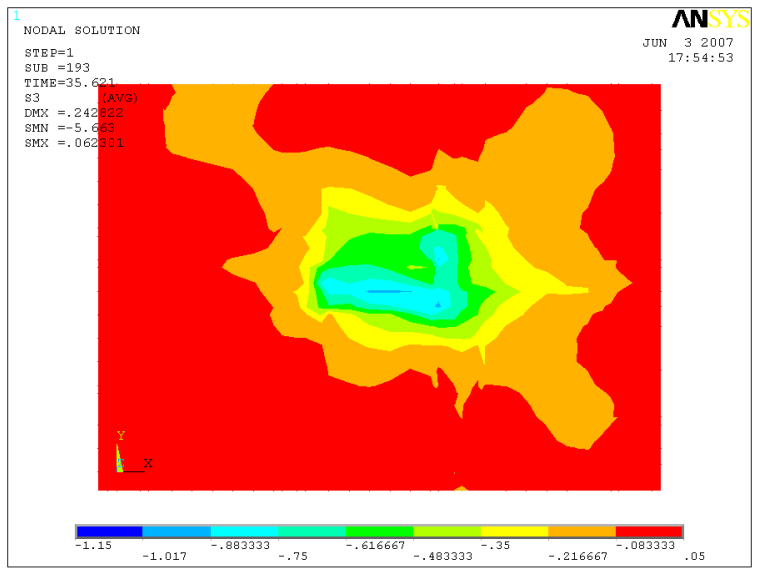

(b) $40 \mathrm{~cm}$

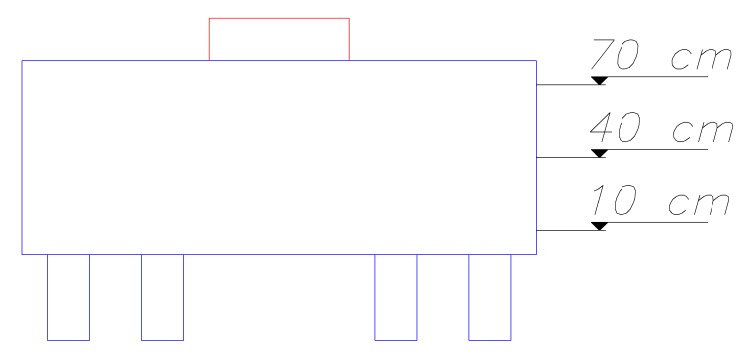

(d) alturas

Figura 6.61: Campos de tensão de compressão - bloco com altura de $80 \mathrm{~cm}$ para solo deformável - valores em $\mathrm{kN} / \mathrm{cm}^{2}$

Por meio da figura 6.61 pode se observar: as tensões junto a cabeça da estaca para uma altura de $10 \mathrm{~cm}$ (a); tensões no bloco a meia altura (b); e tensões próxima ao pilar (c). Percebe-se que nesse caso as tensões junto a cabeça da estaca (a) são maiores nas estacas próxima da estaca de número 6 e 8. A tensão nessa região atingiu 10,17 MPa. Na região próxima ao pilar, item (c), a tensão foi de 24,39 MPa. 
A figura 6.62 apresenta as tensões principais de compressão na seção transversal do bloco ao longo de sua altura para bloco com altura de $80 \mathrm{~cm}$, e vinculação das estacas para solo do tipo indeformável.

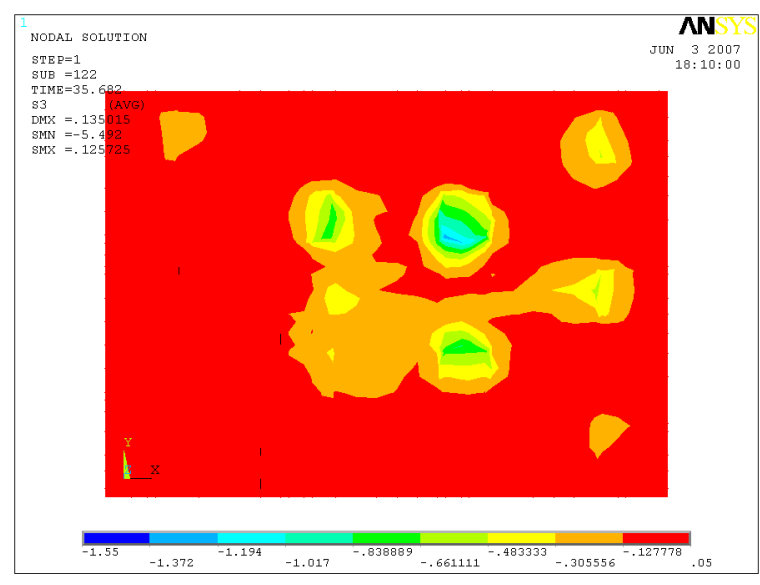

(a) $10 \mathrm{~cm}$

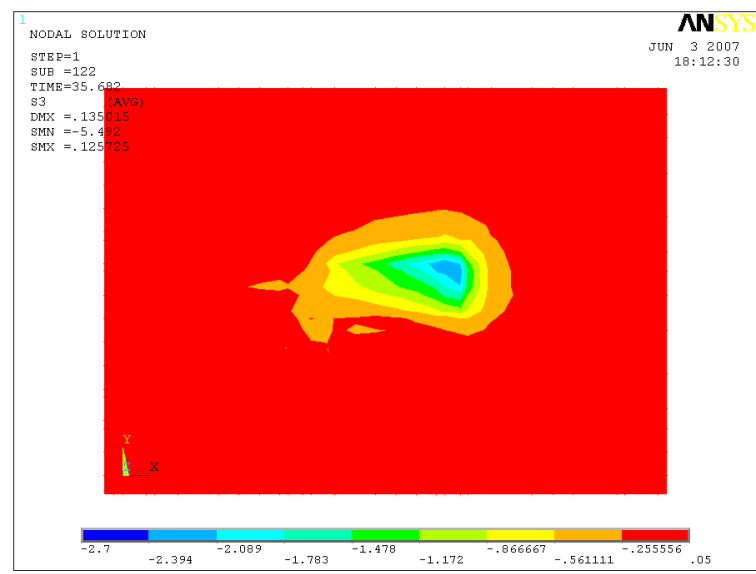

(c) $70 \mathrm{~cm}$

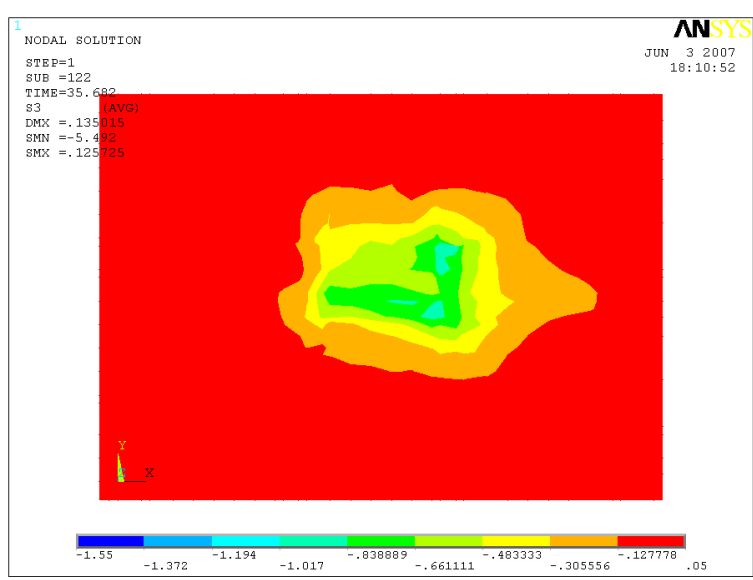

(b) $40 \mathrm{~cm}$

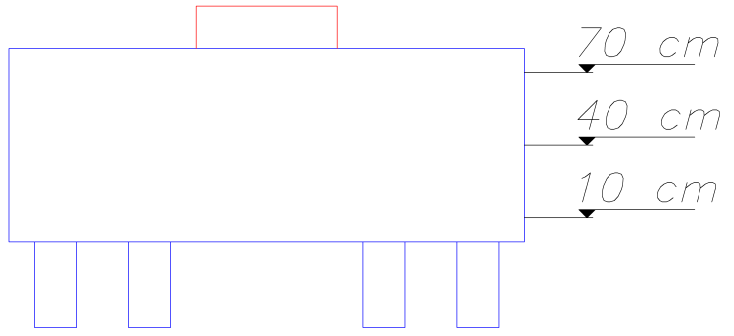

(d) alturas

Figura 6.62: Campos de tensão de compressão - bloco com altura de $80 \mathrm{~cm}$ para solo indeformável - valores em $\mathrm{kN} / \mathrm{cm}^{2}$

Conforme a figura 6.62 pode se observar que nesse caso as tensões de compressão junto a cabeça da estaca (a) são maiores quando comparado com as tensões para o mesmo bloco com estacas apoiadas em solo deformável. A região central do bloco junto a cabeça das estacas foi a região mais comprimida, e a estaca de numero 6 teve tensões que chegaram a 13,72 MPa. Na região próxima ao pilar, item (c), a tensão foi de 23,94 MPa. 
A figura 6.63 apresenta as tensões principais de compressão na seção transversal do bloco ao longo de sua altura para bloco com altura de $115 \mathrm{~cm}$, e vinculação das estacas para solo do tipo deformável.

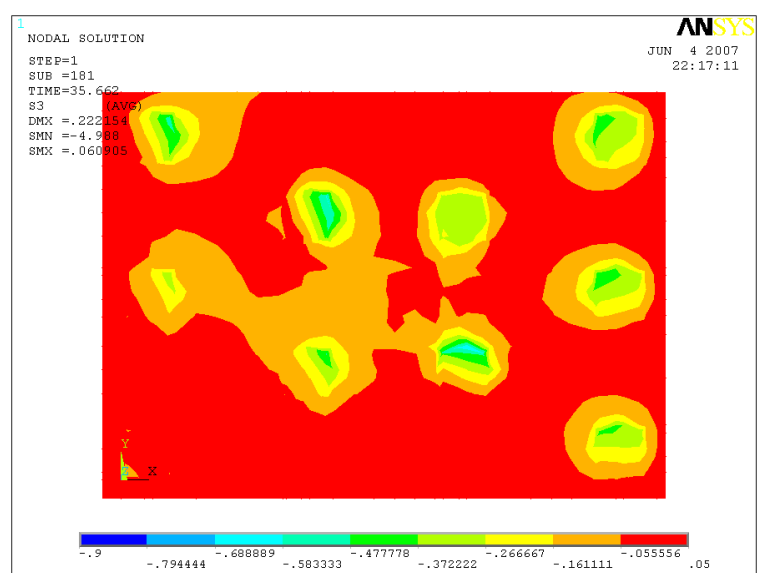

(a) $10 \mathrm{~cm}$

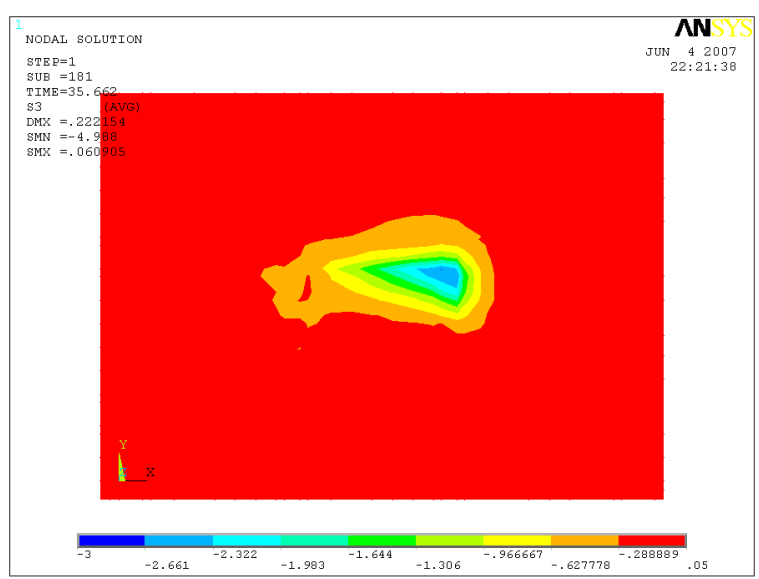

(c) $110 \mathrm{~cm}$

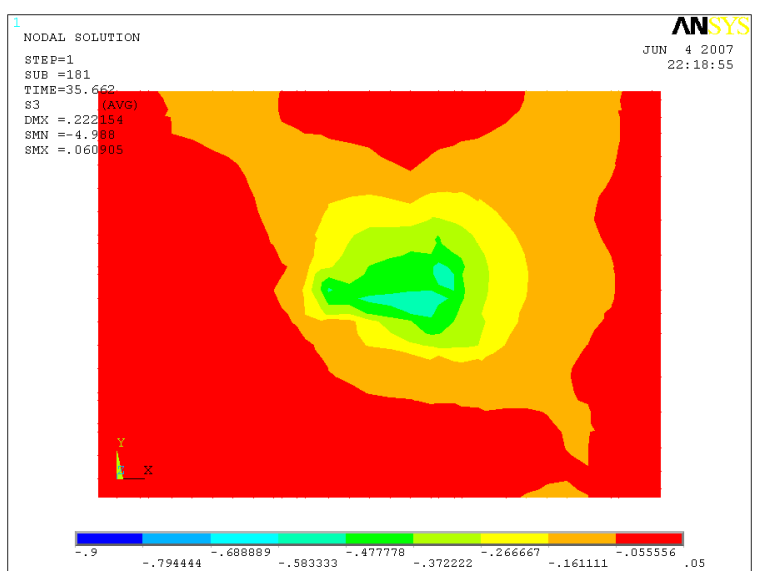

(b) $60 \mathrm{~cm}$

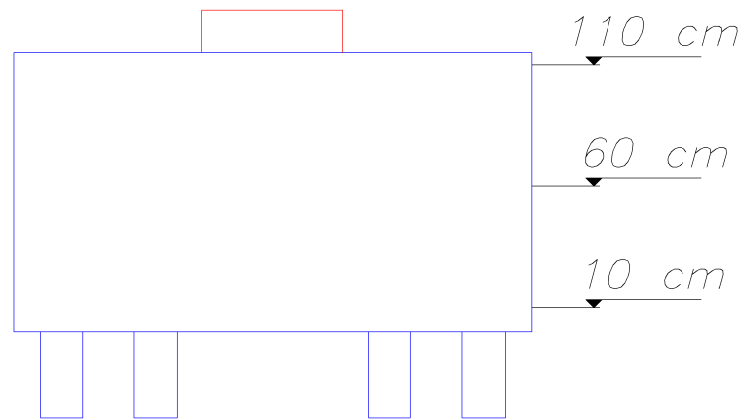

(d) alturas

Figura 6.63: Campos de tensão de compressão - bloco com altura de $115 \mathrm{~cm}$ para solo deformável - valores em $\mathrm{kN} / \mathrm{cm}^{2}$

Conforme a figura 6.63 pode se observar que nesse caso as tensões de compressão junto a cabeça da estaca (a) são menores quando comparado com as tensões para bloco com altura de $80 \mathrm{~cm}$ com estacas apoiadas em solo deformável. Para este caso as tensões de compressão na cabeça da estaca chegaram a 5,8 MPa. Nessa caso a estaca de número 6 não chegou a este valor, como já tinha ocorrido para o Caso 2 e 3. Na região próxima ao pilar, item (c), a tensão foi de 26,6 MPa. 
A figura 6.64 apresenta as tensões principais de compressão na seção transversal do bloco ao longo de sua altura para bloco com altura de $115 \mathrm{~cm}$, e vinculação das estacas para solo do tipo indeformável.

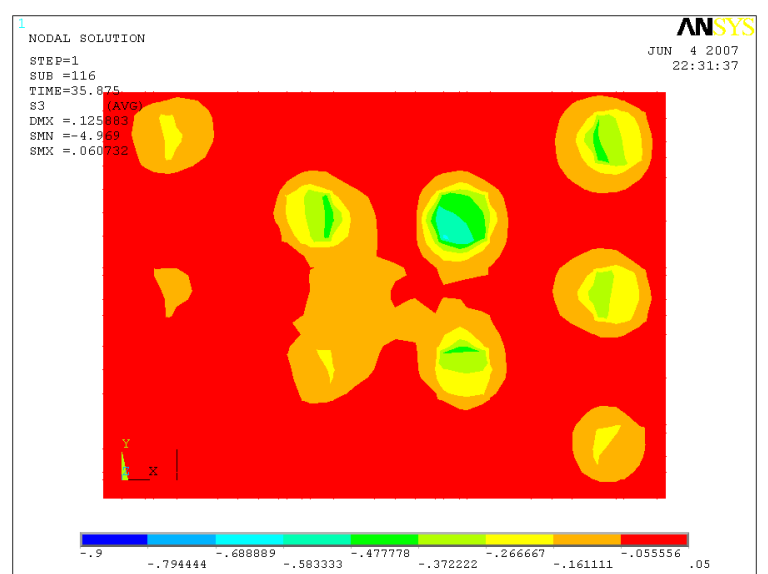

(a) $10 \mathrm{~cm}$

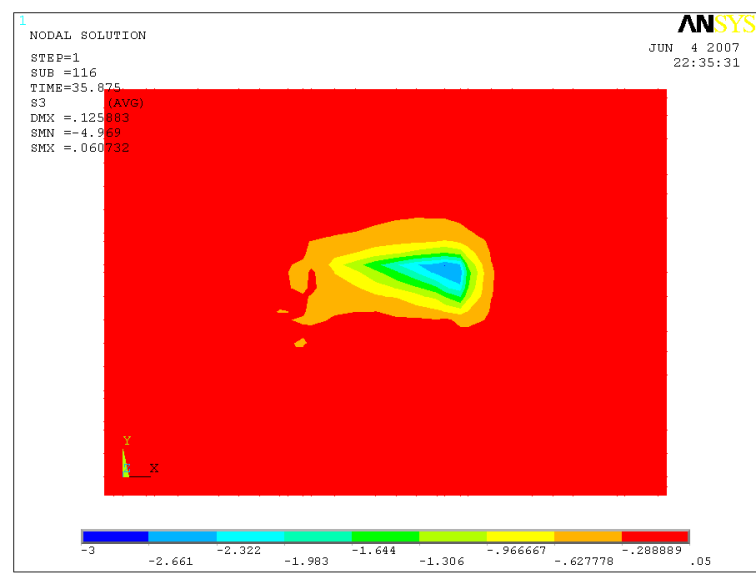

(c) $110 \mathrm{~cm}$

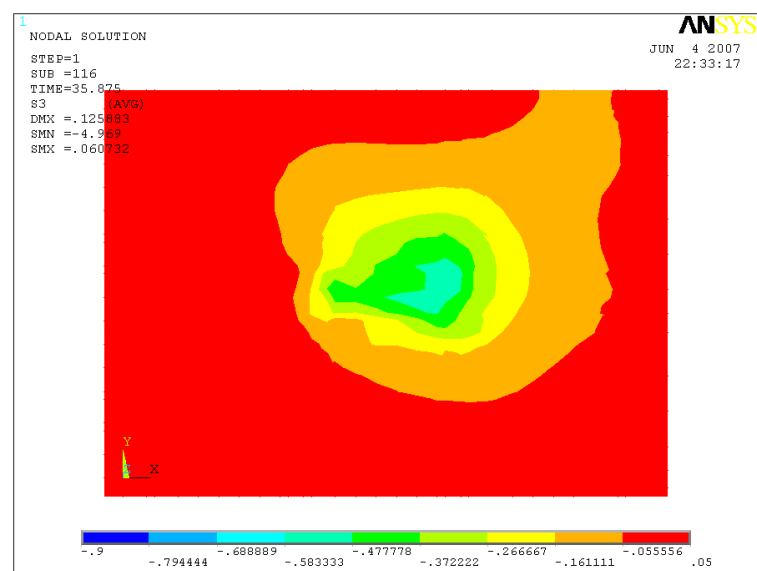

(b) $60 \mathrm{~cm}$

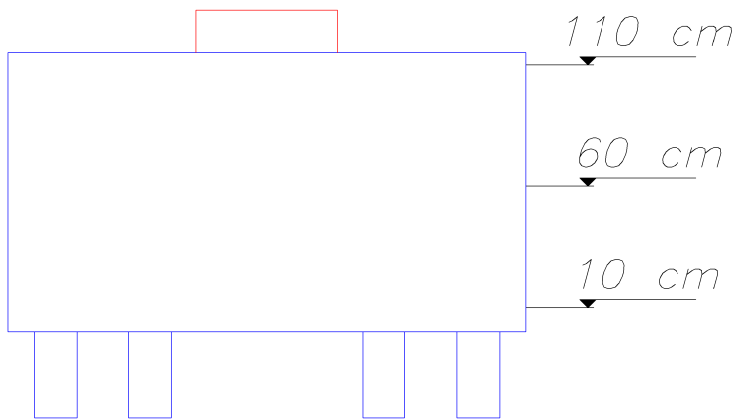

(d) alturas

Figura 6.64: Campos de tensão de compressão - bloco com altura de $115 \mathrm{~cm}$ para solo indeformável - valores em $\mathrm{kN} / \mathrm{cm}^{2}$

Conforme a figura 6.64 pode se observar que nesse caso as tensões de compressão junto a cabeça da estaca (a) são menores quando comparado com as tensões para bloco com altura de $80 \mathrm{~cm}$ com estacas apoiadas em solo indeformável. Para este caso as tensões de compressão na cabeça da estaca chegaram em 6,88 MPa. Na região próxima ao pilar, item (c), a tensão foi de 26,6 MPa. 
A figura 6.65 apresenta as tensões principais de compressão na seção transversal do bloco ao longo de sua altura para bloco com altura de $200 \mathrm{~cm}$, e vinculação das estacas para solo do tipo deformável.

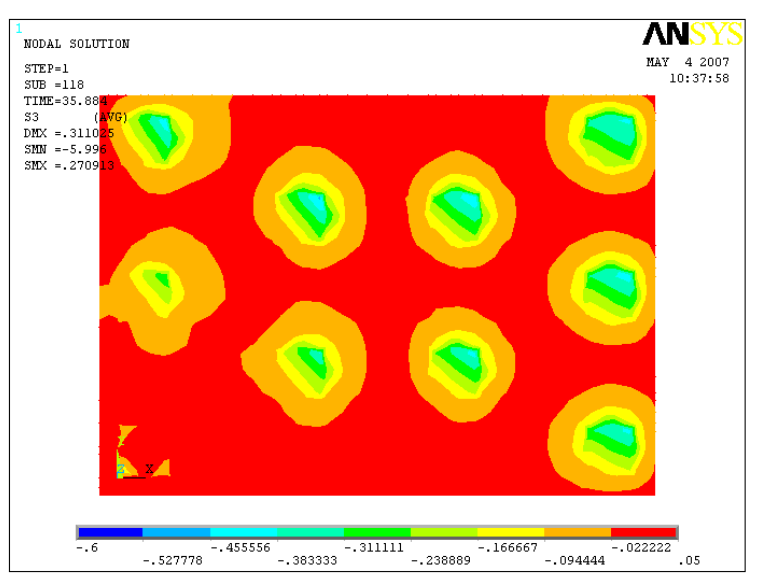

(a) $10 \mathrm{~cm}$

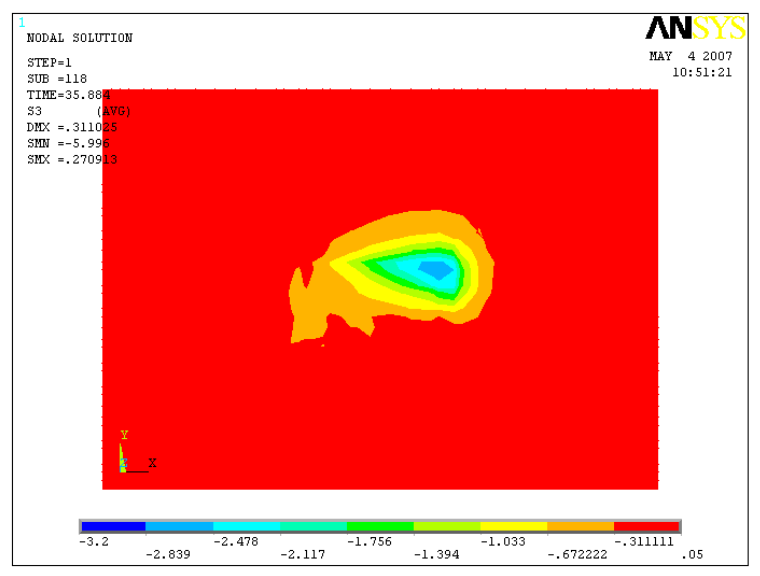

(c) $190 \mathrm{~cm}$

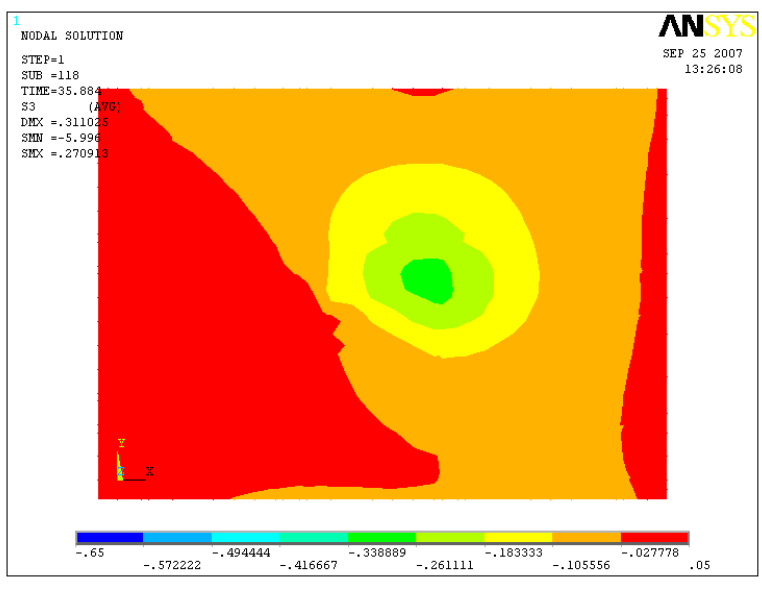

(b) $120 \mathrm{~cm}$

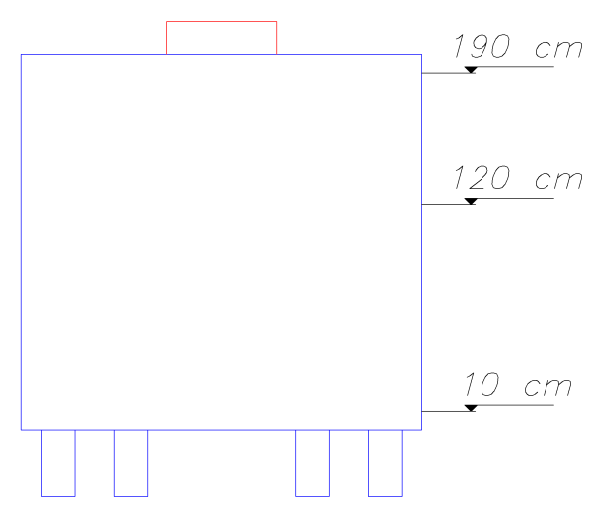

(d) alturas

Figura 6.65: Campos de tensão de compressão - bloco com altura de $200 \mathrm{~cm}$ para solo deformável - valores em $\mathrm{kN} / \mathrm{cm}^{2}$

Conforme a figura 6.65 pode se observar que nesse caso as tensões de compressão junto a cabeça da estaca (a) são menores quando comparado com as tensões para bloco com altura de $80 \mathrm{~cm}$ e $115 \mathrm{~cm}$ com estacas apoiadas em solo deformável. Para este caso as tensões de compressão na cabeça da estaca chegaram em 4,56 MPa. Na região próxima ao pilar, item (c), a tensão foi de 28,39 MPa. 
A figura 6.66 apresenta as tensões principais de compressão na seção transversal do bloco ao longo de sua altura para bloco com altura de $200 \mathrm{~cm}$, e vinculação das estacas para solo do tipo indeformável.

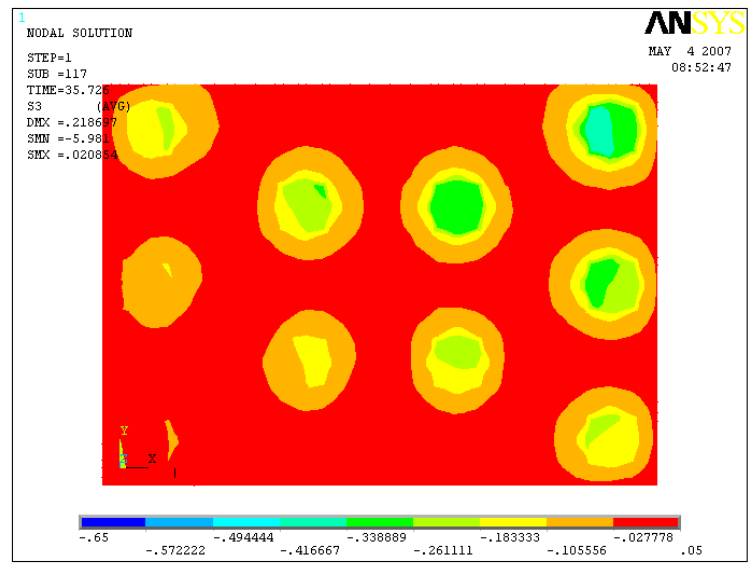

(a) $10 \mathrm{~cm}$

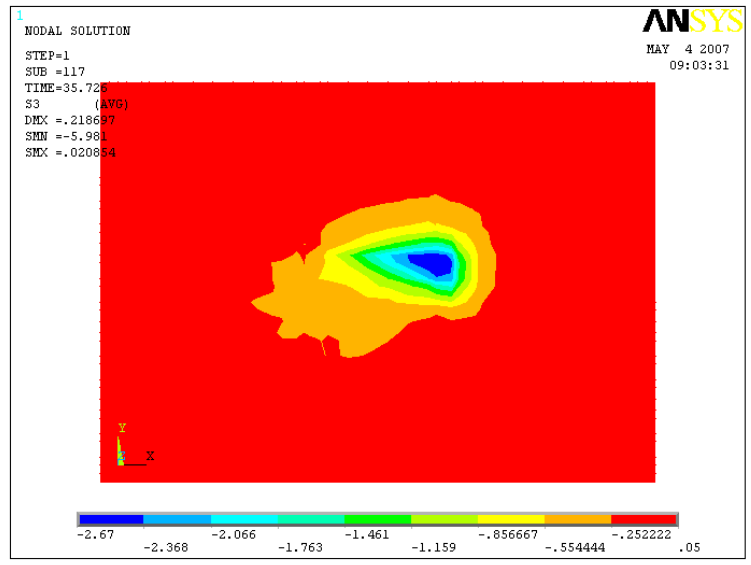

(c) $190 \mathrm{~cm}$

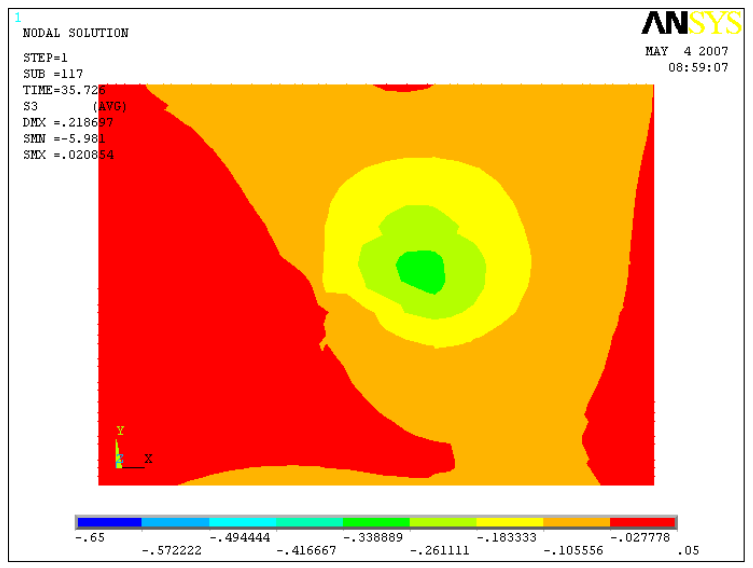

(b) $120 \mathrm{~cm}$

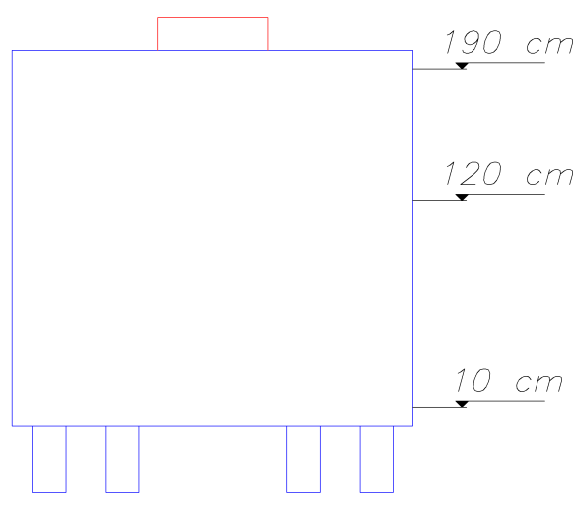

(d) alturas

Figura 6.66: Campos de tensão de compressão - bloco com altura de $200 \mathrm{~cm}$ para solo indeformável - valores em $\mathrm{kN} / \mathrm{cm}^{2}$

Conforme a figura 6.66 pode se observar que nesse caso as tensões de compressão junto a cabeça da estaca (a) são menores quando comparado com as tensões para bloco com altura de $80 \mathrm{~cm}$ e $115 \mathrm{~cm}$ com estacas apoiadas em solo deformável. Para este caso as tensões de compressão na cabeça da estaca chegaram em 4,17 MPa. Na região próxima ao pilar, item (c), a tensão foi de 26,7 MPa. 


\section{CAPÍtulo}

\section{Conclusão}

Este trabalho teve como meta inicial estudar o comportamento de bloco apoiado sobre dez estacas. O estudo foi feito pela importância que esses elementos desempenham perante a segurança de toda a estrutura. E para isso optou-se pela utilização dos métodos numéricos, visto suas vantagens econômicas comparado aos ensaios experimentais e sua capacidade de variação. O intuito era avaliar os critérios de projetos existentes atualmente e comparar com os resultados obtidos numericamente. Optou-se em utilizar o programa para computador Ansys versão 9.0 para a simulação numérica via Métodos dos Elementos Finitos (MEF), adotando para tanto elementos finitos disponíveis na biblioteca do programa em questão.

Em função dos resultados obtidos pela simulação numérica conclui-se que os resultados são de grande relevância e divergem dos critérios usuais de dimensionamento de blocos sobre muitas estacas, pois não levam em consideração alguns parâmetros fundamentais como altura do bloco e o tipo de vinculação empregada. A variação da resistência característica à compressão do concreto mostrou não ter influência na rigidez do bloco. Sendo mais importante o tipo de vinculação empregada e a altura do bloco.

A análise numérica de bloco sobre estaca realizada mostrou resultado muito importante do ponto de vista do comportamento estrutural de bloco. Pois se esperavam resultados mais próximos dos valores calculados analiticamente, porém, os resultados obtidos mostraram que há uma grande diferença. Principalmente quando é levada em consideração a interação da estrutura com o solo onde o bloco está apoiado.

Algumas das opções importantes adotadas para a modelagem foram a utilização de molas. Para que houvesse a interação da estrutura com o solo foi proposta a utilização dessas molas. O comportamento adotado para essas molas foi por meio da curva cargarecalque. A curva carga-recalque considerou o comportamento completo da interação entre a estaca e o solo. Alguns fatores importantes do comportamento estão considerados 
implicitamente nessa curva, como por exemplo, o comprimento da estaca e o atrito lateral, entre outros. Pelos resultados apresentados pode-se afirmar que é possível utiliza-la como um parâmetro que represente o comportamento do solo.

Foram propostos quatro Casos de aplicação de forças, Caso 1, 2, 3 e 4 . Em todos os Casos consideravam a aplicação da força vertical. Os Casos 2, 3 e 4, além da força vertical, a atuação de momentos nas duas direções x e y, variando apenas a intensidade em cada Caso. Sendo assim, apenas o Caso 1 não considerava momentos.

Os resultados mostram que com o aumento da altura do bloco as reações nas estacas variaram consideravelmente, e com alturas de blocos maiores há uma tendência de uniformização das reações nas estacas. Ou seja, o aumento da altura o bloco faz com que o bloco fique mais rígido.

Analisando os resultados a situação mais crítica para o bloco foi aquela em que se consideravam as estacas apoiadas em solo do tipo indeformável, chegando-se a resultados de reação da estaca com diferenças acima de $200 \%$. Foi possível perceber que mesmo com solo do tipo deformável as estacas na região central do bloco foram as mais solicitadas.

Esses resultados mostraram que o atual conhecimento do comportamento de blocos apresenta lacunas e indica que há muito trabalho a fazer. É necessário que se aprofundem mais nos estudos, tanto em análise numérica quanto em análise experimental.

O autor sugere como uma forma de continuação da pesquisa a análise de outros tipos de blocos sobre muitas estacas, alterando a forma geométrica e também outras variáveis de interesse (vinculos, dimensões dos pilares, etc.), para que possa chegar a resultados consistentes que viabilizem a proposição de um processo de dimensionamento mais preciso, refinado e confiável, visto que essa modelagem aplicada nesse trabalho não é a mais completa, pois não são considerados os efeitos triaxiais do concreto, é considerada a interação perfeita entre o aço e concreto, entre outros.

Para contribuir com trabalhos futuros, que envolva o tema, é apresentado (Apêndice A) a listagem de comandos necessário para a elaboração do modelo numérico script no programa de computador Ansys. 


\section{Referências}

ADEBAR, P.; KUCHMA, D.; COLLINS, M. P. (1990). Strut-and-tie models for design of pile caps: an experimental study. ACI Journal, v. 87, p. 81-91, Jan/Feb.

ALONSO, U. R. (1983). Exercícios de Fundações. Ed. Edgard Blücher Ltda., São Paulo.

AMERICAN CONCRETE INSTITUTE (1995). ACI 318 - Building code requirements for reinforced concrete. Detroit, USA.

ANSYS USER'S MANUAL (2004). Theory Manual, Ansys revision 9.0 .

ASSOCIAÇÃO BRASILEIRA DE NORMA TÉCNICAS (2003). NBR 6118:2003 - Projeto de estruturas de concreto. Rio de Janeiro.

BRITISH STANDARD FOR STRUCTURAL USE OF CONCRETE (1985). BS 8110 - Code of practice for design and construction. Part 1.

BLÉVOT, J.; FRÉMY, R. (1967). Semelles sur piex. Analles d'Institut Technique du Bâtiment et des Travaux Publics, Paris, v. 20, n. 230, p. 223-295, fev.

CALAVERA, J. (1991). Calculo de estructuras de cimentacion. Instituto Técnico de Materiales y Construcciones - INTEMAC. Ed. Torreangulo Arte Gráfico, ed. 3a , Madrid, Espanha.

COMITE EURO-INTERNACIONAL DU BÉTON (1970). CEB-FIP, Recommandations particulières na calcul et à l'execution des semelles de fundations. Bulletin D'Information, Paris, n. 73.

DELALIBERA, R. G.; GIONGO, J. S. (2004 - a). Influência da rigidez do bloco de coroamento nos estaqueamentos em linhas. $46^{\circ}$ Congresso Brasileiro do Concreto. CD-ROM, Florianópolis.

DELALIBERA, R. G.; GIONGO, J. S. (2004 - b). Simulação numérica nãolinear de blocos de concreto armado. XXXI Jornadas Sul-Americanas de Engenharia Estrutural. CD-ROM, Mendonza, Argentina.

DELALIBERA, R. G. (2006). Análise experimental e numérica de blocos de concreto armado sobre duas estacas submetidos à ação de força 
centrada e excêntrica. São Carlos. Tese (Doutorado) - Escola de Engenharia de São Carlos, Universidade de São Paulo.

DESAYI, P.; KRISHNAN, S. (1964). Equation for the Stress-Strain Curve of Concrete. Journal of the American Concrete Institute. v. 61, p. 345-350, March.

INSTRUCCIÓN DE HORMIGÓN ESTRUCTURAL (2001). EHE, Comisión Permanente del Hormigón, Ministerio de Fomento. Centro de Publicaciones, Madrid.

IYER, P. K.; SAM, C. (1991). 3-D elastic analysis of three-pile caps. Journal of Engineering Mechanics, ASCE, v. 117, n. 12, p. 2862-2883, Dec.

IYER, P. K.; SAM, C. (1992). Three-dimensional analysis of pile caps.

Computers and Structures v. 42, n. 3, p. 395-411, Feb.

IYER, P. K.; SAM, C. (1995 - a). Nonlinear finite element analysis of reinforced concrete four-pile caps. International Journal of Structures v. 15, n. 1, p. 18-34, Jan/Jun.

IYER, P. K.; SAM, C. (1995 - b). Nonlinear finite element analysis of reinforced concrete two-pile caps. Computers and Structures v. 57, p. 605-622, Nov.

GUERRIN, A. (1955); Traité de béton armé, Ed. Dunod. Paris.

MAUTONI, M. (1972). Blocos sobre dois apoios. São Paulo, Grêmio Politécnico.

MIGUEL, G. M. (2000). Análise experimental e numérica de blocos sobre três estacas. Tese (Doutorado) - Escola de Engenharia de São Carlos, Universidade de São Paulo, São Carlos.

MOntoyA, P. J.; MESEGUER, A.; CABRE, M. (2000). Hormigón armado. 14 ${ }^{\text {a }}$ Edición basada em EHE ajustada al Código Modelo y al Eurocódigo. Gustavo Gili, Barcelona, Espanha.

MORAES, M. C. (1976). Estruturas de Fundações. Ed. McGraw-Hill do Brasil, São Paulo.

MUNHOZ, F. S. (2004). Análise do comportamento de blocos de concreto armado sobre estacas submetidos à ação de força centrada. Dissertação (Mestrado), Escola de Engenharia de São Carlos, Universidade de São Paulo, São Carlos.

MUNHOZ, F. S.; DELALIBERA, R. G.; GIONGO, J. S. (2004 - a). Análise numérica elástica linear de blocos de concreto armado sobre duas estacas. XXXI Jornadas Sul-Americanas de Engenharia Estrutural. CD-ROM, Mendonza, Argentina.

MUNHOZ, F. S.; DELALIBERA, R. G.; GIONGO, J. S. (2004 - b). Avaliação da rigidez de blocos de coroamento em estaqueamentos paralelos com ações 
verticais excêntricas. $46^{\circ}$ Congresso Brasileiro do Concreto. CDROM, Florianópolis, SC.

MUNHOZ, F. S.; DELALIBERA, R. G.; GIONGO, J. S. (2005). Análise do comportamento de blocos de concreto armado sobre cinco estacas submetidos à ação de força centrada. $47^{\circ}$ Congresso Brasileiro do Concreto. CDROM, Olinda, PE.

PFEIL, W. (1983). Pontes em concreto armado. Rio de Janeiro : Livros Técnicos e Científicos Editora S.A. 3. ed.

TAYLOR, H. P. J.; CLARKE, J. L. (1976). Some detailing problems in concrete frame structures. The Structural Engineer, January. 


\section{APÊNDICE A - Script do Bloco}

Esta é a lista de comandos, usualmente chamada de script, necessário para que o programa Ansys interprete e monte o modelo numérico do bloco. Este script é para um bloco de $115 \mathrm{~cm}$ de altura e Caso 4 .

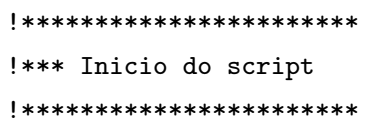

/CONFIG, NPROC, 2 !USAR DUPLO PROCESSADOR

/CONFIG, NRES, 3000 ! AUMENTAR O NÚMERO DE SUBSTEPS

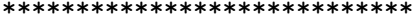

!*** PARÂMETROS DE ENTRADA

$! * * * * * * * * * * * * * * * * * * * * * * * * * * * *$

fck=25 !Resistencia caracteristica do concreto a compressão(MPa)

Pc=0.2 !Coeficiente de Poisson do concreto

Es=21000 !Modulo de elasticidade do aço

Ps=0.3 !Coeficiente de Poisson do aço

Escoa=50 !Tensão de escoamento do aço

CTCCC=1.0 ! Coeficiente de Transferencia de cisalhamento para fissuras abertas

CTCFC=1.0 !Coeficiente de Transferencia de cisalhamento para fissuras fechadas

$\operatorname{delta}=0.1$

!*** Escolhendo apenas a opcao Estrutural

! $* * * * * * * * * * * * * * * * * * * * * * * * * * * * * * * * * * * * * * * * * * * *$

/NOPR

/PMETH, OFF, 0

KEYW , PR_SET , 1

KEYW,PR_STRUC, 1

KEYW, PR_FLUID , 0

KEYW, PR_MULTI , 0 
/GO

/COM,

/COM,Preferences for GUI filtering have been set to display:

/COM, Structural

! $* * * * * * * * * * * * * * * * * * * * * * * * * * * * * * * *$

!*** Escolhendo os Elementos

! *********************************

/PREP7

ET,1,SOLID65 !Escolhendo o elemento de solido para Concreto

KEYOPT $, 1,1,0$

KEYOPT , 1, 3, 0

KEYOPT $, 1,5,2$

KEYOPT $, 1,6,3$

KEYOPT $, 1,7,1$

KEYOPT , 1, 8, 0

ET,2,LINK8 !Escolhando o elemento de barra para as armaduras

ET, 3,COMBIN39 !Escolha do elemento Mola

KEYOPT , 3, 1, 0

KEYOPT , 3, 2, 0

KEYOPT , 3, 3, 3

KEYOPT , 3, 4, 0

KEYOPT , 3, 6, 0

ET,4,SOLID45 !Escolha do elemento sólido para a chapa do pilar

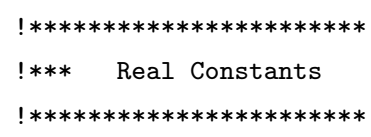

$\mathrm{R}, 1,,,,,$,

RMORE, , , , , , ,

RMORE, , Constantes para o concreto

$\mathrm{R}, 2,2.01$, , !Constantes para o aço na direção X

$\mathrm{R}, 3,0.005,1.25,0.008,2.5,0.011,3.75$, !Constantes para a Mola de rocha

RMORE, 0.014, 5, 0.017, 6.25, 0.024, 7.5,

RMORE, $0.036,8.75,0.054,10,0.074,11.25$,

RMORE, $0.11,12.5,0.16,13.75,0.23,15$, 
RMORE , 0.39, 16.25, 0.87, 17.5, 4, 18.75, RMORE , $0,0,0,0,0,0$, RMORE, $0,0,0,0$,

R,4,19.7, , ! Constantes para o pilar

$\mathrm{R}, 5,2.01$, , Constantes para o aço na direção $\mathrm{Y}$

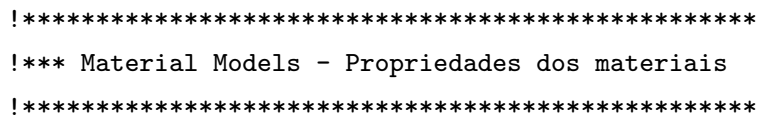

$\mathrm{Ec}=((5600 * \mathrm{fck} * * 0.5) * 0.85) / 10$ !Modulo de elasticidade do concreto

MPTEMP, , , , , , , , !Propriedade do Concreto

MPTEMP , 1,0

MPDATA,EX,1, Ec !Modulo de elasticidade E=2380 kN/cm2

MPDATA, PRXY, 1, Pc !Coeficiente de Poison $=.2$

eu=.2*fck/Ec !deformação do concreto ultima

$\mathrm{T} 1=0.3 * \mathrm{fck} * .1$

$\mathrm{D} 1=\mathrm{T} 1 / \mathrm{Ec}$

D5 $=\mathrm{eu}$

$\mathrm{D} 2=((\mathrm{D} 5-\mathrm{D} 1) / 4)+\mathrm{D} 1$

$\mathrm{T} 2=(\mathrm{Ec} * \mathrm{D} 2) /(1+(\mathrm{D} 2 / \mathrm{eu}) * * 2)$

D3 $=(($ D5 $-\mathrm{D} 1) * 2 / 4)+\mathrm{D} 1$

$\mathrm{T} 3=(\mathrm{Ec} * \mathrm{D} 3) /(1+(\mathrm{D} 3 / \mathrm{eu}) * * 2)$

$\mathrm{D} 4=((\mathrm{D} 5-\mathrm{D} 1) * 3 / 4)+\mathrm{D} 1$

$\mathrm{T} 4=(\mathrm{Ec} * \mathrm{D} 4) /(1+(\mathrm{D} 4 / \mathrm{eu}) * * 2)$

$\mathrm{T} 5=\mathrm{f} \mathrm{ck} * .1$

TB,MISO, 1,1,5,0 !Multilinear Isotropic para o Concreto

TBTEMP, 0

TBPT , ,D1, T1

TBPT , , D2, T2

TBPT , , D3, T3

TBPT , ,D4 , T4

TBPT , , D5 , T5

fct_in=0.3*0.1*fck**(2/3) !Tensão de tração do concreto médio (NBR6118:2003 - 8.2.5)

TB, CONC,1,1,9, !Propriedades do concreto - tração, cisalhamento, compressão

TBTEMP , 0

TBDATA, , CTCCC , CTCFC, f ct_in, -1 , ,

TBDATA , , , , , ,

MPTEMP, , , , , , , !Propriedade do Aço

MPTEMP , 1, 0

MPDATA,EX,2, Es !Modulo de elasticidade E=21000 kN/cm2 
MPDATA,PRXY, 2, ,Ps ! coeficiente de Poison $=.3$

TB,BISO, 2, 1,2, !Bilinear Isotropic

TBTEMP, 0

TBDATA, ,Escoa, 0, , , ,

MPTEMP, , , , , , , !Propriedade da Mola

MPTEMP , 1, 0

MPDATA , EX , 3, , 21000

MPDATA, PRXY, $3, ., 2 \quad$ !Poison $=.3$

MPTEMP, ,,,,,,, !Aço para a placa do pilar

MPTEMP , 1,0

MPDATA , EX , 4, , 2.105E+005

MPDATA, PRXY , 4, , . 3

$! * * * * * * * * * * * * * * * * * * * * * * * * * *$

!*** Dados para a criação

!****************************

Dim_est=35 !Diametro da estaca

$\mathrm{X}=100$ !Posição $\mathrm{X}$ da estaca

$Y=100$ !Posição $Y$ da estaca

Comp_est=50 !Comprimento da estaca

Alt_Bloc=115 !Altura do Bloco

Alt_Pilar=50 !Altura do Pilar

$\mathrm{dx}=5$

$d y=5$

$! * * * * * * * * * * * * * * * * * * * * * *$

!*** Criando o bloco

!************************

BLOCK , $-12,135,-12,100,0, \mathrm{Alt}$ _Bloc , !Bloco

BLOCK $, 0,7 * d x, 0,7 * d y, 0, A l t \_B l o c$, ! estaca

FLST , 3, 1, 6, ORDE, 1 ! Copiando

FITEM , 3, 2

VGEN , 2,P51X, , ,100,50, , , 0

FLST , 3, 2, 6, ORDE, 2 ! Subtraindo

FITEM , 3, 2

FITEM , 3, -3

VSBV, $\quad 1, \mathrm{P} 51 \mathrm{X}$ 


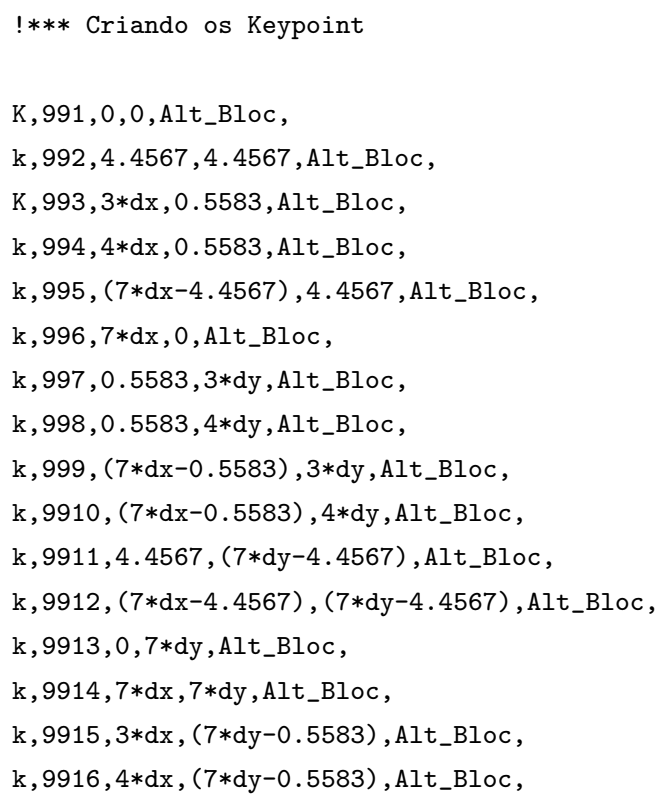




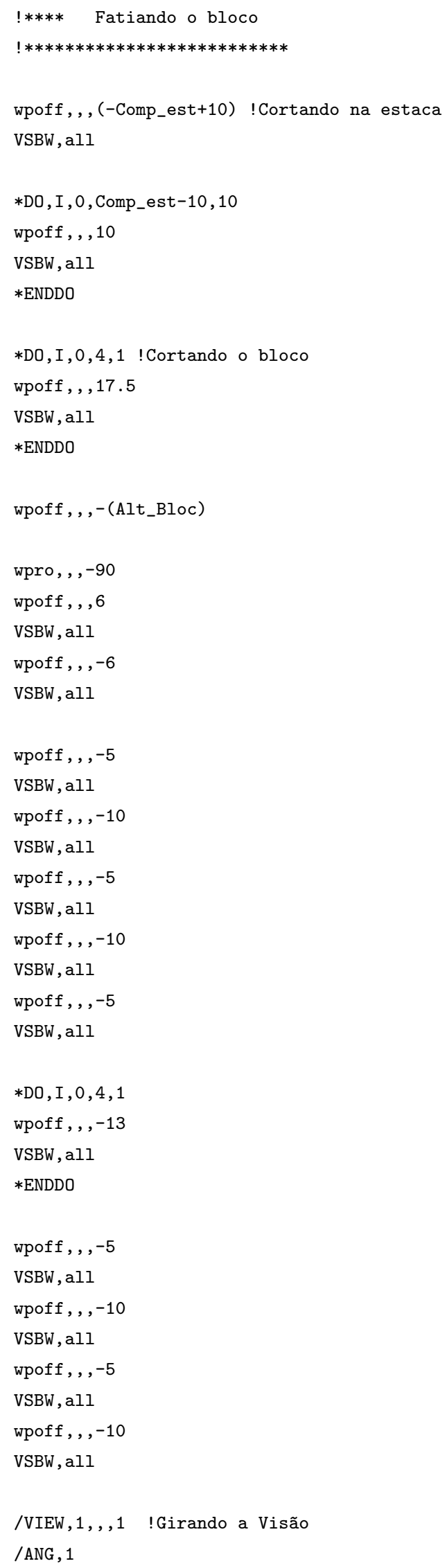


/REP, FAST

wpro,,90 !Começando a cortar na outra direção

wpoff, , , 6

VSBW, all

wpoff , , , -6

VSBW, all

wpoff, , , -5

VSBW, all

wpoff , , , -10

VSBW, all

wpoff, , , -5

VSBW, all

wpoff , , , -10

VSBW, all

wpoff , , , -5

vSBW, all

$* \mathrm{DO}, \mathrm{I}, 0,1,1$

wpoff , , , -7.5

VSBW, all

$*$ ENDDO

wpoff , , , -5

VSBW, all

wpoff , , , -10

VSBW, all

wpoff, , , ,-5

VSBW, all

wpoff, , , -10

VSBW, all

wpoff , , , -5

VSBW, all

wpoff, , , , -7.5

VSBW, all

!*** Copiando volumes da estaca

VSEL , S , LOC , X , 0,35

VSEL , R, LOC, Y , 0,35

VGEN, 2,all, , ,0,200, , ,0

VSEL , S, LOC , X , 0 , 35

VSEL , $R$, LOC , Y , 0,35

VGEN, 2,all, , ,0,100, , ,0

VSEL , S , LOC , X , 0,35

VSEL , $R, L O C, Y, 0,35$

VGEN , 2, all , , ,100,150, , ,0

VSEL , $\mathrm{S}, \mathrm{LOC}, \mathrm{X}, 0,35$ 
VSEL , R, LOC, Y , 0,35

VGEN, 2, all, , ,100,50, , , 0

VSEL , S , LOC , X , 0 , 35

VSEL , R, LOC , Y , 0,35

VGEN , 2, all, , ,200,150, , , 0

VSEL , S , LOC , X , 0,35

VSEL , R, LOC , Y , 0,35

VGEN, 2, all, , ,200,50, , ,0

VSEL , S , LOC , X , 0,35

VSEL , R, LOC , Y , 0,35

VGEN , 2, all, , ,300, 200, , ,0

VSEL , S , LOC , X , 0, 35

VSEL , R, LOC, Y , 0, 35

VGEN , 2, all, , 300,100, , , 0

VSEL, S, LOC , X , 0, 35

VSEL, R, LOC, Y , 0,35

VGEN , 2, all, , ,300,0, , , 0

VSEL , S , LOC , X , $0,-12$

VSEL , R , LOC , Y , $0,-12$

VGEN , 2, all, , ,0,247, , , 0

VSEL , S , LOC , X , $0,-12$

VSEL, R, LOC , Y , $0,-12$

VGEN , 2, all , , 347,0, , , 0

VSEL , S , LOC , X , 0 , -12

VSEL , R, LOC , Y , $0,-12$

VGEN , 2, all , , ,347, 247, , , 0

VSEL , S, LOC , X , 0,35

VSEL , R, LOC , Y , $0,-12$

VGEN , 2, all, , , 0,247, , , 0

VSEL , S , LOC , X , 0,35

VSEL , R , LOC , Y , $0,-12$

VGEN , 2, all, , ,300, 247, , , 0

VSEL , S , LOC , X , 0, 35

VSEL , R , LOC , Y , $0,-12$

VGEN, 2, all, , ,300,0, , ,0

VSEL, S , LOC , X , 0 , -12

VSEL, R, LOC, Y , 0, 35

VGEN , 2, all, , , 0,100, , ,0

VSEL , S , LOC , X , 0 , -12

VSEL, R, LOC, Y, 0,35

VGEN , 2, all, , 0,200, , , 0 
VSEL , S, LOC , X , $0,-12$

VSEL , R, LOC , Y , 0,35

VGEN, 2, all, , ,347,0, , ,0

VSEL , S, LOC , X , O, -12

VSEL, $R, L O C, Y, 0,35$

VGEN , 2, all , , 347,100, , ,0

VSEL , S , LOC , X , O , -12

VSEL , R, LOC , Y , 0,35

VGEN, 2, all, , ,347,200, , ,0

VSEL , S, LOC , X , 0, -12

VSEL , $R, L O C, Y, 35,100$

VGEN, 2,all, , ,347,0, , ,0

VSEL , S , LOC , X , 0, -12

VSEL , $R$, LOC , Y , 35, 100

VGEN, 2 , all , , ,347, 100, , ,0

VSEL , S, LOC , X , 0, -12

VSEL , R, LOC , Y , 35, 100

VGEN, 2,all, , ,0,100, , ,0

VSEL , S , LOC , X , 35, 100

VSEL , $R, L O C, Y, 0,-12$

VGEN, 2,all, , ,100,0, , ,0

VSEL , S , LOC , X , 35, 100

VSEL , $R, L O C, Y, 0,-12$

VGEN, 2,all, , ,200,0, , ,0

VSEL , S , LOC , X , 35, 100

VSEL , $R, L O C, Y, 0,-12$

VGEN, 2 , all , , , 0,247, , ,0

VSEL , S , LOC , X , 35, 100

VSEL , $R, L O C, Y, 0,-12$

VGEN , 2, all , , ,100,247, , ,0

VSEL , S , LOC , X , 35, 100

VSEL, $R$, LOC, $Y, 0,-12$

VGEN, 2,all, , ,200,247, , ,0

VSEL , S , LOC , X , 100, 135

VSEL , $R, L O C, Y, 0,-12$

VGEN, 2,all, , ,0,247, , ,0

VSEL , S , LOC , X , 100, 135

VSEL , $R, L O C, Y, 0,-12$

VGEN, 2, all, , ,100, 247, , ,0

VSEL , S , LOC , X , 100,135 
VSEL , R , LOC , Y , 0, -12

VGEN , 2, all, , ,100,0, , ,0

VSEL , S , LOC , X , 0, 35

VSEL , R , LOC , Y, 35, 100

VGEN, 2, all, , ,0,100, , ,0

VSEL , S , LOC , X , 0 , 35

VSEL , R, LOC , Y , 35, 100

VGEN, 2, all, , ,300,0, , ,0

VSEL , S , LOC , X , 0, 35

VSEL , R, LOC , Y , 35, 100

VGEN , 2, all, , ,300,100, , ,0

VSEL , S, LOC , X , 0,35

VSEL , R , LOC , Y , 35, 100

VGEN, 2, all , , 100,50, , ,0

VSEL , S , LOC , X , 0, 35

VSEL , R, LOC , Y, 35, 100

VGEN, 2, all, , ,200,50, , ,0

VSEL , S , LOC , X , 35, 100

VSEL , R , LOC , Y, 35, 100

VGEN, 2, all, , ,0,100, , ,0

VSEL , S , LOC , X , 35, 100

VSEL , R, LOC , Y , 0,35

VGEN, 2, all, , ,0,100, , , 0

VSEL , S , LOC , X , 35, 100

VSEL , R, LOC, Y , 0,35

VGEN, 2, all, , , 0,200, , ,0

VSEL , S , LOC , X , 35, 100

VSEL , R, LOC , Y , 0,235

VGEN, 2, all, , ,100,0, , , 0

VSEL , S , LOC , X , 35, 100

VSEL , R, LOC , Y , 0,235

VGEN , 2, all, , ,200,0, , , 0

VSEL , S , LOC , X , 100, 135

VSEL, R, LOC, Y , 0, 35

VGEN , 2, all, , ,0,200, , ,0

VSEL , S , LOC , X , 100, 135

VSEL, R, LOC, Y , 0, 35

VGEN , 2, all, , ,100,200, , ,0

VSEL , S , LOC , X , 100,135

VSEL , R, LOC, Y , 0,35

VGEN , 2, all, , ,100,0, , ,0 
VSEL , S, LOC, X , 100, 135

VSEL , $R$, LOC , $Y, 35,50$

VGEN, 2,all, , ,100,0, , ,0

VSEL , S, LOC , X , 100, 135

VSEL , $R, L O C, Y, 35,50$

VGEN, 2, all, , ,0,150, , ,0

VSEL , S , LOC , X , 100, 135

VSEL , $R, L O C, Y, 35,50$

VGEN, 2,all, , ,100,150, , ,0

WPCSYS, $-1,0$ ! Voltar o eixo para a origem

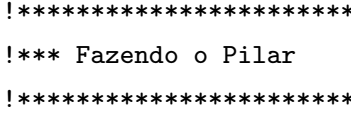

VSEL , S , LOC , X , 120, 215

VSEL , $R, L O C, Y, 100,135$

VSEL , R, LOC , Z, (Alt_Bloc-2*17.5), Alt_Bloc

VGEN, 2 , all, , , 0, 0, (2*17.5), ,0

ALLSEL, ALL

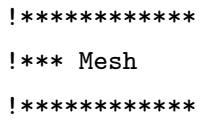

NUMMRG , ALL ， ， , ,LOW ! Murge

LESIZE, ALL, , ,1, ,1, , ,1, ! Tamanho do Mesh

allsel, all

VSEL , U, LOC , Z , 132 . 5, 150

VSEL, U, LOC , Z , -40, -50

type, 1

mat, 1

real, 1

esys, 0

secnum,

MSHAPE, $0,3 \mathrm{~d}$

MSHKEY , 1

VMESH,all !mesh do concreto

allsel, all

VSEL , S, LOC , Z , 132.5, 150

VSEL , A , LOC , Z , $-40,-50$ 
type, 4

mat, 4

real, 1

esys, 0

secnum,

VMESH,all !mesh da chapa no topo do pilar e da placa da base da estaca

WPCSYS, -1,0 !Voltar o eixo para a origem

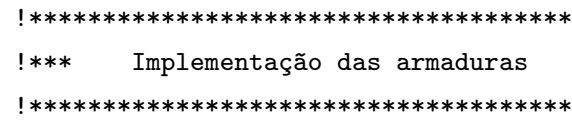

!****Direção $\mathrm{X}$

type, 2

mat, 2

real, 2

esys, 0

secnum,

*DIM, armadurax , ARRAY , 40

*DIM , armaduray , ARRAY , 40

*DIM , armaduraz , ARRAY , 40

$\operatorname{armadurax}(1)=-6$

$\operatorname{armaduray}(1)=0$

$\operatorname{armaduraz}(1)=27.5$

$\operatorname{armadurax}(2)=-6$

$\operatorname{armaduray}(2)=0$

$\operatorname{armaduraz}(2)=10$

$\operatorname{armadurax}(3)=0$

$\operatorname{armaduray}(3)=0$

$\operatorname{armaduraz}(3)=10$

$\operatorname{armadurax}(4)=5$

$\operatorname{armaduray}(4)=0$

$\operatorname{armaduraz}(4)=10$

$\operatorname{armadurax}(5)=15$

$\operatorname{armaduray}(5)=0$

$\operatorname{armaduraz}(5)=10$

$\operatorname{armadurax}(6)=20$

$\operatorname{armaduray}(6)=0$

$\operatorname{armaduraz}(6)=10$

$\operatorname{armadurax}(7)=30$

$\operatorname{armaduray}(7)=0$

$\operatorname{armaduraz}(7)=10$

$\operatorname{armadurax}(8)=35$

$\operatorname{armaduray}(8)=0$

$\operatorname{armaduraz}(8)=10$

$\operatorname{armadurax}(9)=48$

$\operatorname{armaduray}(9)=0$

$\operatorname{armaduraz}(9)=10$ 


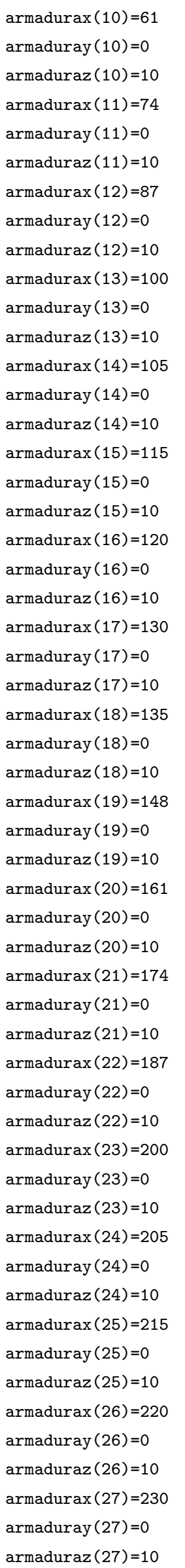


$\operatorname{armadurax}(28)=235$

armaduray $(28)=0$

$\operatorname{armaduraz}(28)=10$

$\operatorname{armadurax}(29)=248$

$\operatorname{armaduray}(29)=0$

$\operatorname{armaduraz}(29)=10$

$\operatorname{armadurax}(30)=261$

$\operatorname{armaduray}(30)=0$

$\operatorname{armaduraz}(30)=10$

$\operatorname{armadurax}(31)=274$

$\operatorname{armaduray}(31)=0$

$\operatorname{armaduraz}(31)=10$

$\operatorname{armadurax}(32)=287$

armaduray $(32)=0$

$\operatorname{armaduraz}(32)=10$

$\operatorname{armadurax}(33)=300$

$\operatorname{armaduray}(33)=0$

$\operatorname{armaduraz}(33)=10$

$\operatorname{armadurax}(34)=305$

$\operatorname{armaduray}(34)=0$

$\operatorname{armaduraz}(34)=10$

$\operatorname{armadurax}(35)=315$

$\operatorname{armaduray}(35)=0$

$\operatorname{armaduraz}(35)=10$

$\operatorname{armadurax}(36)=320$

armaduray $(36)=0$

$\operatorname{armaduraz}(36)=10$

$\operatorname{armadurax}(37)=330$

$\operatorname{armaduray}(37)=0$

$\operatorname{armaduraz}(37)=10$

$\operatorname{armadurax}(38)=335$

$\operatorname{armaduray}(38)=0$

$\operatorname{armaduraz}(38)=10$

$\operatorname{armadurax}(39)=341$

$\operatorname{armaduray}(39)=0$

$\operatorname{armaduraz}(39)=10$

$\operatorname{armadurax}(40)=341$

$\operatorname{armaduray}(40)=0$

$\operatorname{armaduraz}(40)=27.5$

desloy $=0$

*DIM , desl_y , ARRAY , 6

$\operatorname{desl}_{-} \mathrm{y}(1)=0$

desl_y $(2)=5$

$\operatorname{desl}_{-} \mathrm{y}(3)=15$

desl_y $(4)=20$

desl_y $(5)=30$

desl_y $(6)=35$

$* \mathrm{DO}, \mathrm{k}, 1,5,1$ !faixas

*DO,j,1,6,1 !número de armadura 
*DO, i, 1, 39, 1

NSEL , S , LOC , X , (armadurax (i) -delta), (armadurax (i) +delta)

NSEL , R, LOC, Y , (armaduray (i)-delta+desloy+desl_y (j)) , (armaduray (i) +delta+desloy+desl_y (j))

NSEL , R, LOC , Z , (armaduraz(i) -delta), (armaduraz(i) +delta)

*get, nome_no1, node, 0, num, $\max$

NSEL , S , LOC , X, (armadurax $(i+1)$-delta), (armadurax $(i+1)+$ delta)

NSEL , R, LOC , Y, (armaduray (i+1) -delta+desloy+desl_y $(j)),\left(\operatorname{armaduray}(i+1)+\operatorname{delta+desloy+desl\_ y(j))~}\right.$

NSEL , R, LOC , Z, (armaduraz (i+1) -delta), (armaduraz $(i+1)+\operatorname{delta)}$

*get,nome_no2, node, 0 , num, $\max$

E,nome_no1,nome_no2

*ENDDO

*ENDDO

$\operatorname{desloy}=\operatorname{des} l o y+50$

*ENDDO

!****Direção Y

real, 5

*DIM , armadurax2 , ARRAY , 39

*DIM , armaduray2 , ARRAY , 39

*DIM , armaduraz2, ARRAY , 39

$\operatorname{armadurax} 2(1)=0$

armaduray $2(1)=-6$

$\operatorname{armaduraz} 2(1)=27.5$

$\operatorname{armadurax} 2(2)=0$

armaduray $2(2)=-6$

$\operatorname{armaduraz} 2(2)=10$

$\operatorname{armadurax} 2(3)=0$

armaduray $2(3)=0$

$\operatorname{armaduraz} 2(3)=10$

$\operatorname{armadurax} 2(4)=0$

armaduray $2(4)=5$

$\operatorname{armaduraz} 2(4)=10$

$\operatorname{armadurax} 2(5)=0$

armaduray $2(5)=15$

$\operatorname{armaduraz} 2(5)=10$

$\operatorname{armadurax} 2(6)=0$

armaduray $2(6)=20$

$\operatorname{armaduraz} 2(6)=10$

$\operatorname{armadurax} 2(7)=0$

$\operatorname{armaduray} 2(7)=30$

$\operatorname{armaduraz} 2(7)=10$ 
$\operatorname{armadurax} 2(8)=0$

armaduray $2(8)=35$

$\operatorname{armaduraz} 2(8)=10$

$\operatorname{armadurax} 2(9)=0$

armaduray $2(9)=42.5$

$\operatorname{armaduraz} 2(9)=10$

$\operatorname{armadurax} 2(10)=0$

armaduray $2(10)=50$

$\operatorname{armaduraz2}(10)=10$

$\operatorname{armadurax} 2(11)=0$

armaduray $2(11)=55$

$\operatorname{armaduraz} 2(11)=10$

$\operatorname{armadurax} 2(12)=0$

armaduray $2(12)=65$

$\operatorname{armaduraz} 2(12)=10$

$\operatorname{armadurax} 2(13)=0$

$\operatorname{armaduray} 2(13)=70$

$\operatorname{armaduraz} 2(13)=10$

$\operatorname{armadurax} 2(14)=0$

armaduray $2(14)=80$

$\operatorname{armaduraz} 2(14)=10$

$\operatorname{armadurax} 2(15)=0$

armaduray $2(15)=85$

$\operatorname{armaduraz} 2(15)=10$

$\operatorname{armadurax} 2(16)=0$

armaduray $2(16)=92.5$

$\operatorname{armaduraz} 2(16)=10$

$\operatorname{armadurax} 2(17)=0$

armaduray $2(17)=100$

$\operatorname{armaduraz2}(17)=10$

$\operatorname{armadurax} 2(18)=0$

armaduray $2(18)=105$

$\operatorname{armaduraz2}(18)=10$

$\operatorname{armadurax} 2(19)=0$

armaduray $2(19)=115$

$\operatorname{armaduraz2}(19)=10$

$\operatorname{armadurax} 2(20)=0$

$\operatorname{armaduray} 2(20)=120$

$\operatorname{armaduraz} 2(20)=10$

armadurax $2(21)=0$

armaduray $2(21)=130$

$\operatorname{armaduraz} 2(21)=10$

$\operatorname{armadurax} 2(22)=0$

armaduray $2(22)=135$

$\operatorname{armaduraz} 2(22)=10$

$\operatorname{armadurax} 2(23)=0$

armaduray $2(23)=142.5$

$\operatorname{armaduraz2}(23)=10$

$\operatorname{armadurax} 2(24)=0$

armaduray $2(24)=150$

armaduraz2 $(24)=10$

armadurax $2(25)=0$

armaduray $2(25)=155$

$\operatorname{armaduraz} 2(25)=10$ 
$\operatorname{armadurax} 2(26)=0$

armaduray $2(26)=165$

$\operatorname{armaduraz} 2(26)=10$

$\operatorname{armadurax} 2(27)=0$

$\operatorname{armaduray} 2(27)=170$

$\operatorname{armaduraz} 2(27)=10$

armadurax $2(28)=0$

armaduray $2(28)=180$

$\operatorname{armaduraz} 2(28)=10$

$\operatorname{armadurax} 2(29)=0$

armaduray $2(29)=185$

$\operatorname{armaduraz} 2(29)=10$

$\operatorname{armadurax} 2(30)=0$

armaduray $2(30)=192.5$

$\operatorname{armaduraz} 2(30)=10$

$\operatorname{armadurax} 2(31)=0$

$\operatorname{armaduray} 2(31)=200$

$\operatorname{armaduraz} 2(31)=10$

$\operatorname{armadurax} 2(32)=0$

armaduray $2(32)=205$

$\operatorname{armaduraz} 2(32)=10$

$\operatorname{armadurax} 2(33)=0$

armaduray $2(33)=215$

$\operatorname{armaduraz} 2(33)=10$

$\operatorname{armadurax} 2(34)=0$

$\operatorname{armaduray} 2(34)=220$

$\operatorname{armaduraz} 2(34)=10$

$\operatorname{armadurax} 2(35)=0$

armaduray $2(35)=230$

armaduraz2 (35) =10

$\operatorname{armadurax} 2(36)=0$

armaduray $2(36)=235$

$\operatorname{armaduraz} 2(36)=10$

$\operatorname{armadurax} 2(37)=0$

$\operatorname{armaduray} 2(37)=241$

$\operatorname{armaduraz} 2(37)=10$

$\operatorname{armadurax} 2(38)=0$

armaduray $2(38)=247$

$\operatorname{armaduraz} 2(38)=10$

$\operatorname{armadurax} 2(39)=0$

$\operatorname{armaduray} 2(39)=247$

$\operatorname{armaduraz} 2$ (39) $=27.5$

$\operatorname{des} l o x=0$

*DIM, desl_x , ARRAY , 6

$\operatorname{des} 1 \_x(1)=0$

$\operatorname{des} l_{-} x(2)=5$

desl_x $(3)=15$

desl_x $(4)=20$

desl_x (5) $=30$

desl_x $(6)=35$ 
$* \mathrm{DO}, \mathrm{k}, 1,4,1$ !faixas

$* \mathrm{DO}, \mathrm{j}, 1,6,1$ !número de armadura

$* \mathrm{DO}, \mathrm{i}, 1,38,1$

NSEL , S , LOC , X , (armadurax2(i) -delta $\left.+\operatorname{deslox}+\operatorname{des} l_{-} x(j)\right),\left(\operatorname{armadurax} 2(i)+\operatorname{delta}+\operatorname{deslox}+\operatorname{des} l_{-} \mathrm{x}(j)\right)$

NSEL , R , LOC , Y , (armaduray2(i) -delta), (armaduray2(i) +delta)

NSEL , R, LOC , Z, (armaduraz2(i) -delta), (armaduraz2(i) +delta)

*get,nome_no1, node, 0 ,num, max

NSEL , S , LOC , X, (armadurax2(i+1) -delta +deslox +desl_x $(j)),\left(\operatorname{armadurax} 2(i+1)+\operatorname{delta}+\operatorname{des} l o x+d e s l \_x(j)\right)$

NSEL , R , LOC , Y, (armaduray2 (i+1) -delta), (armaduray2 $(i+1)+$ delta)

NSEL , R , LOC , Z , (armaduraz2 (i+1) -delta) , (armaduraz2(i+1) +delta)

*get,nome_no2, node, 0, num, $\max$

E,nome_no1,nome_no2

*ENDDO

*ENDDO

deslox $=\operatorname{des} l o x+100$

*ENDDO

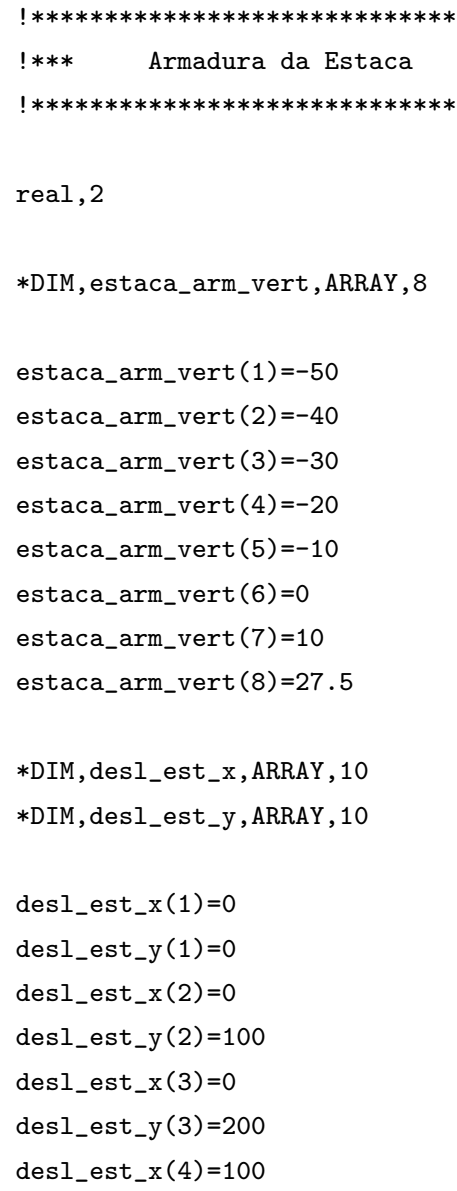


desl_est_y $(4)=50$
desl_est_x $(5)=100$
desl_est_y (5) $=150$
desl_est_x $(6)=200$
desl_est_y $(6)=50$
desl_est_x $(7)=200$
desl_est_y $(7)=150$
desl_est_x $(8)=300$
desl_est_y $(8)=0$
desl_est_x $(9)=300$
desl_est_y $(9)=100$
desl_est_x $(10)=300$
desl_est_y $(10)=200$
$* D I M$, desl_ex $, A R R A Y, 13$
$* D I M$, desl_ey $, A R R A Y, 13$

desl_ex $(1)=5$

desl_ex $(2)=5$

desl_ex (3) $=5$

desl_ex $(4)=5$

desl_ex $(5)=15$

desl_ex $(6)=20$

desl_ex $(7)=30$

desl_ex $(8)=30$

desl_ex $(9)=30$

desl_ex $(10)=30$

desl_ex (11) $=20$

desl_ex (12) $=15$

desl_ex (13) $=5$

desl_ey $(1)=5$

desl_ey $(2)=15$

desl_ey $(3)=20$

desl_ey $(4)=30$

desl_ey $(5)=30$

desl_ey $(6)=30$

desl_ey $(7)=30$

desl_ey $(8)=20$

desl_ey $(9)=15$

desl_ey $(10)=5$

desl_ey $(11)=5$

desl_ey $(12)=5$

desl_ey $(13)=5$

*DO,k,1,10,1 !número de estacas

*DO,j,1,10,3 !número de armadura na estaca

*DO, i, 1,7,1 !Uma barra

NSEL ,S,LOC,X, ( -delta +desl_ex $(j)+$ desl_est_x $(\mathrm{k})),(+$ delta + desl_ex $(j)+$ desl_est_x $(k))$

NSEL , R, LOC,Y, ( -delta +desl_ey $\left.(j)+\operatorname{des} l_{\text {_est_y }}(\mathrm{k})\right),\left(+\operatorname{delta}+\operatorname{des} l_{-}\right.$ey $\left.(j)+\operatorname{des} l_{-} e s t \_y(k)\right)$

NSEL , R, LOC,Z, (estaca_arm_vert(i) -delta), (estaca_arm_vert(i) +delta) 
*get,nome_no1,node, 0, num, max

NSEL , S, LOC,X, ( -delta +desl_ex $(j)+$ desl_est_x $(k)),(+$ delta + desl_ex $(j)+$ desl_est_x $(k))$

NSEL , R, LOC,Y, ( -delta +desl_ey $(j)+$ desl_est_y $(k)),\left(+\operatorname{delta}+\operatorname{des} l_{-}\right.$ey $(j)+$ desl_est_y $\left.(k)\right)$

NSEL , R, LOC , Z, (estaca_arm_vert $(i+1)$-delta), (estaca_arm_vert $(i+1)+$ delta)

*get,nome_no2, node, 0 , num, max

E,nome_no1, nome_no2

*ENDDO

*ENDDO

*DO, m,1,6,1 !Camadas dos estribos

*DO,j,1,12,1 !Uma barra do estribo

NSEL, S, LOC,X, ( -delta +desl_ex $(j)+$ desl_est_x $(k)),\left(+\right.$ delta + desl_ex $\left.(j)+d e s l_{-} e s t \_x(k)\right)$

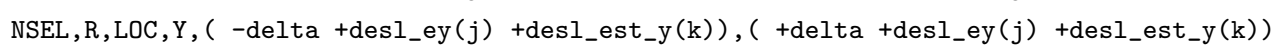

NSEL , R, LOC, Z, (estaca_arm_vert (m) -delta), (estaca_arm_vert(m) +delta)

*get,nome_no1,node, 0, num, $\max$

NSEL , S , LOC,X, ( -delta +desl_ex $(j+1)+$ desl_est_x $(\mathrm{k})),(+$ delta + desl_ex $(j+1)+$ desl_est_x $(k))$

NSEL , R, LOC, Y, ( -delta +desl_ey $(j+1)+\operatorname{des} l_{-}$est_y $\left.(k)\right),\left(+\operatorname{delta}+\operatorname{des} l_{-} e y(j+1)+\right.$ desl_est_y $\left.(k)\right)$

NSEL , R, LOC , Z, (estaca_arm_vert (m) -delta), (estaca_arm_vert(m) +delta)

*get,nome_no2, node, 0 ,num, $\max$

E, nome_no1, nome_no2

*ENDDO

*ENDDO

$*$ ENDDO

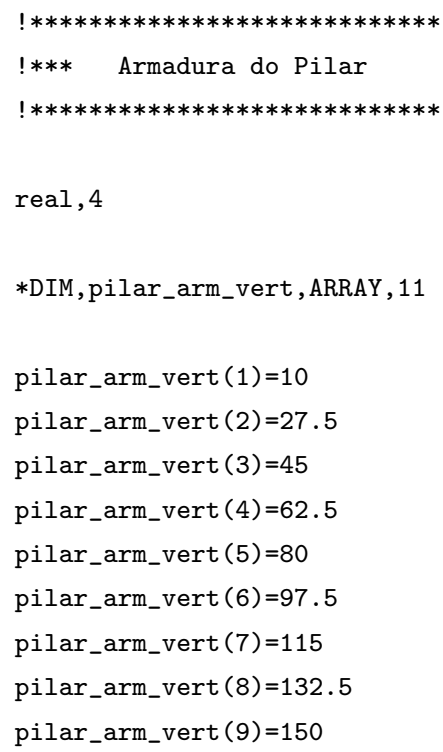


pilar_arm_vert (10) $=167.5$

pilar_arm_vert $(11)=185$

*DIM, desl_px , ARRAY , 17

*DIM, desl_py , ARRAY, 17

desl_px (1) $=130$

desl_px (2) $=130$

desl_px (3) $=130$

desl_px $(4)=130$

desl_px (5) =148

desl_px (6) $=161$

desl_px (7) $=174$

desl_px $(8)=187$

desl_px (9) =205

desl_px (10) $=205$

desl_px (11) $=205$

desl_px (12) $=205$

desl_px (13) $=187$

desl_px (14) $=174$

desl_px (15)=161

desl_px (16) $=148$

desl_px (17) $=130$

$\operatorname{des} I_{-}$py (1) $=105$

desl_py (2) $=115$

desl_py (3) $=120$

desl_py $(4)=130$

desl_py (5) $=130$

desl_py (6) $=130$

$\operatorname{des} I_{\text {_py }}(7)=130$

$\operatorname{desl} \_$py $(8)=130$

desl_py (9) $=130$

desl_py (10) $=120$

desl_py (11) $=115$

desl_py (12) $=105$

desl_py (13) $=105$

desl_py (14) $=105$

desl_py (15) $=105$

desl_py (16) $=105$

desl_py (17) $=105$

*DO,j,1,16,1 !número de armadura no pilar

*DO,i,1,8,1 !Uma barra

NSEL , S, LOC, X, (-delta + desl_px $(j)),\left(+\operatorname{delta}+\operatorname{des} I_{-} p x(j)\right)$

NSEL , R, LOC, Y, (-delta + desl_py $(j)),\left(+\operatorname{delta}+\operatorname{des} I_{-}\right.$py $\left.(j)\right)$

NSEL , R, LOC, Z, (pilar_arm_vert(i) -delta), (pilar_arm_vert(i) +delta)

*get,nome_no1, node, 0 , num, $\max$

NSEL , S, LOC, X, (-delta +desl_px $(j)),\left(+\operatorname{delta}+\operatorname{des} l_{-} \mathrm{px}(j)\right)$

NSEL , R, LOC, Y, (-delta +desl_py $(j)),\left(+d e l t a+d e s l_{-}\right.$py $\left.(j)\right)$

NSEL , R, LOC, Z, (pilar_arm_vert (i+1) -delta), (pilar_arm_vert (i+1) +delta) 
*get,nome_no2,node, 0, num, max

E,nome_no1, nome_no2

*ENDDO

*ENDDO

*DO, m, 7,9,1 !Camadas dos estribos (3)

*DO,j,1,16,1 !Uma barra do estribo

NSEL , S , LOC , X, (-delta +desl_px $(j)),\left(+\operatorname{delta}+\operatorname{des} l_{-} \mathrm{px}(\mathrm{j})\right)$

NSEL , R, LOC ,Y, (-delta +desl_py $(j)),\left(+d e l t a ~+d e s l_{-} p y(j)\right)$

NSEL , R, LOC , Z, (pilar_arm_vert(m) -delta), (pilar_arm_vert(m) +delta)

*get,nome_no1,node, 0, num,max

NSEL , S, LOC , X, (-delta +desl_px $(j+1)),(+$ delta + desl_px $(j+1))$

NSEL , R, LOC , Y, (-delta +desl_py $(j+1)),(+$ delta + desl_py $(j+1))$

NSEL , R, LOC, Z, (pilar_arm_vert(m) -delta), (pilar_arm_vert(m) +delta)

*get,nome_no2,node, 0 ,num, max

E, nome_no1, nome_no2

*ENDDO

*ENDDO

!*** Renumerando os elementos

ALLSEL , ALL

NUMMRG , ALL , , , ,LOW ! Murge

NUMCMP , ALL

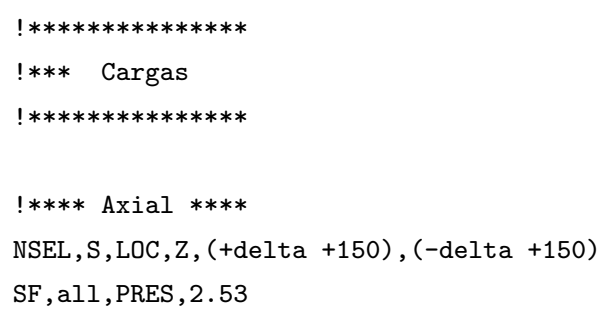




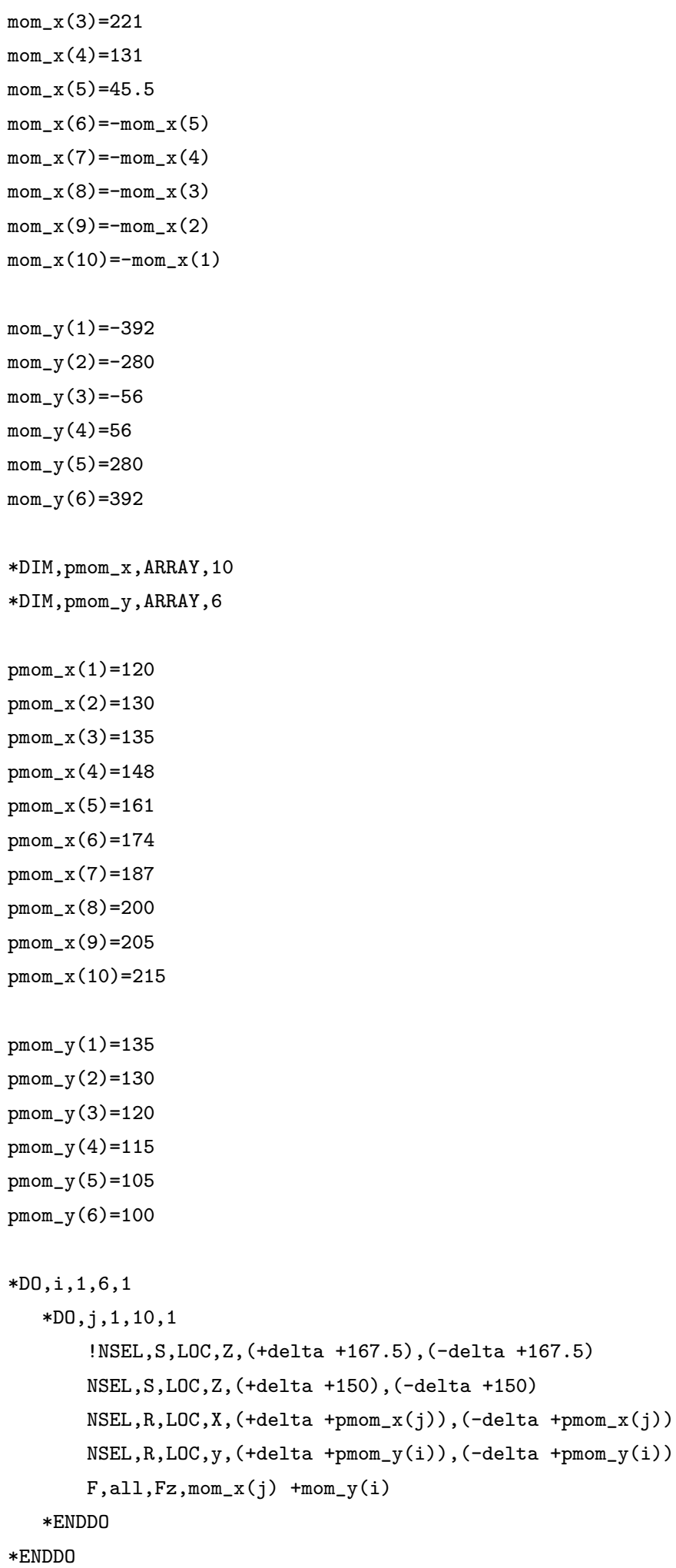

type, 3

mat, 3 
real, 3

allsel, all

*DIM , nox , ARRAY , 36

*DIM , nOy , ARRAY , 36

*DIM, nOz , ARRAY , 36

$\operatorname{nox}(1)=5$

$\operatorname{noy}(1)=15$

$\operatorname{noz}(1)=-50$

$\operatorname{nox}(2)=0.5583$

$\operatorname{noy}(2)=15$

$\operatorname{noz}(2)=-50$

$\operatorname{nox}(3)=5$

$\operatorname{noy}(3)=5$

$\operatorname{noz}(3)=-50$

$\operatorname{nox}(4)=4.255814061$

$\operatorname{noy}(4)=5$

$\operatorname{noz}(4)=-50$

$\operatorname{nox}(5)=30$

$\operatorname{noy}(5)=15$

$\operatorname{noz}(5)=-50$

$\operatorname{nox}(6)=34.4417$

$\operatorname{noy}(6)=15$

$\operatorname{noz}(6)=-50$

$\operatorname{nox}(7)=30$

$\operatorname{noy}(7)=5$

$\operatorname{noz}(7)=-50$

$\operatorname{nox}(8)=30.74418594$

$\operatorname{noy}(8)=5$

$\operatorname{noz}(8)=-50$

$\operatorname{nox}(9)=15$

$\operatorname{noy}(9)=15$

$\operatorname{noz}(9)=-50$

$\operatorname{nox}(10)=15$

$\operatorname{noy}(10)=5$

$\operatorname{noz}(10)=-50$

$\operatorname{nox}(11)=20$

$\operatorname{noy}(11)=15$

$\operatorname{noz}(11)=-50$

$\operatorname{nox}(12)=20$

$\operatorname{noy}(12)=5$

$\operatorname{noz}(12)=-50$

$\operatorname{nox}(13)=4.4567$

$\operatorname{noy}(13)=4.4567$

$\operatorname{noz}(13)=-50$

$\operatorname{nox}(14)=5$

$\operatorname{noy}(14)=4.255814061$

$\operatorname{noz}(14)=-50$

$\operatorname{nox}(15)=30$

$\operatorname{noy}(15)=4.255814061$

$\operatorname{noz}(15)=-50$

$\operatorname{nox}(16)=30.5433$ 


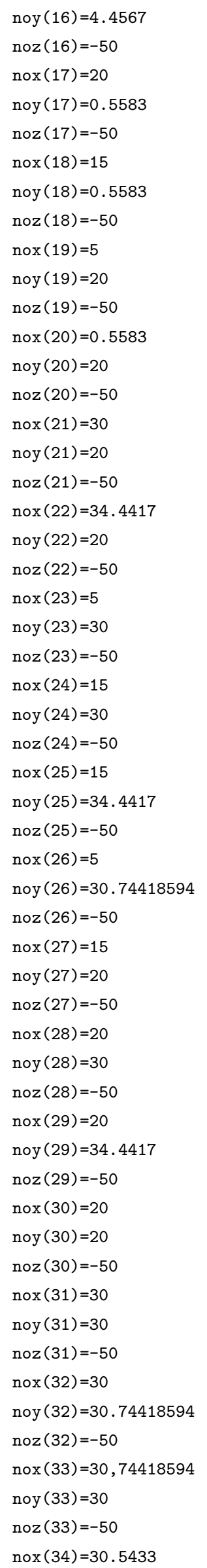




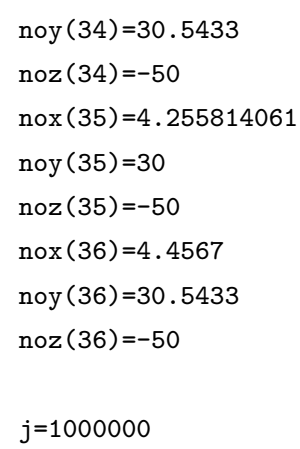

$* \mathrm{DO}, \mathrm{k}, 1,10,1$ !número de estacas

*DO,i,1,36,1 ! molas por estacas

NSEL , S , LOC , X, (nox $(i)$-delta +desl_est_x(k)), (nox(i) +delta +desl_est_x(k))

NSEL , R, LOC, Y, (noy (i) -delta +desl_est_y(k)), (noy(i) +delta +desl_est_y(k))

NSEL , R, LOC , Z, (noz (i) -delta), (noz(i) +delta)

*get,nome_no,node,0,num,max

$N, j,\left(\operatorname{nox}(i)+d e s l_{\text {est_ex }}(k)\right),\left(\operatorname{noy}(i)+\operatorname{des} l_{-} e s t \_y(k)\right),(\operatorname{noz}(i))$

E, nome_no, j

$D, j,,,,,$, UZ , , , , , !restrição

$\mathrm{j}=\mathrm{j}+1$

*ENDDO

*ENDDO

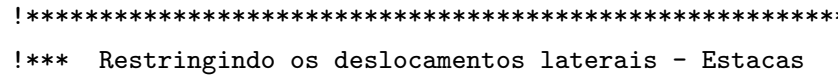

! $* * * * * * * * * * * * * * * * * * * * * * * * * * * * * * * * * * * * * * * * * * * * * * * * * * * * * * * * * * * * * *$

NSEL, S, LOC , X , (0.55830 -delta), (0.558300 +delta)

NSEL , R, LOC , Y, (15 -delta), (220 +delta)

NSEL, R, LOC , Z, (-10 +delta), (-40 -delta)

D,all, , , , ,UX, UY, , , !restrição

NSEL , S , LOC , X , (34.44170 -delta), (34.44170 +delta)

NSEL, R, LOC , Y, (15 -delta), (220 +delta)

NSEL , R, LOC , Z, (-10 +delta $),(-40-$ delta $)$

D,all, , , , , UX, UY, , , !restrição

NSEL , S , LOC , X, (100.5583 -delta), (100.5583 +delta)

NSEL , R, LOC, Y, (15 -delta), (220 +delta)

NSEL , R, LOC , Z, (-10 +delta), (-40 -delta)

D,all, , , , , ,UX, UY, , , !restrição

NSEL, S, LOC , X , (134.4417 -delta), (134.4417 +delta)

NSEL , R, LOC , Y, (15 -delta), (220 +delta) 
NSEL , R, LOC , Z, (-10 +delta), (-40 -delta)

D,all, , , , ,UX,UY, , , !restrição

NSEL , S , LOC , X , (200.5583 -delta), (200.5583 +delta)

NSEL , R, LOC , Y, (15 -delta), (220 +delta)

NSEL , R, LOC , Z, (-10 +delta), (-40 -delta)

$\mathrm{D}, \mathrm{all}$, , , , , ,UX, UY, , , , !restrição

NSEL , S , LOC , X , (234.4417 -delta), (234.4417 +delta)

NSEL , R, LOC, Y, (15 -delta), (220 +delta)

NSEL , R, LOC , Z, (-10 +delta), (-40 -delta)

D,all, , , , ,UX,UY, , , !restrição

NSEL , S, LOC , X, (300.5583 -delta), (300.5583 +delta)

NSEL , R, LOC, Y, (15 -delta), (220 +delta)

NSEL , R, LOC , Z, (-10 +delta), (-40 -delta)

D,all, , , , , ,UX,UY, , , , !restrição

NSEL , S , LOC , X, (334.4417 -delta), (334.4417 +delta)

NSEL , R, LOC , Y, (15 -delta), (220 +delta)

NSEL , R , LOC , Z, (-10 +delta), (-40 -delta)

D,all, , , , , ,UX,UY, , , , !restrição

NSEL , S , LOC ,X, (15 -delta), (320 +delta)

NSEL, R, LOC, Y, (0.5583 -delta), (0.5583 +delta)

NSEL, R, LOC , Z, (-10 +delta), (-40 -delta)

D,all, , , , ,UX,UY, , , !restrição

NSEL , S, LOC , X, (15 -delta), (320 +delta)

NSEL , R, LOC, Y, (34.4417 -delta), (34.4417 +delta)

NSEL , R, LOC , Z, (-10 +delta), (-40 -delta)

D,all, , , , ,UX,UY, , , !restrição

NSEL , S, LOC, X, (15 -delta), (320 +delta)

NSEL , R, LOC , Y , (50.5583 -delta) , (50.5583 +delta)

NSEL , R, LOC , Z, (-10 +delta), (-40 -delta)

D,all, , , , , ,UX,UY, , , !restrição

NSEL , S , LOC, X, (15 -delta), (320 +delta)

NSEL , R, LOC , Y, (84.4417 -delta) , (84.4417 +delta)

NSEL , R, LOC , Z, (-10 +delta), (-40 -delta)

D,all, , , , , ,UX,UY, , , , !restrição

NSEL , S, LOC, X, (15 -delta), (320 +delta)

NSEL , R, LOC , Y, (100.5583 -delta), (100.5583 +delta) 
NSEL , R , LOC , Z, (-10 +delta) , (-40 -delta)

D,all, , , , ,UX,UY, , , !restrição

NSEL , S, LOC, X, (15 -delta), (320 +delta)

NSEL , R , LOC , Y, (134.4417 -delta) , (134.4417 +delta)

NSEL , R, LOC , Z, (-10 +delta), (-40 -delta)

D,all, , , , ,UX,UY, , , !restrição

NSEL , S, LOC , X , (15 -delta), (320 +delta)

NSEL , R, LOC , Y, (150.5583 -delta), (150.5583 +delta)

NSEL , R, LOC , Z, (-10 +delta), (-40 -delta)

D,all, , , , , UX, UY, , , !restrição

NSEL , S , LOC , X, (15 -delta), (320 +delta)

NSEL , R , LOC , Y, (184.4417 -delta), (184.4417 +delta)

NSEL , R , LOC , Z, (-10 +delta $),(-40-$ delta $)$

D,all, , , , ,UX, UY, , , !restrição

NSEL , S , LOC ,X, (15 -delta), (320 +delta)

NSEL , R, LOC , Y , (200.5583 -delta), (200.5583 +delta)

NSEL , R, LOC, Z, (-10 +delta), (-40 -delta)

D,all, , , , ,UX, UY, , , !restrição

NSEL , S, LOC, X, (15 -delta), (320 +delta)

NSEL , R, LOC , Y, (234.4417 -delta), (234.4417 +delta)

NSEL , R, LOC , Z, (-10 +delta $),(-40-$ delta $)$

D,all, , , , , ,UX,UY, , , , !restrição

!*** Renumerando os elementos

allsel, all

NUMCMP , ALL

$1 * * * * * * * * * * * * * * * * * * * * * * *$

!*** Opções Gráficas

$1 * * * * * * * * * * * * * * * * * * * * * *$

/COLOR , NUM , 14, 1

/COLOR, NUM, 12,2

/PNUM , TYPE, 1

/NUMBER, 1

ESEL , S , MAT , , 1

/TRLCY, ELEM, 0.5, all 
ALLSEL , ALL

/COLOR, OUTL, BLAC

/REPLOT

FINISH

/SOL

$! * * * * * * * * * * * * * * * * * * * * * * * * *$

!*** Opções da análise

$1 * * * * * * * * * * * * * * * * * * * * * * * *$

ANTYPE,0 !Análise estática

CNVTOL , F , , 5e-2, , ,

DELTIM, $0.001,0.000000000001,0.35$

OUTRES, ERASE

OUTRES, NSOL , ALL

OUTRES , RSOL , ALL

OUTRES , ESOL , ALL

OUTRES, NLOA, ALL

OUTRES , STRS , ALL

OUTRES, EPEL , ALL

OUTRES , EPPL , ALL

NCNV , 2, 0, 0, 0, 0

NEQIT , 250

TIME, 100

RESCONTRL , DEFINE , ALL , ALL , 1

NLGEOM , 1

NROPT , FULL , , ON

LUMPM , 0

EQSLV, , 0 ,

PRECISION, 0

MSAVE, 0

PIVCHECK , 1

SSTIF

PSTRES

$! * * * * * * * * * * * * * * * * * * * * * * *$

!*** Fim do script

$! * * * * * * * * * * * * * * * * * * * * * * * *$ 


\section{APÊEDICE B - Resultados Extras}

Tabela B.1: Reações nas estacas para o Caso 1 em bloco com altura de $115 \mathrm{~cm}$ e concreto de $20 \mathrm{MPa}$

\begin{tabular}{|c|c|c|c|c|c|c|}
\hline \multicolumn{7}{|c|}{ Caso $1 ; \mathrm{h}=115 \mathrm{~cm} ; 20 \mathrm{MPa}$} \\
\hline & \multicolumn{3}{|c|}{ Deformável } & \multicolumn{3}{|c|}{ Indeformável } \\
\hline & Modelo & Modelo & & Modelo & Modelo & \\
\hline & Numérico & Analítico & & Numérico & Analítico & \\
\hline Estacas & $F_{k, n}(\mathrm{kN})$ & $F_{k, a}(\mathrm{kN})$ & $F_{k, n} / F_{k, a}$ & $F_{k, n}(\mathrm{kN})$ & $F_{k, a}(\mathrm{kN})$ & $F_{k, n} / F_{k, a}$ \\
\hline 1 & 183,1 & 300 & 0,61 & 287,4 & 300 & 0,96 \\
\hline 2 & 221,8 & 300 & 0,74 & 292,1 & 300 & 0,97 \\
\hline 3 & 183,1 & 300 & 0,61 & 287,0 & 300 & 0,96 \\
\hline 4 & 456,0 & 300 & 1,52 & 316,4 & 300 & 1,05 \\
\hline 5 & 455,9 & 300 & 1,52 & 316,3 & 300 & 1,05 \\
\hline 6 & 456,0 & 300 & 1,52 & 316,5 & 300 & 1,06 \\
\hline 7 & 455,9 & 300 & 1,52 & 316,4 & 300 & 1,05 \\
\hline 8 & 183,1 & 300 & 0,61 & 287,8 & 300 & 0,96 \\
\hline 9 & 221,8 & 300 & 0,74 & 292,5 & 300 & 0,97 \\
\hline 10 & 183,1 & 300 & 0,61 & 287,4 & 300 & 0,96 \\
\hline
\end{tabular}

Tabela B.2: Reações nas estacas para o Caso 1 em bloco com altura de $115 \mathrm{~cm}$ e concreto de $30 \mathrm{MPa}$

\begin{tabular}{|c|c|c|c|c|c|c|}
\hline \multicolumn{7}{|c|}{ Caso $1 ; \mathrm{h}=115 \mathrm{~cm} ; 30 \mathrm{MPa}$} \\
\hline & \multicolumn{3}{|c|}{ Deformável } & \multicolumn{3}{|c|}{ Indeformável } \\
\hline & Modelo & Modelo & & Modelo & Modelo & \\
\hline & Numérico & Analítico & & Numérico & Analítico & \\
\hline Estacas & $F_{k, n}(\mathrm{kN})$ & $F_{k, a}(\mathrm{kN})$ & $F_{k, n} / F_{k, a}$ & $F_{k, n}(\mathrm{kN})$ & $F_{k, a}(\mathrm{kN})$ & $F_{k, n} / F_{k, a}$ \\
\hline 1 & 184,1 & 300 & 0,61 & 289,5 & 300 & 0,96 \\
\hline 2 & 222,5 & 300 & 0,74 & 293,3 & 300 & 0,98 \\
\hline 3 & 184,1 & 300 & 0,61 & 289,1 & 300 & 0,96 \\
\hline 4 & 454,6 & 300 & 1,52 & 313,9 & 300 & 1,05 \\
\hline 5 & 454,6 & 300 & 1,52 & 313,8 & 300 & 1,05 \\
\hline 6 & 454,6 & 300 & 1,52 & 313,9 & 300 & 1,05 \\
\hline 7 & 454,6 & 300 & 1,52 & 313,8 & 300 & 1,05 \\
\hline 8 & 184,1 & 300 & 0,61 & 289,7 & 300 & 0,97 \\
\hline 9 & 222,5 & 300 & 0,74 & 293,6 & 300 & 0,98 \\
\hline 10 & 184,1 & 300 & 0,61 & 289,3 & 300 & 0,96 \\
\hline
\end{tabular}


Tabela B.3: Reações nas estacas para o Caso 1 em bloco com altura de $115 \mathrm{~cm}$ e concreto de $45 \mathrm{MPa}$

\begin{tabular}{|c|c|c|c|c|c|c|}
\hline \multicolumn{7}{|c|}{ Caso $1 ; \mathrm{h}=115 \mathrm{~cm} ; 45 \mathrm{MPa}$} \\
\hline & \multicolumn{3}{|c|}{ Deformável } & \multicolumn{3}{|c|}{ Indeformável } \\
\hline & Modelo & Modelo & & Modelo & Modelo & \\
\hline & Numérico & Analítico & & Numérico & Analítico & \\
\hline Estacas & $F_{k, n}(\mathrm{kN})$ & $F_{k, a}(\mathrm{kN})$ & $F_{k, n} / F_{k, a}$ & $F_{k, n}(\mathrm{kN})$ & $F_{k, a}(\mathrm{kN})$ & $F_{k, n} / F_{k, a}$ \\
\hline 1 & 184,9 & 300 & 0,62 & 291,1 & 300 & 0,97 \\
\hline 2 & 223,1 & 300 & 0,74 & 294,3 & 300 & 0,98 \\
\hline 3 & 184,9 & 300 & 0,62 & 290,7 & 300 & 0,97 \\
\hline 4 & 453,5 & 300 & 1,51 & 311,8 & 300 & 1,04 \\
\hline 5 & 453,5 & 300 & 1,51 & 311,6 & 300 & 1,04 \\
\hline 6 & 453,5 & 300 & 1,51 & 311,8 & 300 & 1,04 \\
\hline 7 & 453,5 & 300 & 1,51 & 311,7 & 300 & 1,04 \\
\hline 8 & 184,9 & 300 & 0,62 & 291,3 & 300 & 0,97 \\
\hline 9 & 223,1 & 300 & 0,74 & 294,5 & 300 & 0,98 \\
\hline 10 & 184,9 & 300 & 0,62 & 291,0 & 300 & 0,97 \\
\hline
\end{tabular}

Tabela B.4: Reações nas estacas para o Caso 2 em bloco com altura de $115 \mathrm{~cm}$ e concreto de $45 \mathrm{MPa}$

\begin{tabular}{|c|c|c|c|c|c|c|}
\hline \multicolumn{7}{|c|}{ Caso $2 ; \mathrm{h}=115 \mathrm{~cm} ; 45 \mathrm{MPa}$} \\
\hline & \multicolumn{3}{|c|}{ Deformável } & \multicolumn{3}{|c|}{ Indeformável } \\
\hline & Modelo & Modelo & & Modelo & Modelo & \\
\hline & Numérico & Analítico & & Numérico & Analítico & \\
\hline Estacas & $F_{k, n}(\mathrm{kN})$ & $F_{k, a}(\mathrm{kN})$ & $F_{k, n} / F_{k, a}$ & $F_{k, n}(\mathrm{kN})$ & $F_{k, a}(\mathrm{kN})$ & $F_{k, n} / F_{k, a}$ \\
\hline 1 & 181,9 & 297,9 & 0,61 & 290,0 & 297,9 & 0,97 \\
\hline 2 & 157,9 & 237,9 & 0,66 & 250,4 & 237,9 & 1,05 \\
\hline 3 & 86,2 & 177,9 & 0,48 & 152,6 & 177,9 & 0,86 \\
\hline 4 & 453,2 & 309,3 & 1,47 & 322,0 & 309,3 & 1,04 \\
\hline 5 & 362,7 & 249,3 & 1,45 & 288,6 & 249,3 & 1,16 \\
\hline 6 & 545,9 & 350,7 & 1,56 & 349,1 & 350,7 & 1,00 \\
\hline 7 & 451,0 & 290,7 & 1,55 & 320,5 & 290,7 & 1,10 \\
\hline 8 & 286,5 & 422,1 & 0,68 & 367,0 & 422,1 & 0,87 \\
\hline 9 & 288,5 & 362,1 & 0,80 & 344,8 & 362,1 & 0,95 \\
\hline 10 & 186,0 & 302,1 & 0.62 & 314,8 & 302,1 & 1,04 \\
\hline
\end{tabular}

